\title{
Early Childhood Teachers' \\ Thinking and Reflection within their \\ Communities of Practice
}

\author{
by \\ Susan Ann Cherrington
}

\author{
A thesis \\ submitted to Victoria University of Wellington \\ in fulfilment of the \\ requirements for the degree of \\ Doctor of Philosophy \\ in Education
}

Victoria University of Wellington

2011 


\begin{abstract}
This multiple-case study investigated teachers' thinking and reflection about their interactions with children in three early childhood (EC) centres. Located within a constructivist-interpretive paradigm, the study used video-stimulated recall interviews as the primary data source. Teachers' interactions with children were video-recorded and used in group interviews with the teaching team to uncover teachers' thinking and reflections at the time of the interactions and their individual and collective reflections on the episodes. Group interviews enabled insights into teachers' thinking and reflection to emerge, which would be unlikely in individual interviews.
\end{abstract}

The study drew upon several theoretical constructs, including reflection-in- and -onaction (Schön, 1983, 1987), interactive thinking (Mitchell \& Marland, 1989), communities of practice (Lave \& Wenger, 1991; Wenger, 1998) and the literature on professional learning communities to understand teachers' thinking and reflection and how these were mediated by the team.

The study found that children are central to teachers' thinking about their interactions. Teachers held extensive knowledge about individual children, and their emphasis on relationships and being responsive to children provides empirical evidence of relational pedagogy (Papatheodorou \& Moyles, 2008) and of teachers' engagement with the philosophical underpinnings of Te Whāriki (Ministry of Education, 1996). The study also found teachers were less able to articulate their thinking and reflections about their own teaching intentions, use of teaching strategies, and the theories and principles influencing their practices.

These findings are represented in a model of EC teacher thinking, using a mat or whāriki as a metaphor for teachers' thinking. The model presents a whāriki that, woven from broad, robust child- and curriculum-focused strands and narrower, weaker teacher-focused strands, has gaps and thus, is weakened. The thesis 
argues that the child-centred discourse evident in the data is reflective of a broader early childhood education (ECE) discourse that backgrounds teaching, and that greater attention to teaching and to teacher thinking is necessary to strengthen teaching and learning in ECE settings.

The study revealed how each case study team operated as a uniquely framed and patterned community of practice, providing empirical evidence of the usefulness of Wenger's (1998) community of practice model for understanding how teaching teams mediate individual teachers' thinking and practices. Concepts from professional learning community literature informed analysis of teachers' engagement in collective reflection about their practices, resulting in a contribution to this literature from an EC perspective. 


\section{Acknowledgements}

My sincere thanks and appreciation go to many people whose guidance, support and practical assistance contributed to this thesis.

I am indebted to the teachers at Moana Early Learning Centre (ELC), Summer Kindergarten and Ngā Rangatahi Tamariki ELC who so generously welcomed me into their centres and shared their thinking and reflections with me. Their openness and willingness to de-privatise their thinking and practices is testament to their professionalism and commitment to teaching.

My supervisors, Dr Judith Loveridge and Professor Luanna Meyer, offered an empowering blend of challenge, support and guidance throughout the project. I learnt so much from their collective expertise as researchers and supervisors whilst their practical support enabled me to juggle the demands of PhD study with full-time employment. I thank them for their enormous contribution to my development as a researcher and a scholar.

Throughout this project I received support from colleagues across the Faculty of Education. In particular, I thank my ECE colleagues and my colleagues in the Faculty Office for their positive encouragement, for the on-going conversations about the project, and for their forbearance when my study impacted on my work. I am most grateful to Dr Mary Jane Shuker for taking on my role for six months whilst I wrote up the thesis and to the Dean, Professor Dugald Scott, for his on-going support. I feel very fortunate to have undertaken this PhD within such a collegial and supportive workplace.

I am grateful for the financial support offered by the Faculty of Education which enabled a period of leave during the proposal preparation, six months leave in the latter stages to write up the thesis, and support for transcribing interviews. I am most grateful to Warren Butcher for his expertise in editing the video-taped episodes for 
the interviews, and to Susan Kaiser for her expertise with the final formatting of the thesis.

Finally, I thank my husband, Bruce, and son, Michael, for their unwavering support and faith in my ability to complete the project. They have lived this journey with me, and I will always appreciate their generosity and love as they shared their lives with my PhD. 


\section{Table of Contents}

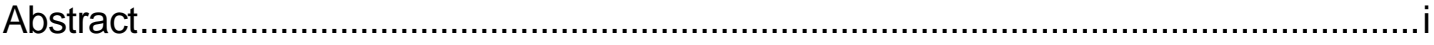

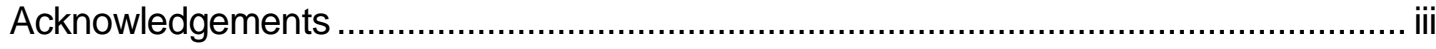

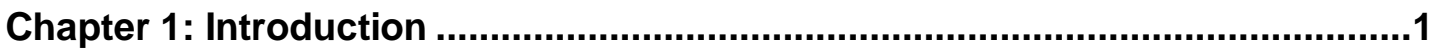

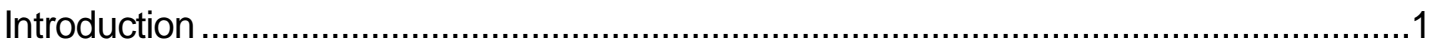

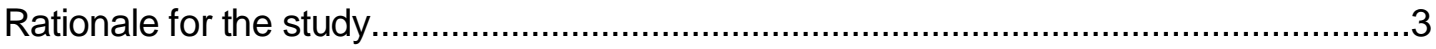

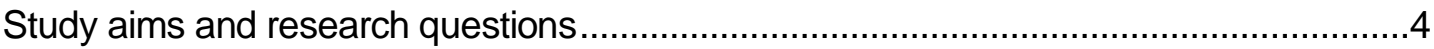

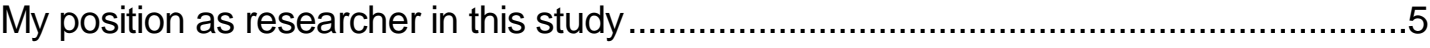

The New Zealand context: Theoretical paradigms influencing pedagogical practices .....7

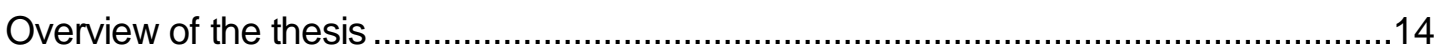

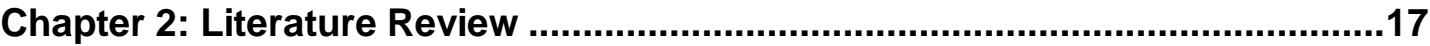

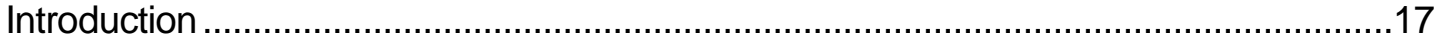

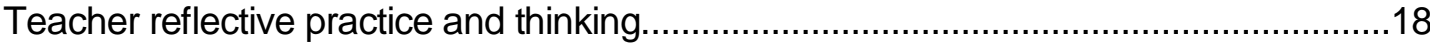

Key theoretical influences on reflective practices .......................................18

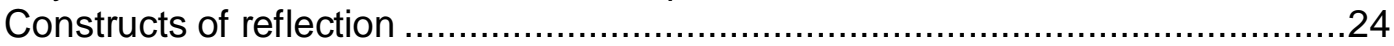

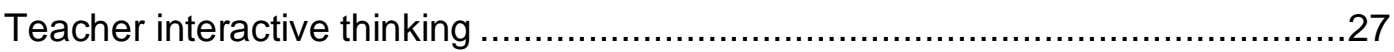

Reflective practice in early childhood education .........................................28

$\begin{array}{ll}\text { Reflection as a component of pedagogical practice } & 29\end{array}$

$\begin{array}{ll}\text { Teacher beliefs } & 31\end{array}$

Tacit knowledge $\quad 33$

Collaborative reflection $\quad 34$

Reflection-in-action $\quad 35$

Empirical studies of pedagogical practices in early childhood education......................36

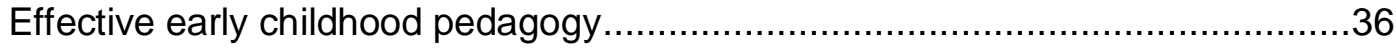

Patterns of teacher interactions............................................................. 40

Affective aspects of pedagogy .............................................................. 40

Teacher language interactions to support children's learning .........................41

Specific teaching strategies ....................................................................... 43

Content knowledge and pedagogical practices ....................................... 45

Social contexts for teacher thinking and reflection.......................................................46

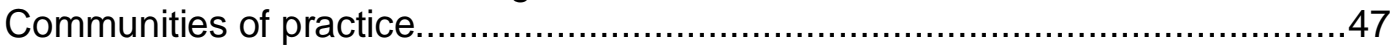

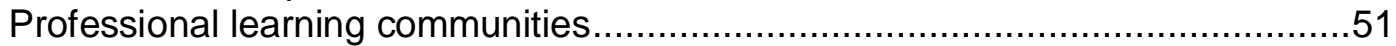

Empirical studies using a "community of practice" or "professional learning

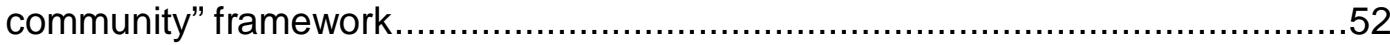

Communities of practice and teams in early childhood education ......................58

Group dynamics and interpersonal aspects $\quad 61$

Pedagogical dimensions of working in teams 63

$\begin{array}{ll}\text { Teacher discourses about teams } & 63\end{array}$

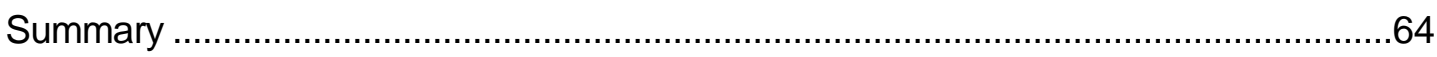

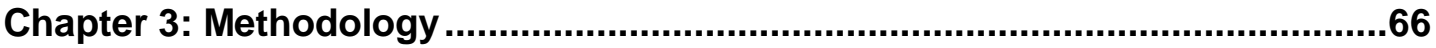

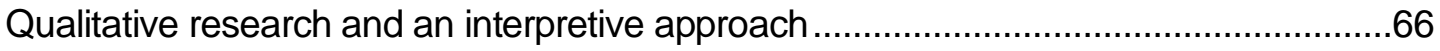

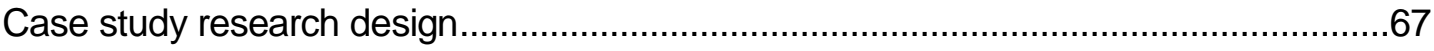




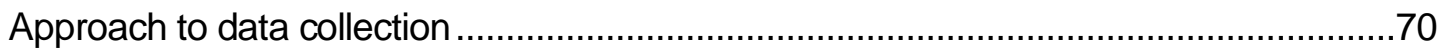

Video stimulated recall interviews ....................................................... 70

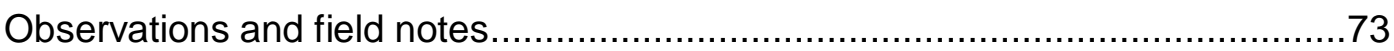

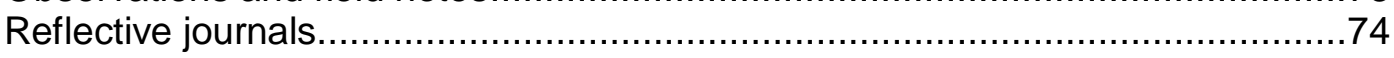

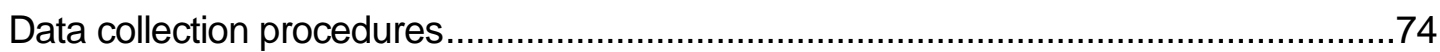

Selection of the cases .......................................................................... 74

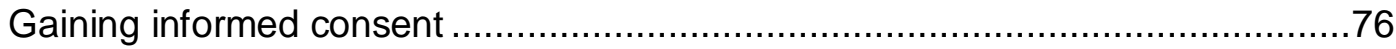

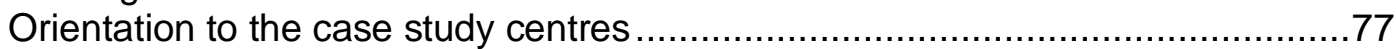

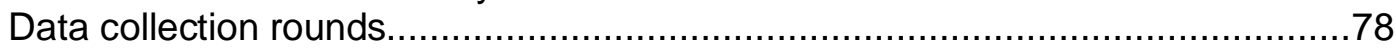

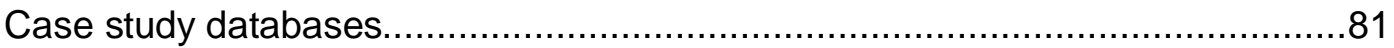

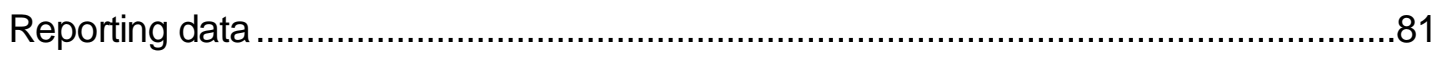

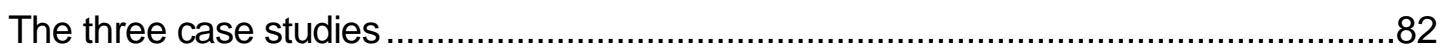

Case Study One: Moana Early Learning Centre......................................... 82

Case Study Two: Summer Kindergarten ......................................................84

Case Study Three: Ngā Rangatahi Tamariki Early Learning Centre...................86

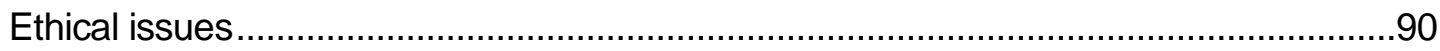

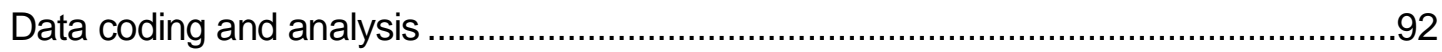

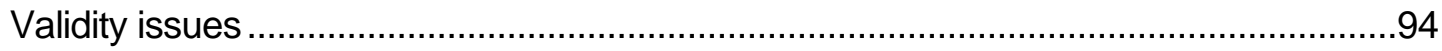

Chapter 4: Case Study One: Moana Early Learning Centre ..............................98

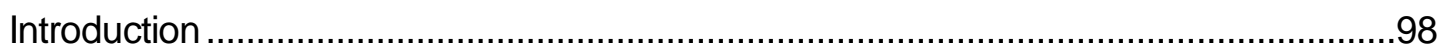

Teacher thinking and reflection at Moana Early Learning Centre ................................98

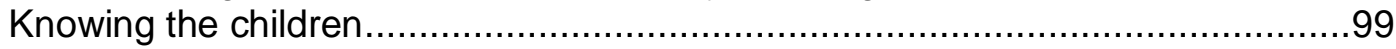

Teacher intentions, teaching strategies and interactions ............................ 104

'Busyness', multi-tasking and broader teaching roles ...................................113

New understandings emerging from the video-SR process ........................... 115

Beliefs, principles and theories underlying the Moana ELC teachers' practices.......... 117

The influence of a community of practice on teacher thinking and reflection............... 120

Alignment behaviours amongst Moana ELC teachers ..................................122

Negotiating meaning within the teaching team ......................................... 125

Chapter 5: Case Study Two: Summer Kindergarten .....................................132

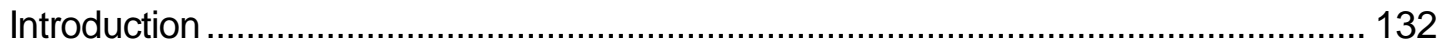

Teacher thinking and reflection at Summer Kindergarten ....................................... 132

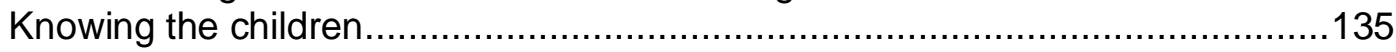

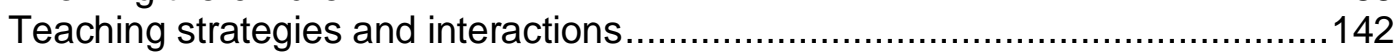

Dealing with multiple demands....................................................... 149

Beliefs, principles, and theories underlying the Summer Kindergarten teachers'

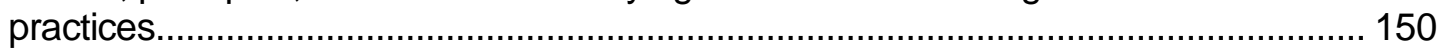

Teacher beliefs and knowledge about their teaching roles and behaviours .......150

Teacher beliefs about knowing the children .................................................. 154

Teacher knowledge and beliefs about children's learning and development .....155

Teacher beliefs and knowledge about the learning programme ......................158

Teacher beliefs about equity and fairness ................................................ 159

The influence of a community of practice on Summer Kindergarten teachers'

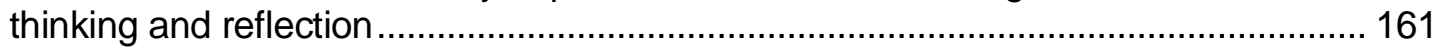

Alignment behaviours amongst Summer Kindergarten teachers ......................161

Negotiating meaning within the teaching team ......................................... 164 


\section{Chapter 6: Case Study Three: Ngā Rangatahi Tamariki Early Learning}

Centre

Introduction

Teacher thinking and reflection at Ngā Rangatahi Tamariki ELC .............................. 172

Knowing the children............................................................................ 173

Teaching strategies and interactions ....................................................... 180

Insights gained from the stimulated recall interview process .........................186

Beliefs, principles and theories underlying the Ngā Rangatahi Tamariki ELC

teachers' practices.

The influence of the RIE-Pikler philosophy on the infant teachers' practices .....189

Valuing the team ethos: The older group teachers' beliefs ............................190

The influence of a community of practice on teacher thinking and reflection............... 192

Alignment behaviours amongst Ngā Rangatahi Tamariki teachers ..................193

Negotiating meaning within the teaching team ........................................... 194

Chapter 7: Discussion and implications ..................................................200

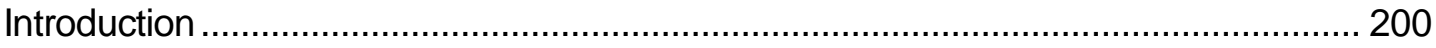

Teacher thinking and reflection about their interactions ........................................... 200

Teacher modes and patterns of reflection ..............................................201

The centrality of children in teachers' thinking and reflection............................204

Teacher intentions and use of teaching strategies .......................................209

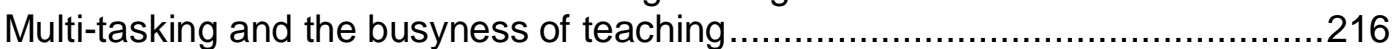

Principles, theories, and beliefs influencing teachers' thinking and reflections on practice

The influence of a community of practice on teacher thinking and reflection.............. 223

Maintaining social cohesion through alignment behaviours ............................224

Negotiating meaning within communities of practice ...................................226

Patterns of teacher talk as an influence on reflection-on-action within

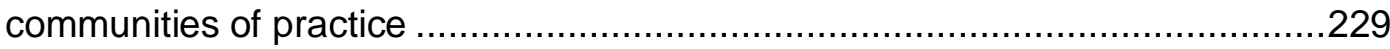

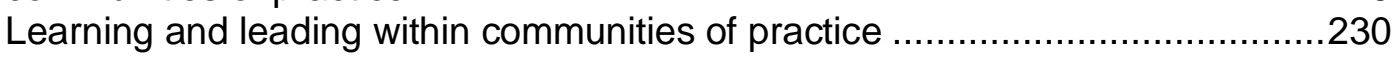

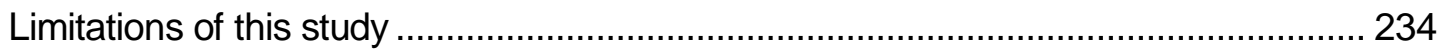

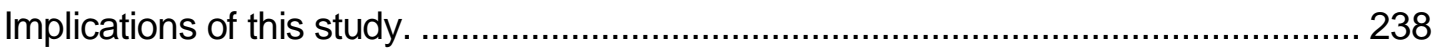

A model of teacher thinking and reflection within a community of practice ........238

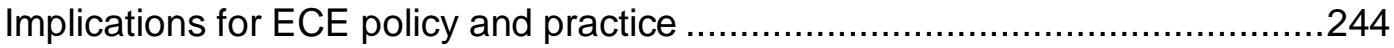

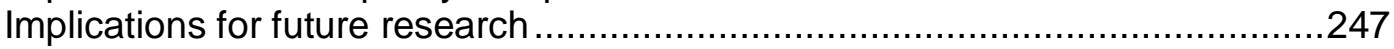

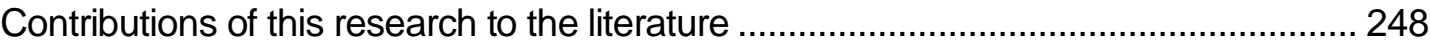

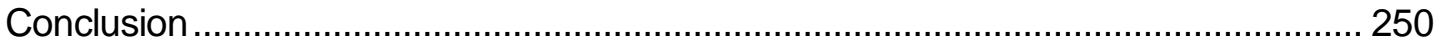

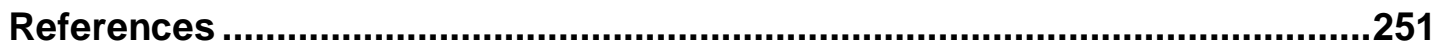

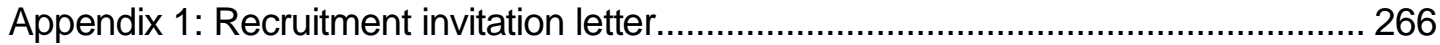

Appendix 2: Employer information letter and consent form...................................... 269

Appendix 3: Teacher information letter and consent form....................................... 272

Appendix 4: Parents information letter and consent form......................................... 277

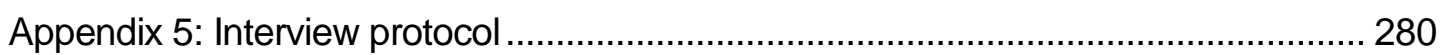

Appendix 6: Data analysis - final coding categories ............................................... 283

Appendix 8: Transcriber confidentiality form ............................................................. 293 


\section{List of Figures}

Figure 7.1: A model of teacher thinking and reflection within a community of practice

\section{List of Tables}

Table 4.1: Teacher knowledge about Alastair 101

Table 4.2: Examples of teaching strategies arising from teachers' knowledge of children........................................................................... 104

Table 4.3: Teachers' use of specific teaching strategies...................................106

Table 4.4: Making sense of an unexpected incident .......................................127

Table 5.1: Illustrative example of teachers' interactive thinking, reflection-inand - on-action.......................................................................... 133

Table 5.2: Teachers' knowledge about Zane and their subsequent interactions ...... 137

Table 5.3: Examples of children's learning discussed during the interviews ........140

Table 5.4: Teachers' use of specific teaching strategies..................................146

Table 5.5: Extract illustrating teachers adding new ideas and deepening

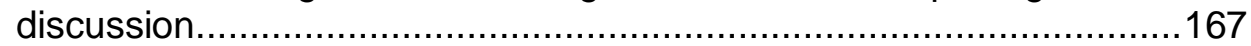

Table 5.6: Shifting discussions towards broader aspects of practice ...................169

Table 6.1: Teacher interpretations of, and responses to Jessie .........................173

Table 6.2: Teachers' discussion about Sharee's thinking ..................................177

Table 6.3: Ngā Rangatahi Tamariki teachers' use of general ECE teaching strategies 


\section{Chapter 1: Introduction}

\section{Introduction}

A general consensus exists about the importance of teacher thinking and reflection on practice as integral aspects of teacher effectiveness and on-going development (Clarke, 1995; Day, 1999; Jay \& Johnson, 2002; Luttenberg \& Bergen, 2008). However, considerable debate remains about what characterises effective reflection (e.g., Boud, 2009) and constructs and typologies abound in the literature (Zeichner (1994) and Zeichner \& Liston (1996)). Numerous empirical studies have focused on understanding the links between teacher thought and action, as evidenced by Mena Marcos and Tillema's (2006) review of 50 studies published between the years 2000 and 2005.

To date, much of the research into these aspects of teachers' work has been located in the compulsory school sector or in teacher education programmes within higher education institutions. Few studies have focused on early childhood (EC) teachers' thinking and reflection about their pedagogical practices. Existing studies have addressed aspects of reflection and teacher thinking as part of projects focused on teachers' tacit knowledge (e.g., Black \& Halliwell, 2000), pedagogy (e.g., Moyles, Adams \& Musgrove, 2002a, 2002b), play (e.g., Wood \& Bennett, 2000), and the impact of teacher beliefs on their thinking (e.g., Degotardi \& Davis, 2008). This multiple-case study project has sought to address this gap by contributing to understandings about teachers' reflection and thinking within early childhood education (ECE) settings. More specifically, within the New Zealand context little is known about whether and how EC teachers engage in reflection and thinking on their practices, and what theoretical paradigms influence their interactions with children.

The conceptual development of this study was underpinned by several key ideas. First, the notion of teachers as reflective practitioners (Calderhead, 1989; Schön, 1983, 1987; Zeichner \& Liston, 1996) who are thoughtful (Clark, 1995), particularly 
around their selection and use of pedagogical strategies and the impact of these on children's learning, was adopted. Second, effective pedagogical practices are central to quality ECE (Fleer, Anning \& Cullen, 2009; Moyles et al., 2002a; SirajBlatchford, Sylva, Muttock, Gilden \& Bell, 2002; Wylie, 2001); such pedagogy is complex and dynamic, and requires practitioners to draw upon their professional knowledge as part of reflecting on their practice (MacNaughton \& Williams, 2009; Moyles et al., 2002a). These ideas accorded with my own beliefs about EC teaching identified in a researcher memo prepared during the development of the research proposal (see p. 6).

Third, in New Zealand ECE services, teachers almost always teach in teams within shared physical spaces and with a common group of children. Researchers have become increasingly interested in the influence of the team on teachers' practices (Dalli, Kibble, Cairns-Cowan, Corrigan, \& McBride, 2009; K. Edwards, 2009; Haggerty, 1998; Nuttall, 2004; Ryder, 2007). Wenger's (1998) communities of practice has been used as a conceptual framework for studies of individual centres (Bary et al., 2007; Grey, 2010) and of communities drawing teachers from across centres (Aitken, 2005; Thornton, 2009). In order to examine the contextual influence of the team, this study has drawn on Wenger's (1998) community of practice model as a conceptual framework for understanding how such team-teaching structures influence individual teachers' thinking and reflection and contribute to the negotiation of shared understandings between team members.

In order to examine teachers' thinking and reflections about their pedagogical interactions with children a constructivist-interpretive approach (Cohen, Manion \& Morrison, 2000) was taken. This approach recognised that teachers' thinking and reflections were grounded in their own contexts and experiences and that naturalistic methodological procedures were required (Denzin \& Lincoln, 2008). A multiple-case study design enabled teachers' thinking and reflection to be explored over three structurally different ECE centres, with cross-case analysis allowing the 
particular features of each case to be compared and contrasted with those of the other cases. Group video stimulated recall (video-SR) interviews were undertaken using episodes of teachers' interactions with children in order to gain access to their thinking and reflections during and after the episodes.

\section{Rationale for the study}

The focus for this study emerged through various roles I have undertaken within EC teaching and teacher education, most particularly as a previous coordinator of teaching experiences (practicum) and as leader of EC teacher education programmes within my institution. During practicum visits to assess students' practices, I experienced the phenomena of students who were able to be "in tune" with the children they were teaching through to those who clearly struggled with this aspect of practice. I observed that those who struggled appeared to have a mismatch between their teaching intentions and the children's learning interests and that their interactions interrupted rather than interwove with the children's actions.

Around that time, the work of several people was influential in my thinking about what was happening when effective teaching was occurring in an EC context. Schön's (1983) concept of reflection-in-action - the ability to reflect upon unexpected situations and adjust one's practices - offered a model for explaining the moment-by-moment adjustments that teachers make in their interactions with children (see Chapter 2 for further discussion of Schön's work on the reflective practitioner). Eisner's (1998) artistry of teaching notion that framed teaching as complex and responsive rather than as merely technical, sat well with my own personal beliefs about teaching. Goodfellow's (1998) discussion of facets of EC teaching practices valued by practicum supervising teachers in Australia emphasised student teachers being in tune with children, and offered a typology of behaviours that she argued demonstrated what Noddings (1984) describes as 'a caring relation'. 
I began exploring some of these ideas with students and other staff through a final year teaching experience. Students were required in the practicum assignment to record narratives of their teaching and to unpack their reflections about their teaching and the theoretical underpinnings of their teaching decisions. The increasing use of video in this assignment was often instrumental in students being able to closely reflect on a number of elements of their practice.

In designing this study I deliberately moved away from an explicit focus on student teachers to working with (mostly) qualified practising teachers in three ECE centres. This move recognised the uneven power relationships with students who were enrolled in programmes for which I was responsible. Working with teachers outside the programmes (although I had existing relationships with two-thirds of the participating teachers) was intended to reduce the potential for ethical situations concerning status and power to emerge. Furthermore, I assumed that qualified teachers would have a stronger base of theory and understanding of reflective practice than would student teachers. My assumption was supported by Cooke (1991) who noted the literature in cognitive psychology suggests that experts "hold a much larger body of stored knowledge in content areas relevant to the problem than novices, and the organisation of their knowledge is more complex and integrated than that of novices" (p. 4). In addition, Allen and Casbergue (1997) found that intermediate and expert teachers were able to engage in more accurate recall of their own and students' actions during teaching episodes than novice teachers. I felt it reasonable, therefore, to expect that qualified practising teachers would be more able to recall and discuss their teaching practices, including their reflection and decision making, than student teachers.

\section{Study aims and research questions}

This study is intended to make a theoretical contribution by providing insights into EC teachers' thinking and reflection, both individually and within their community of practice, 
and how these aspects influence their use of interactive pedagogical strategies. As a teacher educator it is also my intention that the study helps illuminate the complexities of effective practice with children and enables links between theory and professional practice to be more explicit and visible to both student teachers and practising teachers.

To achieve these aims the following research questions were initially developed:

- What do teachers in the three case study centres think about and reflect on with regard to their interactions with children?

- What guiding principles/theories underlie these teachers' practices, and to what extent are these articulated or implicit?

During data analysis, the second question was amended to specifically include a focus on teacher beliefs. Teachers' beliefs were generally revealed much more explicitly during the interviews than were the principles and theories that underpinned their practices, although discerning between beliefs and underlying theories was not always straightforward. The expanded research question thus read:

- What guiding principles/theories and beliefs underlie these teachers' practices, and to what extent are these articulated or implicit?

A third research question was developed during the project in response to the literature and a key theme emerging from the data concerning the influence of the centre's community of practice on individual teachers' thinking and reflection. This final question was framed as:

- How does being a member of a community of practice influence teachers' thinking and reflection on their teaching interactions?

\section{My position as researcher in this study}

I entered into this study with extensive experience in EC teaching and teacher education: 11 years experience as a kindergarten teacher and senior teacher, and 
15 years' experience in teacher education. Amongst my roles in teacher education I had, as noted above, been responsible for the practicum component within my institution's EC teacher education programmes for four years and responsible for the programmes for six years.

In addition to identifying key ideas influencing my thinking during the development of my proposal, I took Maxwell's (2005) advice and wrote a researcher's identity memo in which I articulated my goals, previous experiences, assumptions, feelings and values as they related to this project, including the following four key assumptions and beliefs:

- First, I believe that EC teaching is complex, intellectual and emotional work. Expert teachers often make teaching look straightforward and easy - their interactions have a flow and continuity resulting from their ability to read the situation, and adapt and change their interactions moment by moment to match those of the children.

- Second, I believe that teachers should proactively adjust their interactions to match the children's. Teachers, as adults, are significantly more experienced in engaging in interactions than are young children and thus should use their expertise and skills to adapt to the child rather than expecting children, as more novice interactors, to adapt to them.

- Third, I feel that teacher responsiveness involves significant amounts of thinking in the moment as teachers analyse and reflect on what they think is going on and then tailor their responses as a result of these understandings.

- Finally, I believe that effective learning in ECE is enhanced by teachers who can recognise and follow children's cues, agendas and learning interests, not just in traditional learning activities and play contexts (such as sand play and blocks) but also in routine and incidental moments such as during transitions and meal-times.

My previous experiences and the values and assumptions I brought with me to this research project were both helpful and challenging. My familiarity with the sector and my credibility as a practitioner eased my entrance into the three centres. 
However, familiarity has its drawbacks: I found the transition from practitioner and lecturer to researcher challenging at times, particularly in terms of my role during the interviews. Familiarity can also inhibit one's ability to use new lenses to examine data, and I had to practise stepping back from the familiar in order to interrogate the data.

\section{The New Zealand context: Theoretical paradigms influencing pedagogical practices}

The broad context within which this study was undertaken is now examined, with a particular focus on the theoretical paradigms that have influenced pedagogical practices in New Zealand ECE settings. This is important given this study's focus on how EC teachers' reflection and thinking influences and impacts on their pedagogical interactions with children, and what theoretical positions underlie their practices. A brief overview of two key theoretical stances influencing pedagogy in New Zealand ECE is provided before addressing several specific approaches that have gained currency in recent years.

Traditionally, ECE services in New Zealand had been philosophically and pedagogically positioned within child study and developmental psychology paradigms, with a strong Piagetian influence on teaching practice (Cullen, 1996; Farquhar \& Fleer, 2007; Hedges, 2000). The development of the EC curriculum document, Te Whāriki (Ministry of Education, 1996), presented a broader theoretical focus by positioning socio-cultural influences alongside the dominant developmental paradigm. Today, the official discourse of EC curriculum and pedagogy in New Zealand is more firmly situated within a socio-cultural paradigm (see, for example, Ministry of Education resources such as Kei Tua o te Pae, 2004, 2009) although Farquhar and Fleer (2007) argued that "developmentalism is still a feature of current policy and curriculum in Aotearoa/New Zealand" (p. 34). 
The influence of developmental psychology has been reflected in the notion of the whole child and an emphasis within ECE philosophy and pedagogy on a childcentred, integrated, play-based and informal approach to curriculum and learning (Cullen, 1996; National Association for the Education of Young Children (NAEYC), 1997). Piagetian theory, in particular his view that children progress through qualitatively different stages of development and that they actively construct knowledge and understanding through engagement with the environment (Bee \& Boyd, 2010), has influenced the organisation and resourcing of New Zealand EC environments and teachers' conceptions of their teaching role. Robinson's (2007) study identified that Piagetian influences endure. She found EC teachers used several discourses to construct their work including a "discourse of childcentredness" which "positions the teacher to assess and meet children's individual needs in terms of the stage of their development" (p. 87).

The concept of developmentally appropriate teaching practices was initially founded on the dimensions of age and individual appropriateness (Bredekamp, 1987) that acknowledged that whilst developmental research indicates universal and predictable sequences of growth and development, each child is unique and there are individual variations in development. Later, NAEYC's (1997) revised statement on developmentally appropriate practices expanded the underpinning theoretical bases to include socio-cultural perspectives:

1. what is known about child development and learning - knowledge of agerelated human characteristics that permits general predictions within an age range about what activities, materials, interactions, or experiences will be safe, healthy, interesting, achievable, and also challenging to children;

2. what is known about the strengths, interests, and needs of each individual child in the group to be able to adapt for and be responsive to inevitable individual variation; and 
3. knowledge of the social and cultural contexts in which children live to ensure that learning experiences are meaningful, relevant, and respectful for the participating children and their families (NAEYC, 1997, pp. 4-5, italics in original).

Grieshaber (2008), whilst noting that this revised statement acknowledges the critical role of the teacher, has also argued that it continues to "privilege development over learning by consistently locating development first and learning second" (p. 508), a stance reflective of Piagetian theory that development precedes learning. According to Grieshaber, within developmentally appropriate programmes "teaching and teachers...take a back seat to children's development and learning" (p. 506). The role of the teacher is generally positioned as non-directive, facilitative (Siraj-Batchford, 2009) and reactive, with establishing and maintaining the learning environment one of their main responsibilities (Grieshaber, 2008). Such an approach makes it challenging for teachers to enter children's conceptual space (Fleer, 2010) and has been criticised by Fleer (1995) who stated that:

\footnotetext{
While DAP [developmentally appropriate practice] is useful, it does not provide a complete picture of the teaching-learning process for either the child or the teacher. The focus on the child is important, as too is a sound understanding of child development, but this emphasis only paints half of the cultural picture. Equal research and thinking needs to be directed to the role of the teacher and teacher-child interactions within cultural situations and contrived learning contexts such as centres and classrooms. (p. 15)
}

Similar criticisms of the dominance of developmental theory on ECE pedagogical practices are evident within the New Zealand context (Cullen, 1996; Farquhar \& Fleer, 2007; Jordan, 2009; Meade, 1999). More recently, writers have suggested that the view that developmental theory accords teachers a limited role has been due to "(mis)interpretations of Piaget's research and theory by early childhood educators" (Fleer et al., 2009, p. 197) (see, also, Siraj-Blatchford, 2009).

The theoretical shift towards socio-cultural influences in ECE was noted by Anning, Cullen and Fleer (2004): 
it is now well-accepted that early childhood education has been challenged by a theoretical seachange that has seen individualistic developmental explanations of learning and development replaced by theories that foreground the cultural and socially constructed nature of learning. (p. 1)

More recently, these approaches have been reframed as sociocultural-historical theory in order to encompass a broader range of theoretical developments (Anning et al., 2009), including Vygotsky's (1998) influential cultural-historical theory. Vygotsky argued that learning precedes development with learning occurring first on a social plane before being internalised and transformed by the learner. Central to Vygotsky's theory are the concepts of the zone of proximal development, the use of cultural tools within social contexts in order to mediate learning, and the transformational nature of learning (Wood \& Attfield, 2005). Drawing upon socio-cultural approaches, Grieshaber (2008) suggests that "the education of young children is better when it involves proactive teaching and focused interactive teaching" (p. 506), a more active role for EC teachers in children's learning than has traditionally been conceptualised in approaches based on developmental theories (Fleer, 1995; Hedges, 2000).

The increasing influence of a broad range of sociocultural-historical theories has led to a re-conceptualisation of pedagogy in ECE settings. Fleer and Richardson (2009) referred to Vygotsky's argument for "pedagogy which looked forward (towards tomorrow) in child development rather than being situated always in the past" (p. 131). Such an argument positions teachers as actively engaged in contributing to children's learning, particularly through the use of pedagogical strategies such as scaffolding and co-construction. In keeping with this notion, MacNaughton and Williams (2009) describe teaching as "a complex, highly interactive process" ( $p . x)$ requiring judgement of both timing and choice of interactive strategies in order to best support children's learning, whilst Hedges (2000) noted that teachers need to have "a range of flexible and dynamic teaching strategies at their fingertips to respond to children's changing interests, abilities, and needs" (p. 19). According to Jordan (2009), teachers who do have access to that full range of pedagogical 
strategies are able to move flexibly between scaffolding and co-construction in response to the learning situation.

More recently, Fleer (2010) has presented a model of pedagogy positioned within a cultural-historical framework through which teachers are able to support children's conceptual learning within play-based settings, thus attending to both traditional emphases on social learning and more recent demands for conceptual learning in, particularly, literacy and numeracy. In this model, children's everyday concepts and the related scientific (or academic) concepts are seen as dialectically related. Teachers engage in pedagogical framing to explicitly link these everyday and scientific concepts in order to create contextual and conceptual intersubjectivity between teacher and children. According to Fleer (2010), this model theorises the pedagogical practices necessary for teachers to engage in "sustained shared thinking" (Siraj-Blatchford et al., 2002, p. 147; see Chapter 2 for further discussion of this concept) with children.

Recognition of the influence of developmental and sociocultural perspectives on EC pedagogical practices is clearly evident in the literature (Anning et al., 2009; S. Edwards, 2007; Fleer, 2010). In addition, a number of specific theoretical and philosophical approaches to learning and pedagogy currently influencing New Zealand ECE services are briefly introduced: learning dispositions (Claxton \& Carr, 2004) and learning stories (Carr, 2001), the Reggio Emilia approach (Wright, Ryder \& Mayo, 2006), schema (Meade with Cubey, 1995; van Wikj et al., 2006), relational pedagogy (Papatheodorou \& Moyles, 2008), and the Pikler/Resources for Infant Educarers (RIE) approach (Gerber \& Weaver, 2002).

Learning dispositions refers to the attitudes and attributes learners possess that enable them to be "ready, willing and able" to engage in learning activities (Claxton \& Carr, 2004, p. 87, italics in original). Within Te Whāriki, learning dispositions are explicitly identified as important outcomes for children, supporting the development 
of children's working theories (Ministry of Education, 1996). Te Whāriki identifies five specific learning dispositions - “'taking an interest', 'being involved', 'persisting with difficulty', 'expressing an idea or a feeling' and 'taking responsibility or taking another point of view'" (Carr \& Claxton, 2001, p.22) - with Carr's (2001) learning stories framework providing a tool to document the emergence of these dispositions within the context of children's learning interests and strengths. Positioned within a socio-cultural paradigm, learning stories have become an increasingly influential approach to assessment (see, for example, the EC assessment exemplars within Kei Tua o te Pae (Ministry of Education, 2004, 2009)), foregrounding the development of learning dispositions as an important aim for EC education (Cowie \& Carr, 2009).

Several aspects of the Reggio Emilia philosophy and approach to early education have been influential with New Zealand EC practitioners, including Malaguzzi's oftcited vision of children as "rich in potential, strong, powerful, competent, and most of all, connected to adults and other children" (Malaguzzi, cited in Dahlberg, Moss \& Pence, 1999, p. 50) that aligns with the notion of children as competent and confident learners within Te Whāriki's (Ministry of Education, 1996) aspiration statement. The project approach, together with an emphasis on aesthetic physical environments, visual art as a means for children to express their thinking, and the importance of pedagogical documentation, are elements of Reggio Emilia pedagogy that have been of particular interest here (Anning et al., 2009; Hatherly \& Richardson, 2007; Pohio, 2009; Terreni, 2010) with two dedicated organisations established (Terreni, 2010) and a range of professional development opportunities available for practitioners. Whilst little research has been undertaken to date on how aspects of Reggio Emilia philosophy and pedagogy are being incorporated into New Zealand pedagogical practices, the New Beginnings Centre of Innovation project drew explicitly on Reggio Emilia philosophy in the development of their project focused on visual arts and project work (Wright et al., 2006). 
Schema theory (Athey, 2007) has been used by EC practitioners to understand patterns in children's thinking and behaviour, particularly in the mathematical and scientific domains, and to plan for, and engage in, pedagogical interactions that support children's exploration of schema (Meade, with Cubey, 1995) such as enveloping, rotation, and connecting. Schema refers to the form of children's thinking, fed by the content or curriculum experiences: Meade, with Cubey (1995) suggests that children may explore schema across a range of experiences and likens this to bees gathering nectar from many sources. Action research projects in New Zealand have assisted practitioners to identify children's schemas in action and to explore pedagogical practices that support schema exploration (Meade, with Cubey, 1995; van Wijk et al., 2006) such as providing resources that extend exploration, and engaging in responsive interactions, including conversations focused on schema concepts (Meade, with Cubey, 1995).

The term relational pedagogy is a relatively recent addition to the discourse on pedagogy in ECE, but the concepts underpinning it are familiar. In New Zealand, Te Whāriki positions relationships at the heart of the curriculum (Peters, 2008) through the guiding principle that "children learn through responsive and reciprocal relationships with people, places and things" (Ministry of Education, 1996, p. 14). Within relational pedagogy, teachers acknowledge that children's previous experiences and knowledge act to filter and inform new experiences and knowledge. Papatheodorou (2008) suggests that through relational pedagogy learners are empowered to become partners in their own learning; the teacher-learner relationship is founded on respect and attention to power dynamics, and teachers are also positioned as learners (Peters, 2008). Relational pedagogy requires that teachers are fully attentive and listen carefully to children, including their non-verbal cues and communication. According to Papatheodorou (2008), relational pedagogy "bridges dichotomies and polarised discourses such as child-centred/initiated versus 
adult-centred learning" (p. 11), and thus provides a useful theoretical tool for overcoming developmental versus socio-cultural debates.

Interest in the philosophical and pedagogical approach to infant care and education developed by Dr Emmi Pikler in Hungary and further developed as the RIE philosophy by Magda Gerber in the United States is increasing in this country (e.g., Dalli et al., 2009). Pikler's approach grew out of her role as director of the Loczy Institute which operated an orphanage for children aged from birth through three years. Two key themes run through the Pikler/RIE approach: first, that children are treated with respect manifested through careful and sensitive observation, development of trust, and freedom to explore, and second, that children are allowed to develop at their own pace without pressure to do more than they are capable of (Gerber \& Johnson, 1998).

The focus on respect promotes particular pedagogical practices, including telling the child what the adult is going to do before doing it, creating a calm atmosphere, and engaging in focused attentive interactions where the adult tries to read the child's non-verbal cues. Children are given space and time, and are encouraged to solve their own problems (Gerber, 1979). Alongside an emphasis on children's developing competency, fostered by sensitive, responsive interactions, children are not taught physical skills that they are likely to develop naturally if given space and time: "The infant is never put in a more advanced position, in order to promote gross motor development, than he is able to attain by himself from a basic supine position" (Pikler, 1970, cited in Gerber, 1979). Thus, children are allowed unrestricted movement rather than being placed in walkers or being propped up by cushions.

\section{Overview of the thesis}

This chapter introduced the thesis topic, outlined the research questions, presented the rationale for undertaking this study, and identified several key influences on my stance as a researcher. The broad context for this study has been considered by 
describing key theoretical influences on New Zealand ECE teachers' pedagogical practices. This final section outlines the organisation of the thesis.

Chapter 2 reviews the literature in order to position this study within a broader theoretical and empirical landscape. The chapter is organised into three sections, the first of which discusses theoretical constructs of reflective practice and reviews empirical studies of teacher reflection undertaken within EC contexts. Section two reviews recent empirical studies focused on EC teachers' understanding and use of different pedagogical practices, thus informing analysis and interpretation of the pedagogical decision-making and actions taken by the teachers in this study. Section three discusses situated perspectives of teachers (Greeno \& The Middle School Through Applications Project Group, 1998) within the social learning theory of communities of practice (Lave \& Wenger, 1991; Wenger, 1998) and reviews the literature around professional learning communities in order to consider the social influences on teachers' reflection and thinking about their practice. Studies of communities of practice or professional learning communities in ECE contexts are examined, together with New Zealand studies addressing aspects of EC team teaching.

Chapter 3 presents the interpretive paradigm underpinning this project and discusses methodological decisions to use multiple-case study design and qualitative data collection strategies, including group video-SR interviews. Detail is presented of the selection of the three case study centres, ethical consent procedures, and data collection processes. The three case study centres are then introduced. The chapter concludes with a discussion of ethical aspects, data coding and analysis, and issues of validity.

Chapters 4 through 6 present the results for each of the three case studies: Moana Early Learning Centre (Moana ELC), Summer Kindergarten, and Ngā Rangatahi 
Tamariki Early Learning Centre (Ngā Rangatahi Tamariki ELC) ${ }^{1}$. A similar format is used for each case whereby results for each of the three research questions are presented. Finally, in Chapter 7 the results for each case study are discussed and cross-case analysis is undertaken, again organised by the three research questions. The limitations of the research are identified and discussed before the implications of the study for policy and practice and for research are presented. The chapter concludes with a summary of the contributions of this study to the literature.

1 Teachers in each case study identified a pseudonym for their centre. 


\section{Chapter 2: \\ Literature Review}

\section{Introduction}

This chapter examines a range of literature in order to position this study within relevant theoretical frameworks and related empirical studies. The chapter is organised into three sections which reflect the research questions and the conceptual frameworks that underpin the research. These sections - teacher reflection and thinking, EC pedagogical practices, and the social contexts for teacher thinking and reflection - are not bounded but overlap and interweave in ways that reflect researchers' interest in understanding teachers' thinking, reflection and pedagogical practices in a range of educational settings.

In the first section conceptual frameworks for understanding teachers' thinking and reflection are examined. The discussion of existing research on teacher reflection and thinking situated within EC contexts positions this study within that empirical landscape and enables evaluation of its potential contribution to the field. Section two reviews recent empirical studies focused on EC teachers' understanding and use of different pedagogical practices to inform the analysis and interpretation of the pedagogical decision-making and actions taken by the teachers in this study.

The third section focuses on the social contexts within which teachers engage in thinking and reflection about their pedagogical practices to provide an underpinning theoretical framework for the study. As noted in the introductory chapter, EC teachers in New Zealand generally teach in teams and so this research has investigated influences of the team on individual teachers' thinking and reflection, drawing on situated perspectives of teachers (Greeno et al., 1998) within the social learning theory of communities of practice (Lave \& Wenger, 1991; Wenger, 1998) and the literature around professional learning communities. Studies of communities of 
practice or professional learning communities in ECE contexts are reviewed, together with New Zealand studies that have addressed EC team teaching more generally.

In sum, this review of the literature examines existing scholarly work concerning teacher reflection and thinking, EC pedagogical practices, and the social contexts of teaching in EC educational settings to inform aspects of this research. It also establishes gaps not previously focused on in research in EC teaching.

\section{Teacher reflective practice and thinking}

The importance of teachers' thinking and reflection as integral to effective teaching and on-going development as a teacher has received widespread acknowledgement (Clarke, 1995; Day, 1999; Jay \& Johnson, 2002; Luttenberg \& Bergen, 2008).

\section{Key theoretical influences on reflective practices}

The theoretical and empirical literature reveals numerous definitions and conceptualisations of what is meant by teacher reflection. According to Calderhead (1989) and Zeichner (1994), the notion of reflective practice is often bandied about by teacher educators and researchers with little understanding of the underpinning theoretical constructs. It is important, therefore, to identify relevant constructs and provide definitions of reflection that have informed this study before reviewing empirical studies of teacher reflection. Calderhead summed up the various approaches to reflection in teaching thus:

Looking across the concepts of reflective teaching that have been employed in discussions of professional training, they vary in terms of how they view the process of reflection (e.g., reflection-in-action, curricular deliberation), the content of reflection (e.g., teachers' own values, societal context, educational theory), the preconditions of reflection (e.g., the attitudes for reflection, the tutorial context in which reflection occurs), and the product of reflection (e.g., effective teaching, emancipation, an understanding of the relationship between values and practice). (1989, p. 44, italics in original)

Whilst settling on one definition of reflective practice is challenging, given the multiple stances and philosophical approaches evident in the literature (Zeichner, 1994), Zeichner and Liston (1996) suggest that: 
Reflective teaching entails the critical examination of experiences, knowledge and values, an understanding of the consequences of one's teaching, the ability to provide heartfelt justification for one's beliefs and actions and a commitment to equality and respect for difference. (p. 48)

This definition positions teachers' reflections on practice as occurring after the event but does not address reflection that teachers engage in during their practice. In this study, teacher reflection is viewed as an integral part of the complex work of teaching undertaken by thoughtful teachers (Clark, 1995), especially around their use of pedagogical strategies and the impact of these on children's learning. In particular, interest is focused on reflection that teachers engage in during the moment-by-moment activity of teaching and in the collective dialogue that occurs within teaching teams.

Three theorists have been highly influential in developing understandings around reflective practices in education: Dewey (1933), van Manen (1977), and Schön (1983, 1987). Dewey is widely acknowledged as having pioneered discussions of reflective practice in teaching (Calderhead, 1989; Jay \& Johnson, 2002; Zeichner \& Liston, 1996) from a stance of empowering teachers to improve schools and education (Yost, Sentner \& Forlenza-Bailey, 2000). His work is foundational to contemporary understandings of reflection in teaching (Zeichner \& Liston, 1996).

Dewey (1933) conceived reflection as an active, thoughtful, continuing process of examining beliefs and knowledge. He believed that reflection was holistic and proposed three fundamental attitudes necessary for teachers to engage in reflective practice: open-mindedness - considering perspectives other than one's own; responsibility - considering the consequences of their actions before, during and after an event; and wholeheartedness - scrutinising their own attitudes and practices with a view to growing and enhancing their own practice.

Van Manen (1977) was the first to propose a developmental framework for theorising reflective practice. He argued that reflection moves through three distinct stages, starting with an emphasis on technical aspects of teaching, followed by reflection on the assumptions underlying classroom practices (and the effects of 
those assumptions on learners), and concluding with reflection focused on the moral and ethical dimensions of teachers' decisions. Van Manen's framework has influenced the development of constructs for reflective practice (Grimmett. MacKinnon, Erickson \& Riecken, 1990) and teacher education approaches designed to address issues of social justice and equity (Gilbert, 1994). Both Dewey's and van Manen's writings are important to this study because of their contributions on reflective practice and for their additional theoretical lenses with which to explore and understand the reflective practices of the teachers in my study.

Schön's $(1983,1987)$ work on reflective practice has also been influential within teacher education (Clarke, 1995; Zeichner \& Liston, 1996) and has been pivotal for the conceptual understanding and design of this study. Arising from a "context of strong opposition to technicist approaches to professional development" (Gilbert, 1994, p. 515), Schön (1987) theorised that highly competent professionals engage in professional artistry as they manage complex situations to which there are no standard answers. Three concepts are central to Schön's (1987) theory: knowing-in-action, reflection-inaction, and reflection-on-action. Schön described knowing-in-action as the tacit knowledge revealed through our actions but which we are unable to describe easily. Reflection-in-action occurs in situations where our knowing-in-action has resulted in a surprising or unintended outcome that attracts our attention. In such situations:

We may reflect in the midst of action without interrupting it. In an actionpresent - a period of time, variable with the context, during which we can still make a difference to the situation at hand - our thinking serves to reshape what we are doing while we are doing it. (Schön, 1987, p. 26)

According to Hatton and Smith (1995), the attention to multiple factors in the midst of complex professional action is what makes reflection-in-action the most challenging type of reflection to undertake. Schön (1987) further noted that:

What distinguishes reflection-in-action from other kinds of reflection is its immediate significance for action. In reflection-in-action, the rethinking of some part of our knowing-in-action leads to on-the-spot experimentation and further thinking that affects what we do - in the situation at hand and perhaps also in others we shall see as similar to it. (p. 29) 
The immediacy of reflection-in-action is highlighted by Barnes (1992) who notes that teachers must respond to student behaviours and engagement in the classroom alongside their thinking about the achievement of long-term goals. In this study, the concept of reflection-in-action is useful for exploring the moment-by-moment adjustments made by EC teachers in their interactions with children.

The third concept, reflection-on-action, refers to reflection occurring before or after an event (Zeichner \& Liston, 1996), and may include reflecting on earlier reflectionin-action (O'Connor \& Diggins, 2002). According to Schön (1983) the two modes, reflection-in-action and reflection-on-action, assist practitioners to "surface and criticise the tacit understandings that have grown up around the repetitive experiences of a specialized practice" (p. 61). Thus, teachers engage in a spiral of reflection involving appreciation, action and re-appreciation. Teachers draw on their professional knowledge, values and existing practice to interpret what has occurred within the classroom and to determine how to proceed. Their actions, having been mediated by this first step of reflection, then lead to further reflection and a reinterpretation of the events (Zeichner \& Liston, 1996).

Whilst Schön's work on reflection has been highly influential in teaching, it is not without its critics. First, Zeichner and Liston (1996) argue that Schön's emphasis on the teacher's practice at an individual level ignores the influence and impact of external social conditions on teaching and learning. This view is shared by Convery (1998) who, in research focused on his own teaching, found that Schön's definition of reflection-in-action could cover almost all elements of a teacher's work from planning through to teaching and evaluation so that almost all his own reflection could be considered reflection-in-action rather than reflection-on-action. According to Convery, teachers adopting Schön's model tend to focus their reflection on their immediate classroom performance rather than on wider, more emancipatory issues. 
Convery highlights a second major critique levelled against Schön's work, the emphasis on reflection as a solitary activity, suggesting that the fundamentally private activity of reflecting-in-action binds practitioners into a process in which they are likely to maintain and defend current practices rather than opening themselves up to new possibilities of practice. Francis (1995), Yost et al. (2000), and Zeichner and Liston (1996) all argued that engagement in collaborative reflective dialogue with others enhances the quality of individual reflection, whether in-action or onaction. In advocating for collaborative approaches to reflection, Convery (1998) noted:

that reflection is not a cognitive activity which can be imposed on the social and emotional experience that is teaching; reflection must be recognised as an activity that can only be developed in conducive social and emotional circumstances. (p. 203)

Such circumstances, according to Convery, include critical, yet respectful, support from others.

The third major critique of Schön's work concerns his concept of reflection-in-action, which, according to Roth, Lawless and Masciotra (2001), is unworkable. Teachers, they suggested, do not have the luxury of time in the immediacy of classroom interactions to engage in reflection-in-action about either their use of pedagogical strategies or the students' learning. Drawing upon data from a larger study on teaching science, they presented vignettes of discussions between teachers and students that demonstrated the immediacy of the teacher's choice of strategies in response to the students' cues. They suggested that, rather than reflecting-in-action, the teacher has Spielraum or room to manoeuvre in the situation by making tacit use of a range of strategies. They note:

Spielraum, therefore, contributes to classroom interactions in two distinct ways. First, the teacher's readiness for action allows an unfolding of a realm of appropriate possibilities with the immediacy of the student-teacher transaction. Second, this realm of possibilities, in turn, allows the teacher a point of entry to unfold the reality of the students' understanding. (p. 187) 
Roth et al.'s (2001) focus on the practical, tacit knowledge of teachers and dismissal of reflection has in turn been criticised by Beck and Kosnik (2001). In a response to Roth et al.'s article, Beck and Kosnik acknowledged the importance of teachers being responsive to the cues received from the learner but argued that this did not preclude engagement in reflection-in-action. Instead they claimed "that teachers can reflect whilst teaching; that we commonly do; and that we must reflect while teaching if we are to be attentive and responsive" (p. 220, italics in original). They go on to state:

There are many advantages to reflecting and making adjustments while we teach: there is less danger of forgetting what actually happened; we can be more realistic about the circumstances; we can get just the right shading in our solutions through immediate feedback; we can improve our teaching in this lesson rather than waiting until a future one; and the students can see us making on-the-spot adjustments and learn through modelling how to do the same in their practical endeavours. (p. 222, italics in original)

Beck and Kosnik further suggested that Roth et al.'s (2001) position created a dichotomy between tacit knowledge and reflection that presents reflection as objective and detached from practice, a stance that they say reflects Dewey's (1933) views rather than Schön's. Beck and Kosnik (2001) noted that Schön sought to overcome any dichotomy between reflection and practice, seeing reflection instead as integral to and embedded within practice, and part of the ordinary work of teachers.

These criticisms of Schön's work are relevant to understanding the reflection-inaction of teachers in my study - what they were thinking about when engaged in interactions with children across a wide range of curriculum experiences - as well as for investigating the impact of team teaching on their reflection, both in- and onaction. My parallel interests in the private and the collective thinking and reflection of EC teachers determined that the methodology would need to enable individual teachers' reflection-in-action to be elicited within the context of a group process, and so may provide insights about whether the first two criticisms of Schön's work (i.e., reflection as a solitary activity focused on immediate teaching performance) were 
applicable to EC teaching. The third criticism, that reflection-in-action was unworkable for teachers, is one that this research may also provide insights into from the perspective of EC teaching. Given that both Roth et al.'s (2001) and Beck and Kosnik's (2001) arguments were located in a different educational context, there may be differences in whether and how EC teachers engage in reflection-in-action compared to colleagues in the compulsory school sector due to variations in both curriculum demands and pedagogical practices.

\section{Constructs of reflection}

Zeichner (1994) distinguished between different notions of reflection evident in the teaching and teacher education literature including: reflection which occurs before, during, or after action; reflection as an individual about one's teaching in comparison with reflection about the social conditions that impact upon teaching; reflection as a private activity as opposed to reflection as a collaborative, social practice; and, reflection as a rational, logical activity versus reflection that is also concerned with ethical and caring perspectives. Across these distinctions, a search of the literature reveals a number of models (e.g., Korthagen, 2004), typologies (e.g., Griffiths \& Tann, 1992; Jay \& Johnson, 2002), and traditions of reflective practice (Zeichner, 1994; Zeichner \& Liston, 1996). These are briefly reviewed now, in order to highlight the diversity of approaches used to investigate teacher reflective practice, and to provide a context for this study.

According to Zeichner (1994, p. 14), a "historical amnesia" exists regarding the traditions and conceptual frameworks underpinning much of the research into reflective practice. Zeichner identified five major traditions of reflection within teaching and teacher education in the United States: academic, social-efficiency, developmentalist, social-reconstructionist, and generic traditions. Within the academic tradition, reflection is focused on subject matter and how teachers can promote student understanding of content. The social-efficiency tradition emphasises the use of research to guide and inform teacher practices, either by directing teacher 
behaviour or by supporting teachers to develop and exercise their professional judgement whilst drawing upon research evidence. The developmentalist tradition is focused on students, emphasising their development, interests, and learning. The fourth tradition, social-reconstructionist, emphasises reflection on the social conditions that support or hinder learning, and the teacher's practices within these social conditions. Finally, the generic tradition concentrates on notions of reflection per se without considering the content or quality of the reflection. Zeichner and Liston (1996) emphasise that individual teachers tend to draw upon each of these orientations to reflection, rather than relying upon one specific approach.

Korthagen's (2004) "onion" model of change, which positions five levels of the teacher (behaviour, competencies, beliefs, identity, and mission) within concentric circles surrounded by the environment (the school, class and students) as a sixth layer, provides a framework of possible content for teacher reflection. According to Korthagen, attention is most often focused on the outer layers - behaviour and competencies - and it is important to support teachers' and student teachers' reflections on the inner layers, on what he described as "core reflection" (p. 90). Such reflection surfaces teachers' core qualities (such as empathy, understanding, compassion, and tolerance) and supports them to recognise and encourage these same qualities in their students.

Griffiths and Tann's (1992) typology of five levels of reflection - rapid reflection, repair, review, research, and re-theorising - positions reflection as increasing in depth and degree of abstraction at each level. Both rapid reflection and repair are acts of reflection-in-action whilst the levels of review, research, and re-theorising sit within the construct of reflection-on-action. Zeichner (1994) has criticised this approach as hierarchical, suggesting that it "devalues technical skill and the everyday world of teachers which is of necessity dominated by reflection at the level of action" (p. 14). Instead, Zeichner suggested these levels should be viewed as domains of reflection to avoid hierarchical thinking. 
The final typology of reflection discussed here is that developed by Jay and Johnson (2002) in order to teach reflective practice to student teachers. This typology draws heavily on Schön's work and presents the first dimension as descriptive reflection, which 'involves the intellectual process of 'setting the problem'; that is, determining what it is that will become the matter for reflection" (p. 77). This first level of reflection is followed by the comparative dimension, where the teacher reframes the issue to consider it from a number of different frames or perspectives. The highest level of reflection, the critical dimension, requires the teacher to consider the implications of the different dimensions and to deliberate before making a decision for action.

Whilst this research is not designed around Korthagen's (2004) model, or modelled on Griffith and Tann's (1994) or Jay and Johnson's (2002) typologies, their work contributes to the mapping of the reflective practice landscape within which my work will be positioned and may offer insights to help explain teachers' reflective practices in this study.

Overall, the literature supports reflection in teaching as positive and a good thing for teachers to engage in. However, a number of writers have cautioned against what Zeichner (1994) described as "an uncritical celebration of teacher reflection" (p. 18). It is not enough simply for teachers to engage in reflection (Loughran, 2002; Zeichner \& Liston, 1996) or make their tacit practice explicit (Zeichner, 1994). Furthermore, Loughran argued that "rationalisation may masquerade as reflection" (p. 35) and Zeichner suggested that there is potential for reflection to "legitimate and strengthen practices harmful to students" (p. 18). Davis's (2006) work has made a useful contribution in clarifying the differences between productive and unproductive reflection. She suggested that unproductive reflection is predominantly descriptive, lacks focus, does not include analysis or evaluation but may be judgemental. In contrast, productive reflection incorporates a number of features, including: questioning assumptions, being open to different perspectives and "ways of seeing" 
(Loughran, 2002, p. 35), being analytical, integrating knowledge, and being able to "see, attend to, and analyse the connections and relationships in a classroom" (Davis, 2006, p. 283) - a process which she argued is akin to Sherin and Han's (2004, p. 179) notion of "professional vision". Whilst Davis's articulation of productive reflection is positioned within student teachers' written reflections, she provides useful frames for examining and questioning teacher reflection within my study. Were they, for example, focused on describing what was going on during their interactions with the children or drawing on the features outlined by Davis to engage in productive reflection about their thinking and practices?

Finally, a number of authors have commented on factors that promote teacher reflection. The critique of Schön's work above included discussion of the importance of group collaboration and dialogue (Francis, 1995; Yost et al., 2000) and of multiple perspectives (Clarke, 1995) in enhancing reflection. To some extent these factors are accommodated in the research design of my study that incorporates opportunities for the team to engage in reflective dialogue in addition to initial individual teacher reports on their reflection-in-action. Whilst further studies in the vein of Clarke (1995) and Davis (2006) exist, their focus on assisting student teachers to develop reflective practices sits outside the scope of my study and, thus, these studies have not been included in this review.

\section{Teacher interactive thinking}

Schön's (1987) concept of reflection-in-action focuses on the practitioner engaging in reflection as a result of an unexpected outcome that attracts our attention. However, teacher thinking during interactions may not be limited to reflection in situations of surprise but may also include what Marland and Osborne (1990) have described as "teacher interactive thinking" (p. 94). Such thinking includes teachers considering how best to relate and respond to students, "based on their interpretations of student cues, verbal and non-verbal" (Mitchell \& Marland, 1989, p. 118), in a highly individualised manner. Several potential models of teacher 
interactive thinking were developed from exploratory studies: customised-response, opportunity seeking, problem-avoidance, and mood-assessment models (Marland, 1986; Mitchell \& Marland, 1989). In the customised-response model teachers thought about how to respond to students, both individually and as groups, drawing on their perceptions and interpretations of events. Teacher thinking within the opportunity-seeking model referred to those instances where teachers drew upon principles to shape their practice in the moment of their teaching. The problemavoidance model refers to teachers' thinking where they actively tried to cope with problems that arose during their teaching or aimed to anticipate and address potential problems that they foresaw arising later in their lesson. Finally, teachers' thinking located within a mood-assessment model referred to that undertaken by teachers whereby their judgements of the class (and individual students') mood influenced their choice of interactive behaviours with which to begin the lesson (Marland, 1986; Mitchell \& Marland, 1989). Whilst located in the school sector, the concept of interactive thinking is a useful one for this study and the models described above may contribute to data analysis.

\section{Reflective practice in early childhood education}

The empirical literature includes studies focused on reflection, teacher thinking, and teacher practical knowledge located within ECE contexts. Thirteen studies which addressed one or more of these aspects relevant to the present study are reviewed here. Studies that involved student teachers or teacher education programmes in ECE are not included; these often focused on descriptions of programmes designed to foster reflection in student teachers, and thus were outside the major focus for this study.

The thirteen studies located varied considerably in terms of their size from, for example, a comprehensive, multi-method study designed to develop a framework for effective pedagogical strategies in the early years (Moyles et al., 2002a, 2002b) through to studies that focused on a single teacher (Deans, Brown \& Young, 2007; 
Kugelmass \& Ross-Bernstein, 2000) or a single EC setting (K. Edwards, 2009). Similarly, a wide range of methodologies was utilised (with several studies using a multi-method approach), including stimulated recall interviews, or variants (see Chapter 3, p. 66 for discussion of this method) (Berthelson \& Brownlee, 2007; Cremin, Burnard \& Craft, 2006; Degotardi \& Davis, 2008; Kugelmass \& RossBernstein, 2000; Moyles et al., 2002b; Pui-Wah \& Stimson, 2004; Wood \& Bennett, 2000), group processes of reflective inquiry (Black \& Halliwell, 2000; Wood \& Bennett, 2000), observation of teacher practices (Kugelmass \& Ross-Bernstein, 2000; Stephen \& Plowman, 2008; Stipek \& Byler, 1997; Vartuli, 1999), questionnaires eliciting teacher self-reports (Stipek \& Byler, 1997; Vartuli, 1999), interviews (Berthelson \& Brownlee, 2007; K. Edwards, 2009; Moyles et al, 2002a; Pui-Wah \& Stimson, 2004), and teacher journals (Deans et al., 2007). Five themes are used here to organise the review, with some studies contributing to more than one theme: (a) reflection as a component of pedagogical practice; (b) teacher beliefs; (c) tacit knowledge; (d) collaborative reflection; and (e) reflection-in-action.

\section{Reflection as a component of pedagogical practice}

Four studies addressing pedagogical practices included a focus on reflection. Of these the most useful for my study is Moyles et al.'s (2002a) project that investigated the characteristics of effective pedagogy in practitioners teaching 3 - 5 year olds in order to develop a pedagogical framework. Three facets of this research are particularly relevant. First, Moyles (2002b) and her colleagues found that in interviews practitioners were able to describe their practices but not why they engaged in particular practices, despite being "implicitly steeped in the principles, philosophies, theories and beliefs upon which they based their practice" (p. 467). This finding led to the second key aspect - methodological developments in the project - with the introduction of a variant of video-SR interviews described as reflective dialogues to enable teachers to reflect on their practices when viewing examples of their teaching they felt were effective. They reported that: 
Video evidence of practitioners' roles has given clear insights into their understanding and ability to:

- reflect upon that practice;

- interrogate their own principles underpinning practice;

- reflect on their own qualities, knowledge and thinking and how these impact upon practice;

- articulate their own understanding of effective pedagogy. (Moyles et al., 2002a, p. 3)

The third relevant aspect was the inclusion of reflective practice within a framework of effective pedagogy conceptualised around three interwoven dimensions practice, principles, and professional - each with three sub-dimensions. The professional dimension incorporated a focus on reflection and thinking with elements of effective pedagogy organised under the root sentence "Effective practitioners are reflective and thoughtful people who..." (Moyles et al., 2002a, p. 57) and encapsulated in twelve key statements. Moyles et al.'s (2002a, 2002b) finding that reflective dialogues were useful in supporting teachers to access their tacit knowledge supports my use of video-SR interviews in this study. Additionally, their inclusion of reflective practice as a key component of effective pedagogical practices, underpinned by both their data and an extensive literature review, supports the proposition that effective EC pedagogy is complex and dynamic, as well as the hypothesis that teachers' thinking and reflection influences their use of interactive pedagogical strategies.

Three other studies on reflection and thinking relating to pedagogical practices were exploratory, small-scale, and had a relatively narrow focus. Cremin et al. (2006) used videos of three teachers' interactions with children in stimulated recall interviews to facilitate reflection on how their pedagogical practices supported children's possibility thinking. Their results highlight three pedagogical strategies used by the teachers: standing back in order to carefully observe the children whilst still being available to them; prioritising learner agency and giving children room to make decisions and initiate their own activities; and creating time and space in which to utilise a wide range of resources creatively. Kugelmass and RossBernstein's (2000) case study of one teacher's understandings of her interactions 
with her class of 4- and 5-year-old children also used video recordings of the teacher's interactions together with interviews. Their analysis identified both explicit and implicit influences on the teacher's interactions, highlighting both the role of context in teacher-child interactions and the importance of teachers engaging in critical reflection on their roles and interactions. Degotardi and Davis's (2008) study of how 24 EC practitioners interpreted the actions and behaviours of infants is useful because of its attention to practitioners' reading of, and attention to, behavioural cues given by non-verbal children. Being in tune with and responding sensitively to young children is, as Degotardi and Davis asserted, important in the development of relationships that enhance children's learning and development.

\section{Teacher beliefs}

Kugelmass and Ross-Bernstein's (2000) and Degotardi and Davis's (2008) research also investigated teacher beliefs and their impact on teacher thinking, reflection, and practice. Both studies found that a mix of explicit and implicit beliefs impacted upon the thinking and reflection of practitioners. In particular, Degotardi and Davis found little connection between the interpretations of infants' behaviour made by the practitioners in their study and what they describe as "professionally informed beliefs" (p. 229) with, instead, a high reliance on naive beliefs. Parallels with this last study are evident in the work of Berthelson, Brownlee and Boulton-Lewis (2002) who explored the epistemological beliefs of practitioners working with children aged under-3 years in childcare and how these beliefs impacted on their practices. They found that epistemological beliefs were related to metacognitive capacity such that practitioners who had "conceptions of caregiving that integrated ideas and evidenced a deeper understanding of the relationship between teaching and learning were more likely to practice in ways that engage teacher and learner in active learning partnerships" (Berthelson et al., 2002, p. 13).

More recent analyses have applied a framework of teaching functions to determine whether these practitioners conceptualise their roles in terms of affective (care), 
cognitive (education) or executive (overarching principles informing practice) roles. Berthelson and Brownlee (2007) determined a continuum of "sophisticated beliefs", which are "derived from a thoughtful evaluation of experiences, reflecting individuals' capacities to be reflective about the knowledge that informs their practices" (p. 349). Thirty percent of their participants were at the low end, $60 \%$ were at the medium level, and $10 \%$ were at the high end of the continuum, and Berthelson and Brownlee suggested a link between educational levels and more sophisticated belief systems. Findings such as those reported by Degotardi and Davis (2008) and Berthelson and Brownlee (2007) support the intention in the present research to focus on qualified, experienced teachers rather than on student or unqualified teachers.

Two other studies on teachers' beliefs and the impact of these on practice report contradictory results. Wood and Bennett's (2000) investigation of the relationship between nine teachers' theories of play and their practices encouraged participants to reflect on their own beliefs and practices. Reflection was stimulated through individual reflections around teachers' narratives of their practice, through video-SR interviews, and through participation in group discussions. The use of video-SR was "reported by the teachers to be a particularly powerful medium for confronting them with their practice, and more importantly, enabling them to perceive the discontinuities between their intentions and action" (р. 639). It resulted in an unintended outcome of the study whereby each teacher reported changing her beliefs, practices or both as a result of involvement in the research.

In contrast, Pui-Wah and Stimson (2005) noted little change in the beliefs and/or practices of the six Hong Kong kindergarten teachers who participated in their yearlong exploration of these teachers' personal theories of play-based learning, and how they were enacted in practice. Results indicated that there was significant disparity between most teachers' espoused and actual practice, with only one teacher engaging in practices reflecting a child-centred, constructivist approach to play consistent with the official discourse on kindergarten pedagogy and curriculum. 
They attributed the teachers' failure to implement a child-centred, constructivist approach primarily to an inability to engage in critical thinking and reflection about practices and underpinning theories. These studies indicate the interplay between teachers' beliefs (both explicit and implicit) and teachers' ability to engage in the metacognitive activity of reflection (whether in-action or on-action), as well as the impact on their pedagogical practices in EC settings.

Two final studies which focus on teacher beliefs in ECE sought to examine the relationship between teacher beliefs and classroom practices but do not include an explicit focus on teacher reflection as part of the research design. Through the use of teacher self-reports of their beliefs and practices and through classroom observations, both Stipek and Byler (1997) and Vartuli (1999) found more congruence between the beliefs and practices of pre-kindergarten and kindergarten teachers than those of teachers in grade one classrooms or in grade one through three classrooms respectively. The researchers in both studies suggested that teachers working with younger children found it easier to enact their beliefs due to less pressure to conform to school district requirements for particular curricular approaches. Whilst conforming to external demands for particular curriculum delivery approaches is unlikely to be an issue faced by the teachers in my study, given the philosophical approach within Te Whāriki (Ministry of Education, 1996) whereby services weave their own curriculum whāriki, or mat, reflecting their community, programme philosophy and service structure, these studies highlight the potential for incongruency between espoused beliefs and actual practices.

\section{Tacit knowledge}

The tacit nature of much teacher knowledge is recognised in the wider literature on teacher thinking and reflection (Schön, 1987; Zeichner, 1994; Zeichner \& Liston, 1996) and has been acknowledged as a feature in several of the EC studies discussed above (Degotardi \& Davis, 2008; Kugelmass \& Ross-Bernstein, 2000; Moyles et al., 2002a, 2002b). Black and Halliwell's (2000) research specifically 
focused on teacher reflection as a vehicle to uncover and explore the tacit knowledge that participating teachers used to inform their everyday teaching practices. In their study, teachers engaged in cycles of reflective inquiry using reflective conversations, storytelling, drawing, metaphor and journals as data gathering methods. Teachers reportedly found the process of reflecting on themselves in relation to challenging teaching situations very liberating, and Black and Halliwell noted the potential for such processes to be utilised in teacher education and professional development programmes.

Stephen (2010) suggested that there is a "taken-for-granted nature of pedagogical actions" which she believed "contributes to the apparent reluctance of practitioners to talk about their own pedagogic approach" (p. 23). Her view was that:

\footnotetext{
The construction of their own behaviour as instinctive may lead early childhood practitioners to undervalue the contributions which their actions make to children's learning and also limit the opportunities for enhancing practice that can be derived from reflection on actions and interactions in the early years playroom or classroom. Seen from a sociocultural theory perspective, interactions with adults are a key ingredient in the learning process. (p. 23)
}

Thus, research to date provides evidence of the influence of tacitly held knowledge and the challenges teachers face in trying to articulate that knowledge. Data gathering methods that allow teachers to consider actual episodes of their own teaching and of children's learning appear most productive in supporting teachers in the process of unearthing and articulating their knowledge and intentions. The use of video-SR in this project to explore teachers' thinking and reflection is thus supported by existing research in this area.

\section{Collaborative reflection}

Earlier discussion has highlighted that engagement in collaborative reflective dialogue with others enhances the quality of individual reflection, whether in-action or on-action (Convery, 1998; Francis, 1995; Yost el al., 2000; Zeichner \& Liston, 1996). Within ECE contexts, Black and Halliwell (2000) highlighted benefits of 
teacher collaborative reflection, including providing emotional support and reducing isolation, giving confidence in professional decision making, and identifying knowledge needed for dealing with challenges in the workplace. Wood and Bennett (2000) emphasised that the research methodology employed in their study enabled participants to engage in a reflective process alongside others who, through virtue of their similar backgrounds and knowledge base, could offer knowledgeable alternatives to their perspectives. Only one other ECE study was located that addressed collaborative reflection. K. Edward's (2009) study of New Zealand EC teachers' perceptions of teaching science included the use of group interviews and found that the debates that arose during these interviews "served to provoke reflection about the way the centre as a whole supported children's scientific learning and the dialogue between the participants created a forum for critique and encouraged reflection" (p. 113). K. Edwards further noted the interplay between individual and collective reflections, suggesting that group dialogue has an important role to play in assisting individual teachers to identify and think about their beliefs and pedagogy as they related to science education.

\section{Reflection-in-action}

Although each of the studies discussed above has focused in some way on the beliefs and reflection of EC teachers, and how these intersect with and inform their decision-making and practices, none have done so by investigating EC teachers' reflection-in-action. A search of the literature found only one small study that explicitly focused on reflection-in-action: Deans et al. (2007) provided a detailed description of a drama teacher's reflection-in-action during a session with a group of 4- and 5-year-olds. Told through the teacher's voice, the description illustrates the complexity of the teacher's thinking and her roles as she co-constructs the story with the children, and the challenges of trying to reflect on her own actions in the midst of the drama. Through re-telling this teacher's story, Deans et al. (2007) aimed to "deprivatise" and make explicit her reflective dialogue. 
The empirical literature reviewed above reveals that little research has been undertaken focusing on teachers' reflection and thinking about their pedagogical interactions with children in ECE contexts. The connections between my study and those reviewed above have been identified and clearly there is a gap in the literature. This study stands alone in terms of its focus on teachers' reflections and thinking about their teaching interactions in three diverse ECE settings.

\section{Empirical studies of pedagogical practices in early childhood education}

Within recent years a diverse literature on research into pedagogical practices has emerged including studies that investigate: (a) the effectiveness of different pedagogical practices used by EC teachers (e.g., Moyles et al., 2002a; SirajBlatchford et al., 2002); (b) patterns of teacher interactions with children (e.g., de Kruif, McWilliam, Maher Ridley \& Wakely, 2000); (c) affective aspects of teacher relationships with children (e.g., Goodfellow, 1998); (d) the use of language to support children's learning in specific areas (e.g., Frampton, Perlman \& Jenkins, 2009); (e) the use of specific teaching strategies (e.g., Jordan, 2009); and (f) research into pedagogical practices related to curriculum content (e.g., K. Edwards, 2009).

\section{Effective early childhood pedagogy}

Two extensive empirical studies into effective EC pedagogy were located. The first of these, Siraj-Blatchford et al.'s (2002) Researching effective pedagogy in the early years (REPEY) project, offers concepts of effective practice and analytical constructs useful for understanding the pedagogical intentions and actions of the teachers in my research. Their study aimed to identify the pedagogical strategies used in effective EC settings, building upon the earlier Effective provision of preschool education (EPPE) longitudinal study (Sylva, Siraj-Blatchford, Sammons, Melhuish \& Taggert, 1999) of young children's developmental progress. Twelve 
services from that project, where children had achieved higher than expected developmental outcomes, were identified for in-depth case studies. The major data source was observations (400+ hours) undertaken in ten services of practitioners' interactions with 254 target children of different ages, ability and gender. Learning episodes within a random sample of these observations were identified and analysed to determine whether activities were child- or teacher-initiated, and the level of cognitive challenge, adult contributions, available learning resources and materials, and influence of routine events and rules (Siraj-Blatchford et al., 2002).

The findings of the REPEY study indicate that there is no single effective pedagogical practice but that effective practitioners "orchestrate pedagogy" (SirajBlatchford et al., 2002, p. 43), planning their interactions and adapting these to match the learning intentions of the activity and the individual child's zone of proximal development. Offering a balance between teacher-led planned activities and child-initiated play activities in which teachers participate to extend children's learning was identified as an important aspect of effective pedagogy.

Practitioners in effective settings engaged in more cognitive (sustained shared thinking, direct teaching, monitoring) than social (encouraging, behaviour management, social talk, care) pedagogical interactions. A key finding was that episodes of sustained sharing thinking between children and adults were more likely to occur in excellent (i.e., those whose EPPE profiles showed that children achieved outstanding cognitive and/or social outcomes) settings, often in learning episodes initiated by children in which adults extended the cognitive challenge. In contrast, monitoring was the cognitive pedagogical practice used most frequently by staff in good (i.e., very good outcomes were achieved) centres. Episodes of sustained shared thinking were described as ones:

in which two or more individuals 'worked together' in an intellectual way to solve a problem, clarify a concept, evaluate activities or extend narratives etc. During periods of sustained shared thinking both parties contributed to the thinking and developed and extended the discourse. (Siraj-Blatchford, 2009, p. 157) 
When learning episodes were analysed for their level of cognitive challenge, similar proportions were recorded across the excellent (26\% of episodes) and good (22\%) centres. However, almost half these episodes in the excellent centres involved adult involvement that extended a child-initiated activity compared with one-sixth of those in good centres. Differences in social pedagogical practices were also evident between the staff in excellent and good centres. Staff in excellent centres used more encouragement and social talk with children whilst those in good centres engaged in more interactions around behaviour management.

A contemporaneous project, Moyles et al.'s (2002a) Study of pedagogical effectiveness in early learning (SPEEL) ethnographic study was referred to in the earlier section on teacher reflection. In contrast to the REPEY study (Siraj-Blatchford et al., 2002), this study directed its focus on practitioners rather than on outcomes for children. It aimed to identify elements of effective pedagogy for teaching children aged 3 - 5 years in British EC contexts and to develop a framework of these characteristics for use with early years' practitioners. Attention here is given to their findings concerning effective pedagogical practices rather than to the resultant framework.

Moyles et al.'s (2002a) findings revealed the complexity of effective EC pedagogy, and that many practitioners were surprised at this complexity. Despite these centres being identified as excellent, significant variations in the quality of practices were evident with few practitioners working at an excellent level. Practitioners were generally uncomfortable with the discourse of teaching, preferring to position their work as enabling, facilitating, and supporting children's development and learning. Variations in practitioners' awareness of their impact on children's learning were evident, and when teaching did occur this was not always linked to children's learning interests and needs. Although play was highly valued, practitioners' understandings of their role in enhancing children's learning in play contexts was not well understood; similarly, using scaffolding as a strategy was challenging for many due to limited understanding of the concept. 
The focus on both thinking (highlighted in the earlier section on teacher reflection) and practice within this study is what makes it influential in terms of my research. Whilst the final SPEEL framework provides a useful tool for examining data from my case studies, it is the findings noted above that highlight potential issues that might arise with the teachers in my study. Alongside the REPEY results discussed earlier, they alert to potential variability in pedagogical practices that may emerge and the challenges that the teachers may face in articulating their practice.

The above discussion of the REPEY and SPEEL studies highlights direct pedagogical interactions between teachers and children. Temporal distinctions between teachers' pedagogical practices were also noted in the REPEY study and are evident in another study focused on pedagogical practices that support children's learning through information and communication technologies (Stephen \& Plowman, 2008). When Stephen and Plowman investigated the use of guided interaction, or adult assistance, designed to overcome children's unsuccessful interactions with technologies in eight Scottish pre-schools, they found such assistance did not occur only through direct interactions. They elaborated their initial concept of guided interaction to include both distal (indirect) and proximal (direct) aspects wherein the former occurs when the children are not present and includes planning and arranging access to materials. Proximal guided participation involved teachers' direct actions such as their spoken and non-verbal language, physical behaviours, and engagement in reciprocal interactions (Stephen \& Plowman, 2008).

In the REPEY study Siraj-Blatchford et al. (2002) distinguished between pedagogical interactions and pedagogical framing - the former encapsulates teacher behaviours whilst the latter includes those activities that occur as a backdrop to the interactions such as planning, setting up the environment, and organising routines. Given that both Siraj-Blatchford et al. (2002) and Stephen and Plowman (2008) found indirect facets of pedagogy contributed to enhancing children's learning, it will be important to be alert to teachers' reflections about these aspects in my data. 


\section{Patterns of teacher interactions}

Attention is now turned to empirical studies which focus on more specific aspects of teacher interactions and pedagogy. In the United States, measures of interactions (redirecting, introducing, elaborating, following, informing, acknowledging, and praising) were used to investigate the interactive patterns of 63 teachers working with infants and toddlers. Teachers' interactions reflected four clusters of behaviour patterns: elaborative, controlling, non-elaborative, and average (de Kruif et al., 2000). Teachers identified as controlling behaved quite differently from teachers identified in the other three categories, exhibiting high levels of re-directing behaviour and low ratings on the remaining six interactive behaviours. Children in classrooms with these teachers were observed to be less engaged than children in other classrooms (de Kruif et al., 2000). Their findings indicate the importance of sensitive teacher interactions, a facet of pedagogical practice that the following two small-scale studies suggest promoted strong relationships between teachers and children, and supported teachers in developing intersubjectivity with children.

\section{Affective aspects of pedagogy}

In Australia, Goodfellow's (1998) narrative inquiry research into the views of five teachers responsible for student teachers on practicum found that being able to engage in caring relations (Noddings, 1984) with children was perceived as a key quality of effective teaching. Her data revealed that such relationships incorporated the elements of affection, attunement, receptiveness, respectfulness, responsiveness, empathy, engrossment, and ethical ideal (Goodfellow, 1998).

Brennan's (2007) ethnographic case study focused on how children are enculturated into an EC centre culture and learn to be part of a New Zealand group childcare community. One phase of her data gathering involved daily observations of the social practices associated with mealtimes over a period of four months. This routine event was often a source of tension between the structural demands of the group childcare setting and individual children's ability to manage those demands when 
tired and hungry. Brennan found the relationships established between teachers and children were critical in supporting children's induction into the group and in maintaining group cohesion. Teachers invested significant energy in developing and maintaining those relationships and were found to use a number of strategies, including gentle teasing, humour, and tenderness, to both support children's participation at mealtimes and ensure that their emotional needs were met. Collectively, these studies suggest that affective elements of teacher interactions are important aspects of EC pedagogy. This stance is explicitly embedded within $T e$ Whāriki (Ministry of Education, 1996) and is thus likely to feature in the reflections of teachers in my study.

\section{Teacher language interactions to support children's learning}

Several studies have focused on aspects of teachers' language interactions with children. These include Durden and Dangel's (2008) exploratory study of conversations between teachers and children in small-group activities, Kontos's (1999) study of 40 Head Start teachers' involvement and talk during free play episodes, and Kugelmass and Ross-Bernstein's (2000) case study of an experienced teacher's interactions with children (referred to in the section on teacher reflection above). Participant observations and video-recordings in this last study revealed the teacher's patterns of verbal and non-verbal interactions with the children. The latter included ways in which the teacher positioned herself in relation to the children, maintained eye contact, touched and held children whilst distinct temporal patterns were found in her verbal interactions through which the teacher actively made connections between past, present and possible future events (Kugelmass \& Ross-Bernstein, 2000).

Kontos (1999) audio-taped the verbal interactions of 40 teachers in 22 Head Start classrooms in order to examine the roles and talk they used during free play time. Teachers were found to have different patterns of participation across different types of play activities, and different patterns of roles within them. Both activity setting and 
teacher roles had a mediating effect on teacher talk. Kontos found that although $68 \%$ of teachers' talk was directly related to the children's play, indicating their active involvement with the children during these free play sessions, their conversations lacked stimulating content to extend learning. Similarly, Durden and Dangel's (2008) exploratory study of conversations between two teachers and young children in small-group activities found little evidence of cognitivelychallenging talk with, instead, teacher-dominated conversations, an over-emphasis on simple questions, and IRE (initiate, respond, evaluate) patterns of questioning.

The use of questions by teachers was specifically addressed in two reports. Further analyses of data collected in the REPEY study (Siraj-Blatchford et al., 2002), referred to earlier, examined teachers' use of questions. Fine-grained definitions of the purposes of both open-ended and closed questions were applied to 5808 questions recorded during 400 hours of observations. Of these, only $5.5 \%$ were coded as open-ended questions likely to encourage children's thinking and engagement in sustained conversations (Siraj-Blatchford \& Manni, 2008).

A smaller study of 20 Pasifika teachers in A'oga Amata (Pacific Island Immersion ECE centres) (Mauigoa-Tekene, 2006) also found high usage of low-level, closed questions by teachers, together with minimal use of wait time for responses and patterns of asking questions mostly of children within teachers' immediate line of sight. Following an action research professional development intervention, MauigoaTekene found a "substantial improvement" (p. 19) in the complexity of questions asked and the use of wait time, although the research design did not enable longterm effects of the intervention to be measured.

Two studies were located that focused on teacher language use for particular purposes or within a specific activity. Frampton et al.'s (2009) study of 393 teachers in 103 classrooms investigated the extent to which teachers used metacognitive language during their interactions with children. Results indicate that teachers used 
mental state language (indicated by the use of words such as think, know, believe, wonder, and emotional states) in $22 \%$ of the 20 -second snapshots in which they were observed, perspective taking statements in $3 \%$ of the observations, and questions related to the child's activity in $12 \%$ of the observations. The authors posited that the considerably higher proportion of mental state utterances may relate to the types of activities commonly found in EC centres, such as storytelling and dramatic play, and suggested teachers may need to consciously and intentionally utilise metacognitive language focused around children's activities and perspective taking.

Teachers' use of language in specific activities also appears limited. A Canadian study of the language support practices of 22 educators with 4-year-old children during snack-time used an observational rating scale to measure practices that were: (a) oriented towards the child's involvement in interactions; (b) promoted social interaction; and (c) modelled and extended language (Bouchard et al., 2010). The authors found that teachers used such practices infrequently during the snack time routine with few opportunities provided for children to initiate interactions and little evidence of teachers listening to, or following, children's lead in conversations.

Collectively, the studies reviewed here indicate that EC teachers' use of language interactions, whether generally or in more specific situations, are frequently pitched at a low level, involving minimal cognitive challenge and lacking genuinely reciprocal conversations with children. The studies provide insights into what is known about teachers' use of language interactions in EC contexts that will inform the analysis of the teachers' thinking and decision-making around this aspect of pedagogy in my study.

\section{Specific teaching strategies}

Empirical evidence is also available concerning EC teachers' use of pedagogical strategies such as scaffolding, co-construction, and guided participation. As part of a larger study into preschool classroom instruction, Pentimonti and Justice (2010) 
reported how five teachers working in Head Start classrooms used specific scaffolding behaviours with 4-year-old children during group read-aloud sessions. A professional development intervention focused on scaffolding strategies intended to support children's successful participation in literacy activities that may be challenging for them (high-level support) and to encourage their continued participation in activities they were already competently engaged in (low-level support). Pentimonti and Justice found that low-level scaffolding strategies (generalising, reasoning and predicting) were used most often, despite teachers' beliefs that they used high- (co-participating, reducing choices, and eliciting) and low-level strategies equally.

In a second study, Williams, Mastergeorge and Ontai (2010) focused on how caregivers in three EC centres used scaffolding and guided participation to support infants' social encounters with their peers. Video-taped time-sample observations of 36 infants' interactions with peers and teachers were undertaken and questionnaires rating the children's social behaviours were completed by teachers at the time of observation and six months later. After analysing the observations, teachers' social scaffolding strategies were identified as adult-centred (i.e., classroom management-style strategies directed by the adult), child-centred (i.e., strategies that followed the child's lead and were generally non-directive) or group (i.e., where the teacher interacted with two or more infants simultaneously) interactions. Teacher use of particular social scaffolding approaches was found to predict infants' later social competence with peers; both adultcentred and group-based scaffolds were linked to less peer sociability over time.

Jordan's (2009) action research project involved teachers in four EC centres collectively examining their interactions with children to identify episodes when children were most empowered in their learning; it was in such episodes that differences between scaffolding and co-constructive strategies became apparent. Jordan developed a model of intersubjectivity that distinguished between situations where adult and child are equal partners and co-constructors in the interaction (and 
where full intersubjectivity is practised), where adults are directing the interactions and hence are scaffolding children's learning, and where the child is directing the interaction and the adult is supporting but not adding to the discussion or activity. In the latter two situations, Jordan identified that the area of shared learning or intersubjectivity is less than it might be. In order to engage in co-construction with children, Jordan found that teachers needed excellent communicative skills and a willingness to gain relevant content knowledge underpinning children's interests. Two New Zealand studies that included a focus on this latter aspect, curriculum content knowledge, are the focus of the final part of this section of the chapter.

\section{Content knowledge and pedagogical practices}

Hedges (2007) investigated how a community of inquiry might be co-constructed in two New Zealand EC centres, using participant observation, formal and informal interviews with teachers, parents and children, and "facilitated inquiry sessions" (p. 123). Children's interests and how these were enacted within the centres, together with how teachers recognised and responded to these interests, were examined using a funds of knowledge approach as the conceptual framework. Teachers were found to engage with children and their interests variably, with their knowledge of children and families' funds of knowledge, their own funds of knowledge, and the interactive styles of children all influencing which children's interests were recognised and engaged with. Implications for teaching practice relevant to this study were identified, including the importance of teachers engaging in sustained interactions with children where they listen to, support and challenge their ideas. Hedges (2007) suggested that engagement in such interactions requires that teachers consider structural and organisational factors to create uninterrupted time for interactions, focus carefully on the centre environment and how children are revealing their interests through their interaction with the environment, and develop strong partnerships with children's families in order to gain insights into the funds of knowledge that children tap into outside of the centre environment. 
Finally, K. Edwards (2009) investigated the perceptions that teachers in one EC centre held about teaching science. Teachers recorded instances of children engaging in scientific learning and participated in individual and focus group interviews. Teachers in this study conceptualised their role as supporting children's scientific knowledge, understandings and ability to use scientific processes, and scientific learning dispositions (K. Edwards, 2009) by following children's interests spontaneously and in planned experiences. A constructivist approach was employed by the participants in her study, with teachers using a range of teaching strategies that mostly sat towards the non-directive end of Bredekamp and Rosegrant's (1992) continuum of teaching interactions.

To conclude, the purpose of this section of the review was to identify the empirical evidence concerning EC pedagogical strategies and interactions, in order to understand more clearly the teachers in my study and to be able to position their thinking and practices within current knowledge about EC pedagogy. Taken together, these empirical studies demonstrate that effective teaching in EC contexts is complex and challenging, and that many EC practitioners struggle to consistently engage in pedagogical practices that enhance children's learning. Many studies have focused on particular pedagogical interactions or practices located in specific learning contexts and, therefore, their value lies in their collective attention to a broad range of effective interactions and teaching strategies that the teachers in my study may identify that they used (whether deliberately or tacitly) as they reflect on their teaching across a range of episodes.

\section{Social contexts for teacher thinking and reflection}

This study is focused on teachers' reflection and thinking about their interactions with children, both as individuals and as team members teaching in EC centres. This section of the chapter discusses the social learning theory of communities of practice (Lave \& Wenger, 1991; Wenger, 1998) as a conceptual framework for this aspect of the study. Parallels between this work and professional learning 
communities evident in the literature on school improvement and professional development are then discussed. Factors that support or inhibit effective communities of practice and professional learning communities, together with interactive patterns and styles that influence dialogue, thinking, and reflection in such communities, are identified from empirical research undertaken across the wider education sector. Although located in settings beyond ECE, these findings provide useful analytical tools for considering the data in this study. The chapter concludes by reviewing empirical studies using a community of practice framework in EC settings and studies highlighting the team teaching nature of New Zealand EC services in order to establish the existing research landscape and the gaps that this study is intended to fill.

\section{Communities of practice}

Theories of learning tend to position learning as occurring either as an individual psychological process (such as in Piaget's constructivist approach) or within a sociocultural context (such as Vygotsky's focus on individuals learning within communities and through interaction with others). Within the latter context, Lave \& Wenger's (1991) work on situated cognition challenged the then-dominant, behaviourist views on how and where learning might take place (Kimble \& Hildreth, 2008) with its emphasis on the situated nature of learning, particularly in workplaces, and the concept of legitimate peripheral participation. Positioned within the social theory paradigm and drawing on theories of social structure and of situated experience, Wenger's (1998) later work elaborated and expanded this focus on communities of practice into a theory of learning in which he argued that learning is fundamentally a social phenomenon that occurs when people actively participate in the practices of social communities. This study uses Wenger's theory to examine and understand the influence of the community of practice (i.e., the teaching team) on individual teachers' thinking and reflection about their pedagogical practices. In preparation for this 
analysis, four interconnecting concepts central to Wenger's theory - meaning, practice, community, and identity - are explained.

Individuals actively try to understand, or make meaning of, their experiences. Within social communities, Wenger asserted, we negotiate meaning through every experience we have, and that process of negotiation requires the interaction of two fundamental aspects - participation and reification. Participation involves the active engagement of individuals within the community, and the relationships developed with others that reflect this engagement. Thus, participation combines social, affective and cognitive aspects in order to negotiate meaning within specific experiences and contexts. Participation shapes both our own identity and that of the communities of practice to which we belong (Wenger, 1998). The second core aspect of negotiating meaning, reification, refers to the processes and artifacts used by a community to make practices and abstract ideas concrete and through which negotiated meanings are shared amongst community members. According to Wenger (1998), whilst participation and reification are distinct elements, they complement each other and act as a duality to enable one another. He argued that "processes of reification and participation can be woven so tightly that the distinction between them seems almost blurred" (p. 62).

The second core concept within Wenger's theory is practice. Learning occurs through engaging in practice which, according to Wenger:

includes both the explicit and the tacit. It includes what is said and what is left unsaid; what is represented and what is assumed. It includes the language, tools, documents, images, symbols, well-defined roles, specified criteria, codified procedures, regulations, and contracts that various practices make explicit for a variety of purposes. But it also includes all the implicit relations, tacit conventions, subtle cues, untold rules of thumb, recognizable intuitions, specific perceptions, well-tuned sensitivities, embodied understandings, underlying assumptions, and shared world views. (1998, p. 47)

Wenger's third core concept, communities, refers to those social collectives within which we are able to undertake worthwhile activities and be seen as competent. Communities of practice exist in all spheres of daily life, are frequently informal, and 
are so familiar and pervasive that they often go unexamined. Wenger identified three dimensions of practice necessary for the formation and continuance of communities of practice: mutual engagement; a joint enterprise; and, a shared repertoire.

According to Wenger, mutual engagement is what distinguishes a community of practice from a team, network, or social group, and entails the active participation of community members in collective endeavours in order to negotiate shared understandings. Mutual engagement requires full inclusion of members at the individual level and attention to "community maintenance" (Wenger, 1998, p. 74) at the community level, in order to foster and preserve the community's coherence. Mutual engagement does not require homogeneity between members and, furthermore, communities are not always peaceful entities. Indeed, participation may occur through disagreement and challenge as much as through cooperation. The second characteristic of community, joint enterprise, refers to the activities that the community negotiates and engages in together. Such activity is not limited to those official enterprises expected of the community but also includes their negotiated, unofficial responses to the demands and constraints of outside contexts, resulting in a unique enterprise. Wenger's third characteristic of a community, shared repertoire, refers to the shared processes and resources that members of the community use to negotiate shared meaning.

The final core concept within Wenger's (1998) theory is identity. Identities are built out of our negotiated experiences of membership within social communities and hence are bound to our practice within a community. According to Wenger, five characteristics shape the development of our identities: identity as negotiated experience (where our experiences, and others' views, of our participation within communities help define who we are); identity as community membership (where our identities are defined by the communities that we belong to as well as those we do not); identity as a learning trajectory (where our identities are shaped by our 
previous learning paths as well as our future learning possibilities); identity as a nexus of multimembership (where our identities are shaped by the ways in which we resolve the different identities that we may have in different communities); and, identity as a relation between the local and the global (where how we negotiate ways of belonging to both local communities and broader constellations contributes to the building of our identities).

These core concepts from Wenger's theory lay the groundwork for the argument made later in this thesis that each of the three case study teams form a distinctive community of practice within which teachers' on-going thinking and reflection (and hence their learning) is influenced by how they negotiate meaning about their practices within their community. To support this argument, each centre team will be considered in light of the following indicators proposed by Wenger (1998) that demonstrate a community of practice has formed:

1) sustained mutual relationships - harmonious or conflictual

2) shared ways of engaging in doing things together

3) the rapid flow of information and propagation of innovation

4) absence of introductory preambles, as if conversations and interactions were merely the continuation of an ongoing process

5) very quick setup of a problem to be discussed

6) substantial overlap in participants' descriptions of who belongs

7) knowing what others know, what they can do, and how they can contribute to an enterprise

8) mutually defining identities

9) the ability to assess the appropriateness of actions and products

10) specific tools, representations, and other artifacts

11) local lore, shared stories, inside jokes, knowing laughter

12) jargon and shortcuts to communication as well as the ease of producing new ones

13) certain styles recognized as displaying membership

14) a shared discourse reflecting a certain perspective on the world. (Wenger, 1998, pp. 125-126)

Although Lave and Wenger (1991) and Wenger's (1998) work is focused predominantly on the learning of newcomers to a community, Wenger acknowledged that communities of practice are not limited to such learning but can become learning communities that create knowledge, regardless of whether its members are 
newcomers or old-timers. Thus, although most teachers in the case study centres would be described as old-timers, the potential for learning and the creation of new, shared understandings that exist as teachers collectively reflect on their teaching enable these communities of practice to become communities of learning. This construct of a learning community is discussed in the next section.

\section{Professional learning communities}

Alongside Lave and Wenger's (1991) and Wenger's (1998) work on situated cognition and the concept of communities of practice is parallel literature focused on professional learning communities (also referred to as teacher learning communities and learning communities). In a review of the literature on professional learning communities, Stoll, Bolam, McMahon, Wallace and Thomas (2006) suggested the notion of professional learning communities comes from several sources, most particularly the educational reform movement and the literature on self-evaluating schools and teacher reflection. They noted that, whilst there is no clear definition, such communities are:

groups of people sharing and critically interrogating their practice in an ongoing, reflective, collaborative, inclusive, learning-orientated, growthpromoting way (Mitchell \& Sackney, 2000; Toole \& Louis, 2002); operating as a collective enterprise (King \& Newmann, 2001). (p. 225)

Two commentaries were located which bridge the parallel theoretical paradigms of communities of practice and professional learning communities. Lieberman and Miller's (2008) close examination of eight empirical studies of professional learning communities is explicitly informed by Wenger's (1998) thinking on communities of practice, identity, and learning, as well as by the literature more readily associated with professional learning communities. Similarly, Putnam and Borko (2000) drew on the work of social theorists such as Greeno (1997), Greeno et al. (1998) and Lave and Wenger (1991) to argue that a situative perspective in which "cognition is (a) situated in particular physical and social contexts; (b) social in nature; and (c) distributed across the individual, other persons, and tools" (p. 4) can support 
powerful shifts in teacher thinking and practices through their participation in discourse communities. Borko's (2004) later discussion on the design of effective teacher professional development programmes continues to bridge the two paradigms by drawing upon situative perspectives whilst simultaneously using terms such as professional learning communities and teacher learning communities to describe such programmes.

Stoll et al.'s (2006) definition suggests that professional learning communities are likely to be established and maintained in a more deliberate manner and for a more specific purpose (Bary et al., 2007; Johnson \& Scull, 1999) than would necessarily be the case with Wenger's (1998) communities of practice. However, the two concepts share many fundamental similarities, including the development of shared understandings and beliefs, active participation of members, the mutual influence of members on the community and vice versa, and a collaborative approach to negotiating meaning, and thus learning, within the community (Hipp, Huffman, Pankake \& Olivier, 2008; Johnson \& Scull, 1999; Stoll et al., 2006; Wenger, 1998).

Attention is now turned to empirical studies positioned within a community of practice or professional learning community conceptual framework. Whilst much of the communities of practice literature is located within the management and organisational studies (see, for example, Kerno (2008) for a discussion on the challenges in using this approach in organisations) and human resource development fields (see, for example, Fenwick (2008) for a review of research in workplace learning that has used a communities of practice framework), this review will concentrate on studies located within educational contexts.

\section{Empirical studies using a "community of practice" or "professional learning community" framework}

Extensive empirical literature exists that utilises either a community of practice framework or a professional learning community framework within educational 
contexts. Much of this research is positioned in educational contexts other than ECE and the findings are generally beyond the scope of this review. However, several of these wider studies include findings on the conditions that contribute to, or mitigate against, effective communities of practices. These findings are summarised here to inform the analysis of group practices evident within the three case study centres in my research:

- A safe environment: Numerous studies highlight the importance of developing a safe, collegial environment (Blair, 2008; Frank \& Keith, 2008; Harford \& MacRuairc, 2008; Paulus, 2009; Yildirim, 2008) where community members are supported and respected (Borko, Jacobs, Eiteljorg \& Pittman, 2008) and a collaborative culture is established (Habhab-Rave, 2008). Central to such an environment is the development of trust between members of the community (Blair, 2008; Chen \& Wang, 2009; Cosner, 2009; Habhab-Rave, 2008; Herrington et al., 2008; Stoll et al., 2006).

- Creating a language of practice: The importance of a shared discourse (Reid, 2007) or language of practice (Blanton \& Stylianou, 2009) through which members were able to engage in "collegial dialogue, informed by ideas, theory, inquiry and reflection on professional experience" (Niesz, 2010, p. 40) is revealed as an important factor in effective communities.

- Quality of leadership and facilitation: Printy's (2008) quantitative study found the quality of the community's leadership to be strongly influential in determining the quality of teachers' participation, a finding supported by Stoll et al. (2006) and Johnson and Scull (1999). Cosner (2009) noted the importance of community leaders setting, reinforcing, and at times, enforcing group behavioural norms in order to promote trust amongst members. In related findings, Frank and Keith (2008) identified that effective facilitation is required in order to build relationships and to deal with tensions arising as members of new communities negotiate the work of the community whilst Hibbert and Rich (2006) found that 
the group leader had a critical role in establishing the tone of on-line virtual communities of practice.

- Group dynamics: Stoll et al.'s (2006) empirical literature review identified that managing group dynamics, including diverging views and values amongst group members, is an important factor contributing to the success (or otherwise) of learning communities, as is the willingness and ability of individual members to engage in learning and the work of the community. Furthermore, Borko (2004) identified that supportive, yet challenging, conversations are critical if change is to occur in teachers' thinking and practices. Earl and Timperley (2008) asserted that "relationships of respect and challenge" (p. 9) are crucial to effective learning conversations amongst educators.

- Time and space: Creating time for teachers to engage in the level of dialogue necessary for deep learning to take place requires organisational commitment, such as timetabling meetings and providing cover for teachers to engage in professional dialogue (Stoll et al., 2006). Insufficient time to engage in on-line forums constrains the development of an effective on-line community of practice (Carr \& Chambers, 2006). Co-located spaces that enable both formal and informal meetings support collegiality and dialogue (Habhab-Rave, 2008; Stoll et al., 2006).

A number of studies have gone beyond identifying that a safe, collegial, collaborative environment is an essential component of an effective community of practice or professional learning community to focus on the specific nature of the interactions between members that promote dialogue, reflection, and learning. Scoping what is known about these aspects, which may be applicable across different educational contexts, provides analytical tools for considering the nature of interactions that occurred within the case study teaching teams during the video-SR interviews and which are likely to reflect their community practices. 
Borko et al. (2008) identified several specific behaviours displayed by members of their professional learning community as they viewed and discussed episodes of their teaching during their two-year mathematics professional development programme that they assert enhanced dialogue and reflection. During discussions teachers empathised with the focus teachers, provided suggestions and encouragement, and pointed out the strengths of the focus teachers. Observing teachers asked clarifying questions, made connections between what they were observing and practices in their own classrooms, and offered critiques and positive reinforcement of others' practices. Similarly, Niesz (2010) found that teachers in her professional learning community demonstrated empathy with their colleagues, especially over the differences in the professional learning climate between their network and each individual's school.

Two studies of on-line or virtual communities analysed the contributions made by group members. Chen and Wang (2009) identified significant levels of social talk which they suggested had a positive effect on the group in terms of developing group cohesion and which acted as a bridge to engaging in serious talk. Social talk included access rituals when entering the community, providing accounts for their lack of recent on-line involvement, giving details of their upcoming schedules so that others would know of their availability, and offering apologies for absences from the community. Similarly, Paulus (2009) analysed the on-line contributions (email, synchronous chat and asynchronous discussion forums) of on-line student communities in terms of off-task contributions. Such contributions were categorised as logistical (managing the collaborative demands of the course tasks), technical (managing the technical aspects of the on-line platform and software) and social. Across each of these forms of off-task interactions, Paulus found the students were "responsive, responsible and relational with each other" (p. 235) and that these interactions contributed towards developing common ground between community members. Although located in the on-line environment, these studies highlight the importance of social interactions in developing connections and building group cohesion. 
Studies that focused on the nature of the contributions that community members made to group discussions were also located. Sherin and van Es's (Sherin \& van Es, 2009; van Es \& Sherin, 2008) research into video clubs as sites for teacher professional learning draws on analyses of teacher contributions to investigate the development of teachers "learning to notice" students' learning (van Es \& Sherin, 2008, p. 244) and developing "professional vision" (Sherin \& van Es, 2009, p. 22). Teacher contributions during the video club sessions and in interviews were analysed in terms of who they focused on (the actor: student, teacher, self, curriculum developers, other), what they focused on (the topic: mathematics thinking, pedagogy, climate, management, and other), the "stance" (van Es \& Sherin, 2008, p. 254) they took in their contributions (descriptive, evaluative, interpretive), the degree of specificity used in their contributions, and whether their contributions referred to the video episode or other events. Results indicated that teachers made changes in their analyses of video episodes over time, becoming more interpretive, specific, and focused on student learning over the course of the programme, suggesting that repeated opportunities to engage in, and develop, such dialogue may be necessary.

Finally, two recent studies involving teacher learning communities analysed the dialogue that occurred in different groups of teachers, and the impact that different "conversational routines" (Horn \& Little, 2010, p. 184) had on their engagement and discussion. Horn and Little's analysis focused on "problems of practice", arguing that "the treatment of such problems presents a significant barometer of a group's collective capacity to support professional learning and stimulate instructional improvement" (p. 189). Their data revealed that the conversational routine frequently included normalising responses in which other teachers would indicate that problems of practice identified by a teacher were a normal part of teaching. Of more interest, though, was that normalising responses could act to turn the conversation "toward the teaching or away from the teaching as an object of collective attention" (p. 192, italics in original). Responses turning conversation away from the teaching 
problem were offered in sympathetic ways but tended to position the teacher as disempowered or passive. In contrast, conversations turned towards teaching led to sustained discussions about the problems raised and teachers relating the problems were more active in elaborating on the problem and in identifying possible solutions. In addition, such conversations tended to involve what Horn and Little described as principled talk whereby the specifics of the situation were linked to principles of teaching, thus giving agency and affording more learning for the group members.

Horn and Little's (2010) discussion of conversational routines also highlights what they describe as rough draft talk, a concept also discussed by Crespo (2009) in her analysis of different styles of talk in a mathematics teachers' discussion group. Crespo identified that teachers engaged in either exploratory talk or expository talk within their study groups, drawing upon Barnes' (1976) categories of exploratory and final draft talk used by students in his study of classroom talk. Rough draft or exploratory talk has high levels of involvement by members of the group, is characterised by tentativeness and a thinking out loud style, and allows for disagreement between members (Crespo, 2009). In contrast, expository or final draft talk is often framed in the past tense, does not involve other members of the group, and does not involve explicit disagreements. Thus, Crespo suggested, teacher groups that use expository talk are unlikely to develop into communities that engage in on-going learning about their practices.

The studies reviewed above reveal specific interactive patterns evident within some communities of practice which lead to thoughtful reflection and dialogue about the participants' practices. These interactive patterns provide analytical suggestions for considering how the communities of practice within my study influence the thinking and reflection of individual members in those communities. 


\section{Communities of practice and teams in early childhood education}

The final section of this chapter shifts attention to studies specifically focused on EC educational contexts in order to position this study within the existing landscape of research that has used either a community of practice or professional learning community framework. Despite frequent use of the concepts of communities of practice and communities of learning within current EC discourse (Bary et al., 2007), few studies have been undertaken that draw on these as conceptual frameworks. Four New Zealand studies were located and are discussed here: Aitken's (2005) study of newly qualified EC teachers' experiences in their centre community of practice; Bary et al.'s (2007) Centre of Innovation project researching the impact of pedagogical leadership on children's dispositions to enquire; Thornton's (2009) study of the use of blended action learning to support leadership development; and, Grey's (2010) case study of self-review.

Aitken (2005) researched the experiences of eight newly qualified EC teachers over a year as they made the transition from student to qualified teacher and negotiated their participation in the community of practice of their EC centre. Their experiences are interesting, given the wider policy and professional imperatives of the time which saw enormous pressure placed on newly graduated teachers to take on positions of responsibility. Aitken found these teachers often experienced dual, conflicting identities as both novice and expert teachers; as beginning teachers they wanted ongoing support and feedback as they settled into their new roles whilst their status as qualified teachers meant that they were frequently positioned as experts within the centre and pressured to take on higher levels of responsibility. Whilst Aitken's focus is generally different to that of my study, several of her findings are very relevant:

(a) The centre culture and organisation/type were influential in shaping these teachers' identities and thinking. Structural features impacted on the functioning of the community of practice, and thus on the identities of these new teachers. 
(b) The collective team teaching approach typical in New Zealand EC centres was a powerful influence on their experiences, participation and sense of belonging in the centre. Effective team functioning was seen as crucial to their transition from student to being a full member of the team.

(c) Teaching in EC settings, especially for qualified staff, involved a complex mix of roles and responsibilities, many of which interrupted and diverted their attention from teaching the children.

(d) Being a newcomer applied not only to newly qualified teachers but also to those staff new to a centre who had to adjust to new ways of 'doing things'. For some teachers in Aitken's study, being the newcomer lasted until the next new staff member was appointed.

(e) Conflict and power struggles were evident in some teachers' communities of practice, often centred on differences in philosophy or attempts to change existing practices within the centre.

(f) Full membership of the community was influenced by factors such as qualifications, responsibilities held, longevity in the centre, experience, and shared beliefs and values. Being part-time, a reliever or holding different philosophical views was perceived to inhibit full membership.

These findings are helpful when considering the communities of practice that each of the case study centres in my research represent, and how they influence individual teachers' thinking and reflections about their interactions with children. However, the centres represented in Aitken's (2005) study reflect wider variations in factors such as teacher qualifications and staff turnover than were present in my study, with these factors appearing to have influenced how the communities of practice were enacted.

In a second study underpinned by a community of practice conceptual framework, Bary et al. (2007) undertook an action research project as a Centre of Innovation to 
investigate how distributed leadership within a community of practice impacts on infants' and toddlers' dispositions to enquire. In findings relevant to my study Bary et al. (2007) expanded their views on communities of practice to see them as:

- Fostering emergent leadership and taking on leadership roles;

- Establishing support networks and collaborative relationships; and

- Sharing expertise, questioning and challenging, engaging in critical reflection. (Bary et al., 2007, p. 42)

Bary et al. also found a number of factors contributed to the effectiveness of their community of practice including strong leadership, social cohesion, collective responsibility, respect, trust, and effective communication and shared understandings. These findings parallel those of studies conducted in other educational contexts discussed earlier in this chapter, lending support to my intention to use such findings to inform the analysis of the group practices of the case study centres in my study.

Both Grey (2010) and Thornton's (2009) studies used the concept of communities of practice to describe the groups of teachers involved in their research. Grey's (2010) case study of an EC centre team undertaking self-review using a practical philosophy approach adopted the constructs of community of practice and situated learning (Lave \& Wenger, 1991; Wenger, 1998) to position the project within a social-constructivist paradigm. Grey noted the importance of factors such as trust and caring between members, and the quality of leadership in supporting the community to work effectively together, recommending that teaching teams needed to be supported to develop negotiating skills and a "culture of listening" (2010, p. 279). Furthermore, she argued that "it is by constructing an authentic community of practice to engage in dialogue to build a shared understanding of practice that a solid foundation for children's learning is formed" (p. 275).

Thornton's (2009) work draws upon the concept of a community of practice as a site for workplace learning in her study of how ICT can be used to support leadership development in the New Zealand ECE sector. Thornton drew together concepts of 
communities of practice, reflective practice and action learning in her development of a blended learning professional development approach for ECE leaders, and noted that membership of the community acted to provide support to participants during the programme.

The paucity of EC studies utilising a community of practice conceptual framework can be offset to some extent by also considering recent New Zealand empirical research where team aspects have been a feature of the research. A number of these studies have been small-scale, often carried out towards post-graduate qualifications, have utilised case study methodology to investigate aspects of teacher practices, and the EC teaching team and centre has been the case, rather than the individual teachers (Clarkin-Phillips, 2007; K. Edwards, 2009; Haggerty, 1998; Nuttall, 2004; Ryder, 2007). These and other recent studies are organised by their inclusion of team aspects focused on a) group dynamics and interpersonal aspects; b) pedagogical aspects; and c) teacher discourses.

\section{Group dynamics and interpersonal aspects}

Four studies with findings concerning group dynamics and interpersonal aspects within teams were located including two focused on curriculum enactment within EC settings. Haggerty's (1998) study into the implementation of the-then recently released EC curriculum, Te Whāriki (Ministry of Education, 1996), used video as a professional development tool for recording, analysing and discussing curriculum implementation and teacher practices. Video technology was seen as a particularly useful tool for examining the group activity of curriculum implementation as individual teachers' practices were of interest to the rest of the team. Although the group viewing of practices provided a catalyst for discussion, Haggerty (1998) noted that group dynamic issues emerged in some centres, including participant feelings of powerlessness, vulnerability and exposure, and argued that "the centrality of the team dynamic can tend to introduce a host of possibilities and complexities, which 
may be markedly different from many school settings, where individual practitioners tend to be considerably more self-contained" (p. 176).

Nuttall's (2004) research on how teachers in one EC centre collectively understood and enacted curriculum showed a divide between the official discourse of the teachers and the day-to-day reality of curriculum implementation. The teachers managed this divide through the use of "a range of shared cognitive strategies that allowed them to 'do childcare' on a day-to-day basis whilst simultaneously maintaining this theory/practice divide" (p. 165). Despite the maintenance of social cohesion that these strategies afforded, Nuttall found that the structural constraints of the centre organisation and management reduced opportunities for communication and decision-making and resulted, at times, in the professional isolation of members of the team.

Ryder (2007) reported findings related to group dynamics in her case study of how five teachers within a centre worked through their teacher registration advice and guidance programme as a group, under the supervision of the centre's leader. As the group proceeded through the registration process, members moved through five phases of behaviour or action from a group think stance where the loudest voices prevailed through to a position where they could appreciate the different contributions and approaches of each individual teacher. Ryder (2007) suggested that by the end of the process a collective approach to teaching and learning that recognised the individual contributions and expertise of teachers had developed.

Finally, Clarkin-Phillip's (2007) study of the development of distributed leadership through involvement in an EC professional development programme used centre teams as the cases. Her detailed attention to features of the participating teams, each representing different service types, acknowledged the influence of this structural aspect of ECE in New Zealand, and supports my decision to use the centre teams as the cases, rather than the individual teachers. 


\section{Pedagogical dimensions of working in teams}

Two studies were located addressing the pedagogical dimensions of working in teams. K. Edwards' (2009) investigation of teachers' perspectives of how they supported children's scientific learning (referred to in the earlier section on reflection) paid close attention to the team teaching nature of EC contexts. Her use of Rogoff's (2003) three foci of analysis enabled her to consider the teachers' thinking and practices from a team (interpersonal) as well as an individual (personal), and contextual, cultural (cultural-institutional) stance. K. Edwards found that her participants deliberately drew on the collective scientific knowledge of the team to support children's learning, with more expert teachers supporting those with lesser scientific knowledge.

Even closer attention to team elements of pedagogy in a New Zealand EC centre was revealed by Dalli et al. (2009) in an article on their Centre of Innovation action research project focused on peaceful caregiving as curriculum. Following their first action research cycle, team members became aware of the nature and form of their interactions with each other: "we recognised that this team approach of sensitively responding to colleagues' signs and gestures enhances continuity for the child and deepens the relationship between the child and the teacher" (2009, p. 41). Such responses included constant communication between team members, looking out for ways to support each other, anticipating what a teacher might need, and creating time and space for teachers to engage in sustained, unhurried, uninterrupted interactions with the children.

\section{Teacher discourses about teams}

The final study reported in this section sought to identify the discourses that teachers constructed about their teaching in full-day education and care settings. Robinson (2007) identified eight key discourses of teaching, including the discourse of team-player. According to Robinson, this discourse positioned teachers:

- To communicate with other staff

- To pull one's weight and stay working with the children, even when tired 
- To stay in position when carrying out assigned tasks

- To get along with other members of the team. (p. 65)

Robinson argued that the discourse of team-player is a "bottom-up" (p. 76) one that emerged from the context of the centre and which served to pull people together, despite structural constraints and in the face of the multiple demands and emotional exhaustion that come from teaching in full-day settings.

The seven studies reviewed in this final section highlight the influence of the structural condition of team teaching on New Zealand EC teachers' pedagogical practices, thinking and reflection. In doing so, they support the decision to position the centres, rather than the individual teachers, as the cases in this study, and the importance of considering the influence of the team on individual teachers' thinking and reflection. This review also reveals the lack of previous research that has investigated EC teachers' thinking and reflection from the stance of the social context of their teaching team, indicating that the research presented in this thesis addresses gaps in our knowledge of teaching in ECE, particularly within the New Zealand context.

\section{Summary}

This chapter has reviewed theoretical and empirical literature relevant to the focus of this investigation. Discussion of theoretical approaches to reflective practice, and learning within communities of practice (or professional learning communities) established the conceptual frameworks underpinning this research. The review of empirical literature reveals that little research has been undertaken focusing on, first, EC teachers' reflection and thinking about their pedagogical interactions with children or, second, the influence of the social context (i.e., the teaching team) on such reflection and thinking. This study proposes to address these gaps.

Findings from empirical research into EC pedagogy suggest that teaching in this sector is complex work and is, therefore, worthy of the effort and energy that 
teachers invest in thinking about, and reflecting upon, their interactions with children. Thus, investigating how teachers think about and reflect on their interactions with young children in EC settings is also worthwhile and may contribute to greater understandings about the intellectual demands of such work. 


\section{Chapter 3:}

\section{Methodology}

\section{Qualitative research and an interpretive approach}

Qualitative approaches to research emphasise that our understandings of the world are socially constructed and highlight the value-laden nature of research (Denzin \& Lincoln, 2008; Merriam, 1998). Researchers endeavour to understand how people make sense of their worlds and the meanings they bring to social phenomena (Denzin \& Lincoln, 2008). Sensitivity to the contexts that influence behaviour and ensuring that interpretations remain holistic are fundamental aspects of interpretive approaches (Wiersma \& Jurs, 2009).

A qualitative research approach was determined most appropriate for this investigation as it would enable teachers' thinking and reflection to be investigated within the natural setting of the EC centre (Denzin \& Lincoln, 2008). Taking a qualitative approach recognised that teaching is complex work and acknowledged the specific contexts within which these teachers worked (Cohen et al., 2000). Merriam (1998) highlighted that understanding phenomena from the "emic, or insider's perspective" (p. 6) is critical to qualitative research, a stance essential for the focus of my study.

Qualitative research encompasses many interpretive paradigms, each reflecting different epistemological, ontological and methodological assumptions and beliefs (Denzin \& Lincoln, 2008). Understanding and being explicit about these underlying premises is important in order that the research design achieves congruency between the theoretical paradigm, strategies of inquiry, and methods for data collection. This study is grounded in a constructivist-interpretive paradigm which endeavours to "understand and interpret the world in terms of its actors" (Cohen et al., 2000, p. 28). A constructive-interpretive paradigm draws on the ontological premise of relativism, the epistemological assumption that understandings are co- 
constructed, and naturalistic methodological procedures (Denzin \& Lincoln, 2008). Thus, this study recognises that teachers will participate in, and experience, their world of teaching from their own perspective - their own reality - and that the understandings resulting from this research will have emerged from their perspectives. The methodological choices made in this study - case study and video-SR interviews - offer a way of examining the teachers' perspectives and understandings about their thinking and reflection in actual teaching situations as naturally as possible.

Summarising the features of interpretive paradigms, Cohen et al. (2000) suggested that individuals actively construct their social worlds, and act intentionally on the basis of their interpretation of situations and context. The fluid nature of such situations and contexts affects both understandings and behaviour. Thus, multiple interpretations of events are possible, reality is multi-layered, and understandings of individuals and events are largely non-generalisable. Theory generated from interpretive research is grounded in, and emerges from, the data. These features necessitate researchers studying the social world in its natural state, from participants' perspectives rather than their own. Remaining faithful to what is being studied and avoiding a reductionist approach to interpretations is essential (Cohen et al., 2000). The next section of this chapter outlines the multiple-case study design developed for this project, located within and addressing the requirements of an interpretive paradigm.

\section{Case study research design}

Strategies of inquiry provide the link between a study's underlying paradigm and the methods used to collect the "empirical materials" (Denzin \& Lincoln, 2008, p. 34). Within the constructivist-interpretive paradigm, the case study is an appropriate strategy to utilise and thus was chosen for this investigation. Case studies are undertaken in naturalistic settings, have a holistic focus (Denscombe, 2007), and 
are useful when processes rather than outcomes are the focus of investigation (Merriam, 1998). Denscombe (2007) noted the main benefit of the case study approach is that it "allows the researcher to deal with the subtleties and intricacies of complex social situations" (p. 45, italics in original).

Central to case study research is that the case is a bounded system; in other words the individuals, events or phenomena under study have clear boundaries that delineate the case from the contexts within which they exist (Stake, 2008). Merriam (1998) identified that case studies are, first, particularistic in their focus on situations, phenomena and events; second, richly descriptive; and third, have a heuristic quality, enhancing the reader's understanding of the phenomena under study.

Case study research definitions abound in the literature (Merriam, 1998; Stake, 2008). Yin's (2009) explanation of the scope of a case study is used in this project:

1. A case study is an empirical inquiry that

- investigates a contemporary phenomenon in depth and within its reallife context, especially when

- the boundaries between phenomenon and context are not clearly evident. (p. 18)

Different purposes for undertaking case studies have also been identified (Merriam, 1998; Stake, 2008; Yin, 2009). The collective case studies (Stake, 2008) in this research are intended to interpret (Merriam, 1998) and explain (Yin, 2009) the phenomenon of teachers' thinking and reflection on their interactions within their communities of practice. Interpretive case studies, also known as analytic case studies, use descriptive data to "develop conceptual categories or to illustrate, support, or challenge theoretical assumptions held" (Merriam, 1998, p. 38) whilst explanatory case studies are appropriate for investigating research questions of a "how" or "why" nature, particularly where the researcher has little control over the actions of those involved in the study and where the focus is on contemporary rather than historical events (Yin, 2009). According to Stake (2008), the primary purpose of 
an instrumental study is to gain insight into an issue; collective, or multiple case studies, are instrumental studies extended beyond the single case.

This project uses a multiple-case research design (Yin, 2009) in which each case is the teaching team within an ECE centre and the centre team is the unit of analysis ${ }^{2}$. The organisation and structure of the third case study centre meant an adaptation to the research design, whereby the three smaller teams within the centre became embedded units of analysis (Yin, 2009). This allowed for within-case analysis at the case level (the whole centre team) and at the level of each smaller team whilst still preserving the ability to undertake cross-case analysis. Each case is intrinsically bounded (Merriam, 1998), able to be studied individually and separately from the other cases.

Yin (2009) recommended developing propositions from the research questions to focus attention on particular aspects that should be addressed during the study. Chapter 1 outlined the aim of this project and the two research questions developed when the study was designed:

- What do teachers in the three case study centres think about and reflect on with regard to their interactions with children?

- What guiding principles/theories (and beliefs) underlie these teachers' practices, and to what extent are these articulated or implicit?

Several ideas underpinning the research questions were identified at the outset of the project and through the literature review, although not articulated as formal propositions at the time. Thus, I was interested in how teachers stayed in tune or developed intersubjectivity with young children during interactions (Jordan, 2009), and whether and how they reflected-in-action (Schön, 1983, 1987) during their teaching. I was also interested in the congruency between teachers' articulated

2 For ease of communication, each case is referred to as the CS centre rather than the CS teaching team. 
theory base and their practices, and the extent to which their knowledge was tacit or explicit (Black \& Halliwell, 2000; Zeichner, 1994; Zeichner \& Liston, 1996). I wanted to know whether there were differences in teachers' practices when responding to child-initiated activities and when leading the learning activity, and the extent to which they engaged in both pedagogical interactions and pedagogical framing (Siraj-Blatchford et al., 2002; see also, Stephen \& Plowman, 2008). Finally, because these teachers work in a team I was interested in the influence that teaching in a team context had on individuals' reflection and pedagogical practices (Aitken, 2005; Bary et al., 2007; Grey, 2010; Putnam \& Borko, 2000). During the project, this significance of this last issue became increasingly apparent, leading to the formal development of a third research question:

- How does being a member of a community of practice influence teachers' thinking and reflection on their teaching interactions?

\section{Approach to data collection}

The major data source for this study was video-SR interviews in which the teachers viewed episodes of their interactions with children, described their thinking and reflections at the time of the interactions and engaged in collective reflections about the interactions. Supporting sources were reflective journals maintained by the teachers and myself together with observations and field-notes of the programme, centre environment, and planning meetings.

\section{Video stimulated recall interviews}

Stimulated recall (SR) methodology utilises retrospective reporting to elicit data about cognition on the assumption that "humans have access to their internal thought processes at some level and can verbalize those processes" (Gass \& Mackey, 2000, p. 1). Proponents of SR methods argue that it reveals the natural, complex world of professionals who regularly engage in decision-making 'on the wing', allowing them to describe their thinking and decision-making without the 
interference that 'thinking-aloud' methods have on their activities, especially when these require considerable verbal interaction such as in teaching (Lyle, 2003).

First used by Bloom in the 1950s to investigate students' thinking during university lectures and discussions (Calderhead, 1981), SR has been widely used across several disciplines including second language teaching and learning (e.g., Evans, 2009), nursing (e.g., Antonsson, Graneheim, Lundstrom \& Astrom, 2008) and education, with increasing popularity over the last two decades. In educational contexts research has examined teachers' thinking and reflection (e.g., Schepens, Aelterman \& van Keer, 2007); teacher beliefs (e.g., Wood \& Bennett, 2000); teacher pedagogical knowledge and practices (e.g., Hennessey \& Deaney, 2009); student teachers and teacher education programmes (e.g., Grainger, 2003); and differences between novices and experts (e.g., Ethell \& McMeniman, 2000). Such studies are predominantly small-scale, focus on individuals, and utilise case study methodology. Thus, video-SR interviews are an appropriate method for collecting empirical materials within case studies focused on EC teachers' thinking and reflections.

SR methodology typically involves playing video- or audio-taped episodes of behaviour or interactions to stimulate participants' recall of their thinking during the actual episode. The tape is stopped at points throughout the episode to enable the participant to describe his or her thinking at the time. Prompt questions may be used to probe more deeply into participants' thinking (Gass \& Mackey, 2000).

Every research method has limitations which researchers must attend to, first, when designing a study and, second, when developing protocols for undertaking the research, in order to increase construct validity. The key theoretical issue concerning SR methods is "whether retrospective reports accurately represent access to direct, unordered accounts of previous thought processes without any intermediate ordering of reflections on reasoning" (Lyle, 2003, p. 865). Distinguishing between participants' recall of, and reflection on, an event can be 
difficult (Gass, 2001). Yinger (1986) suggested participants may respond to the new event of viewing the video recording rather than recall their thinking during the original event. Factors influencing how teachers recall and report their thinking include how they are prepared for the interview process (Calderhead, 1981; Gass \& Mackey, 2000) and anxiety about viewing themselves on video, particularly when they focus on their physical attributes (Calderhead, 1981). More fundamentally, Calderhead noted that teacher knowledge (especially that of experienced teachers) may be tacit and thus not easily verbalised.

Recommended strategies for interview protocols include scheduling interviews without delay following the recording of events (Gass \& Mackey, 2000; Lyle, 2003) and using carefully crafted, standardised instructions (Gass \& Mackey, 2000) that emphasise recall of the episode rather than reflection on the event. Interview probes should be unambiguous (Gass \& Mackey, 2000), interviewers should be unobtrusive (Lyle, 2003), and participants should have control over when to pause the replaying of the episode (Gass \& Mackey, 2000; Lyle, 2003). To address participants' anxiety, Calderhead (1981) suggested interviewers establish rapport and familiarise participants with the interview procedures. Gass and Mackey (2000), however, recommended minimal training be given to avoid influencing participants' responses. Details of the protocols developed for this study are described below (see p. 79).

At the time this study was planned, a review of empirical studies using video-SR interviews indicated they were undertaken with individual participants using protocols similar to those outlined above. An exception was Moyles et al.'s (2002b) study which used a variant of video-SR described as reflective dialogues to investigate the characteristics of effective pedagogy in practitioners teaching 3 - 5 year-olds. In this study, the practitioner and researcher viewed the video-recording independently before watching it together and discussing both the observed practices and their views of effective practice. 
Recently there has been a significant increase in studies using variations to standard video-SR methods. Most relevant to this study are those using collaborative or group interviews. In Hennessey and Deaney's (2009) study the individual focus teacher, a school colleague selected by the teacher, the two researchers, and an independent subject specialist individually watched and analysed episodes of the teachers' use of interactive whiteboards before collectively identifying critical episodes, refining an analytic framework and identifying emerging themes.

Methodological modifications made during Anderson, Nashon and Thomas's (2009) multi-year, multi-case study of high school students' metacognition included shifting from individual SR interviews to group interviews. Anderson et al. argue that "the use of group interaction and engagement and the collective group reflection of learning experiences [was] a powerful mechanism that reveals metacognition in ways that solitary experiences cannot" (p.192). The successful use of video-SR in these studies supported the use of a group interview protocol with the teachers in my study.

\section{Observations and field notes}

A secondary data source was that of field-notes recording details about the learning environment and programme, teacher roles, and the data collection rounds (see p. 78 below). As supporting data, given that the focus of this study was on teacher thinking, these field-notes were intended to collect data about environmental conditions (Yin, 2009) and contextual aspects (Merriam, 1998; Stake, 2008) that may influence teacher practices and thinking.

Maintaining a journal is recommended as an integral component of qualitative research design to enable researchers to deliberately record their impressions, insights and reflections throughout their project (Maykut \& Morehouse, 1994). This strategy recognises that the case study researcher's thinking is reflective (Stake, 
2008) and assists development of the chain of evidence from data collection through analysis and reporting that is essential in ensuring construct validity (Yin, 2009) (see pp. 95-96 for discussion of construct validity in this study). Individual journals were established for each CS centre to preserve the boundedness of each case, with an overall researcher journal maintained for the whole project.

\section{Reflective journals}

As a secondary data source, teachers were requested to maintain a reflective journal throughout the data collection period in their centre to provide additional opportunities for gathering teacher reflections about their practices. This strategy recognised that reflection is not a linear process and that teachers' thinking about their practices would not be confined to the interview situation.

\section{Data collection procedures}

\section{Selection of the cases}

Various strategies are available to the researcher to guide the selection of cases (Eisenhardt, 2002; Mertens, 1998). Purposively selecting cases that provide maximum opportunities to learn (Stake, 2008) and that are information rich (Merriam, 1998) is recommended. The following criteria were identified to assist with selection:

- teacher-led services

- at least $80 \%$ of staff were qualified, registered teachers

- not engaged in a research project within the previous three years

- coverage of state kindergarten, education and care centre, and an infants and toddlers education and care centre

- smaller staff team - less than 6 FTEs

- staff employed predominantly full time, rather than part time

- all staff wanted to be involved

- located in different geographical communities, in the west of the lower North Island region 
- $\quad$ stable staffing situation - staff turnover in the six months preceding involvement in the study did not exceed one staff member in centres with up to three teachers, and two staff members in centres with four to six teachers.

These criteria were based on a mix of factors including quality indicators (e.g., qualified staff), manageability of the project (e.g., smaller centres, proportion of fulltime staff, and location), and motivation (e.g., staff commitment to project). As the focus of the research was on professional teacher practices, centres were selected from teacher-led rather than from parent- or whānau-led services. The criterion regarding involvement in other research projects addressed the potential for some centres to become "research-saturated" due to their location, accessibility and reputation whereby they may no longer illustrate typical situations and interactions.

Three ECE centres participated in this research. The first case study (Moana ELC) was undertaken in a community-based sessional centre catering for children aged from 2 - 5 years, whose teachers had requested involvement in the study. The centre met all the selection criteria outlined above. A purposeful sampling approach for the two remaining cases was taken (Merriam, 1998) in order to reflect some of the diversity existing within the sector. Thus, my intention was to select a free kindergarten (children aged 3 and 4 years) and an infants and toddlers centre. Whilst not intending to generalise across these cases, investigating teacher thinking and practices in different contexts and with children of different ages might reveal interesting insights. Furthermore, the perspectives and experiences of teachers were likely to resonate more clearly with readers from similar contexts (Lincoln \& Guba, 2002), facilitating their vicarious experience of the case (Stake, 2008).

Having taught in the kindergarten service and in EC teacher education for almost three decades, I had worked alongside or trained significant numbers of EC teachers. Thus, it was likely that I would have an existing professional relationship with teachers in the participating centres. To reduce the risk of coercion to 
participate in the project I wrote to eligible centres in the selected geographic area and invited those that met the selection criteria to indicate their interest in being involved, rather than directly approaching any to request access (see Appendix 1). Giving centres this choice also maximised the opportunities to learn from the cases (Stake, 2008) as those centres that responded may have been more open to the external gaze of a researcher. Approval to approach kindergartens was also sought from the local Association. One kindergarten (Summer Kindergarten) and one centre catering predominantly for children aged under-two years (Ngā Rangatahi Tamariki ELC) indicated their interest in participating in the project. The kindergarten met all the selection criteria whilst the education and care centre met most of the criteria.

Three of the four staff at Moana ELC and all three teachers from Summer Kindergarten had completed their pre-service teacher education programme at the institution I work at. Within Ngā Rangatahi Tamariki ELC, four of the teachers were past students, two were current students (although I was not involved in teaching them during the data collection period) and I knew the manager through my professional networks. Each centre was used by the institution I work in for students' practicum placements.

Once centres expressed interest in participating, I met with the teachers to outline the project and sent information letters to the centre management committees (see Appendix 2). At that point each teaching team agreed to participate in the project.

\section{Gaining informed consent}

Informed consent to participate in the research was sought from each teacher and the parents of all attending children in the three centres (see Appendices $3 \& 4$ ). Teachers distributed and collected consent forms from parents prior to my arrival in the centres for the orientation period. Gaining consent continued throughout the data collection period due to the continuous enrolment of new children, particularly in the kindergarten where the data collection period stretched from November 2008 
to April 2009. The orientation period was a useful time to discuss the research and consent process with parents. One parent refused consent, and I worked around this by filming in other areas of the centre on days the child attended. If consent forms had not been returned by the beginning of data collection, I did not film those children until consent had been given. Although consent was not sought specifically from the children, on two occasions I stopped filming: first, when one child was very distressed at her mother's departure from the kindergarten, and second, when a child appeared uncomfortable with my presence.

\section{Orientation to the case study centres}

During the two to four day orientation period in each centre I was introduced to the children and parents. I gathered detailed field-notes on the daily programme and environment (both indoors and outside) and recorded the teachers' philosophy statement.

This period provided opportunities to re-position myself as a researcher, rather than as a university lecturer, with the teachers. Although initial conversations naturally included reference to existing relationships, later these were deliberately framed as research conversations. Part of this shift included reassuring the teachers that I was not there to judge their teaching performance (as would have occurred during practicum assessments for students).

During this period I was introduced to older children formally during a mat-time as someone who would be visiting the centre, writing down and video-recording what the teachers did. As I moved around the centre, teachers and I informally reminded the children who I was and what I was doing, when children expressed interest. I aimed to achieve a balance between being an uninteresting observer who children would generally ignore, and not being so distant as to cause discomfort to children used to interacting with responsive adults in the centre. Whilst writing field-notes and when video-taping, I sat unobtrusively and avoided initiating interactions (Merriam, 
1998). In practice, when children approached me I tried to keep my responses brief and direct them to teachers for assistance. My researcher journal notes that teachers viewed my interactions with children positively, and I wondered whether this might have a positive effect on my credibility and enhance their openness in sharing their thinking.

I regularly used the video-camera during this period so that teachers and children became familiar with its presence. Its small size and adjustable view-finder meant that I could use the camera discreetly, either on my knee or on adjacent furniture. Whilst some filming was undertaken so that I could check light and noise levels, on most occasions during this time I used the camera without actually recording. Digital cameras were familiar in each centre and children almost always ignored the videocamera. Over 16 days of filming for the video-SR interviews, children engaged with the camera on only four occasions, looking through the view-finder and asking to control it. Each time I gave the children a turn before saying that I needed to continue with my work and asking for the camera back.

\section{Data collection rounds}

Five data collection rounds were undertaken in each of the first two case studies. In the third case, the teachers generally worked as three smaller teams and rather than involving the whole team in each interview, two data collection rounds were undertaken with each smaller team. Each round involved filming the teachers' interactions with children across the day followed by selecting episodes for use in video-SR interviews scheduled for the following day.

Each day of filming resulted in two to three hours of recorded episodes, spread across the programme. A flexible approach was required, given the free-flowing nature of children's activities and teacher movements across the programme, including the flow between the inside and outdoor environments. Several factors influenced the choice of episodes filmed, including achieving a balance across the 
teachers, coverage of a wide range of play contexts, regular events and routines, and not recording children for whom consent had not been received. I also did not film teachers engaged in in-depth discussions with parents or visitors. As data collection proceeded in each centre, filming became increasingly purposeful to cover the breadth of play contexts and regular events in the programme, and to ensure that each teacher was focused on to a similar degree. Some episodes involved more than one teacher.

After filming, the episodes were reviewed and details logged in the case journal. Episodes affected by high noise levels, sun-strike, frequent interruptions or poor quality camerawork were discarded. From the remaining episodes, up to 60 minutes of interactions were selected and organised for editing. Episodes were selected to ensure all teachers featured and that a broad range of situations was covered. Episodes less than ten minutes were used in entirety; longer episodes were edited into shorter sections using naturally occurring shifts and transitions (e.g., selecting the section of the episode focusing on the teacher's interactions with a specific child). Selected episodes were organised so that each teacher was focused on in turn and most interviews involved each teacher in two episodes. Full details of selection decisions were recorded in the case journal.

The digital video tapes were edited onto a DVD by a technician the following day in preparation for the interview, scheduled for a time convenient to the teachers (either after the session or in the evening). Most interviews for Moana ELC took place at a teacher's home whilst all other interviews were undertaken in the centres. I provided refreshments for the interviews.

Interview protocols (see Appendix 5) were developed to encourage teachers to focus on their thinking and actions at the time and to manage the interviews as a group process (Calderhead, 1981; Gass \& Mackey, 2000; Lyle, 2003). Instructions were given at the start of the first interview with each teaching team and briefly 
reviewed at subsequent interviews. The focus teacher in each episode was asked to stop the DVD at any point at which she/he wished to describe what they were thinking about at the time (Gass \& Mackey, 2000). Other teachers were asked to refrain from commenting until the end of the focus teacher's discussion. The protocol included prompt questions for use as necessary (Gass \& Mackey, 2000) and my role in the interview process was clearly stated.

Two-hour interviews were scheduled with the teaching teams. Moana ELC and Ngā Rangatahi Tamariki ELC interviews occasionally included teachers from the team who were not involved in filming for that round of data gathering, either because they were part-time teachers or because of their absence at the time of filming (due to a range of factors including sick children, their own illness, or attendance at initial teacher education classes). Each interview was video- and audio-taped. The audiotapes were transcribed, with the video-tapes used as a back-up and to support accurate transcripts. Interviews were transcribed by an external transcriber; I then checked each transcript against the audio tape for accuracy. In total, more than 26 hours of video-SR interviews were recorded.

Detailed field-notes were completed for each data-collection round, recording each part of the process and my reflections on the process and the data being generated. I attended, and video- and audio-recorded, planning sessions in each centre (totalling almost five hours), which were also transcribed.

Participating teachers were supplied with a notebook for their reflective journals and were also offered digital recorders to record their reflection orally, on the basis that some might want to use the recorders as they worked alongside the children. The reflective journals were moderately successful overall: four teachers (all from Ngā Rangatahi Tamariki ELC) did not keep a journal, and 15 recorded entries at various degrees of depth and detail. Two teachers (one each from Moana ELC and Summer Kindergarten) emailed further reflections several months after the completion of data 
collection, indicating how their thinking and practices had evolved after participating in the research. The use of digital recorders to enable teachers to record their thinking as they worked alongside children was unsuccessful as children's interest in the recorders meant that recordings were of the teachers' interactions with children rather than their thinking and reflections about these interactions.

At the conclusion of data collection in each case study centre, a thank-you letter was given to the parents of each child attending to indicate that this part of the research was now complete and I took morning-tea for the staff as a small token of thanks for their participation in the project. Christmas cards and occasional emails were sent to the centres to keep them updated on the project, given the time-lag between data collection and thesis completion.

\section{Case study databases}

Following Yin (2009), a database for each CS centre was established, including electronic and hard-copies of empirical materials (interview transcripts, reflective journals, field-notes, photographs and researcher journals) together with documentation concerning access, ethics and informed consent. The original digital video tapes and the DVDs used for each interview were labelled and logged. Transcripts, reflective journals and field-notes were uploaded into separate case study folders within Nvivo as part of the data coding and analysis procedures (see pp. 92-94 for further discussion).

\section{Reporting data}

The interviews and staff meetings were transcribed verbatim in order to record teachers' thinking and reflections. Transcripts included many instances where teachers made a 'false start' and either did not complete a sentence or shifted direction in their thinking. Particular idiosyncrasies, such as 'you know' and 'sort of', seemed to act as fillers, creating space for further thinking. Such false starts and fillers demonstrate the reality of teachers recalling their thinking and reflecting on 
their practices, but their density makes it harder for the reader to understand their thinking and so, to improve clarity, extracts from the data have been edited (indicated by use of ...) to remove such fillers.

\section{The three case studies}

\section{Case Study One: Moana Early Learning Centre}

Moana ELC is a teacher-led, community-based education and care centre located in a semi-rural community, and licensed for a maximum of 23 children. Sessions run from 9am to $3 p m$, four days per week, and from 8.30 am to $12.45 \mathrm{pm}$ on Fridays. Moana ELC is staffed by four qualified, registered EC teachers. Rachel, the head teacher, and Jane are full time whilst a third position is job-shared by two teachers, Meg and Inez, who each teach two days plus alternate Fridays. Rachel qualified 10 years ago and has been the head teacher of the centre for $3^{1 / 2}$ years. Jane is a beginning teacher in her first year of teaching. Inez has 17 years' experience whilst Meg has 22 years' ECE teaching experience in New Zealand and overseas. All four teachers are New Zealand Pākehā.

Thirty-six children attended the centre during the data collection period, with most children attending three or four sessions per week. Children ranged in age from 2 years 3 months to 4 years 11 months and there were more girls than boys on the roll. Thirty-three children were New Zealand Pākehā, two children Māori and one child New Zealand-born Asian. During data gathering, four children left the centre (e.g., to start school) and seven new children began attending.

The centre is managed by an elected committee of parents and the supervisor. A parent roster provides cover so staff can take lunch-breaks three days per week, and parents support centre events and excursions. Other members of the community contribute to the centre programme. The centre is adjacent to the local school, is often involved in school events, and is able to use school facilities such as the library. 
The programme begins each day at 9am. Lengthy conversations between parents, teachers and children are common as parents settle their children into the session. Children have free access to activities set up inside, under the covered veranda and outside until the group morning tea at 10.30am. Morning tea is followed by a brief mat-time, usually involving singing and a story, after which children are free to choose where they play until lunchtime at 12.30pm. After lunch the free play programme resumes except on Tuesdays when the centre visits the school's library for a large group story-time before breaking into small groups to read together. Afternoon tea is held at $2.30 \mathrm{pm}$ followed by a farewell mat-time. On Fridays the session starts at $8.30 \mathrm{am}$ and finishes for the day at $12.45 \mathrm{pm}$. The usual morning tea/mat-time and lunchtime routines occur but the day concludes with a mat-time after lunchtime. This session feels less busy than other days of the week with generally a younger group of children attending.

Staff are rostered with one teacher on inside duty, one on outside duty, and the third 'floating' to provide coverage where needed. The floating teacher ensures that the morning tea, lunch and afternoon tea routines are prepared. The indoor and outdoor teachers swap roles after morning tea time.

Teachers meet after each session to discuss the day and update their planning. A formal planning session is held fortnightly with recorded plans including links to $T e$ Whāriki (Ministry of Education, 1996), required resources, and community contributions. Alongside these plans, a programme book is maintained and shared with parents. Teachers reported parents were very positive about this approach to sharing programme information.

Data collection at Moana ELC took place between June and September 2008. A four-day orientation period was followed by five rounds of data gathering on:

- $9^{\text {th }}$ and $10^{\text {th }}$ June

- $1^{\text {st }}$ and $2^{\text {nd }}$ July

- $12^{\text {th }}$ and $13^{\text {th }}$ August 
- $25^{\text {th }}$ and $26^{\text {th }}$ August

- $16^{\text {th }}$ and $17^{\text {th }}$ September

One scheduled session in July was cancelled due to staff illness. Dates were planned to enable filming of both part-time teachers.

\section{Case Study Two: Summer Kindergarten}

Summer Kindergarten is a sessional, community-based kindergarten operated by a large kindergarten association. Located in a seaside suburb, the kindergarten is licensed for 43 children in the morning session and 35 children in the afternoon session. Older children (generally 4 years old) attend five morning sessions of between three and four hours whilst younger children (aged 2 and 3 years) attend three $2 \frac{1}{2}$ hours afternoon sessions. The kindergarten is staffed by three qualified, registered EC teachers, all employed full time. The head teacher, Marilyn, began teaching at the kindergarten in 2004, and was appointed as permanent head teacher mid-way through the data collection period. Poppy had been teaching at the kindergarten since 2006. Diana was employed as a long-term reliever shortly before data gathering commenced and was appointed permanently towards the end of my fieldwork with the kindergarten. Diana had taught in a number of ECE centres prior to starting at Summer Kindergarten. All three teachers are New Zealand Pākehā.

During data collection 35 children were enrolled in the afternoon group and 43 in the morning session. During fieldwork, several children left the morning session to start school, and were replaced by 11 children from the afternoon group. Eleven new children then started in the afternoon group. Children attending the kindergarten were predominantly New Zealand Pākehā, with some Māori, Samoan or Chinese. Relatively even numbers of girls and boys were enrolled across the two groups.

The kindergarten association provides governance, professional support, financial and property management whilst a local committee undertakes fundraising and supports the teachers in the day-to-day running of the kindergarten. Parents often 
participate in the sessions, although not formally rostered to help. The local school is adjacent and frequent contact between school children and the kindergarten teachers and children occurs over the fence. The kindergarten has access to the school playing field and regularly uses this space for games. During fieldwork, four students (from different teacher education institutions) undertook practica at the kindergarten. One student had been employed by the Kindergarten Association as an additional part-time teacher whilst training. Two Education Support Workers $(E S W)^{3}$ also worked at the kindergarten supporting two children with special needs. Student teachers and ESW were not included in the project but informed consent was sought to cover any peripheral inclusion in the video-recorded episodes.

Children in both groups have access to activities in the indoors and outside environment from the start of the session. In the morning session a short mat-time is held at 9.30am, typically involving singing, a story, and discussions on kindergarten events. Following this, children have free access to the play environment until shortly before the end of the session when tidy-up time begins. A farewell mat-time is held at the end of the session. Children choose when they wish to eat their morning tea which is brought from home.

Several regular events occur each week during the morning session. On Tuesdays teachers often take the children to the school field for games and physical play whilst on Thursdays the teachers split the group into three smaller groups for a Perceptual Motor Programme (PMP). On Wednesdays a Kapa Haka ${ }^{4}$ session is run by an outside facilitator, Manawa. Each week a simple cooking activity (e.g., making sandwiches) and a more challenging cooking experience occur.

The pace of the afternoon sessions is slower with children arriving over a longer timeframe. Around 1.30pm two teachers lead an afternoon mat-time, similar to the

3 Education Support Workers are employed by the Ministry of Education to support the inclusion of children with special educational needs.

4 Māori cultural activities, including waiata (songs) and haka (dance). 
morning one. Children eat their afternoon tea any time during the session up until tidy-up time which begins around $2.45 \mathrm{pm}$. The final farewell mat-time and end of the session is often hectic as parents meet older siblings from school and come across to the kindergarten to pick up children.

Teachers follow a weekly roster with one teacher inside, one outside, and the third acting as 'resource teacher' to provide coverage where needed. The indoor and outdoor teachers swap roles after the mid-session mat-time, and take turns to lead and support the mid-session and end-of-session mat-times.

Teachers spend significant periods of time writing up assessments of children's learning (using a Learning Story format) and planning the programme. Collectively over 20 hours per week are spent on writing learning story assessments, whilst a planning meeting is held weekly. Teachers also take work home at night or on the weekends to complete.

Data collection at Summer Kindergarten took place between November 2008 and April 2009. Three days of orientation visits took place in November, followed by two rounds of data collection in November and December. The remaining data collection rounds took place in March and April, 2009. A staff meeting in early April was attended and audio- and video-taped. One interview was rescheduled due to technical difficulties delaying preparation of the DVD. The five data gathering rounds took place on:

- $26^{\text {th }}$ and $27^{\text {th }}$ November 2008

- $8^{\text {th }}$ and $9^{\text {th }}$ December 2008

- $5^{\text {th }}$ and $9^{\text {th }}$ March 2009

- $17^{\text {th }}$ and $18^{\text {th }}$ March 2009

- $31^{\text {st }}$ March and $1^{\text {st }}$ April 2009.

\section{Case Study Three: Ngā Rangatahi Tamariki Early Learning Centre}

Ngā Rangatahi Tamariki ELC is a suburban centre licensed for 32 children, including a maximum of 24 children aged under-two. The centre is located in a 
purpose-built facility, adjacent to a local school, and operated under a charitable trust. The centre manager and supervisor are responsible for day-to-day management. Ngā Rangatahi Tamariki ELC operates from 8.30am to 3.30pm with most children attending between 9am and 3pm. Although open during term breaks, children's attendance is generally lower at these times. The centre is organised into three distinct groups within the open-plan environment based on children's development: immobile infants who may begin attending from four weeks of age; crawlers and toddlers; and completely mobile children ranging from about 18 months to just over four years.

Fourteen staff are employed at Ngā Rangatahi Tamariki ELC. Sabby, the centre manager, is a highly experienced teacher and manager who has been involved in ECE for more than 30 years. The supervisor, Spring, and two of the three team leaders, Juanita and Bernice, are qualified whilst the third team leader, Summer, has partially completed her training. Three other teachers (Anastasia, Conrad and Alexis) are also qualified whilst three staff are enrolled in centre-based EC teacher education programmes: Jayde has almost completed her qualification and Storm and Paige are in their first year of study. Two staff, Giselle and Autumn, are untrained. Juanita is the most experienced teacher (other than Sabby) with more than twenty years teaching; most other staff have between 5 and 10 years' teaching experience, including experience prior to or during their initial teacher education programme for some. Georgia, the cook, is responsible for preparing morning and afternoon teas and a hot cooked lunch daily.

Ngā Rangatahi Tamariki ELC's teacher:child ratios are considerably better than the regulated ratios, primarily because of the very young age that most children begin attending and the support given to parents. The improved ratios mean that outside relievers are seldom utilised, with cover for staff absences managed within the team. Although the centre operates as three groups, considerable interchange occurs between them. The open-plan environment enables frequent communication 
between both children and staff across the groups and the two older groups share a common outdoor area.

During data collection 40 children were enrolled: 12 were aged under 1 year, 16 were between 1 and 2 years, eight were between 2 and 3 years, and four were three years or older. The children reflect a range of ethnicities, with a large proportion of Māori and Pasifika children. Similarly, staff have diverse backgrounds with four Pasifika, four Māori and six New Zealand Pākehā staff.

Children attending the centre come from a wide geographical area. Mothers breastfeeding their infants are in and out of the centre throughout the day whilst other parents often call in during their lunch-break. The differing needs of children in each of the groups results in distinctive daily programmes. Elements of the RIE philosophy were introduced for the infant group in late 2008, and teachers have adapted their practices to follow the infants' cues and Baby Moves (Hermsen-von Wanrooy, 2002). ${ }^{5}$ Infants' individual sleeping and feeding routines are followed and when not sleeping, feeding or having nappies changed, teachers encourage floor play appropriate to their development. As the babies develop strength and coordination they are encouraged to reach for and hold objects and to begin moving around the floor. The teachers have a distinct role in that they are 'present' with the infants (lots of eye contact, soft voices and descriptive language) during floor play but do not intervene and assist unless the infant is at risk of being hurt or is becoming frustrated. Teachers believe this approach helps children develop persistence and belief in their own abilities, and supports smooth transitions to the toddler group.

The toddler group has a slightly more structured flow to the day, although this is adjusted to meet individual children's needs. Children have morning tea together at 9.30am and lunch at 11am. Most children have a bottle after lunch and are settled

5 A New Zealand book drawing on Pikler's philosophy that babies should be given time and space to develop their physical skills naturally. 
for a sleep about 11.30am with most sleeping for between one and $1 \frac{1 / 2}{2}$ hours. Afternoon tea is provided about $2.30 \mathrm{pm}$. In between these routine events, children have access to a range of experiences, with outside play available during suitable weather. A small covered veranda area enables limited outdoor play experiences during inclement weather, and this space is often used for meal-times so the inside play environment is left undisturbed. Many children are developing skills and confidence in walking and climbing, and teachers position themselves closely to provide physical and emotional assistance and to prevent accidents.

The older children's programme begins with indoor activities until morning tea at 9.30am. Following morning tea children have full access to the indoor and outdoor areas until about 11.30am when they come together for lunch. As children finish lunch, teachers support them to settle for a rest or sleep. Children start waking about $1.30 \mathrm{pm}$ and have a range of quieter play activities available until all the children are awake. Afternoon tea is at $2.30 \mathrm{pm}$ with children collected by parents from around 2.45 .

Teachers are all employed full time. There are rosters for morning tea and lunch breaks, with some flexibility within teams to minimise impact on the children. Planning and assessment activities are undertaken after 3.30pm.

Data gathering at Ngā Rangatahi Tamariki ELC took place between June and August 2009. Orientation visits took place over two days, followed by six rounds of data gathering. Two data gathering rounds were undertaken with each of the three teams, taking place on:

- $16^{\text {th }}$ and $17^{\text {th }}$ June (older group)

- $22^{\text {nd }}$ and $23^{\text {rd }}$ June (toddler group)

- $1^{\text {st }}$ and $2^{\text {nd }}$ July (infant group)

- $29^{\text {th }}$ and $30^{\text {th }}$ July (older group)

- $3^{\text {rd }}$ and $4^{\text {th }}$ August (toddler group)

- $13^{\text {th }}$ and $14^{\text {th }}$ August (infant group) 
I also attended and audio- and video-taped staff meetings for each team. Staff meetings included a mix of discussion around centre organisational issues and children's learning story assessments.

\section{Ethical issues}

Ethical approval for this study was gained from the Victoria University of Wellington College of Education Ethics Committee (Reference COE/2008/14, RM 15639) on 20 May 2008. The New Zealand Association for Research in Education Code of Ethics was used for ethical guidance.

Earlier sections have referred to procedures used to invite participation from suitable centres and to gain informed consent from teachers and parents. Procedures concerning the selection of episodes, both at the time of filming and for inclusion in the interviews, have also been discussed. These procedures were underpinned by my awareness that selection decisions would privilege certain episodes, activities and teaching situations over others. Thus, when preparing for each data gathering round, filming the teachers, and selecting episodes to use in the interviews, I aimed for transparency in my thinking, reflected on my choices, and recorded my decisions.

Strategies for maintaining confidentiality about the participating teachers and children were also implemented. Each teacher identified their own pseudonym and the teams chose a centre pseudonym. I selected pseudonyms for each child and for any parents or visitors identified during the interviews. The technician who edited the video footage and the interview transcriber signed confidentiality agreements (see Appendices $7 \& 8$ ). Finally, I have tried to avoid including identifying details in the description of each centre, and either did not use or altered teachers' interview descriptions where these might identify the centre.

Several potential ethical issues were identified when the study was designed, including the participation of all members of the teaching team, the impact of my 
presence on children's well-being, what images of children were portrayed on the video, and the potential to film inappropriate teaching practices. The identification of the EC centre as the case presupposed that all teachers in the team would be involved. Although a criterion for the centre's selection was that all the staff were willing to be involved, I was aware of the possibility that some staff may have felt unable to object to being involved prior to, or may have wished to withdraw consent during, the project. I prepared strategies to deal with this possibility but, in the event, all staff across the three cases were willing to be involved throughout the project.

In addition to being sensitive to children's cues about the impact of my presence, I had previously thought about and was sensitive to the images of individual children captured on film. Thus, I determined I would cease filming if children were clearly distressed for more than a few minutes and I would regularly review recorded episodes so that children were not repeatedly portrayed in a negative light (e.g., constantly being re-directed by a teacher). In practice, there was one instance where I stopped filming due to a child's on-going distress at her mother's departure. In selecting episodes for the interviews I was alert to how children were portrayed. Whilst not wanting to avoid episodes where teachers guided children's behaviour or where children displayed challenging behaviours (given these are part of a teacher's typical experiences), I was sensitive to the frequency of such instances and ensured that individual children did not feature more than once in such circumstances.

The research methodology meant there would always be potential for inappropriate or poor quality teaching behaviours to be recorded. I was conscious of the ethical issue of exposing team members to unnecessary risk within their team versus avoiding situations where teacher behaviours were of significant or continuing poor quality and, again, prepared strategies for dealing with such episodes should they arise. In the event, this was not an issue in any of the cases. 
An issue not considered prior to data collection was the potential for differences amongst the teachers during the actual interview process. In two of the three cases, individual teachers made much briefer contributions than their colleagues. A number of factors appeared influential, including temperament and conversational style, confidence, and ability to articulate their thinking and reflection. I was conscious that my probing of these teachers occurred more often and at times became more focused, and wondered how evident this was to them and their colleagues and how they felt about it.

\section{Data coding and analysis}

An overall project journal was kept to record my thinking and decisions throughout each stage of the project (Richards, 2005). Following Maxwell (2005), early in the design process I explicitly outlined my assumptions underpinning the project (see Chapter 1) to assist reflection on my biases (Richards, 2005) as I worked with the data. Individual journals established for each case ensured confidentiality was preserved as I recorded field-notes in each centre.

In qualitative research, data analysis begins as the initial data are collected (Merriam, 1998). In this project initial data analysis took two forms: first, the on-going recording of my impressions and reflections throughout the field-work and, second, through initial coding and analysis of the first interview transcript for possible themes and categories. Delays in the transcribing of the other interviews and staff meetings meant that coding and analysis beyond these steps did not occur until after all the interviews were completed. Further insights about possible themes and categories which emerged during transcript checking were recorded. My notes about emerging themes and categories were then collated from across the journals and field-notes and summarised into one document prior to beginning in-depth coding and analysis.

Data coding was undertaken using Nvivo 8. Interview and staff meeting transcripts were formatted to allow for a degree of auto-coding before being uploaded into 
Nvivo, along with the teacher reflective journals and my field-notes. Both topic (e.g., coding all statements made by each teacher; coding everything said about individual children) and analytical coding (e.g., teacher references to coping with multiple demands during teaching interactions) were undertaken (Richards, 2005).

Both inductive and deductive approaches have been drawn upon during data analysis. For example, a key theme of knowing the children emerged inductively from each case whereas categories about aspects of children's learning discussed by teachers were informed by literature (although not pre-determined prior to analysis). Similarly, the original research questions for this study provided frameworks for thinking about possible categories that might emerge from the data.

My initial interest in the influence of the team on teachers' thinking and reflection deepened as the data revealed the value teachers placed on being members of a team and I explored the literature around communities of practice (Wenger, 1998) and professional learning communities (e.g., Stoll et al., 2006). This literature informed the data analysis process and the development of coding categories focused on teachers' use of social cohesion and alignment behaviours and the ways in which their collective negotiation of meaning influenced their reflection.

Iterative processes have been used for data coding and analysis - reading and rereading transcripts, reviewing and re-framing categories, exploring and re-examining data coded within categories - in order to make sense of the data. Several tactics identified by Miles and Huberman (1994) for generating meaning out of the data were used, including noting patterns in the data, clustering data, subsuming specific data into more general categories, and making conceptual links to the data. Appendix 6 presents the final categories developed for this study, including links to sources for categories where applicable, and illustrative examples.

Within-case analysis was undertaken, resulting in an individual case record for each centre (see Chapters 4-6), prior to cross-case analysis (Eisenhardt, 2002; Merriam, 
1998; Yin, 2009) which enabled trends in the data to be compared and contrasted across the three cases (see Chapter 7).

\section{Validity issues}

Concepts of validity have been vigorously contested in qualitative research (Merriam, 1998). Within the constructivist-interpretive paradigm validity issues are often considered in terms of trustworthiness, credibility, transferability and confirmability (Denzin \& Lincoln, 2008), although terms such as reliability, construct validity, and internal and external validity are still present in the literature (Merriam, 1998; Yin, 2009). This section of the chapter outlines the potential threats to the trustworthiness (or validity and reliability) of this study and the steps taken to mitigate against these.

Both Maxwell (2005) and Merriam (1998) note the potential for bias in qualitative research, and earlier sections of this thesis have discussed key assumptions I held about the nature of teaching in the EC context, which I re-examined during data analysis and when writing this thesis in an effort to guard against seeing what I hoped to see in the data. My supervisors assisted this process, reminding me of the shift in stance required to move from practitioner to researcher and challenging me when they felt I was reading too much into the data.

Miles and Huberman (1994) discuss the impact of researcher effects in qualitative research. Researchers may affect the case (e.g., influencing participants' behaviour through their presence) or the case may affect the researcher (e.g., by researchers "going native" (Miles \& Huberman, 1994, p. 265)). In this study, I was aware that my presence, with video camera in hand, may affect teachers' behaviour during their interactions. Furthermore, anxiety at seeing themselves on video may affect participants' recall (see p. 72 for a discussion on strategies to address this). My presence and the video camera did have some impact, particularly for the teachers in the toddler group in Ngā Rangatahi Tamariki ELC who acknowledged on several 
occasions they had "hidden" from the camera and who expressed discomfort at seeing themselves on video. These teachers were among the most reticent in describing their thinking, and my field-notes recorded my uncertainty as to the causes (see also p. 92 for related discussion on the ethical issue of differences in volubility amongst teachers). In contrast, other teachers across the three cases indicated that they ignored me and the camera even when I filmed in close proximity, and appeared comfortable with the interview process. Thus, the researcher and methodological effects apparent here demand caution in interpreting why some teachers were more articulate about their thinking than others.

Previous sections have outlined how I dealt with the potential for bias in determining which teachers' interactions to film and in selecting episodes to use in the interviews. I was also aware of the potential that I might read more significance into my data than existed. I maintained a thorough record of analytic reflections and decisions in order to establish an audit trail (Merriam, 1998) and chain of evidence (Yin, 2009). My supervisors were especially helpful in highlighting where the reality of the data collection process (e.g., unexpected absences from the interviews) influenced how I was interpreting the data, particularly concerning community of practice aspects.

The case study databases and audit trail, and my supervisors' advice, contribute to the reliability and credibility of this study. Further support was given through attention to the construct validity (Yin, 2009) of the project. Discussion in earlier sections of this chapter demonstrated the alignment between the constructivistinterpretive paradigm underpinning this research, case study as a strategy of inquiry, and video-SR interviews as an appropriate method for enabling the hidden world of teachers' thinking and reflection to be accessed.

Triangulation of data sources is a recognised strategy for building construct validity within case study research (Yin, 2009) as multiple sources of evidence strengthen the findings and conclusions reached. An earlier section of this chapter (see pp. 73- 
74) outlined that observations and field notes, a researcher journal, teacher reflective journals and transcriptions of staff planning meetings provided secondary data sources. Data from the observations and field notes were used primarily to draft detailed case records, which were checked for accuracy by the teachers, to support my understanding of each centre's structure, organisation and programme. My researcher journal provided a central location for recording my insights and reflections throughout the project, whilst the individual case journals specifically contributed to developing a chain of evidence (Yin, 2009) from data collection through analysis and reporting.

Whilst the research design intended to use the teachers' reflective journals and staff meeting transcripts to triangulate the primary data gathered through the video-SR interviews, the resulting secondary data were extremely limited. As noted earlier (see pp. $80-81$ ) the reflective journals were only moderately successful: when these data were examined, overall they offered little further evidence of teachers' thinking and reflection about their interactions with children. Similarly, the staff meeting transcripts indicated a primary focus on administrative, rather than teaching and learning aspects of teachers' work. Subsequently these data are not reported in the following chapters.

In quantitative research, external validity concerns the degree to which findings can be generalised beyond the particular participants (or phenomena) to the wider population (Wiersma \& Jurs, 2009). Whilst a construct of external validity based on statistical generalisation is not applicable to case study research, the concept of analytic generalisation and replication logic does address external validity (Yin, 2009). Undertaking multiple cases enables researchers to replicate findings literally (i.e., select cases predicted to have similar results) or theoretically (i.e., select cases predicted at the outset to have contrasting results) (Yin, 2009). In this research, case selection was intended to support literal replication (e.g., choosing teacher-led services with qualified, registered teachers and low staff turnover). The decision to 
include services representing different types of teacher-led services was underpinned by a belief that this would expand the resonance of this study (Lincoln \& Guba, 2002) for teachers across the sector rather than proposing that teachers in different types of centres would think about their interactions with children differently. The multiple-case design used in this study undertook within-case analysis of each case that allowed the unique patterns within the centres to emerge, before examining these patterns across the cases.

This chapter has outlined the constructivist-interpretive paradigm underpinning this project, the case study research design, and the methods used to collect the "empirical materials" (Denzin \& Lincoln, 2008, p. 34). The three case study centres and teachers have been introduced. Ethical aspects and validity issues have been discussed, and the approach to data coding and analysis outlined. Results for the three case studies are presented in the next three chapters, beginning with Moana Early Learning Centre in Chapter 4. 


\section{Chapter 4: \\ Case Study One: Moana Early Learning Centre}

\section{Introduction}

Children were central to the Moana ELC teachers' thinking and reflection about their practices. Teachers' discussions focused heavily on children's actions, their background knowledge of children, and the influence of these aspects on their interactions. In addition, they drew on theoretical understandings and EC principles of practice, and clearly articulated beliefs that underpinned their practices. These teachers were highly interactive during the interviews, frequently shifting between speakers and actively engaging with each other as they collectively constructed understandings of the children and their work as teachers. The findings for Moana ELC are presented in three sections reflecting the research questions: 1) teacher thinking and reflection regarding their interactions with the children; 2) beliefs, principles, and theories that underlie these teachers' practices; and 3) the influence of the team on teachers' thinking and practices.

\section{Teacher thinking and reflection at Moana Early Learning Centre}

Teachers' interactive thinking and reflection-in- and -on-action, focused on four main areas: what they knew about the children and how this influenced their interactions; their own teaching intentions and use of teaching strategies; the "busyness" of teaching, including their thinking about their broader teaching roles; and new-found understandings that emerged from watching the video-recorded episodes.

A specific feature of the Moana ELC teachers' reflection and thinking about their interactions was the way they regularly and persistently shifted their discussion beyond the actual video-recorded episode to talk about other, usually related, episodes and issues. Across the group video-SR interviews, more than two-thirds of the episodes included discussion that moved beyond the actual episode whilst the 
final reflective discussion that wrapped up each interview also explored broader aspects. A predominant focus on the children was evident in these discussions, with teachers sharing knowledge about children's lives outside the centre (e.g., Rachel's conversation with Jimmy's mother about his anxiety in transitioning to school $[\mathrm{CS} / \mathrm{SRI} / \mathrm{E} 4]^{6}$ ) and their families (e.g., Meg's comments about observing similar behaviours when previously teaching an older sibling [CS1/SRI1/E3]). Discussions also drew on earlier episodes within the centre, as teachers contributed their broader understandings sparked by watching the video (e.g., earlier play involving children building a tree 'fort' [CS1/SRI4/E3] and conversations children had been having about attending another child's birthday party [CS1/SRI4/E2 \& CS1/SRI4/E5]). The readiness with which teachers shared knowledge of the children, even when they were not part of the video-taped episode, signified the importance that they placed on knowing their children well in order to inform their teaching.

\section{Knowing the children}

This section explores the influence of these teachers' knowledge of children in terms of their individual interactive thinking and reflection-in-action, their collective reflection-on-action, and their practices. Their knowledge was evident in descriptions such as Rachel's comments about Stephanie:

Quite good for Stephanie, too, because she...needs support with friendships. And so working in a socio-dramatic play like that...well, if you knew Stephanie, she needs to be...the whole time she needs to have that controlling thing.... [CS1/SRI3/E1]

Their focus on the children meant that their teaching interactions were regularly mediated by their existing knowledge of children and in response to their actions, rather than by pre-determined teaching intentions:

Inez:

Michael and Jimmy, really, where is that going, their interaction, their play... Jimmy is our rule-maker, our policeman. And awareness that Scott was upset that the plank had been moved to, from a place where it had previously been

6 References to data sources are provided throughout. Thus, [CS1/SRI4/E3] refers to Case Study 1, Stimulated Recall Interview 4, Episode 3. 
and working with getting that back up to where he was happy with it sitting. Jimmy is giving the low down about not being all right to climb on the blue thing... and here we go, aware of this situation that's coming here - Michael and Scott together...He [Scott] takes a step forward and then he moves back.

Sue:

So, what were you thinking about?

Inez:

I'm just...I'm aware of their personalities together and just thinking, I'll just stand there, just stand there...Scott goes right round, and stays almost out of his way really, makes a point of going... he wants to go across the plank but Michael's on the other side. He has to wait for his opportunity...there could have been a situation easily coming there, and I was just standing by, really. [CS1/SRI1/E2]

Teachers' knowledge of individual children helped them understand and respond to the children's intentions during their play. For example, Rachel drew upon her knowledge of Anton's interest in dinosaurs [CS1/SRI1/E7] when describing her thinking during the episode. Such knowledge also informed teachers' thinking as they initiated interactions with children:

Jane:

And l've actually noticed that with his interactions with mum in the morning too - she'll sit there and pretend to be an animal and he'll actually use the words, "Let's play, I want you to play with me", and I am thinking about how I can extend, what his play is about for him, for how I can... [CS1/SRI1/E8]

Teachers' knowledge of children covered multiple aspects, including their development (e.g., language development, social interactions), their lives outside the centre (e.g., family holidays, family circumstances), their learning interests (e.g., enveloping schema, using technology), and their learning dispositions (e.g., persistence, becoming involved). Teachers used this knowledge during their interactions as they responded to children's learning intentions and cues, as illustrated in Table 4.1 where data are presented about one episode involving a child, Alastair. The left-hand column identifies the knowledge Meg drew on (underlined) and her thinking and interactions during the episode whilst the right-hand column presents data from the episode specifically referring to Alastair. 
Table 4.1: Teacher knowledge about Alastair

\begin{tabular}{|l|}
\hline $\begin{array}{l}\text { Teacher knowledge, } \\
\text { thinking and interactions }\end{array}$ \\
\hline $\begin{array}{l}\text { Provided background } \\
\text { information about Alastair's } \\
\text { attachment to her, and what } \\
\text { she had learnt about his } \\
\text { recent holiday to Samoa. }\end{array}$ \\
Shared mother's concerns \\
about Alastair's colour \\
knowledge, connecting this \\
to child's selection of story.
\end{tabular}

Used questioning as a teaching strategy; referred to knowledge of child's language development.

Used explanation as a teaching strategy

\section{Used explanation}

Made connection between library visit later that day where Alastair had chosen another book about volcanoes.

Used explanation as a teaching strategy; made connection between the two episodes.

Reminded Meg of children's earlier interest in volcanoes in the sandpit.

\section{Extract from episode related to Alastair ${ }^{a}$}

Meg:

Now Alastair is absolutely attached to me since he got back from Samoa. Apparently missed me, he talked about coming back to preschool when he was on holiday... snorkelling and all the rest of it...

But Alastair, we've got a real thing about colours going. And last week after discussion with Mum...Mum's having issues with Alastair not knowing his colours, so after some discussion at the end of the day and l'd spoken to Mum that perhaps all the colours wasn't such a good idea let's just choose one colour and we chose green.... and he'd picked up this 'Green eggs and ham' and I thought, "What a really good reinforcer that's going to be". But funnily enough as the story goes, I probably don't even touch on the colour green because I'm constantly saying "Green eggs and ham....Sam, I am, I don't like green eggs and ham" and the pictures are pretty green...

...I decided I wasn't going to tell them. I wanted to see what they saw so I asked quite a lot of questions... and I'm quite conscious of Alastair's language...

....because he obviously knows the story... and he's convinced the waves are volcanoes but that should come up a bit later on...

I'm just explaining to him that the illustrator's drawn...he thought that they were volcanoes...

Well, actually, the waves are quite peaky, that illustrator. I don't know who actually illustrates Dr Suess books, is it Dr Suess himself?

And these were going to be volcanoes, and yes, they were going to explode. Now in the volcano, so that's why I was explaining to him about that. Now I don't know if you remember when we were in the library, see this is first thing in the morning, nine o'clock in the morning. We were in the library... and I sat - you were reading that story and I sat with Alastair. He had a book, 'Under the sea'. What's on one of the pages, completely along the bottom, is all the volcanoes that are under the sea. Do you remember that?

Sue:

I remember that because I remember you saying, "Here you are with your volcanoes again"

Meg:

"And here you are with your volcanoes again". And I was trying to explain to him that the photography was under-the-sea mountains but that the sea wasn't there for him to see, they like, they had under the sea but the water was taken away. I don't know...how much of that he understood, so it was really interesting from the beginning of the day to the end of the day there was a still a volcano thing.

Rachel:

There had been volcanoes in the sandpit, though, remember, last week were you there? And they were doing all their volcano things, Christopher and they put the...

Meg:

Was that when Alastair was back? Or was that before? How long has he been back?

Rachel:

He was back last week, so that might be something... 


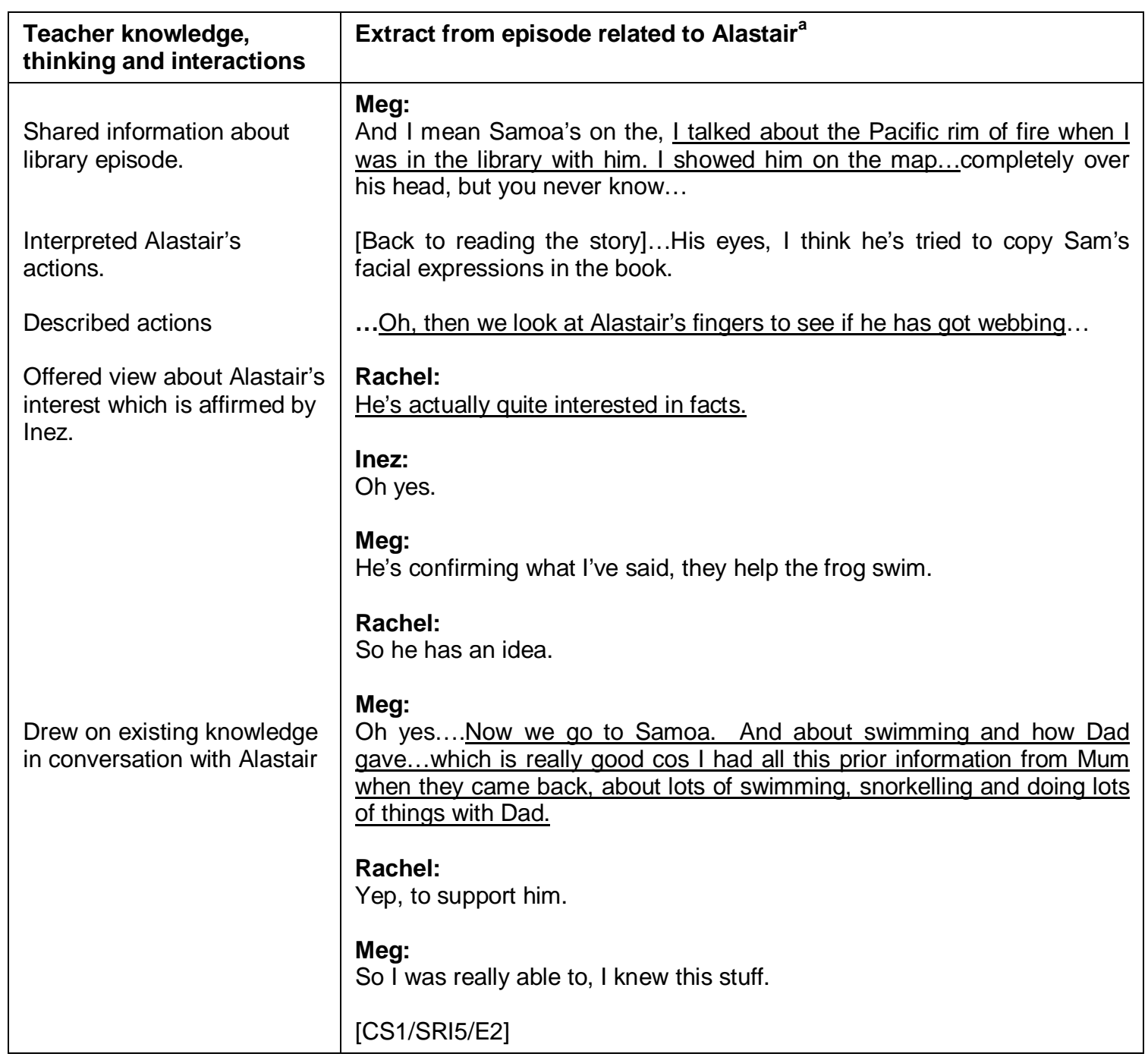

${ }^{a}$ References to knowledge about the children are underlined

Beyond the knowledge about Alastair revealed above, teachers knew a great deal more about him that emerged during their discussions of other episodes, and which had influenced their interactions with him. Teachers knew that Alastair had a passionate interest in boats and was confident with baking. They described him as having a sensitive nature whilst his quietly-spoken approach and delayed language development meant that they could not always understand him and were considering seeking outside expertise for support. They were cautious about trying to interpret what he said to them as they felt he would often agree even when they misinterpreted his meaning. Teachers had open communication with his mother and knew that he was the youngest of four children in a busy household and that there were currently disruptions at home. They felt they needed to provide him with emotional support and to engage with him in unpressured play. 
Teachers' understandings about children were informed by many sources, including their own observations, their discussions within the team, and what both children and their parents shared with them. Conflicting insights were sometimes gained, such as when Erin's version of building a birdcage at home differed from her mother's:

\section{Rachel:}

Well, there's a lot of history there, isn't there? You know like, there's the bird cage. How important was that to mention bird cage because there was a big episode happening at home with Granddad and Dad. And how competent, Dad's really thrilled that his daughter can now use a hammer and how competent she is.

\section{Meg:}

Well, that's not the story I got from Erin because Erin... I was trying to revisit that with...I don't, well you obviously haven't got it [referring to whether this part of an episode had been video-recorded] but she made it and it definitely looked like a bird house to me.

\section{Rachel:}

Well, she did today, didn't she? It looked like a bird house. Looked like a bird cage.

\section{Meg:}

And so I tried to revisit what was going to happen on the weekend..."No", she says, "Dad did it." I said, "Oh, Dad helped you?" "No, Dad did it." He did do it. He took over. He took over and she was like "Well, that was it so I'm going to make another one out of sticks".

\section{Rachel:}

She must have, she must have done some part of it because Andrea [mother] was telling me how proud he was that she could competently hold a... he was actually really surprised that she could hammer in nails and how confident she had become. But he took over?

\section{Meg:}

Well, no, she made that quite clear that, no, he did it. [CS/SRI2/E2]

In summary, teachers' emphasis on knowing the children well was strongly evident. Teachers drew on multiple sources of knowledge and actively shared what they had learnt with each other in order to continually grow their understandings of individual children. Their knowledge mediated both their intentional and responsive teaching interactions with children, and influenced their choice of teaching strategies and 
behaviours during interactions with individual children. The next section of this chapter addresses teachers' thinking and reflections about their teaching intentions and strategies.

\section{Teacher intentions, teaching strategies and interactions}

Teachers' knowledge of the children informed their teaching decisions, as they engaged in interactive thinking and reflected-in- and -on-action. This knowledge helped them to understand children's intentions and respond to their learning interests, to read children's cues and adapt their interactions to suit the child, and to re-visit previous learning and affirm children's lives outside of the centre (see Table 4.2).

Table 4.2: Examples of teaching strategies arising from teachers' knowledge of children

\begin{tabular}{|l|l|}
\hline $\begin{array}{l}\text { Teaching } \\
\text { strategies }\end{array}$ & Illustrative examples from the data \\
\hline $\begin{array}{l}\text { Using prior } \\
\text { knowledge to } \\
\text { understand } \\
\text { children's } \\
\text { intentions and } \\
\text { meaning }\end{array}$ & $\begin{array}{l}\text { Rachel: } \\
\ldots \text {.I'm thinking here too, she's got an eye impediment as well so I'm now thinking.... } \\
\text { also "What's happening here with sight?" And is she actually seeing it clearly?... } \\
\text { but just in that split second I saw the eye...the trouble that we've been having with } \\
\text { the eyes and I saw that...happen as well so I just...I'm...thinking that as well } \\
\text { although trying to still... what's happening in the script with this whole socio } \\
\text { dramatic play... [CS1/SRI3/E1] }\end{array}$ \\
\hline $\begin{array}{l}\text { Following } \\
\text { children's agendas } \\
\text { and learning } \\
\text { interests }\end{array}$ & $\begin{array}{l}\text { Jane: } \\
\ldots \text { as you can see Jacob has just...entered the play and so has Edward, and...I } \\
\text { think this is quite similar to what happened to you (Rachel) earlier in the morning. } \\
\text { Anyway...I've pretty much got Edward pulling me away and really craving my } \\
\text { attention here and I'm still kind of... } \\
\text { Meg: } \\
\text { Yes, he's really pulling you. } \\
\text { Jane: } \\
\text { And that's taken Jacob away from the swings as well, as you can see it's } \\
\text { completely, just by him coming in its completely changed the experience. } \\
\text { Sue: } \\
\text { And what were you thinking as all this is happening? } \\
\text { Jane: } \\
\text { Um, what's his agenda? And when he was coming in and trying to pull me away he } \\
\text { was really wanting to do something, and we were swinging on the swings and we'd } \\
\text { been there for some time so I thought "OK, I'll go with this".... [CS1/SRI1/E3] }\end{array}$ \\
\hline
\end{tabular}




\begin{tabular}{|c|c|}
\hline $\begin{array}{l}\text { Teaching } \\
\text { strategies }\end{array}$ & Illustrative examples from the data \\
\hline $\begin{array}{l}\text { Responding to } \\
\text { children's cues }\end{array}$ & $\begin{array}{l}\text { Rachel: } \\
\text { Oh you could see, well you could see from the, Christopher's face...as soon as I } \\
\text { approached that there was going to be...Well, I was trying not to predict issues but } \\
\text { you... have to have that sense that... } \\
\text { Inez: } \\
\text { Read the body language. } \\
\text { Rachel: } \\
\text {...I wasn't going to be moving away because I just sensed, well, they might need a } \\
\text { little bit of support in there [CS1/SRI4/E3]. }\end{array}$ \\
\hline $\begin{array}{l}\text { Adapting } \\
\text { interactions to suit } \\
\text { the individual child }\end{array}$ & $\begin{array}{l}\text { Rachel: } \\
\text { I think, knowing this girl here too...I wasn't about to say, "Isla, don't do that, ra, rade } \\
\text { ra. Go and it put it in your bag, it's inappropriate, don't do that" because I know that } \\
\text { I would have got a different response from her. So we were able to actually talk } \\
\text { that right through (CS1/SRI5/E1). }\end{array}$ \\
\hline $\begin{array}{l}\text { Re-visiting } \\
\text { learning and prior } \\
\text { experiences }\end{array}$ & $\begin{array}{l}\text { Meg: } \\
\text { She makes this aeroplane and I said to her..."Have you been on an aeroplane?" } \\
\text { Or, "Yes, you have been on an aeroplane". Remember Elise, she came from } \\
\text { England on an aeroplane so she starts to tell me about that but this is the point... } \\
\text { she changes the subject and tells me about going on the train to look at the New } \\
\text { Zealand Ballet dresses. Fortunately I had the conversation with her Mum outside } \\
\text { and Mum had made two bids on two costumes, two outfits. So I had all that } \\
\text { knowledge, prior conversation, and I think it was probably about this point I realise } \\
\text { that's what she's now trying to tell me. It's gone off the aeroplane [CS1/SRI2/E2]. }\end{array}$ \\
\hline $\begin{array}{l}\text { Affirming } \\
\text { children's lives } \\
\text { outside the centre }\end{array}$ & $\begin{array}{l}\text { Rachel: } \\
\text { I think it was Elise, it was. And I didn't even pay much attention to her this morning } \\
\text { with that book but I know that it was there and so just linking it into her game that } \\
\text { Dad's a vet and he's bought her this book and she's brought it in. So it's just subtle } \\
\text { ways of acknowledging that whole community thing and making the links } \\
\text { [CS1/SRI3/E2]. }\end{array}$ \\
\hline
\end{tabular}

Whilst teachers' responses to children's interests and agendas were at the heart of many interactions, their own teaching intentions were also influential. Children's learning interests and play agendas were used as a context within which teachers could work towards achieving their own holistic teaching intentions. For example, teachers described supporting children's social interactions (e.g., helping children join play [CS1/SRI1/E4] and play as a good friend [CS1/SRI4/E5]) and helping children manage transitions [CS1/SRI4/E4] and develop initiative [CS1/SRI4/E3]. Teachers intentionally taught children specific skills to facilitate creativity (e.g. using scissors [CS1/SRI3/E3] and glue guns [CS1/SRI2/E2]), for physical play (e.g., climbing [CS1/SRI2/E8] and ball skills [CS1/SRI4/E3]), and to use equipment (e.g., computers and software programmes [CS1/SRI4/E2] and video-cameras [CS1/SRI4/E9]). Whilst the content of children's learning interests informed teachers' intentions (e.g., Harriet's interest in the sun and solar system [CS1/SRI2/E5]), they 
also deliberately incorporated content knowledge such as healthy food [CS1/SRI3/E1], literacy [CS1/SRI5/E6], numeracy [CS1/SRI3/E1] and te reo Māori ${ }^{7}$ [CS1/SRI4/E4] into their interactions. Blending responsiveness to children's interests with teaching intentions was, at times, difficult and required flexibility on the teachers' part. Reflecting on this at the end of the first interview Rachel commented:

When you think what's going through our head the whole time and we have to be flexible, change, you know, go a hundred miles an hour... [CS1/SRI1/FR]

The Moana ELC teachers described using a broad range of teaching strategies commonly used by EC teachers (see, for example, Bredekamp \& Rosegrant, 1992; MacNaughton \& Williams, 2009) as presented in Table 4.3.

Table 4.3: Teachers' use of specific teaching strategies

\begin{tabular}{|c|c|}
\hline $\begin{array}{l}\text { Teaching } \\
\text { strategies }\end{array}$ & Examples from the data \\
\hline $\begin{array}{l}\text { Directly giving } \\
\text { instruction and } \\
\text { teaching skills }\end{array}$ & $\begin{array}{l}\text { Rachel: } \\
\text { We sat together and there was about } 10 \text { minutes of actual teaching...."Put your } \\
\text { hand here". It wasn't just role modelling, it was hands-on... his whole coordination } \\
\text { there but once he got it he was right and he was dragging and dropping into that } \\
\text { Comic Life. "I can do it now", he said. "I can do it, leave my hand", so he's quite } \\
\text { confident there. [CS1/SRI1/E5] }\end{array}$ \\
\hline $\begin{array}{l}\text { Scaffolding } \\
\text { learning }\end{array}$ & $\begin{array}{l}\text { Rachel: } \\
\text { They want the absolute black and white strategies, and then once they've got that } \\
\text { then you can pull back and do the scaffolding more but unless you actually teach } \\
\text { them or show them...they want to get things done now and...so maybe, the pliers, } \\
\text { they all know about the pliers, but sometimes you need to jump the queue a little } \\
\text { bit in the scaffolding, it's almost like "Do it this way and that might help you reach } \\
\text { that goal" and then when they start, you start doing the scaffolding then and then } \\
\text { withdrawing back... [CS1/SRI1/E2] }\end{array}$ \\
\hline $\begin{array}{l}\text { Encouraging } \\
\text { children }\end{array}$ & $\begin{array}{l}\text { Jane: } \\
\text { And I thought, I've given her one but she's... a bit anxious so I'll get one too, just } \\
\text { to...encourage her to...because she does want to do it but she's just, well, she } \\
\text { seems like she wanted to do it but she's just... [CS1/SRI1/E6] }\end{array}$ \\
\hline Observing children & $\begin{array}{l}\text { Meg: } \\
\text { Even though I don't look like I was aware, but I was, because I was busy thinking } \\
\text { about that drink bottle. I was totally aware that Alice was reading that sign to } \\
\text { Carlos. And telling, giving him to actually, and she was pointing to the words. } \\
\text { [CS1/SRI2/E6] }\end{array}$ \\
\hline $\begin{array}{l}\text { Co-constructing } \\
\text { learning }\end{array}$ & $\begin{array}{l}\text { Rachel: } \\
\text { And I think too that during this, it's actually a shared knowledge here. So it's not } \\
\text { about... This is about her and I working together. This is actually about learning } \\
\text { together. This is not me being the teacher. It's working, working in an equal } \\
\text { partnership. [CS1/SRI2/E5] }\end{array}$ \\
\hline Explaining & $\begin{array}{l}\text { Jane: } \\
\text { Before that he was, we were talking about the clips because he was trying to pull } \\
\text { one onto a bit of wood that didn't have a clip so we had to, I sat there for a while } \\
\text { talking about how many - that some holes actually didn't have clips on them and } \\
\text { then... he found, "Oh we're going to have to pull it on an angle this way to get it on } \\
\text { to this clip"... [CS1/SRI4/E10] }\end{array}$ \\
\hline
\end{tabular}




\begin{tabular}{|c|c|}
\hline $\begin{array}{l}\text { Teaching } \\
\text { strategies }\end{array}$ & Examples from the data \\
\hline Demonstrating & $\begin{array}{l}\text { Meg: } \\
\text { Just reminding them how to wash their hands really. Oh, actually I had to show } \\
\text { Alastair how to wash his hands. } \\
\text { Yes he just stands there. And I had to take that few seconds to show him to put } \\
\text { his hands together and then between his fingers. He doesn't know how to wash his } \\
\text { hands... } \\
\text { And I could hear myself and I actually do remember that and he had red paint and I } \\
\text { showed him if you apply pressure the paint will come off [CS1/SRI2/E6]. }\end{array}$ \\
\hline $\begin{array}{l}\text { Acknowledging } \\
\text { children's efforts }\end{array}$ & $\begin{array}{l}\text { Rachel: } \\
\text { I think going back to the beginning of the day that was actually, he was really quite } \\
\text { proud of this little thing so you're...conscious of not demoralising or deflating his } \\
\text { work there too [CS1/SRI2/E5]. }\end{array}$ \\
\hline $\begin{array}{l}\text { Using non-verbal } \\
\text { communication } \\
\text { and body } \\
\text { language }\end{array}$ & $\begin{array}{l}\text { Meg: } \\
\text { I know one thing I was just going to say about myself, is I do look up and give facial } \\
\text { acknowledgement to them. I might not be saying words but I thought, "Oh, I } \\
\text { actually look up and smile and I actually put...You are there; I know you're there..." } \\
\text { [CS1/SRI2/E2]. }\end{array}$ \\
\hline Questioning & $\begin{array}{l}\text { Rachel: } \\
\text { And really it was just questioning the children to see if they could be more focused } \\
\text { in on this one, especially Caroline and Stephanie [CS1/SRI4/E6]. }\end{array}$ \\
\hline Negotiating & $\begin{array}{l}\text { Rachel: } \\
\text {...Isla's come in with her pocket money and there was a considerable amount of } \\
\text { money... probably about } 6 \text { or } 7 \text { dollars, all piling out of her pocket, and I was a little } \\
\text { bit concerned that this would start disappearing...But with Isla, she's usually got a } \\
\text { strong agenda of where's she's going with that so it was going to be a little bit of } \\
\text { negotiating here and working together [CS1/SRI5/E1]. }\end{array}$ \\
\hline
\end{tabular}

In addition, teachers described using interactive strategies designed to support

children's language development and emerging literacy. Teachers' awareness of individual children's language capabilities meant they incorporated specific vocabulary (e.g., Jane's language in a conversation involving Scott in line with his Individual Development Plan $^{8}$ objectives [CS1/SRI1/E3]) and content language during interactions:

\section{Rachel:}

And I thought to myself, "Right, let's just use the IT language" so we're talking about Google and search station. He's got his book. We've come from the book corner with his dinosaur book... And I was really interested, I was fascinated. I thought, "Oh, I haven't seen these before", so I...was getting a bit excited myself that I'd actually achieved something, and I'm thinking "Oh, slow down a little bit" because...

So again I'm actually thinking my thoughts, as the process going down. "Double click" I'm thinking, "How would I do this? I'd double click", so he's getting the language I would actually be physically doing myself. I was actually surprised, and I shouldn't be, but he picked that up so quick... "Go back to the arrow", "Click", "Double click". He was so on to it - very familiar with it, very capable with the mouse, moving the arrow around, very focused. [CS1/SRI1/E7]

8 IDPs are established for children with special educational needs, with input from the child's parents, special education services and teachers. 
Whilst teachers sometimes described providing a running commentary to make their actions explicit to children [CS1/SRI2/E2] they were conscious of not overloading children with information and keeping their explanations simple [CS1/SRI2/E5]. They were cautious about speaking for the child, knowing that children might agree with teachers' suggestions rather than offer their own ideas (e.g., about their art constructions [CS1/SRI2/E1]).

All teachers incorporated te reo Māori into their interactions, with Jane particularly skilled and confident. She described Carlos' response when they had completed the task of covering the sandpit:

Jane:

And he's really, he picks up on so much. You see just then I said, "Oh, ka mau te wehe" just...under my breath and he said, "What does that mean? What's ka mau te wehe?" And I said, "That's Māori words for awesome" and then he said, "Oh, ka mau te wehe." [CS1/SRI4/E10]

Teachers described modelling a range of literacy strategies, including pointing at words as they read stories at mat-time [CS1/SRI4/E6], spelling out words for children to write in birthday cards [CS1/SRI5/E5], and writing out words for children to copy [CS1/SRI4/E5].

In addition to the above teaching strategies, teachers' discussions revealed the relational pedagogy which underpinned this team's teaching interactions, reflected particularly through the respect shown to children. Teachers demonstrated respect in numerous ways, including telling children why they were moving to a different area of the centre [CS1/SRI1/E3], apologising when they were unable to assist children immediately and indicating when they would be available [CS1/SRI1/E5], respecting children's work and making sure it was kept safe [CS1/SRI2/E5], and asking permission from children before helping them. For instance, Jane described how she had encouraged Nerys to wash dye off her face:

And it got to the point where I could actually help her but even when we were doing that l'd say, "Oh you've got a bit up here - would you mind if...?" You know, just saying, "Can I do that" first instead of just going straight in and doing it. [CS1/SRI1/E6] 
Rachel, in particular, expressed respect for children in terms of power and empowerment. She was conscious of her powerful position as a teacher, monitored her language, tone of voice and body position, and actively aimed to empower children to make choices and decisions during her interactions with them, e.g.,

Very conscious of that power thing, the whole time. So I was sort of moving forward, moving back, moving in, moving out and it's not about scaffolding it any more, it's kind of like working together. It's really on a level plane, so I'm empowering them to make choices and perhaps..., working as a friend together...and just seeing how accepting they are of my opinions... Very conscious of being...if I said something they will go, "Oh well, Rachel said..." [CS1/SR13/E1]

Teachers' thinking about power issues was also reflected in their willingness to trust that children would make the right decisions, such as when Jane was tidying up the outside area and asked Michael (who often struggled with following teachers' requests) to help: "I had faith in him because I knew that I told him earlier that we were going to put it away and I kind of played a game with him" [CS1/SRI4/E10]. Trust was also at the core of Rachel's thinking when she chose to enlist the help of other children to help Christopher remember about walking inside:

You've got to make split decisions running on your feet...thinking that sometimes it just comes naturally, now, because of the experience, maybe. Definitely knowing the children, definitely knowing the children and maybe challenging some of the children to...think, "Well, is this going to work?" You know, challenging me more than anything. Is that going to actually work? Because it could not of and I might have had to change tack altogether. So you are making decisions on the run a lot of the time and trusting the children, knowing the children, trusting the children that they will help me make the right choice, make it work...so we...do it altogether, really, but...that whole thing with Christopher with the art of hīkoi ${ }^{9}$, that was great because...you have this split, this split second decision and they all came in and they all knew...what was correct... [CS1/SRI3/E1]

Teachers' relational pedagogy was evident in how they took advantage of situations to deliberately strengthen the relationships they had with individual children [CS1/SRI1/E4] and how they supported children to be independent [CS1/SRI1/E7] and to take responsibility [CS1/SRI2/E1]. In play situations teachers were comfortable accepting children's direction and engaging as equal play partners

9 Hīkoi - Māori word meaning walk, walking 
[CS1/SRI4/E7]. When competing demands within the session meant they could not respond to children immediately or were interrupted, teachers verbalised their own feelings of frustration to show empathy with the children [CS1/SRI1/E5], and readily acknowledged their mistakes [CS1/SRI4/E9].

Teachers described creating a positive, unpressured climate for children: “... keep it fairly light and just be respectful of how they want to take that" [CS1/SRI3/E3], using teaching behaviours such as being down at the children's level and having a soft tone of voice [CS1/SRI1/E6] and offering reassurance [CS1/SRI1/E1]. They described supporting children's participation and persistence in order that they could make decisions, complete tasks, and achieve success. Rachel reflected on the interactions she used when supporting children, including an episode where she had helped Alastair use scissors:

\begin{abstract}
Unless it's an actual planned activity like the book reading and things like that where you've got a structured situation, the rest is about...empowering the children to make their own choices and decisions and...moving with them and pulling back, the role modelling, making conversation, maybe extending their role. Even... with the scissors..., it wasn't really much scaffolding there. It was a little bit of instruction about what would be the best way to go. But really was just about moving forward and back and coming in and out of their...area and just time and a lot of patience and time. [CS1/SRI3/FR]
\end{abstract}

Being unhurried, allowing children time to explore and play, and moving at the child's pace were ideas that featured in their discussions. Teachers talked about waiting in order to give children space to share their ideas - "this is where you're conscious of spending your time, just waiting and listening" [CS1/SRI2/E5] - and took opportunities for unhurried interactions when they arose such as when Jane worked alongside Carlos to put the cover on the sandpit and reflected on how nice it was "not having to rush it" [CS1/SRI4/E10]. Teachers were alert for opportunities to engage in interactions with children, particularly those who were reserved when in a teacher's presence. In an extensive discussion about Chelsea, Jane described her response in an earlier conversation where Chelsea had spontaneously shared with her: "Oh, I'm grabbing this moment, let's talk about Chinese" [CS1/SRI1/E4]. 
Teachers used several strategies to facilitate children's participation and engagement in learning activities. Inez described moving to where most of the children were in order to be available and encourage participation [CS1/SRI1/E5], Jane described re-directing children back into play [CS1/SRI1/E3], and Rachel described being directive when encouraging a group of boys to join a te reo Māori game at the beginning of the session [CS1/SRI1/E5]. Teachers facilitated children's participation by taking on roles within children's socio-dramatic play-scripts such as Jane's response to Jacob that Edward was "rescuing her" when a fire-fighting playscript developed [CS1/SRI1/E3] and her willingness to engage with children's humour as they created "desserts" containing soap, bubble bath, worms and horses [CS1/SRI4/E4]. Teachers supported children to join in others' play by explaining what was happening in existing socio-dramatic play-scripts [CS1/SRI1/E6] and offering them roles to play [CS1/SRI3/E1].

Teachers described several strategies used to involve children in solving problems, particularly in conflict situations, including using voice to include children on the periphery:

\section{Jane:}

And I just thought here, what I find effective is to take the object away and hold on it and then try and sort out whatever's going on, if it works out... acknowledging what's actually happening, and I like to say that quite loud to encourage other children who are aware or watching to come in, and in this instance Harriet came in and came up with a suggestion which is awesome, always awesome because I like to encourage them to support each other... [CS1/SRI1/E3]

Later in this episode Jane described choosing not to respond to children's behaviour and her approach to managing a conflict between children over equipment:

And in this instance, I take the hose and I explain what is actually happening so that they both understand what's happening instead of they're focused on what I'm doing, "This is mine, I want to do this..." I'm actually saying, "Now hold on a second, 'You want this, is this right?"' and "You want this". I mean in different instances I try and get the child to explain that. "So, what is it that's happening here?" [puts on child's voice] "Well, I want this because I wanna do that", "OK, now what is that is happening here for you, what do you want to do?" I mean to get them to explain to each other... 
And I explained that so Cassie could hear... because she was involved with the hose and she had left. I didn't just say, "Oh, here you go Josh". I said, "Now I'm giving this to Josh because you're doing hula-hooping now and he still wants to use the hose". So I made that clear to both of them and she kind of seemed fine with that, didn't come back, "No, I want the hose still" [CS1/SRI1/E3].

At times teachers adopted a "matter of fact" approach to help children cope emotionally (e.g., Rachel's discussion with children about what had happened in an earlier accident where Anton's finger was caught under a wooden plank that children were standing on [CS1/SRI2/E3]). Rachel summed up the team's approach to guiding children's behaviour with her discussion of encouraging children to come inside for morning tea by giving them a role to play:

...it just swings it around from being...a behavioural management thing to empowering them to be in charge of something... [CS1/SRI3/FR]

The final area that teachers reflected on, in terms of their teaching strategies, related to the organisation and provision of the learning environment and the wider programme. Teachers described scanning the wider environment [CS1/SRI2/E4], listening for disturbances that might suggest conflict was brewing [CS1/SRI5/E2]. They described setting up the physical environment to provoke children's interests [CS1/SRI2/E5] and to support play [CS1/SRI2/E7], providing resources to support content knowledge learning [CS1/SRI2/E5], and maintaining the environment during the session [CS1/SRI4/E5]. Warning children of upcoming transitions within the session was a deliberate strategy used by teachers, as in this example from Jane:

Also just thinking back to the earlier "E toru miniti kei te toi" [3 minutes to go] just giving them obvious warning before morning tea to start thinking about having to stop whatever you are doing to come to morning tea. [CS1/SRI4/E4]

Teachers also reflected on their own management of transitions in order that these times were as smooth as possible [CS1/SRI4/E6].

Teachers' reflection on their teaching strategies revealed the complexity of their work with children. In the next section of this chapter, their reflections on the 'busyness' of teaching and their broader teaching roles are presented. 


\section{'Busyness', multi-tasking and broader teaching roles}

The busy nature of teaching was often referred to as teachers juggled responding to children's differing learning interests, conversations with parents, management and visitors, and fulfilling their broader teaching roles. Meg described "doing major multitasking" [CS1/SRI5/E5] and "having about fifty things going on in my head" [CS1/SRI2/E2] as she worked with children whilst Rachel described her response to children's conversation at morning tea-time: "they're going there at a hundred miles an hour. And I tell you what, at that time, my head's going brrrrrrrrrrr" [CS1/SRI2/E3].

Teachers consciously tried to balance their time and engagement with children, particularly when children actively competed for their attention. Jane described one such situation:

I actually found this instance quite challenging because it came to where everyone was... bidding for my attention and which was quite draining and it wasn't about their play or extending their play. It was, "Look at what I'm doing", "Well, I can do this" and it's just "Hold on a minute, what's happening here maybe I need to..." [CS1/SRI1/E3]

Her acknowledgement of these challenges sparked an in-depth discussion as the teachers analysed the episode and collectively reflected on how else Jane could have responded:

\section{Meg:}

But you had to have a lot of thinking because you were thinking about the right language to use cos Scott was there, the fact that two of them desperately want to be right there with you...and putting into place the strategies that we've also talked as a team about certain children.

\section{Rachel:}

What was their agenda, where were they wanting to go there... where should I be taking this...? Should I be doing this or that because that's those three very strong personalities there and is it, did they want you just to yourself or were they really wanting to play together... there was so much going on there that it was almost... if it escalated too much you'd almost need to have said, "Now, we need to stop now boys and listen to each other speak"... and just brought it down a little bit or... 


\section{Meg:}

Well, the fact that Edward wanted to move you twice, from the swings to the bus, then the bus to wherever...

\section{Rachel:}

Yes, quite persistent

\section{Meg:}

Was he trying to take you away? Or was he trying to make the play go longer?

Jane:

It didn't seem like he was trying to interact with anybody else, it was solely in my...that was the difficult part that it was bids for my attention which I needed to step back from a little bit or maybe explain clearer: "Well hold on" - of which I did try a couple of times - "...I can't be in two places at once" or maybe just being more assertive and more directive, I don't know.

\section{Rachel:}

Or directive into something, maybe...even if it was your fire engine song, that great one that you've brought in from the other centre, on the bus there and maybe where would that have gone, perhaps, or...

\section{Jane:}

Yeah, but see I was thinking, I don't like to...cos it was leading into a dramatic play or something that the children could lead. I didn't want to... say, "All right, let's stop and do something that I..." I dunno, it was a hard one. [CS1/SRI1/E3]

Teachers described the challenge of managing their broader teaching roles alongside their interactions with children, sharing their frustration when visitors or phone calls interrupted their teaching [e.g., CS1/SRI1/FR] and the impact that setting up and maintaining the physical environment had on their interactions with children [CS1/SRI4/E2]. They acknowledged that parents had high expectations of them [CS1/SRI1/FR], and valued supporting and involving parents even when this added complexity to their teaching: they described the beginning of sessions as "like a grand central railway station" [CS1/SRI2/E1] as teachers settled children into the programme and they welcomed and engaged with parents [CS1/SRI2/E5].

The complexity of their broader teaching roles was encapsulated in Meg's description of her thinking during an episode at the collage area: 


\section{Meg:}

I was actually thinking about the end of the day when we do our programming planning and our reflection; that I had to store up quite a lot of information about our ESW and the child concerned and the construction of the kite thing. That's why I had hoped you'd got the kite making part. I was very much role modelling to the ESW how it's done, that we don't make things... And so beforehand, and I was actually trying to think... "I've got to remember all this to talk about with the other staff at the end of the day" [CS1/SRI5/E5]

Meg's reference to their reflection sessions at the end of each day revealed their assessment and planning roles as well as the importance of sharing information with other teachers, in order to build collective knowledge of children and their learning. The nature of the programme, with teachers spread across the physical environment and children having substantial choice about the activities they participated in, meant that teachers could not observe each child all the time. This became readily apparent during the interviews when teachers identified new insights gained about children from watching their colleagues' episodes, as discussed next.

\section{New understandings emerging from the video-SR process}

New insights gained from watching the recorded episodes were about individual children and about the teachers' understandings of their practices and their interactions with specific children. Thus, Inez became aware of Scott's body language during an interaction with other boys [CS1/SRI1/E2] and both Rachel and Jane identified Edward's apparent unawareness of how he dominated other children's space [CS1/SRI1/E3 and CS1/SRI1/E4]. More significant were the new insights Meg gained about Chelsea:

\section{Meg:}

The thing with Chelsea, because I wasn't there yesterday, so that's totally puts what happened this morning...

Sue:

Into context for you?

Meg:

Totally. I was at the play dough table this morning and Chelsea came in with her mum and her sister. And she went straight to that set of tables and scanned it, sat down and drew a picture of a cat with some stripes. And mum was really encouraging what she was doing and [gave] positive reinforcement 
- she was very proud of this. As soon as mum went she came straight to me and said "I want to make a tiara" - I had no idea about the tiaras. She knew exactly what she wanted - red stripy paper and she drew all the zigzags and she started to cut but it wasn't right, so I had to help her cut the points. Everything, she got the elastic out - she had that whole corner to herself, Chelsea did. No-one else was there. [CS1/SRI1/E4]

As a part-time teacher, Meg had not been present the previous day for the filming and was unaware that Chelsea had carefully observed other children making tiaras before later making one herself. Meg's comments moved the discussion beyond the video-recorded episode to focus on Chelsea's clear intention to make her own tiara and her use of strategies modelled the previous day by another child, Isla. Meg's new insights appeared powerful as on several occasions over subsequent interviews she reflected on the level of her interactions with Chelsea and whether Chelsea missed out on adult interactions. Other teachers also appeared to become more aware of Chelsea, her learning interests and their interactions with her.

Watching the video-recorded episodes highlighted that some children were 'invisible', such as Sarah, an independent child who rarely sought adult assistance [CS1/SRI4/E7] and that teachers were unaware that some children needed more support with self-care skills [CS1/SRI2/E6]. Furthermore, the teachers gained insights into their own non-verbal communication [CS1/SRI1/E4] and sub-conscious actions: Rachel reported being "completely oblivious" to Carlos whilst talking with Harriet about the sun, yet the video revealed that when Carlos stood beside her she had put her arm around him and rubbed his back gently [CS1/SRI2/E5]. Teachers then identified other occasions where they had used "automatic body language" to draw children into activities.

In summary, this section of the chapter presents results relating to the first research question. Teachers knew the children well. They used this knowledge to interpret and respond to children's cues and wove their teaching intentions into the children's learning interests. A strong relational pedagogy was evident through the teachers' reflections and discussions around power, respect, and facilitating engagement. 
Teachers aimed to create an unhurried atmosphere, despite their own feelings of "busyness" and their subsequent "multi-tasking". Further insights into children and teachers' own practices were gained from watching the recorded episodes.

\section{Beliefs, principles and theories underlying the Moana ELC teachers' practices}

In this section, data concerning the beliefs, principles and theories underlying the Moana ELC teachers' practices are reported, reflecting the second research question for this study. Data presented previously on teachers' thinking and reflections about their practices are also relevant to this section, particularly in terms of teacher values and beliefs. The discussion of teachers' use of relational pedagogy and their references to power, respect, creating an unhurried, childcentred environment, and guiding children's behaviour revealed elements of their teaching philosophy and the values underpinning this. The results presented in this section do not revisit those aspects but concentrate on data concerning their beliefs and the principles and theories underlying their practices not yet reported.

Teachers' views on children influenced how they perceived their own roles and interactions. Teachers described a holistic approach to thinking about children [CS1/SRI1/E1], regarding them as competent [CS1/SRI3/E1]. Their role was not perceived as straightforward; rather, it involved a balance between being childcentred and initiating learning experiences felt to be beneficial for children [CS1/SRI3/E2]. At different times during the interviews teachers described following children's agendas [CS1/SRI3/E3] and not imposing their own teaching intentions [CS1/SRI5/E4] as well as describing how they had a role in sustaining children's play:

Rachel:

And..., it can go for days, or hours without an adult there but it can, it can also be sustained in more meaningful and more in depth if there's an adult there too so, again, it just depends on...your role in the... play. [CS1/SRI3/FR] 
Teachers described adjusting their teaching interactions as they worked with different children in the episodes, trying to match their interactions and strategies, often using trial and error [CS1/SRI3/E3], to support and enhance children's learning. Rachel, particularly, used phrases such as "moving in and out" and "back and forth" to describe the changes in her interactions as she supported children's play [CS1/SRI3/FR].

These teachers valued being prepared [CS1/SRI3/E2] and flexible [e.g., CS1/SRI1/E5] in order to follow children's learning interests, manage interruptions (such as a parent arriving to enrol a child [CS1/SRI1/E1]) and to take advantage of unexpected opportunities to involve families [CS1/SRI3/E2].

Teachers also described how they valued working as a team in tune with each other: "A lot of team work, bouncing off all the time. Eye contact, body language, pausing, pulling back, moving forward" [CS1/SRI3/E2]. Rachel summed up the importance of working in teams:

I think in early childhood though we're fortunate that we work in teams and I just can't speak highly enough of teamwork...the importance of it. And to....find that philosophy and work together so it's...like this...movement together with the kids all together and I think if once you've got the team moulded in and I don't mean we're all the same, because we're totally different. And we support each other and we've got strengths and weaknesses and...I mean the girls will come and say, "Oh, I've just, don't know what to do now," and I'll go, "Ooh, give me some ideas, this is..." ...but that's the beauty of it because the kids know that now and they, we work as a big unit...everybody does, the management, the kids, the teams and...the community, everybody does....but it's hard work. [CS1/SRI3/FR]

On many occasions, these teachers referred to the interactions that they had with parents and extended family members in ways that indicated how they valued these relationships. Involving families was articulated as central to the centre's philosophy and that "it just wouldn't work otherwise" [CS1/SRI3/E2]. They made sure they acknowledged publicly the support they received from families, such as providing morning tea to Hilda's granddad after he had made some games for the centre: 
And we so wanted to, because he'd been doing so much for us and we now email him photos too. Because he just so is open to ideas and what have you. So when we heard he was coming down there was just no...question. The big card got done... and we said, "Oh no, let him stay for morning tea, we'll make you some scones or something." [CS1/SRI3/E2]

During the interviews teachers' descriptions included several, although relatively infrequent, direct references to different theoretical positions. Reference to sociocultural approaches to teaching and learning were most common with teachers referring to scaffolding learning [CS1/SRI5/E1] and co-constructing understandings with children, such as when Rachel supported Holly's interest in the solar system:

And I think too that during this, it's actually a shared knowledge here. So it's not about...This is about her and I working together. This is actually about learning together. This is not me being the teacher. It's working, working on an equal partnership. [CS1/SRI2/E5]

Reference was also made to children's exploration of schema (e.g., Nerys's engagement in an enveloping/enclosure schema [CS1/SRI2/E4]) and their developmental stages (e.g., Rachel drawing on her knowledge of Alastair, Jacob and Edward's ages and their engagement in parallel play at the water trough [CS1/SRI1/E1]). Learning dispositions were also referred to on several occasions, particularly around persistence [CS1/SRI1/E4] and finding something of interest [CS1/SRI2/E2].

The choice of episodes used in the interviews created opportunities for discussion around some particular issues that revealed teachers' values and beliefs. For example, separate episodes involving Inez and Rachel working with children on the computer [CS1/SRI1/E5 \& CS1/SRI1/E7] led to a lengthy discussion about the role of computers in ECE, the ethics of children's use of computers, and the impact on children's social engagement with others. Children's competency and confidence in using equipment, especially when staff were grappling as learners, was acknowledged and celebrated whilst recognising their responsibilities concerning internet safety: 


\section{Rachel:}

And the kids actually become the leaders because they just, their minds just aren't cluttered and they just give it a go whereas I'm thinking "Oh, I'm going to freeze it any minute," so it has been quite an exciting couple of days.

Jane:

I remember how blown away I was, you know when I...dabbled with computer stuff last year. Sally could do control, shift, greater, smaller than, to make the font go larger and smaller and she played with that for ages. And just different things that they could do, it's amazing. Anton has been out there for a long time. He can click into games, and sit there and play. We should watch it really on what he gets up...

Inez:

Yeah, where he goes. Actually we should do some work with Hector the Dolphin - that stuff around the internet.

Meg:

That's the safeguard thing, isn't it?

Inez:

We should really get into that.

Rachel:

Yes, I'm very conscious of that, the whole cyber-safety thing. [CS1/SRI1/E7]

Data presented in this section focused on the values, beliefs, teaching principles and theoretical positions evident in the teachers' thinking and reflections about their interactions with children. Woven through their discussion is a discourse influenced by Te Whāriki that views children from a credit stance. Teachers regularly referred to children as "capable", "confident" and "competent" mirroring the phrase from the aspiration statement in Te Whāriki for children "to grow up as competent and confident learners" (Ministry of Education, 1996, p. 9).

\section{The influence of a community of practice on teacher thinking and reflection}

The final section of this chapter reports data concerning the third research question, namely the influence of the Moana ELC team on individual teachers' thinking and reflection. The data were examined for patterns of behaviour during the interviews 
that indicated alignment within a community of practice and demonstrated how they negotiated meaning about the video-recorded episodes. Three modes of teacher discussion were identified:

- Focus teacher reflections: The teacher featuring in the episode was the predominant contributor to the dialogue, describing the video-recorded situation, their interactive thinking and reflecting-in- or -on-action, whilst other teachers made minor contributions;

- Co-constructing understandings: The focus teacher together with other teachers co-constructed, interpreted or clarified what was happening, either in the episode or for a particular child;

- Collective reflections: Discussion beyond the episode about similar events, broader issues related to the episode, or previous team discussions.

Moana ELC teachers engaged in focus teacher reflection and collective reflection most often. They actively participated in the interviews with frequent, seamless shifts between discussion modes. For example, in an episode involving Rachel with Christopher and Lewis building a fort outside [CS1/SRI4/E3], discussion moved between different modes of teacher talk on nine occasions. Rachel began in the focus teacher mode, describing the situation and her initial thinking before Inez interrupted to comment on unsafe pieces of wood at the carpentry area that she had disposed of and there was a general conversation (collective reflection) about safety in this area. Jane then shared the antecedents to the episode (co-construction) before Rachel resumed describing her thinking and actions as she worked with the children (focus teacher). At one point she recalled, "I was trying to figure out what was going on between these two boys", and invited the other teachers to offer their ideas about what was going on (co-construction). As the episode progressed, Rachel returned to the focus teacher mode before Meg asked who had hung a ball from the tree, and other teachers shared their knowledge of what had happened 
previously (co-construction). Rachel then returned to the focus teacher mode before the teachers engaged in a final collective reflection about the episode.

\section{Alignment behaviours amongst Moana ELC teachers}

These teachers used a wide range of alignment behaviours frequently during the interviews, including agreement statements, finishing each other's sentences, identifying with what had happened in the situation, affirming and showing interest, reinforcing that teachers had done the best they could, and expressing vulnerability (see Appendix 6 for further details of these categories).

Agreement statements made across all discussion modes were primarily brief affirmations such as "that's right" [CS1/SRI5/FR] or re-stating what a colleague had just said [CS1/SRI4/E7]. Sometimes teachers expressed their agreement by adopting the child's voice in response to others' understandings of the child. For example, Inez described supporting two boys to resolve a conflict over equipment, commenting about Michael, "I'll just let him do his thing. Because I wasn't quite sure what he was trying to achieve". Rachel responded, "He's certainly got clear ideas. He was very focused until he achieved that" and Meg reinforced this by adopting the child's voice, saying, "I want it just right" [CS1/SRI4/E8]. These teachers also indicated agreement by referring to previous discussions and collective understandings. For example, Inez said, "Yeah, we've talked about that a bit, haven't we, lately?" as they discussed children's need for one-to-one attention from the teachers in the after-lunch period [CS1/SRI1/E3].

Numerous instances of teachers finishing each other's sentences occurred (e.g., Jane's comment on Richard and Edward's changing relationship: "The only thing about the relationship with Richard and Edward..." was completed by Inez with, "Is Jacob" [CS1/SRI4/E7]. Such examples suggest that knowledge and understandings about the children were collectively held whilst other examples showed teachers in tune with the content of their colleagues' thinking [CS1/SRI4/E6]. 
Teachers actively encouraged each other during the interview process. They identified with the focus teacher's experiences by, for example, interjecting comments about similar incidents (e.g., Jane responded to Rachel's comment about her thinking and interactions with children with the observation: "Yeah, I had a similar experience this afternoon with the same two" [CS1/SRI1/E1]) as well as agreeing more fully with what their colleague was describing or thinking about [e.g., CS1/SRI4/E5].

Affirming comments that showed interest were characterised by short statements such as "Oh, yes", "Oh, gosh" or "Okay", often offered in response to the focus teacher's explanation. More elaborate responses were noted as in this example where Jane responded to Rachel's description of a sustained conversation with children as they used the internet to find out about dinosaurs:

\section{Rachel:}

Oh, it's great and I think he's actually taking a little bit in, because he does that and he'll remember because he's got such a retentive memory.

Jane:

And obviously Anton's really engrossed as he's there. [CS1/SRI1/E7]

Supportive and empathetic comments were made when teachers suggested that their colleague had done the best that she could in the circumstances. For example, Inez responded to Meg's statement, "I'm trying to think if I even acknowledge Chelsea earlier. I'm sure I did" with the comment, "But you can't be everywhere" [CS1/SRI2/E2], emphasising the demands of teaching. Although supportive, when such comments were limited to expressions of sympathy or briefly offering advice they effectively turned the discussion away from teaching (Horn \& Little, 2010). For example, Rachel talked about her excitement when working with children on a new computer programme, and her frustration when the episode was interrupted by the morning tea routine:

And I think I said "I don't want to go because it's too exciting" (laughter)... and I think that's OK, that's honest, because it was. I almost thought, "I'm going to get told off by somebody in a minute". Yeah, there she's going. But I mean... when I walked away from there I thought, "Oh, this is what the kids feel like all the time, we've stopped them in the middle of their play. 
Inez:

But they can come back to it.

Meg:

But it can be saved.

Rachel:

But it was such a new thing at that particular moment and it was such a precious moment. We were having too much fun, together... [CS1/SRI1/E7]

The reassurance offered by both Inez and Meg, whilst supportive, had the effect of turning the conversation away from the issue of interrupting children's engagement in their play.

An alignment behaviour unique to these teachers was that of expressing vulnerability. Most often it was Rachel who expressed feelings of self-doubt, inadequacy or discomfort. These included general statements such as "Oh, and I fouled up there" [CS1/SRI4/E9] as she watched herself trying to get the video camera to work to film a group of girls presenting a 'concert'. Comments were also made about a lack of expertise in areas such as computers or scientific explanations, for example when Rachel said, “I was really conscious I don't know..., I am not an expert on the computer, number one agenda" [CS1/SRI1/E7].

Finally, at times during the interviews these teachers made statements that could be seen as trivial or irrelevant to the episodes being discussed. A number of these comments related to teachers' observations of children on the periphery of the video-taped episode (e.g., Meg commented, "You can hear Melanie in the background" [CS1/SRI1/E7]) or were irrelevant to the discussion (e.g., Rachel commented, "It's a funny table really" during Jane's description of the play she was supporting in the sandpit [CS1/SRI4/E7]). At times, irrelevant comments took the conversation away from the episode such as when Meg's conversation with a child about animals with webbed feet led to Inez talking about Newfoundland dogs having webbed feet and the recent acquisition of a Newfoundland puppy by one of the 
centre's families [CS1/SRI5/E2]. However, many of these instances appeared to be efforts to contribute to the discussion, despite their off-task nature, and so were considered to be social cohesion actions.

\section{Negotiating meaning within the teaching team}

The Moana ELC teachers actively and supportively engaged in negotiating meaning about what was occurring in the video-taped episodes and beyond, asking questions to clarify what was occurring in the episodes and sharing their ideas and opinions. Focus teachers played a crucial role in assisting the others to understand what was happening in each episode. The background information and contextual details they offered provided an entry point into the episodes for their colleagues, helping them to make sense of what they were viewing. These descriptions included details of earlier events and knowledge of the participating children that they brought to the episode as well as contextual explanations like Rachel's comments about an interruption to her interactions with Alastair and Jacob:

Oh, we've got a visitor coming, which is a bit annoying because now suddenly it all stops. And then I think the supervisor role comes here and I really had to make eye contact with this mother who's coming down here. The kids are interested...just telling them we're having a visitor and that's OK - we'll greet them when they come down. [CS1/SRI1/E1]

Rich descriptions of what had occurred prior to the video-taped episode were provided, such as when Jane had been outside with a child, Nerys, helping her to wash dye off her face:

In the morning Orlando and Nerys, we had the dye out and I saw that they... how they were covered in dye that day. Well, they had the dye out and it had gone everywhere and they were starting to paint a chair so I quickly said, "Oh, come on", and got buckets and filled them up with water and put big paint brushes in. And went to Gregor's [a centre grandfather who had built a playhouse for the children] house and that's where they were involved and that was fine with water because they were already covered with dye from head to toe, so this is....and I was commenting on that with Nerys because it was quite...a humorous...thing that she had dyed her face and they were doing lots of fun work together and... And also with Nerys, I don't know, she just seems to be a child that I don't really have much of a relationship with so this was actually a really awesome experience for our relationship, one on one. [CS1/SRI1/E6] 
Focus teachers shared information about their thinking and actions throughout their episodes as well as what the children were saying and doing. At times this was in the form of a narrative that ran alongside the episode being viewed, but more usually focus teachers wove information about their intentions and their responses to the children into their descriptions.

Teachers were keen to understand what was happening, with all asking clarifying questions. These sought to clarify what individual children had said or were doing (e.g., when Meg asked, "Did Chelsea actually make one?" whilst watching Rachel working with a group of children constructing tiaras at the collage table [CS1/SRI1/E4]) or sought information about children's lives outside the centre. For example, Meg asked Rachel, “Who's getting married?" in response to her comment that a child, Isla, was talking about an upcoming wedding [CS1/SRI5/E1]. Other questions sought to clarify details around episodes, such as Inez's question, "So you're still going even though it's outside", when Jane and Nerys had taken the mirror outside to use when washing the dye off Nerys's face [CS1/SRI1/E6].

As these teachers built understanding about what was occurring in the episodes, they focused intensely on the participating children, rather than on their practices or on the programme. However, in the collective reflection mode these teachers broadened their discussions beyond individual children to focus on their teaching practices, the learning environment, their relationships with parents, the complexities and busyness of teaching, and their own reflections and learning. These discussion sequences were longer, as illustrated in Table 4.4, where the teachers were talking about the impact of visiting Special Education Service (SES) personnel. Over the course of the episode they returned to this incident on three occasions as they collectively attempted to make sense of what happened. 
Table 4.4: Making sense of an unexpected incident

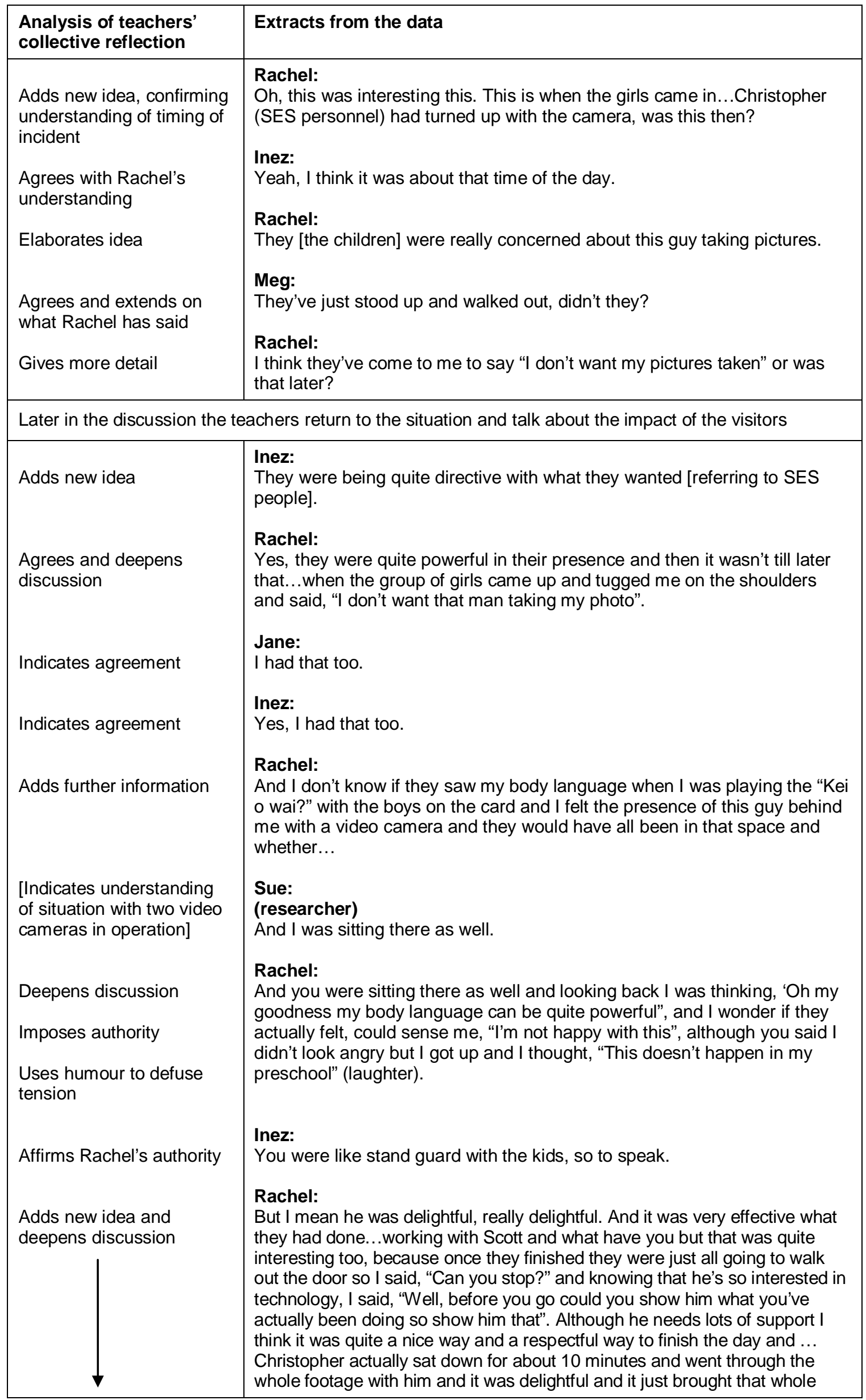


Reinforces Meg's practice

Deepens discussion

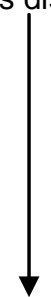

Indicates agreement

Adds new idea moment down and he came to the morning tea fine, didn't he? And for a busy morning for him, I thought, actually it might have thrown him for the day. It actually threw the others - he was fine, he was having them on a treat.

\section{Meg:}

Oh, now that's... This all happened, that happened yesterday and today at the concert and he sat there, and I said to him, "You can be my helper to take the photographs", and he wanted to keep cleaning the buttons and pushing, checking the picture and then I said "I'll take some of you dancing" and there's some lovely photos of him just standing... and then back to show him the photos of him.

\section{Rachel:}

But giving all children...even although he needs lots of support you're actually giving him a sense of achievement there and a role to play and ... he knows that by taking those photos people are going to get pleasure from those because he's experienced that and....we were there for 40 minutes and it was only occasionally that you needed to...

Meg:

Ah, that he just wandered off and... but he was repeating words and in his space and then he came back and I said, "Take some more photos. I'm waiting for the dancers to come out again". I'm going to quickly do some deleting (laughter) - you've probably got photos of the sky and...

Jane:

Oh, you've got all sorts.

Inez:

Be good to get him on to the Comic Life with some of that...it would be really great.

Focus of discussion changes but then returns to further reflection about the filming of Scott by the SES staff.

\section{Deepens discussion}

Humour

\section{Inez:}

It was interesting, the girls...why..., because they actually, they did talk about at the play dough table. "I don't want that man to take my photo", and I said, we talked about they'd really liked the pictures that Matthew had taken of them...Why has that come out?

Jane:

Maybe it was just his presence because...he...came in unannounced - we usually do... preface it, specially with Matthew, "Oh, the photographer's coming in and he's..."

Rachel:

And his whole body language is very, less intrusive... he's down on the kids' level, he talks to them, he shows them the camera, he'll spend time with them and have a look at this one. So he doesn't push them away whereas Christopher came in and he had a mission and he had an agenda and we're going there!

Jane:

To me his filming didn't seem quite natural because Scott was really aware of it and he was like this, following him and Scott was going sideways and back that way (laughter).

Rachel:

It became an enormous game in the end, the grinning was from ear to ear; and he was watching sideways...he'd cued in all right, it was quite funny really.

Sue:

(researcher)

But Christopher wasn't on his own because there was Mary and

Christopher and Tania and all his support people there. 


\begin{tabular}{|l|l|}
\hline & Meg: \\
And all of them lined up... Oh, well, why not put on a performance \\
(laughter). \\
Adds new idea & Rachel: \\
But it was quite a chaotic moment. \\
& Inez: \\
& Start to the day ... \\
& Rachel: \\
& Yeah, caught me off guard really. \\
& [CS1/SRI1/E5] \\
\hline
\end{tabular}

The above illustrates the fluid nature of how these teachers made meaning together. It also offers insights into the roles that different teachers play in this process. Rachel's strong leadership, both pedagogically and as the person responsible for the centre, was clearly evident. She explicitly took charge, indicating her displeasure at the impact of the visitors' presence and also insisting that Christopher spend time showing Scott what he had filmed. Rachel retold the story in detail and it was not until Meg was able to connect what happened in the episode to her interactions with Scott the following day that the discussion pattern shifted to more equal contributions from all the teachers. Both Inez and Jane took a more supportive role, affirming and agreeing with what others had said. Inez was also responsible for introducing new ideas on several occasions, some of which other teachers picked up and built upon.

Rachel's leadership was also evident in other ways. Across the interviews she made the greatest contribution to the discussions, even taking into account that episodes of her teaching featured in each data collection round and that she attended each interview. In addition to taking charge in situations like the one described above, at times she emphasised her authority within the team. Usually this occurred subtly and implicitly in response to other teachers' sharing of information about specific children (e.g., "Oh, I wasn't aware of any of that. Can't be too serious" [CS1/SRI5/E2]). 
Rachel was also particularly strong in offering advice and in reinforcing the thinking and practices of other teachers. She reinforced others in both general statements (e.g., her comment to Meg, "And you finished it off, it's just your lovely teaching skills" [CS1/SRI1/E4]) and more specifically:

Rachel:

What you've done there...

Inez:

Given him a choice.

Rachel:

Well, no, you're very clear in your instructions and you repeated it and you didn't waver so and this using some of the strategies planned through with Mary (Early Intervention teacher). [CS1/SRI4/E8]

Rachel usually offered advice in situations where safety was an issue or where teachers had faced challenges in terms of children's behaviour:

I think you just talk about the safety issues and stuff like that. I think we were going to make that all out of bounds; that it was just for sitting on. I don't know, he finds it, it's not a challenge for him - he's quite enjoying it up there. But I think it could actually lead to more, especially going behind that cupboard with those nails there. [CS1/SRI1/E8]

In summary, this chapter has presented data from case study one, Moana ELC, showing how these teachers engaged in thinking and reflection about their teaching interactions with children. A significant influence for these teachers was their knowledge of individual children which shaped their own teaching intentions and use of teaching strategies. Their philosophy and practices were built upon a relational pedagogy that emphasised respect, empowerment, engagement and adjusting their practices to be in tune with the children, and informed mostly by socio-cultural theory.

Within their community of practice, these teachers actively engaged in behaviours during the interviews that promoted alignment between team members and their individual thinking and practices. Their use of alignment behaviours such as finishing others' sentences and identifying with what had happened in the episodes 
emphasised their shared understandings and collective approach to their teaching. As they actively participated in making sense of and negotiating meaning about the episodes, differences in their roles within the team became apparent. In particular, Rachel's strong pedagogical and managerial leadership was evident as she articulated her thinking and reflections, exerted her authority, and offered advice and feedback to team members. 


\section{Chapter 5: \\ Case Study Two: Summer Kindergarten}

\section{Introduction}

The Summer Kindergarten teachers' thinking and reflections about their interactions with children were influenced by a number of factors, of which their knowledge of individual children and the wider kindergarten group was the most dominant. The teachers' values and beliefs about teaching and learning in ECE and their knowledge of theory and EC principles of practice informed and guided their teaching interactions with children. Their membership in a community of practice and subsequent engagement in collective discussion and practices was also influential. The organisation of this chapter follows that of Chapter 4 , with three sections: 1) teacher thinking and reflection regarding their interactions with the children; 2) beliefs, principles, and theories that underlie these teachers' practices; and 3) the influence of the team on teachers' thinking and practices.

\section{Teacher thinking and reflection at Summer Kindergarten}

The Summer Kindergarten teachers offered detailed descriptions of their thinking and practices and engaged in in-depth discussions together. There were frequent shifts between teachers' interactive thinking and reflection-in- and -on-action, with teachers linking episodes to existing knowledge. The fluid nature of teachers' discussions is illustrated in the annotated episode transcript presented in Table 5.1 where Poppy pays attention to multiple aspects as she intercedes to support Margaret in her efforts to join a group of children, and teachers co-construct their understandings of Margaret and kindergarten practices. 
Table 5.1: Illustrative example of teachers' interactive thinking, reflection-in- and -onaction

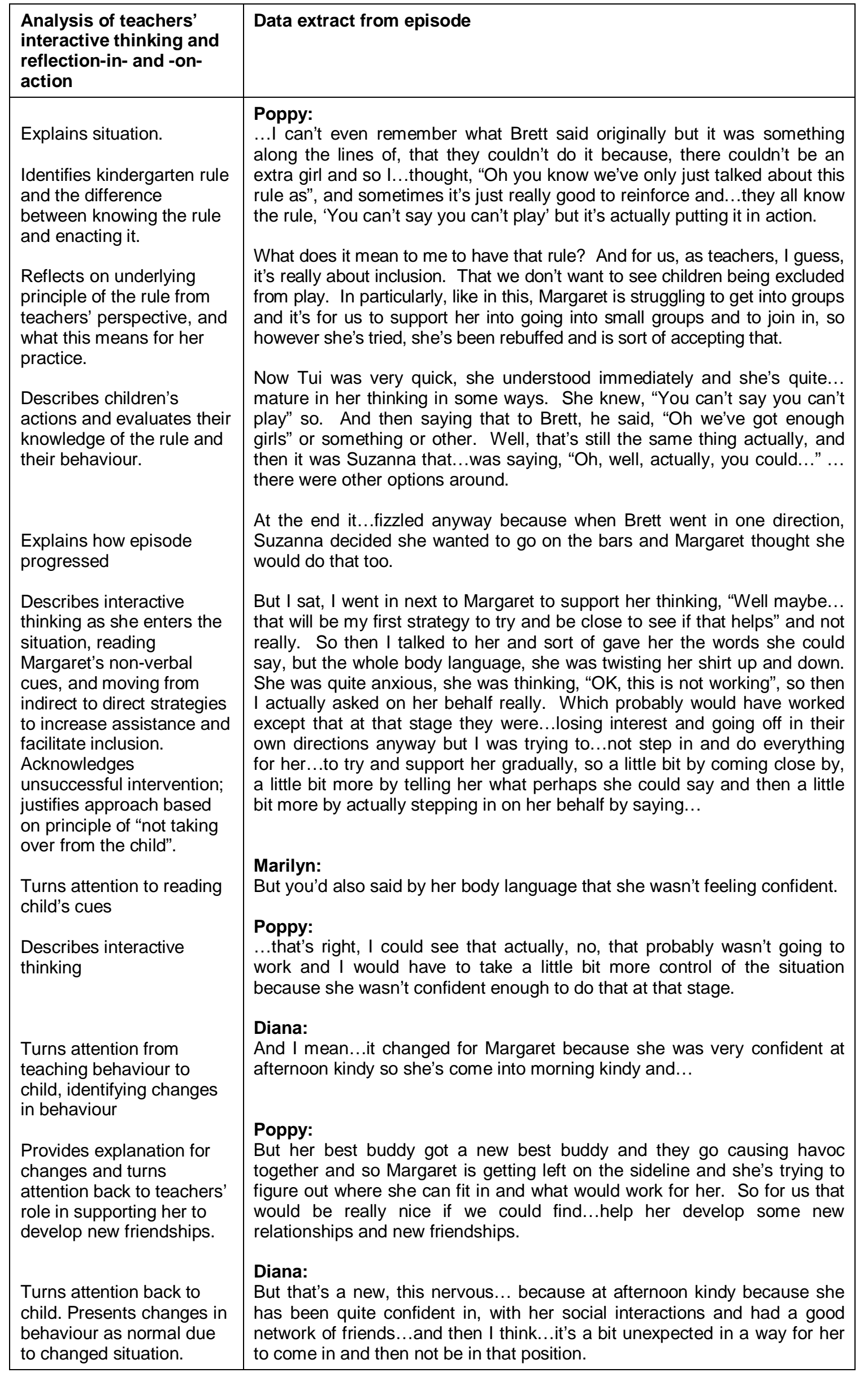




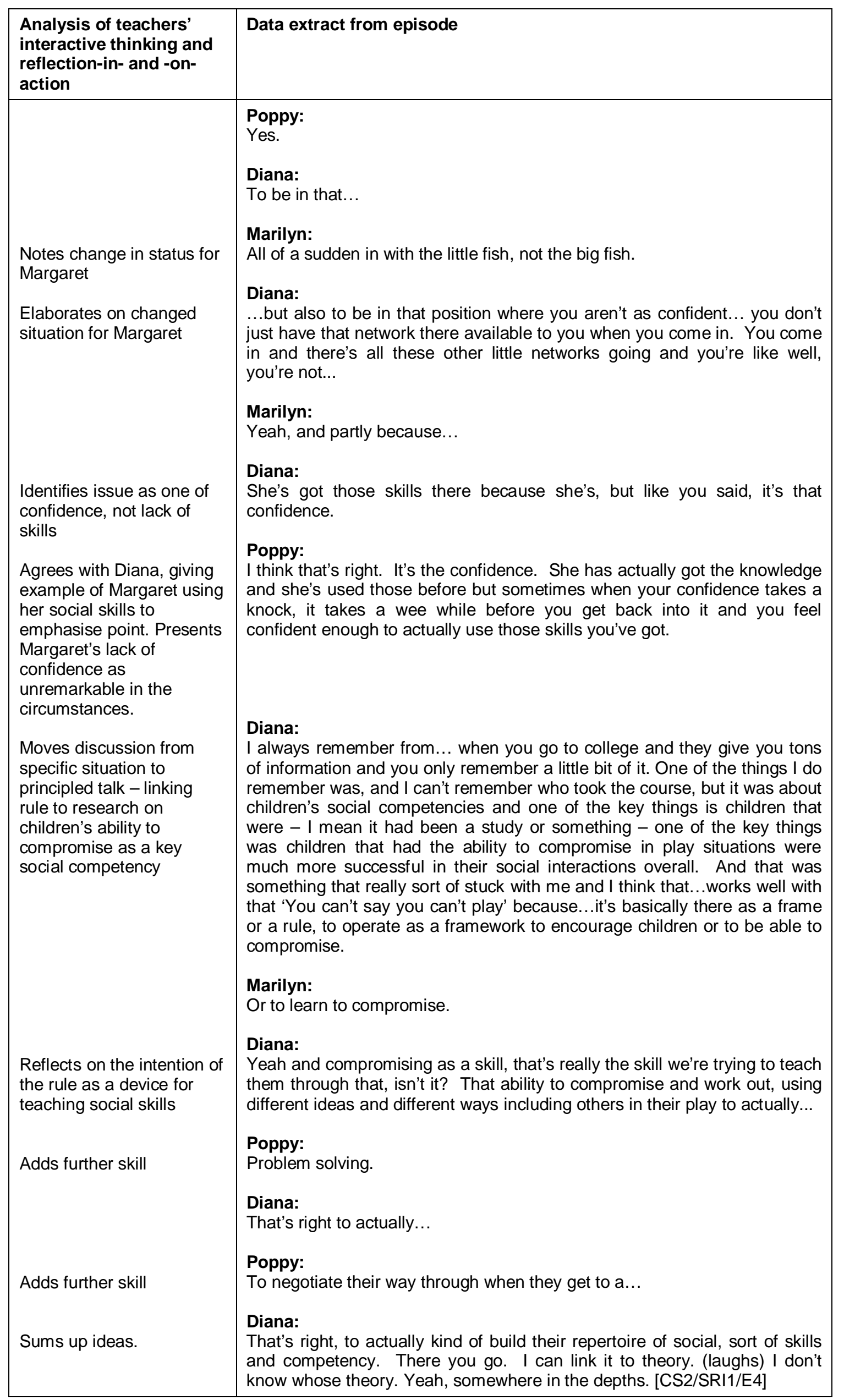


Reflective shifts occurred as Poppy described her interactive thinking and reflectionin-action and the teachers collectively reflected-on-action during their discussion. Movement between focusing on teaching aspects and focusing on the children are evident. The former included the identification of teaching intentions and specific teaching strategies used, adjusting the level of intervention as the situation unfolded, and reading children's cues. Discussions about children were characterised by a credit perspective, with the teachers suggesting explanations for the changes in Margaret's behaviour and presenting these as typical responses to her changed circumstances. Principles underpinning their practice, namely promoting children's inclusion and not taking over, were identified and links made between the intent of the kindergarten rule and knowledge gained from their teacher education programmes.

In this example, Poppy's thinking and reflection-in-action paid attention to both the children and to her teaching. As the discussion shifted towards a collective reflection-on-action, the focus shifted towards understanding children and away from understanding teaching. This detailed focus on children was typical, and in the next section data are reported that highlight the significant influence of teachers' knowledge about children on their thinking and practices. How the Summer Kindergarten teachers' attitudes towards children were reflected in thinking and practices is described, followed by data demonstrating the influence of the teachers' extensive knowledge of children on their thinking.

\section{Knowing the children}

Knowledge these teachers held about individual children appeared central to their thinking about their interactions. Repeated examples were evident where the teachers explicitly described how knowledge of a child drove their responses. This knowledge was built up over time as a result of their own and their colleagues' interactions with the children together with information shared by children's parents and wider whānau. Marilyn and Poppy, having taught at Summer Kindergarten for 
several years, had additional knowledge gained through teaching older siblings and knowing the current children before they began attending kindergarten.

Teachers' knowledge of individual children was wide ranging and frequently detailed. Their knowledge included factual information as well as more interpretive understandings about children. Teachers knew about individual children's interests and friendships, in and outside of the kindergarten [CS2/SRI1/E1] and understood the impact that transitions (e.g., to school) may be having on children [CS2/SRI2/E1]. Their understanding of child development enabled them to interpret and make sense of children's intentions rather than responding just to behaviour:

\section{Poppy:}

And I think with Frederick too that here you're right. He really does like you to understand what the problem is and if you get it wrong, that'll be it. And I think that maybe stems from the fact that his language is sometimes quite difficult to understand so I wonder if in the past he's had people just brushing him off and not giving him a response so now he needs to know that you're... listening. You understand what he is trying to get across and it's well worth spending those extra few minutes to get that with Frederick because otherwise he does get so overwrought...he loses sight of the original problem and then he's beyond... [CS2/SRI1/E8]

Teachers knew about individual children's social competencies and interactions with other children within the kindergarten context [CS2/SRI4/E1] as well as about their families and lives outside the kindergarten [CS2/SRI5/E1]. They drew on information gained from family members in order to make their interactions with children more meaningful [CS2/SRI2/FR]

Teachers' knowledge of the children was used to individualise their teaching interactions, set learning intentions, and respond to cues they received from children. To illustrate the connections between what these teachers knew about the children and their practices, Table 5.2 presents data about one child, Zane. The right-hand column presents all references made by teachers about Zane recorded across the five interviews whilst the left-hand column identifies the teachers' thinking and interactions that arose from these references. 
Table 5.2: Teachers' knowledge about Zane and their subsequent interactions ${ }^{a}$

\begin{tabular}{|c|c|}
\hline $\begin{array}{l}\text { Analysis of teacher thinking and } \\
\text { reflection }\end{array}$ & Extracts from the data about Zane \\
\hline $\begin{array}{l}\text { Draws on previous observations of } \\
\text { Zane's reluctance to independently } \\
\text { eat his afternoon tea. Joins children } \\
\text { and promotes social, relaxed } \\
\text { interactions. }\end{array}$ & $\begin{array}{l}\text { Diana: } \\
\text { Really Zane...still looking for that little bit of adult support so } \\
\text { you're in that thing of adult giving him that support so he's } \\
\text { feeling, and Kerri as well actually... so I'd actually said to them } \\
\text { beforehand, had they had afternoon tea and I was going to have } \\
\text { my afternoon tea and why don't they come and have afternoon } \\
\text { tea and they're really happy, especially Zane, to go and get his } \\
\text { afternoon tea and have it with you. Doesn't seem to like going } \\
\text { and getting it and having it on his own. So they're done that and } \\
\text { l've joined them there so the thinking is really that's a nice time } \\
\text { that you can share together with them when they're having } \\
\text { afternoon tea. It's quite a nice relaxing social time when you can } \\
\text { just have a little chit chat and...have a nosy of what they're } \\
\text { eating and talk about those sort of things. }\end{array}$ \\
\hline $\begin{array}{l}\text { Thinking about upcoming transition. } \\
\text { Uses previous experience to inform } \\
\text { choice of strategy (giving Zane } \\
\text { limited either/or rather than yes/no } \\
\text { choices) to encourage participation. } \\
\text { Responds positively to Zane and } \\
\text { Kerri's choice; being supportive whilst } \\
\text { encouraging independence. } \\
\text { Facilitates transition from afternoon } \\
\text { tea into play experiences by helping } \\
\text { children to plan where they will go } \\
\text { next. }\end{array}$ & $\begin{array}{l}\text { So it's quite relaxed and quite an inclusive sort of time and then } \\
\text { really thinking about moving them when we've finished afternoon } \\
\text { tea, what we're looking at doing. So just giving them those } \\
\text { choices because often, with Zane especially...if you say, "Shall } \\
\text { we go and do such and such" he'll just say, "No." So getting him } \\
\text { to make some choices about it. So first the choice is you can be } \\
\text { inside or you can be outside so making a choice about that and } \\
\text { then, he's going to be outside and I say, "Oh that's good, I'm } \\
\text { going to be outside too,"... and...keeping them, giving them that } \\
\text { support but also trying to encourage them to be a bit more } \\
\text { independent and then making choices about the different areas } \\
\text { that they could choose to be in outside so that... when they } \\
\text { finished afternoon tea they had an idea of where they were } \\
\text { going to - had a plan, "I'm going to go here and I'm going to } \\
\text { such and such" so they know that they're going to be involved } \\
\text { and they've got the next, not just finishing afternoon tea and then } \\
\text { "Oh you know, I don't know what to do now". }\end{array}$ \\
\hline $\begin{array}{l}\text { Helps children with their transition by } \\
\text { actively involving them in collecting } \\
\text { dye for the water-trough } \\
\text { Reads children's cues about their } \\
\text { emotional state }\end{array}$ & $\begin{array}{l}\text { So get them to think about where they could go and what they } \\
\text { could do and then getting them engaged in some sort of activity } \\
\text { that's a good hands-on activity so they're quite excited about } \\
\text { and...they all that. And so we follow through in all of that, we've } \\
\text { got the dye and then went out to the water trough... } \\
\text { [CS2/SRI2/E5] }\end{array}$ \\
\hline $\begin{array}{l}\text { Uses previous observations of Zane's } \\
\text { play partners to suggest grouping } \\
\text { these children for small group news } \\
\text { time. }\end{array}$ & $\begin{array}{l}\text { Diana: } \\
\text {...because Zane and Jackson and Tama had been in this group } \\
\text { of three playing together, } \\
\text { [CS2/SRI3/E1] }\end{array}$ \\
\hline $\begin{array}{l}\text { Uses knowledge of Zane's } \\
\text { preference to have an adult close to } \\
\text { him at kindergarten, and his potential } \\
\text { interest in using Lego. } \\
\text { Identifies learning intentions for Zane } \\
\text { and other children at the Lego. }\end{array}$ & $\begin{array}{l}\text { Poppy: } \\
\text { But they were quite interested, and because Zane was there, } \\
\text { and he quite often likes to have someone around him, and I } \\
\text { thought this might interest him....And so they've only got their } \\
\text { own agenda; ...Kerri's quite independent, building a house, but } \\
\text { the others it's also about partly learning the sorts of things they } \\
\text { can do at kindergarten, that it's a safe place, and they can be } \\
\text { here exploring the different resources... } \\
\text { [CS2/SRI3/E5] }\end{array}$ \\
\hline
\end{tabular}




\begin{tabular}{|c|c|}
\hline $\begin{array}{l}\text { Analysis of teacher thinking and } \\
\text { reflection }\end{array}$ & Extracts from the data about Zane \\
\hline $\begin{array}{l}\text { Uses knowledge of Zane's social } \\
\text { inclusion and confidence to inform } \\
\text { decision to facilitate his involvement } \\
\text { with the group of children in the } \\
\text { sandpit. }\end{array}$ & $\begin{array}{l}\text { Diana: } \\
\text {...the two boys here, Zane and Brett;...Zane was great, he's } \\
\text { down there digging, and he just brought it over as I was very } \\
\text { absent-mindedly filling that up on the one hand; but Zane } \\
\text { and Brett,...Zane's still kind of on the periphery, not quite } \\
\text { sure, needing someone to be that facilitator for him, and... } \\
\text { say, "Well, why don't you use this bucket", "Can you match } \\
\text { this spade?" or, "Here's a spade". } \\
\text { [CS2/SRI4/E6] }\end{array}$ \\
\hline $\begin{array}{l}\text { Uses knowledge of Zane's emotional } \\
\text { and social development in balancing } \\
\text { his need for support with teacher's } \\
\text { goal of independence. } \\
\text { Refers to specific detail about Zane's } \\
\text { recent emotional state and } \\
\text { behaviours } \\
\text { Confirms that this behaviour is still } \\
\text { occurring } \\
\text { Describes his patterns of behaviour } \\
\text { and how with support from teachers } \\
\text { he is able to get involved in play. }\end{array}$ & $\begin{array}{l}\text { Diana: } \\
\text { Zane is another one who has... really needed a lot of adult } \\
\text { support, so it's that thing of supporting him, but encouraging } \\
\text { him to be independent as well;... you don't want to sort of } \\
\text { push them out there too far before they're ready, because } \\
\text { they'll just sink; so you want to be able to do it within their } \\
\text { comfort thing. And he's just recently gone through a little bit } \\
\text { of a teary period with mum too, in the last little while; so he'll } \\
\text { come and find you... } \\
\text { Marilyn: } \\
\text { Just that morning, that day. } \\
\text { Diana: } \\
\text { Yeah, that's right. And he'll come and find you, when he } \\
\text { needs an adult he'll come and sit with you, or sit at what } \\
\text { you're doing, and it doesn't take much to get him involved. } \\
\text { [CS2/SRI4/E6] }\end{array}$ \\
\hline $\begin{array}{l}\text { Uses knowledge of changes in } \\
\text { Zane's family life to explain changes } \\
\text { in his emotional state. } \\
\text { Identifies changes in play patterns } \\
\text { between Zane and Brett which are } \\
\text { seen as helpful for Zane. } \\
\text { Observed Zane's interactions with } \\
\text { Brett }\end{array}$ & $\begin{array}{l}\text { Poppy: } \\
\text { Now, Nana left - she felt that she wasn't engaging very } \\
\text { much with the other children; she was there, and she was } \\
\text { telling me that from quite a distance. And someone else, } \\
\text { who - actually, maybe it was Brett said, "Kindy's not a place } \\
\text { for mums, is it?" Because obviously that's something that } \\
\text { Mum has said. And so, Nana turns around, and says, "No, } \\
\text { but sometimes it's ok for nanas to stay, if they don't see } \\
\text { their grandchildren very often" [laughs] So she must have } \\
\text { been quite happy to stay in for the entire session, but she } \\
\text { could see that this wasn't in Zane's better interests. } \\
\text { Diana: } \\
\text { Yeah. But his mum said she thought that Nana might stay } \\
\text { for the whole thing, and I said, "Oh, that's fine, you know"... } \\
\text { Marilyn: } \\
\text { But she did stay. } \\
\text { Diana: } \\
\text { But I think...he has got the new baby, and he's just got a } \\
\text { little bit insecure again. But...they do play, which is good. } \\
\text { And Brett has got really so much more confident. They kind } \\
\text { of lead the play a little bit more with Zane now, which is } \\
\text { good for Zane, eh. } \\
\text { Marilyn: } \\
\text {...just noticed he was on the outskirts looking at Brett; but } \\
\text { he's not quite giving it to him. } \\
\text { [CS2/SRI4/E6] }\end{array}$ \\
\hline
\end{tabular}




\begin{tabular}{|l|l|}
\hline $\begin{array}{l}\text { Analysis of teacher thinking and } \\
\text { reflection }\end{array}$ & Extracts from the data about Zane \\
\hline $\begin{array}{l}\text { Identifies cricket as a current interest } \\
\text { for Zane, worthy of recording in his } \\
\text { portfolio. }\end{array}$ & $\begin{array}{l}\text { Marilyn: } \\
\text { Actually, like this one with Zane and the cricket, a little bit in his } \\
\text { book about that would be good, because that is a passion of his }\end{array}$ \\
$\begin{array}{l}\text { at the moment. It's a big thing for him, but it...I don't think you } \\
\text { could write a whole learning story on it, it's not what you might } \\
\text { typically look at in a learning story, but it could be a little picture } \\
\text { or something in his book about it, 'cause that is his passion at } \\
\text { the moment. }\end{array}$ \\
\begin{tabular}{l} 
[CS2/SRI5/E2] \\
\hline
\end{tabular}
\end{tabular}

${ }^{\mathrm{a}}$ References to knowledge about the children are underlined

Teachers used their considerable knowledge about Zane, together with their understanding of teaching strategies to support him and achieve their goals. Zane's emotional well-being and social inclusion within the kindergarten were key themes. They were aware of the new baby in Zane's family and linked this to his current emotional state. They referred repeatedly to his need for adult support in order to participate in the kindergarten programme and his desire to be in close proximity to teachers. Knowledge about Zane's recent play partners, his style of interactions with other children, and his patterns of play were shared, and his interests in Lego and in playing cricket were also known.

Teachers talked repeatedly about Zane becoming independent at kindergarten whilst recognising that he needed considerable support towards achieving this. Learning about what you can do at kindergarten and that it is a safe place were aspects of this goal. Teaching strategies used to achieve their goals and respond to what they knew about Zane included: actively inviting him to participate in kindergarten experiences, facilitating social interactions with other children including group experiences, offering him either/or rather than yes/no choices to encourage participation, and being available to him when he sought support. Teachers supported him to make transitions to new experiences by planning the next steps with him and creating space for his active involvement.

Table 5.2 illustrates how Diana 'reads' cues given by Zane and Kerri to recognise and respond to their emotional wellbeing. Such instances indicate teachers' 
interactive thinking and involved them observing children's responses, non-verbal communication and body language, and adapting their interactions accordingly.

Reading children's cues involved teachers interpreting and trying to make sense of children's intentions and behaviours. Teachers recognised that they did not always get it right, illustrated by Poppy's comment during a discussion about her interactions during the small group news-time episode: "You go with the flow. But if you take a punt and it's in the wrong direction, they'll let you know" [CS2/SRI4/E2].

References to children's learning were a specific aspect of teachers' reflections. A strong emphasis on children developing and maintaining relationships and interacting successfully with adults and other children was evident, as was children's learning around their interests, content knowledge, skills and learning dispositions. Table 5.3 provides examples of key aspects of children's learning discussed by teachers.

Table 5.3: Examples of children's learning discussed during the interviews

\begin{tabular}{|c|c|}
\hline Children's learning & Illustrative examples \\
\hline $\begin{array}{l}\text { Developing } \\
\text { relationships and } \\
\text { having successful } \\
\text { interactions with } \\
\text { others }\end{array}$ & $\begin{array}{l}\text { Marilyn: } \\
\text { Those floor puzzles are good like that too, cos it's so big that you can get } \\
\text { enough of the pieces. } \\
\text { Poppy: } \\
\text { And it's nice that you can have a group of children working together; and as I say } \\
\text { just joining small groups and playing together, and talking, and learning to } \\
\text { participate...it's really nice. } \\
\text { [CS2/SRI5/E5] }\end{array}$ \\
\hline $\begin{array}{l}\text { Developing emotional } \\
\text { wellbeing }\end{array}$ & $\begin{array}{l}\text { Marilyn: } \\
\text { She just hasn't quite got that confidence to do it herself yet has she? } \\
\text { Poppy: } \\
\text { No, it's the confidence in trying things that she doesn't know how to do them very } \\
\text { well that she sometimes lacks and yet she can actually do them but it's... } \\
\text { Marilyn: } \\
\text { She likes to have a teacher there just to help. } \\
\text { Poppy: } \\
\text { Yes she does seem to quite like that adult support when she's doing that sort of } \\
\text { thing. } \\
\text { Marilyn: } \\
\text { It's the same with the puzzles isn't it? } \\
\text { Poppy: } \\
\text { Yeah, I suppose it is. } \\
\text { [CS2/SRI2/E2] }\end{array}$ \\
\hline
\end{tabular}




\begin{tabular}{|c|c|}
\hline Children's learning & Illustrative examples \\
\hline $\begin{array}{l}\text { Building content } \\
\text { knowledge }\end{array}$ & $\begin{array}{l}\text { Marilyn: } \\
\text {...Rachel really wanted to carry those shells the whole day round with her. } \\
\text { And she'd already...showed them to me once, but not...to...this extent. So } \\
\text { we were comparing all the different shells in there. She's got all the mussel } \\
\text { shells. She knew the mussel shells; and she's got different sizes, so she } \\
\text { just seriated them into size, which is bigger and which is... } \\
\text { [CS2/SRI4/E5] }\end{array}$ \\
\hline $\begin{array}{l}\text { Developing } \\
\text { communication skills }\end{array}$ & $\begin{array}{l}\text { Poppy: } \\
\text { I know I'm...actually prompting her a lot, but she's quite shy at times in front of a } \\
\text { group like that, so it's encouraging her; and same thing about the fingers, I didn't } \\
\text { want to embarrass her by bringing her attention, "Take her fingers out of her } \\
\text { mouth." Someone else I might have been inclined to suggest that, but with } \\
\text { Laura...she started so beautifully by saying her last name, and that's something } \\
\text { we've said...at mat time, maybe even the previous week... if you can start by } \\
\text { saying.... "My name is Poppy", and then sharing what it is. Sometimes with the } \\
\text { group I'll start off, to give them an idea of what you can say...and I didn't this } \\
\text { time. But I didn't want her to feel awkward about it really, so that's just doing that, } \\
\text { and then she said..., that she'd had some boys to stay at her house and then } \\
\text { she didn't really know what to say next which is why I was sort of prompting her. } \\
\text { [CS2/SRI4/E2] }\end{array}$ \\
\hline & $\begin{array}{l}\text { Marilyn: } \\
\text { And I remember Ricky's throwing...No, he's not batting yet, I don't think. Ricky } \\
\text { threw the ball, did a beautiful throw. } \\
\text { I remembered you saying, was it you, Diana, about last time when he played } \\
\text { cricket. He did really well this time. } \\
\text { Diana: } \\
\text { He always hit, swing the bat early, } \\
\text { Marilyn: } \\
\text { Too early. But he did it really well. It's funny, 'cause I clicked because I } \\
\text { remembered you saying that. He did it really well, he got the timing much better. } \\
\text { [CS2/SRI5/E3] }\end{array}$ \\
\hline Learning dispositions & $\begin{array}{l}\text { Poppy: } \\
\text { There were all those beads, and someone came in and dumped a lot of beads, } \\
\text { and they just kept rolling everywhere. So, Zoe was saying, "Oh, be careful; } \\
\text { someone was coming in with a pram or a little buggy", so she went in and picked } \\
\text { them all up. I thought that was so good...she's quite good at things like that, } \\
\text { actually; she looks at the environment and the bigger picture, she's not just } \\
\text { aware of what she's doing, but what's around her... } \\
\text { [CS2/SRI5/E5] }\end{array}$ \\
\hline Developing skills & $\begin{array}{l}\text { Poppy: } \\
\text {... was working on body awareness, so I knew the song I wanted to use; I knew } \\
\text { that Marilyn had used the bean bags the previous week; I also wanted to throw } \\
\text { in some directional stuff, because of things that we found the previous week, } \\
\text { going to the school... } \\
\text { [CS2/SRI3/E2] }\end{array}$ \\
\hline
\end{tabular}

These examples indicate that teachers used their knowledge of children's learning to plan learning experiences and to respond to situations as they arose. Further knowledge about children's learning was co-constructed by the teachers as they collectively reflected on the episodes. 
In summary, the Summer Kindergarten teachers drew on extensive, wide-ranging knowledge about the children when thinking about and reflecting on their interactions, to the extent that they reflected on their teaching predominantly through this child-focused lens. Their intense focus on the children was not limited to their thinking during the episodes but was also played out during their collective reflections where they continued to co-construct their knowledge and understandings of the children. The next section focuses on the teachers' discussions about their choices of teaching strategies during their interactions with children.

\section{Teaching strategies and interactions}

Summer Kindergarten teachers identified many teaching strategies and behaviours used during their interactions with children. Language used by teachers in their descriptions indicates many teaching strategies were deliberately selected, although there were also more intuitively selected strategies, together with more generalised discussion about interactions. An example of a teacher deliberately selecting a strategy occurred when Diana was supporting Oliver in the sandpit. She described his reluctance to ask for a turn with the hose and outlined her thinking and strategy choice:

\section{Diana:}

And, so I thought...there's a reason why he doesn't want to do it...I was thinking is it that confidence? Is it that language? Or whatever, so that's when I said to him really specifically, "This is who you need to go and ask and this is what you need to say" and then he was sort of a bit hesitant so I gave him that reassurance of saying, "Well, I'll keep an ear out and if it doesn't go well then I'll come and help you" and so I thought that seemed to give him the confidence and so then off he went to do it... [CS2/SRI1/E2]

A more intuitive choice of teaching strategy is evident when Marilyn chooses to read stories to two boys outside:

\section{Marilyn:}

Before the episode, Oliver had been a bit challenging, he'd had a few issues with a few children and he needed to have some sort of direction... Oliver....wanted to read a story and they chose, Oliver and Richard both chose the Maui story... So we went and sat up on the fort and read them over there....But...there was probably that in the back of my mind thinking right...just some nice settling, read a good book that they really enjoy and they were obviously really engaged in it. [CS2/SRI2/E1] 
The teachers' collective reflections included further discussion of teaching strategies, elaborating on those used by the teacher in the episode or describing additional strategies that might be useful. Diana talked about using eye contact and smiles to connect with the children during mat-time, and Poppy shared how she also used body language to help maintain control during a weekly Kapa Haka session with Manawa:

\section{Poppy:}

But you know that mat-time strategy too is something I use with Manawa. If I'm up the front, I'm always eyeballing those guys at the back and smiling at them and soon as they look at me and they see me smile it doesn't matter how much they're acting up, suddenly they're doing the actions a little bit. It's like I spend my life trying to do the actions and smile....

And you know they buy into it, it is, that's right. They get someone's smile, "Oh yeah, I'll smile back".

\section{Diana:}

Well, it's notice and recognition and it's that communication of...l've noticed you, I can see you.

\section{Marilyn:}

And especially that strategy for some of the really quiet, shy ones, it's quite a good like, "Ooh, that's me"... "That's me, they said my name." [CS2/SRI2/E3]

Overall, thirty-one distinct strategies were used by teachers that could be organised into four themes - approaches to teaching; engaging children; teachers' use of specific teaching strategies; and, adjusting teaching. The first theme, approaches to teaching, revealed how their thinking about interactions was informed by particular approaches to their teaching. Teachers followed children's interests during interactions: Diana described the antecedents to an episode where she had gathered tomatoes with a group of children:

But the interesting thing was, with the tomato thing, it started on the Wednesday, no, the Thursday - you know the tears thing and they got the tomatoes and they were going to make tomato soup the next day; and then they came into kindy the next morning, and they brought tomatoes in from home to put in the soup. So then they helped make the soup and the bread, and then we ate it. So that... whole soup, we actually went through a whole sequence. And it was really nice to be able to follow it through like that, and... they were really excited, they'd picked the tomatoes and they cut them up and put them in the soup; I had to just throw the soup on first thing, because it takes a long time to cook, but they made the bread, and they put their tomatoes in. And then they'd eaten it, so... 


\section{Marilyn:}

And it would start previous to that, because they were talking about how they had yellow tomatoes at their house, and I said, "Bring some in and show me some day." [CS2/SRI3/E6]

Teachers also described making children's learning visible to them, such as Poppy's decision to measure the length of children's jumping [CS2/SRI1/E7], and giving children the opportunity to re-visit earlier learning (for example, re-reading and discussing a Māori legend that had been introduced during the previous week's Kapa Haka session [CS2/SRI2/E1]). Teachers deliberately provided children with repeated opportunities to engage in activities, such as through the weekly sandwichmaking activity [CS2/SRI1/E8], and supported children to be decision-makers [CS2/SRI1/E6].

Two other teaching strategies based on particular approaches to teaching were noted: first, the strategies used by teachers to manage large numbers of children leaving the mat-time at once [CS2/SRI2/E3], and second, the teachers' planned use of te reo Māori during group-times [CS2/SRI2/E3]. The first five behaviours outlined above indicate a child-centred approach to teaching, showing teachers' responsiveness to children's interests and their view of children as capable of making appropriate choices and decisions. In contrast, the final two behaviours illustrate a shift in approach concerning group-time routines where the teacher has planned intentions and draws on strategies to control the large group.

The second theme focused on the strategies and interactions that teachers used to support or enhance children's engagement in learning activities. Teachers described being available to children in order to capture teachable moments [CS2/SRI4/E5] and ensuring that their physical placement and positioning supported relaxed interactions [CS2/SRI1/E1]. At times, teachers deliberately engaged with children in order to build and strengthen their relationship with them [CS2/SRI4/E3].

Teachers used their knowledge of individual children and their relationships with other children to organise groups for activities such as the perceptual motor 
programme and news-time [CS2/SRI3/E1] and selected resources that they felt would engage children's interest and support learning [CS2/SRI5/E2]. They actively engaged children in learning activities [CS2/SRI1/E6], extended the complexity of play experiences [CS2/SRI1/E7], and drew on their understandings that children may have different learning styles to individualise their teaching:

\begin{abstract}
Diana:
And also being aware of that thing children do learn in different ways and some children by observation, some children learn through that visual or the verbal or whatever and some learn through, a bit more through the doing... we do see early childhood as a hands-on thing but being able to ensure you're including... all those things in there as much as you can that gives them a greater ability to...utilise that information in a way that's actually going to be successful as well. [CS2/SRI1/E8]
\end{abstract}

The teaching behaviours of being available, building relationships and physical placement are indicative of how these teachers situate themselves, in terms of their teaching roles, in relation to the children. Although actively chosen, these strategies are intended to make it easier for children to approach and initiate interactions, thus they position teachers as responsive rather than directive. In contrast, teaching behaviours of involving children, selecting resources, and organising groups position teachers in a more active role of organising both the environment and children to promote engagement and enhance learning. Being aware of differences in learning styles indicates a willingness to individualise learning experiences whilst their efforts to extend play experiences are intended to engage children in deeper, more complex learning.

The third theme focuses on specific teaching strategies teachers used across a wide range of learning situations. These reflect generic teaching strategies discussed by MacNaughton and Williams (2009) and included in Bredekamp and Rosegrant's (1992) continuum of teaching behaviours that are used in many situations and for many purposes. Table 5.4 provides illustrative examples of teachers' use of these strategies. 
Table 5.4: Teachers' use of specific teaching strategies

\begin{tabular}{|c|c|}
\hline Teaching strategies & Illustrative examples \\
\hline Encouraging children & $\begin{array}{l}\text { Poppy: } \\
\text { I'm not ignoring her, and I'm...trying to prompt her into thinking for herself. She } \\
\text { says, "I want to make a house, I want to make a house". "OK, I'm going to have a } \\
\text { door", so ok, getting her to think about what she needs. } \\
\text { [CS2/SRI3/E5] }\end{array}$ \\
\hline Modelling & $\begin{array}{l}\text { Diana: } \\
\text { This is a good opportunity to put some of those...to model some of those } \\
\text { languages....I guess manners really in terms of that. And not manners because I } \\
\text { think children need to use manners, but manners because it's a strategy children } \\
\text { can use within their life when they need to use them.... basically. They don't have } \\
\text { to use them all the time, it's entirely up to them, but, but being able to give them... } \\
\text { those... } \\
\text { [CS2/SRI1/E8] }\end{array}$ \\
\hline Demonstrating & $\begin{array}{l}\text { Poppy: } \\
\text { Jackson was the only one that I...intersected with there, and physically showed } \\
\text { him. English is his second language, he's speaking very, very little here, so I } \\
\text { thought I would demonstrate to him, and get him to show. But I don't know how } \\
\text { good his understanding is; I suspect it's not bad, but you just don't know....So, for } \\
\text { him I... showed him what to do, whereas the others are taking their cue off - } \\
\text { there'll be one first, and then they'll all...the ones who are a little bit questioning, } \\
\text { they're looking at what their peers are doing, whereas he wasn't, so...that's why I } \\
\text { stepped in with that. } \\
\text { [CS2/SRI3/E2] }\end{array}$ \\
\hline Acknowledging & $\begin{array}{l}\text { Diana: } \\
\text { So making sure that I am paying attention to her, her effort. See Frances's got it } \\
\text { sussed. I could see that Frances has well and truly got the... she knows, she's } \\
\text { been listening, puts a knife in the sink... } \\
\text { [CS2/SRI1/E8] }\end{array}$ \\
\hline Supporting & $\begin{array}{l}\text { Marilyn: } \\
\text { You are very aware, eh, that you've got all these newbies there, that are a little bit } \\
\text { shy, or a little bit, in those afternoon groups, that you've to really try and build up } \\
\text { those relationships with...and I tend to make sure, have I talked to this one today, } \\
\text { no, I haven't talked to Alexandra today, so I go and talk to that one. Always go } \\
\text { and try and have a word to...the really quiet ones, who hardly ever talk. Try and } \\
\text { make sure you always try and find them. } \\
\text { [CS2/SRI3/FR] }\end{array}$ \\
\hline $\begin{array}{l}\text { Facilitating } \\
\text { interactions between } \\
\text { children }\end{array}$ & $\begin{array}{l}\text { Poppy: } \\
\text { Often in the afternoons it is, specifically, giving them the words, and coming } \\
\text { with them. And actually saying the words with them if you have to.... } \\
\text { Occasionally, it doesn't always work...; you're there with the expectation } \\
\text { they're going to say the words, and it doesn't happen; lay out what the } \\
\text { expectations are, that this person is still having their turn, so they're going to } \\
\text { finish their turn; and then it will be your turn, because you've asked - you } \\
\text { need to ask for that person to know that you're waiting, is the other thing, "but } \\
\text { he's had a long turn". If he doesn't know you're waiting and wanting to use } \\
\text { that, then he'll keep on having his turn... } \\
\text { Diana: } \\
\text { You actually need to say what the words are, to ask, "Can I have a turn?", } \\
\text { cos...that's the bit they're missing.... } \\
\text { [CS2/SRI4/E6] }\end{array}$ \\
\hline
\end{tabular}




\begin{tabular}{|l|l|}
\hline Teaching strategies & Illustrative examples \\
\hline Questioning & $\begin{array}{l}\text { Poppy: } \\
\text { When I asked him which was heavier, it was the idea that, well you leave that one } \\
\text { on the table cos it's much easier to manipulate a light piece of paper than a heavy } \\
\text { hole punch but he wasn't quite ready for that yet, he was still exploring the use of } \\
\text { the hole punch and what he could do with it, how it looked. } \\
\text { [CS2/SRI2/E4] }\end{array}$ \\
\hline Directing & $\begin{array}{l}\text { Diana: } \\
\text { Just giving really clear directions so that he can find that thing he was looking for. } \\
\text { [CS2/SRI4/E1] }\end{array}$ \\
\hline Listening to children & $\begin{array}{l}\text { Poppy: } \\
\text { Again...never make assumptions. He said he'd been to the pools with his Nana } \\
\text { and Pop, and so I was thinking, "Well, it wasn't up here, and...it's not [city]", so I } \\
\text { thought he might say [location] pools or whatever...and no, no, he'd been to } \\
\text { Nelson, ok...but it's good that he knew.... } \\
\text { [CS2/SRI4/E2] }\end{array}$ \\
\hline $\begin{array}{l}\text { Offering content } \\
\text { knowledge }\end{array}$ & $\begin{array}{l}\text { Marilyn: } \\
\text { I just sort of see where it flows too. I thought, "Oh, yeah they are obviously really } \\
\text { interested in whales so maybe I could get a whale book out and have a look" or, I } \\
\text { was thinking about getting the laptop but I didn't want the laptop by the water. } \\
\text { [CS2/SRI1/E1] }\end{array}$ \\
\hline $\begin{array}{l}\text { Using non-verbal } \\
\text { communication and } \\
\text { body language }\end{array}$ & $\begin{array}{l}\text { Diana: } \\
\text { One of the things I, not have to remind myself to do, but I'm really aware that } \\
\text { children relate really well to being smiled at. And sometimes you get so busy and } \\
\text { you're monitoring all these...things that you forget. So especially at mat-time I can } \\
\text { see all these... } \\
\text { [CS2/SRI2/E3] }\end{array}$ \\
\hline
\end{tabular}

Many different teaching strategies were selected by the teachers during their interactions with the children, from non-directive (e.g., acknowledging) to demonstrating and directing (Bredekamp \& Rosegrant, 1992). Teachers used these strategies for a range of purposes from helping children learn how to use tools and about sea creatures to facilitating friendships and teaching strategies for social interaction.

The final theme includes teachers' thinking focused around adjusting practices during interactions, or being alert to the potential for such adjustments (through observing children and supervising the wider environment). Teachers described adjusting the level of support that they provided to children, particularly when children were unfamiliar with activities such as sandwich-making [CS2/SRI1/E6]. On many occasions, teachers increased their level of support when it was clear to them that children were unable to manage a process or situation independently. Teachers 
also adjusted the length of time that they spent in individual interactions, taking opportunities for more sustained interactions where these presented themselves [CS2/SRI4/E5], and reframing problems that children might be facing to encourage alternative solutions to emerge [CS2/SRI1/E2]. Teachers actively observed children as they engaged in play in order to build understandings of children's capabilities [CS2/SRI4/E3] and through constant scanning and supervision of the wider environment were alert to where they might be needed:

\section{Poppy:}

From a teacher perspective, from me sitting down there, it's quite different than if I was sitting there in the morning group, perhaps, doing Lego. Because they're far more involved, and you don't have so much, but here every five seconds I'm looking up, looking up, because of something going on over there, and do I need to get up, do I not, no, ok, I'm right here, but...it's... [CS2/SRI3/E5]

These behaviours illustrate the teachers' thinking and reflecting-in-action, as they adapted their behaviours to create a better fit with the child as situations proceeded. Adjusting the level of support provided, re-framing problems and considering timing aspects indicate how teachers adjusted their teaching moment-by-moment in response to unfolding episodes. Scanning and supervising and observing children indicate teachers' awareness of the wider learning environment and readiness to respond to changes.

In summary, Summer Kindergarten teachers articulated a wide range of teaching strategies and behaviours used in interactions with children. They deliberately selected these teaching strategies in many instances, usually in response to children's actions, although evidence of implicit selection of teaching strategies was also found. The teaching strategies and behaviours were organised into four themes of approaches to teaching, engaging children in learning experiences, specific teaching strategies used, and adjusting teaching practices. In addition, an emphasis on relational pedagogy was evident (see pp. 151-152 for presentation of these data). 


\section{Dealing with multiple demands}

An issue specific to this case study centre concerned teachers' thinking about the challenges of working with large groups of children and the multiple demands that this made on them during their interactions. Teachers referred often to these demands, expressing their regret at not always being able to respond to a child as quickly as they would like, the importance of noticing and responding to quieter children as well as those who actively sought their attention, and the need to simultaneously supervise the wider environment alongside working closely with a child or group.

In other instances, teachers reported the challenges of balancing their intention to support an individual child, particularly those new to the session, with the demands of the wider group and their use of strategies for enabling large numbers of children to participate in activities (e.g., making sandwiches). Becoming involved in and extending children's play often drew other children into the play, increasing demands on teachers; similarly, some activities planned by teachers resulted in very busy periods such as the challenge course established by Marilyn in the perceptual motor programme (PMP):

\section{Marilyn:}

No, just it's a really busy time. Mind you, I did make it quite a busy challenge course, but that's partly my own fault, by having the moonhoppers, and the challenge course, and the balls; the three things going on, so you're constantly, constantly being aware of who's where, who's doing what, who's... can balance, who you know can't balance so you're going to have to go and help them across.... [CS2/SRI3/E4]

Teachers referred to ever-changing groups of children attending the morning and afternoon sessions, instigated by the older children's departure for school. Ensuring new children felt supported in new experiences was evident in many discussions. Such new experiences were not limited to the younger children starting in the afternoon session but also affected those transitioning from the afternoon to the morning group who experienced cooking activities and a weekly Kapa Haka session for the first time. Teachers also expressed their awareness that the environment 
could be overwhelming for new children, as in this discussion of the noise level in the afternoon session:

\section{Poppy:}

And...even with the screaming, if you didn't know that it was just children playing, and we all knew - but for new children, what do they feel like? If they come from an atmosphere where they don't know, they don't have siblings...maybe that's a bit disconcerting to get used to. 'Cause I noticed that Anna looks around a few times... and she's thinking....and Ariana was too, and Ariana comes from a family with lots of big, rough brothers...And...it's something else that we have to be aware of, mindful of, I think, it can be quite overwhelming and stressful. I mean, it is for us, at times.

\section{Diana:}

If children are crying, or upset, or things like that....

\section{Poppy:}

Oh, that's when you notice it. For those that are uncertain whether they're leaving mum and dad, and you only need one, you can see a few other wobbles starting immediately.... [CS2/SRI3/E5]

\section{Beliefs, principles, and theories underlying the Summer}

\section{Kindergarten teachers' practices}

This section of the chapter reports beliefs, principles of practice and theoretical knowledge underlying Summer Kindergarten teachers' practices. Analyses of transcripts identified four key themes - teachers' roles and behaviours, knowing the children, children's development and learning, and the learning programme - along with statements that reflected teachers' attention to equity and fairness.

\section{Teacher beliefs and knowledge about their teaching roles and behaviours}

The theme of teacher roles and behaviours included statements where the teacher was the subject and so the focus was specifically on aspects of themselves as teachers, as in Marilyn's comment:

You've also got to be aware, slightly aware of what's going on around the outside of you as well. Because you know every now and then you have to look up and look around and check what's going around the rest of the.... [CS2/SRI1/E1] 
Teachers' beliefs about their "big picture" views of teaching included their thinking about macro-level issues such as accountability and assessment practices and fundamental beliefs about teaching, children and the role of ECE. Teachers' views about supporting children to be successful emerged in several interviews, sometimes expressed as a teacher's primary intention:

\section{Diana:}

Because ultimately what you're trying to do, I guess, is support children to be successful in pursuing the things that they are interested in so, you know, that's your underlying motivation in a way. [CS2/SRI1/E2]

Diana's comment about the centrality of relationships between teachers and children illustrated a fundamental belief:

\section{Diana:}

If you don't value that relationship that you have with the children initially, and in those initial sort of moments are when you're working with children, then nothing after that really is going to be particularly genuine, really. So if you just value the pure interactions you have with the children, you value children for who they are, then from that, I think from that relationship...is what, how those other things sort of grow and build on that. [CS2/SRI5/E1]

Her belief in the importance of her interactions and relationships with children shaped her teaching. She saw these relationships as foundational to children's kindergarten experiences and her work as a teacher, and expressed concern that learning in areas such as literacy and numeracy were being valued over relationships and learning in the social domain. She recognised the potential for teachers' learning intentions to overpower what children wanted from their interactions with the teachers. For Diana, it was more important to take the time to converse with a child about a book of pictures the child's brother had drawn and engage with that child on an emotional level than use the episode as an opportunity to develop literacy as she wrote captions for the pictures [CS2/SRI5/E1].

Diana's emphasis on the importance of relationships was shared by the other teachers. Specific statements about practices indicated how these teachers enacted the development of relationships between themselves and children. Poppy shared 
her practice of taking attendance as she sat alongside children at the dough table so that they could begin to learn one another's names:

\section{Poppy:}

Because again, that's something I notice with the afternoon children, is they don't know each other's names anywhere as well as the morning children, so getting them to build up...have you seen so-and-so, someone might say like Stefanie said, "Oh, he's over there on the bars"... and someone else can turn around and say, "Oh, yeah, that's so-and-so". To build up those connections, that the names become familiar and they know who to expect.... [CS2/SRI4/E4]

Teachers paid active attention to developing relationships with children, especially those who were less likely to initiate interactions with them. They described intentions of being available to assist with transitioning children into the sessions, and seeking out children they hadn't spoken to during the session [CS2/SRI3/FR].

Examples of how teachers respected and valued children were evident in statements about respecting children generally, supporting them to develop a sense of belonging, and being interested in the things they value through to more specific statements about valuing children's views and their contributions:

\section{Poppy:}

They can see that you respect and value each child's contribution and you will be making... doing your utmost to understand and to get that, to help that child to contribute.... [CS2/SRI2/FR]

An important aspect of the discourse of valuing children was teachers' beliefs that children were developing autonomy and that, as much as possible, should be able to make decisions about what they did at kindergarten. The teachers felt that acting autonomously was a new experience for many children and teachers should support them to make informed decisions. Treating children as autonomous influenced teacher interactions:

\section{Diana:}

Y ou're wanting them to have some autonomy over their own bodies. So rather than saying, "You have to put the ice pack on" or "I'm going to put a bandage on that"...you're checking...that they're kind of aware of how they're feeling and where they're at and whether they need a bandage or not... if they're not gushing blood everywhere or whatever. So it's important for them to have that autonomy over their own, over themselves. So even in those...first aid situations...you can just ask them and check with them.... [CS2/SRI1/E6] 
Teachers' beliefs and practices around guiding children's behaviours, particularly social interactions among children, also emerged. The demands on children to turntake and share resources inherent in the group nature of the kindergarten programme were acknowledged by teachers. They believed that such skills often required direct teaching rather than expecting children to learn them through observations of others' modelling:

\section{Poppy:}

Often in the afternoons it is, specifically, giving them the words, and coming with them. And actually saying the words with them if you have to.... Occasionally, it doesn't always work... you're there with the expectation they're going to say the words, and it doesn't happen; lay out what the expectations are, that this person is still having their turn, so they're going to finish their turn; and then it will be your turn, because you've asked - you need to ask for that person to know that you're waiting, is the other thing, "but he's had a long turn". If he doesn't know you're waiting and wanting to use that, then he'll keep on having his turn....

\section{Diana:}

You actually need to say what the words are, to ask, can I have a turn, 'cause... that's the bit they're missing, really. [CS2/SRI4/E6]

Teachers viewed themselves as a resource that children could draw upon to assist them to achieve their aims. Previous teaching experiences had, at times, been instrumental in shaping these teachers' approaches to guiding children's behaviour such as Diana's experience of how children in another centre had responded when she supported their turn-taking behaviours:

It really altered my expectations of children, in that if they had the tools, they knew what to say, and they had the tools to negotiate, they would be quite competent at working out how to take turns in those situations; so... and here we've got the 'playing as a good friend', so that sort of incorporates it forward, so he's got words and so on....So the key for me is that for children like Roger and Terry, they really need to know exactly what to say, and they need to be able to practise it.... [CS2/SRI4/E6]

Teachers' beliefs about specific teaching strategies were also evident. The importance of teachers being actively involved in activities with children was noted, with teachers indicating their belief that this drew children to participate in activities and had a settling effect. Their acknowledgement of an active teaching role was evident in statements about teaching specific interactive and physical skills and 
helping children learn to use tools properly. Being aware of what was happening in the wider environment and keeping children safe influenced where teachers spent their time, as in Marilyn's statement, "If there is a crowd I will tend to go to where there's lots of children" [CS2/SRI1/E1]. Teachers drew explicitly on knowledge about the use of specific teaching strategies gained during their initial teacher education, as in this example:

\section{Diana:}

When I was at teacher's college I do remember...one of the things she talked about with music is don't spend a lot of time flicking around between what you, one thing to the next thing...just get on with it and get on with the next thing...cos it's that fluffing around in between time or if you pause or you're not sure or you're hesitant, that is the time that kids completely lose the interest. [CS2/SRI2/E3]

\section{Teacher beliefs about knowing the children}

The importance of knowing the children was the second theme to emerge from the analysis of how these teachers' beliefs and knowledge influenced their interactions. In contrast to how knowledge of individual children informed interactions, the emphasis here is on two central beliefs underpinning teachers' thinking and practice. First, children were viewed as capable and competent, and worthy of the teachers' respect, and second, they were viewed as individuals.

Teachers' beliefs about respecting children were demonstrated in several ways, including explaining where they were going when they moved away from a child and asking children if they needed or wanted help before assisting. Taking the time to listen carefully to children and enabling unhurried interactions were also reported:

\section{Marilyn:}

I knew that Manawa had already gone in and I thought, "Well". I was waiting for her to answer. So I thought I'll just wait, and give her time and then, then she still didn't answer and I prompted again, and then I waited.

So then I thought I need to make a decision here, it's like I needed to get her to make a decision so I said, "Shall we leave it here?" and gave her that decision for her and then she nodded, "OK, come on then". So...instead of rushing I thought I needed to take that time because she's not a child that deals very well with being rushed into things like that either. [CS2/SRI1/E5] 
By being unhurried and in valuing children's contributions, teachers adjust their pace and interactions to suit the individual child. They demonstrate their respect for children by asking if they want assistance and explaining their actions.

Teachers used knowledge of children's personalities and temperaments and their lives outside the kindergarten in their interactions. Recognising and supporting children's learning interests were highly valued, although the teachers acknowledged that they didn't always succeed [CS2/SRI3/E6]. Whilst seeing children as capable and competent, these teachers recognised their teaching needed to be responsive to children's individual learning needs, particularly given the free-flowing, choice-based nature of the kindergarten programme [CS2/SRI1/E7].

Teachers also paid attention to the emotional aspects of learning, particularly around their goal that children develop independence and in acknowledging that learning involved taking risks. Working within children's comfort levels framed how far they encouraged children to physically challenge themselves or to act independently:

\section{Diana:}

So it's that thing of supporting him, but encouraging him to be independent as well; like, you don't want to sort of push them out there too far before they're ready, because they'll just sink; so you want to be able to do it within their comfort thing. [CS2/SRI4/E6]

\section{Teacher knowledge and beliefs about children's learning and development}

The teachers' knowledge and beliefs about how children learn and develop was the third theme to emerge from the data. An eclectic range of theoretical perspectives appeared to underpin teachers' practices. References to developmental, sociocultural and learning theories were all evident in their discussions.

Developmental perspectives were evident in the language used and the content of their discussions. References to how teachers adjusted their practices to match children's stages of development were made in relation to events such as mat-times: 


\section{Diana:}

And you want it to be a positive experience for them too, you don't want mattime to be the sort of experience where they're getting told to sit down and do this or that all the time either. So you've got to find ways to do it that don't really involve being too disciplinarian, I guess.

\section{Marilyn:}

Which is why we keep those afternoon ones quite short.

\section{Diana:}

Try and tailor it to their level of development really, ay? [CS2/SRI2/E3]

Teachers indicated that they provided children with extensive opportunities to explore using materials and tools as a foundation for their later use in creative endeavours. They spoke of supporting children to delay gratification when harvesting passionfruit from the kindergarten garden. Maturation and processes of physical development were aspects of developmental theory that underpinned discussions about the perceptual motor programme and learning cricket. Poppy's detailed knowledge of children's physical development was used as a rationale for activities such as swinging across the bars in the PMP:

\section{Poppy:}

It's that understanding that your body develops from the inside to the out; so to have really good fine motor coordination down here, you need to have good shoulder strength, good arm strength. Boys are seen as strong, but they run around, they get really lower-body strength, but that upper-body strength they have less of, so this is one way that we can work on incorporating that in what we do here, that we think is quite, quite valuable. It shows through in their finer skills, what they do with drawing, the sorts of things they do here; in their other skills as well. [CS2/SRI3/E3]

The PMP provided an interesting example of theoretical eclecticism for these teachers. Teachers drew upon developmental theory to explain the influence of children's physical development on other developmental domains and Diana used concepts of readiness to help articulate her thinking:

\section{Diana:}

... what I'm thinking about when I'm doing it, judging where the children are at with it, and helping them across and that's all good; but it brings up those ideas for me. Especially when you look at children's development and stuff like that...all those ideas of children crawling before they walk....So it's part of that developmental process, and for me it's trying to understand what that developmental process is in terms of the bars.... [CS2/SRI3/E3] 
In addition, the teachers' thinking about the PMP drew on socio-cultural perspectives with teachers positioned to take an active role in leading children's development through activities that they initiated, working in children's zones of proximal development. Both Poppy and Marilyn articulated the benefits that they believed came from this approach, including enabling children to have success in activities they might not attempt on their own.

Further evidence of teachers' eclectic use of theory was apparent in discussions about children's social interactions. As noted earlier, the development of social competence emerged as a key area of learning for these teachers who readily took an active scaffolding role to enable children to learn strategies to interact successfully with others. Teachers appeared to draw on their knowledge of research in this area:

\section{Diana:}

It was about children's social competencies and one of the key things is children that were - I mean it had been a study or something - one of the key things was children that had the ability to compromise in play situations were much more successful in their social interactions overall. And that was something that really...stuck with me and I think that....works well with that 'You can't say you can't play' because...it's basically there as a frame or a rule, to operate as a framework to encourage children or to be able to compromise. [CS2/SRI1/E4]

Teachers further drew on socio-cultural perspectives about learning and development in their discussions about children's active participation in learning experiences and their engagement in learning. They acknowledged the significance of children's families and prior experiences in engaging children and mediating the learning experience:

\section{Diana:}

So for her, it was all of those emotional connections, they were all things that she'd either all experienced or people that she knew, all those sorts of things. So that's one reason why it was so significant to her. And it was just really nice...to be able to have that kind of relationship with the children, and to support them in that way, in a way which actually means something for her, really. [CS2/SRI5/E1]

Teachers drew on a third theoretical framework, learning theories, to further inform their teaching practices. The extent to which children were intrinsically or extrinsically 
motivated to attempt swinging across the bars during PMP time was debated. In discussing her interactions whilst children made sandwiches, Diana referred to her intention to include interactive strategies that would support children's different learning styles. Breaking down challenging activities into smaller steps was identified as a useful approach to assist children's learning in the sandwich-making activity:

\section{Diana:}

Obviously when you are learning something and yet...you don't know whether the kids have made sandwiches before, like Poppy said, or not. So, but when you are learning something...in terms of, well in my experience of learning things... if you learn it in little bits and then you put it together...it's better. So actually again...saying to her, explaining to her how the knife worked and how the jam worked and showing her and then giving it back to her so she had that go. [CS2/SRI1/E8]

\section{Teacher beliefs and knowledge about the learning programme}

Teachers' beliefs and knowledge about the learning programme formed the fourth theme in this section. Teachers' views about the place of the kindergarten programme included their beliefs that kindergarten provided children with experiences not easily had at home and that there should be strong connections between the kindergarten and the children's families and wider community [CS2/SRI4/E5].

These teachers also expressed their beliefs that there needed to be a balance between teacher-led and child-led experiences in the programme, and that the children's processes of exploration and learning were more important outcomes. That kindergarten was a place where children would want to spend time and have fun was important to these teachers. Poppy articulates this in her comments about children on the four-person swing:

\section{Poppy:}

I guess the only other thing is that they were having fun, and I was just helping them to have fun. And sometimes...you just do that at kindy. You want to do something that's pleasurable, it's a pleasurable sensation - a sensory thing, I guess, that motion - and seeing how fast and how high you can go, and it makes them all shriek; they want you to go higher and faster, it's just about having fun, enjoying each other's company without, yes, I guess, any particular learning opportunities again...they're working together with a bunch of friends and doing something enjoyable. [CS2/SRI5/E2] 
Individual play contexts, such as the sandpit, water trough, puzzle area and dough table were valued for their learning potential. Teachers articulated knowledge of how different contexts supported children's learning in, for example, mathematics, literacy, social competency, content knowledge, developing friendships, and learning how to use tools. The role of locations such as the morning and afternoon tea table and the dough table was highlighted, especially as places where you could observe how kindergarten worked, develop relationships and friendships with others, and set your own pace for participating in the group [CS2/SRI4/E4].

Finally, teacher beliefs about organisational aspects of the learning programme were also apparent. References were made about the importance of organising the environment before children came to the activity and having a range of strategies for managing large group times within the programme. Teachers believed it was important to have sufficient and good quality resources:

\section{Diana:}

I've worked in a lot of environments that had really, really minimal resources, and to know exactly what it's like when you don't have very good resources, it really limits what you can do. It limits the children, and it's just not... really fair on children, that you've got puzzles that have all got a piece missing, and...we had a train set that didn't match up, and... [CS2/SRI4/E6]

\section{Teacher beliefs about equity and fairness}

Teachers' also expressed their beliefs about equity and fairness. Attention to equity was revealed largely through their thinking about the demands they faced as teachers in the kindergarten (see pp. 149-150 for earlier discussion): prioritising which children received their attention (usually on the basis of the child's perceived needs) and balancing the needs of individual children with the needs of the wider group. Specific ways in which they provided equitable access for children included ensuring that children didn't claim undue ownership of kindergarten resources at the expense of other children's participation and being even-handed in how they invited children to help them with kindergarten tasks. 
Although teachers seldom considered equity and fairness in terms of their own responses to children (as opposed to how they managed demands for their attention and resources), on one occasion Diana and several children had been harvesting fruit and vegetables from the kindergarten garden and one child had repeatedly called her "teacher" rather than using her name. Following the episode, she reflected on inconsistencies in her responses to this child and others:

\section{Diana:}

....and this was an interesting point, and I did notice this morning, 'cause Peita always comes and says "Teacher", and he's got quite a big voice, and he'll come and go, and he's very...demanding with it..."Teacher, teacher"; and so quite often, 'cause I've noticed that you guys remind him what your name is; but then I noticed that there was some other kids that do it as well, and I thought, "Oh, I haven't been reminding them what my name is". But they have quite quieter voices, and they're not as insistent, and they'll come up quietly and go, "Oh, teacher, teacher". And I thought, is it because he does that really insistently, so then I had to think about, $\mathrm{mmm}$, maybe I need to modify my approach, and make sure I'm being fair about this, and reminding everybody. [CS2/SRI4/E1]

In summary, the Summer Kindergarten teachers' underlying beliefs, together with their professional and theoretical knowledge, influenced their teaching interactions with children. Core beliefs included respect for children as competent and capable who should be treated as individuals, and their view that relationships were central to their work as teachers. These teachers drew upon knowledge from child development, learning theory and socio-cultural traditions to inform their choices of teaching strategies and interactive approaches, and valued the potential for learning that existed in the different learning contexts they provided as part of the programme. Managing competing demands in large group sizes was framed in terms of equity and fairness. These findings reveal something of the complexities of teachers' thinking about their interactions, perhaps best summed up by one of the teachers:

\section{Diana:}

I guess, the point at which you make those decisions is really critical in terms of your own view, your own knowledge about individual children's...development, but also what you see as the most significant aspects in terms of your, what we would call teaching practice or in terms of what you value the most...in working with young children really. [CS2/SRI5/E4] 


\section{The influence of a community of practice on Summer Kindergarten teachers' thinking and reflection}

The final section of this chapter reports data outlining the particular nature of the community of practice that was the Summer Kindergarten teaching team, and the influences that this had on their individual and collective thinking and reflection about interactions with children. The interview transcripts were examined for patterns of alignment behaviours used by the teaching team, and for the ways in which the teachers negotiated meaning about their thinking and their practices.

In the interviews, Summer Kindergarten teachers engaged predominantly in focus teacher reflection and collective reflection forms of teacher talk. These seemed to reflect teacher:child ratios at this centre, where ratios of 1:12 to 1:15 reduced teachers' observations of one another's interactions with children, and limited opportunities to co-construct meaning about specific episodes. Teachers stressed the importance of sharing their observations with each other and actively engaged in collective reflection where they shared their knowledge of individual children or previous events to build upon what they observed in the recorded episodes [CS2/SRI2/FR].

\section{Alignment behaviours amongst Summer Kindergarten teachers}

The Summer Kindergarten teachers used several specific alignment behaviours during the interviews that reflect how their team worked as a community of practice, including indicating agreement, finishing each other's sentences and expressing different views.

A mix of brief affirmations and longer statements were used to indicate agreement. Teachers used agreement statements to affirm another teacher's understandings and at times built agreement over several statements:

Poppy:

And often she almost likes to make out that she can't do something but actually she can. She just needs that little bit of encouragement and support and she can do it or get someone to help her...to snip the string or whatever she needs to do and off she goes and... 


\section{Marilyn:}

She just hasn't quite got that confidence to do it herself yet, has she?

\section{Poppy:}

No, it's the confidence in trying things that she doesn't know how to do them very well that she sometimes lacks and yet she can actually do them but it's...

\section{Marilyn:}

She likes to have a teacher there just to help.

\section{Poppy:}

Yes she does seem to quite like that adult support when she's doing that sort of thing. [CS2/SRI2/E2]

Sometimes teachers indicated agreement in ways that sought or recognised philosophical common ground between them, such as when Diana and Marilyn discussed how Poppy had facilitated a child's exploration:

\section{Diana:}

That's right and valuing the fact that, how they use and what they do with it and whether they're just sort of...that open-endedness about it as well.

\section{Marilyn:}

Yeah so it's not the, it's not the final product it's that process that counts.

\section{Diana:}

That's right. [CS2/SRI2/E4]

Such attempts may have reflected that Diana had begun teaching at the kindergarten just before data collection so the team was still in the early stages of sharing and negotiating teaching philosophies. The definiteness with which this team of teachers agreed with each other's statements was particularly apparent. A text search for words or phrases indicating strong agreement (i.e., "that's right", "totally", "exactly", "absolutely" and "of course") in data coded as indicating agreement revealed that such language was used frequently by these teachers.

A second alignment behaviour used often was finishing another teacher's sentence. Such interactions indicated shared understandings as in this example where 
teachers repeatedly finished others' sentences. Marilyn was talking about children climbing over the bars on a climbing frame as part of a PMP activity:

I was saying, "Oh, it might be harder to go across", because going across it that way...

\section{Diana:}

If they angle down slightly from that side...

\section{Poppy:}

And that bar's bigger at the top...

\section{Marilyn:}

That top one's wider, and...

\section{Poppy:}

It's not as easy for them to hold on to.

\section{Diana:}

Yeah, otherwise the kids go up and down that...

\section{Marilyn:}

And she's sitting there looking, and I could see from her face, "Well, come and help me down, will you?", so "OK, do you want me to help you down?" [CS2/SRI3/E3]

Teachers at Summer Kindergarten also expressed alternative views but more tentatively, using phrases like "I wonder...", or "it may have been that but...", or "I think..." allowing for different views without directly critiquing others' practices:

\section{Diana:}

So that was all really specifically around him, supporting him to be engaged in that constructive activity really and persisting in it, I haven't actually seen him in the water trough a lot before either.

\section{Marilyn:}

No, he was that morning.

\section{Diana:}

And it was an activity that he initiated with the trucks.

\section{Marilyn:}

I wondered if he maybe didn't want to leave the truck. 


\section{Diana:}

That could have possibly been it.

Marilyn:

Because he thought someone else might get it while he was not there, or something.

\section{Diana:}

Yeah, yeah.

Marilyn:

But I don't know. It would be interesting to see when he comes back.

\section{Diana:}

Yeah, because that does - yeah, sometimes that is a bit of a...yeah, yeah.

\section{Poppy:}

Sometimes they'll ask you hold it though, if that is the case. [CS2/SRI1/E2]

\section{Negotiating meaning within the teaching team}

As noted above, teachers engaged in in-depth discussions in order to negotiate meaning about what was occurring in the video-recorded episodes and beyond. Shared understandings developed from these discussions, with individual teachers frequently making long statements as they described their thinking and actions. Discussions were characterised by principled talk with frequent shifts from specific instances to broader principles of practice.

Asking questions to clarify what was happening in episodes together with offering information and opinions occurred often, especially when the focus teacher was describing her thinking and interactions. Whilst a number of questions sought to clarify which children were involved and what they were saying or doing, teachers also asked questions about the equipment and resources being used by the teacher and children (e.g., Diana asked, "What was the one that you're looking at there?" when Marilyn was reading books to children outside [CS2/SRI2/E1]) and their colleagues' thinking or actions (e.g., Marilyn's question to Poppy, "Did you 
strategically move the particular pieces you needed?" when watching her supporting a group of children to complete a complicated floor puzzle [CS2/SRI5/E5]).

Teachers contributed to the collective task of trying to understand what was happening by offering information or opinions. Most such contributions were short statements, often affirming what another teacher had said with a parallel example. At times, teachers offered comments that confirmed or "rounded out" what another teacher had said. There were also some longer interchanges:

\section{Diana:}

That was Stefani because she'd being doing a lot of the hula hooping and...that whole practising and getting better and better at the hula hooping.

She's got that concept of working at something and then practising...

\section{Poppy:}

Yes, Yes. And she's quite competent physically and that's something she'd like to challenge herself physically in different ways.

\section{Marilyn:}

She never used to be.

\section{Poppy:}

No. She's developed that over the last few months for sure. [CS2/SRI1/E7]

Teachers at Summer Kindergarten made numerous statements reinforcing each other's practices but did not offer advice or engage in criticism, except on one occasion when Marilyn criticised her own practice. They reinforced each other's practices both generally (e.g., Poppy's comment of, "Yeah, good thinking" when Marilyn described how she didn't want to use the laptop to find information with children as it was too close to the water-trough [CS2/SRI1/E1]) and specifically. For example, Diana reinforced the in-depth interaction that Marilyn had with Rachel about shells collected from the beach:

\section{Diana:}

It's nice for her to have someone that is really interested in the things that she values, taking the time just to look at them and explore them.... [CS2/SRI4/E5]

A range of teachers' practices were reinforced, including the relationships they had with, and their knowledge of, children; their use of specific teaching strategies and 
resources; and their individual teaching styles. The complexity of teaching was also acknowledged as in this example where Diana offers the following feedback to Marilyn:

And trying to acknowledge what they're saying and thinking. Like you said where, how do I support this, where do I go with it?....It's a huge juggling act really. When you see it on the big..., when you see it like that really. To do it well... and you did it and....when you do it well like that, really. [CS2/SRI1/E1]

The Summer Kindergarten teachers often offered new ideas to expand discussions. These new ideas addressed a wide range of content, including insights gained about children as a result of watching the DVD, explanations of their teaching that connected with what the focus teacher had done, understandings of what children were learning, and links made to theory and principles of practice. A discussion about the teacher's role in a cooking activity provided numerous examples of teachers adding and picking up on new ideas in a wide-ranging, free-flowing conversation. The episode below began with Diana describing her thinking and interactions as she worked with children in a sandwich-making activity. Several of the children were unfamiliar with the activity, and at one point Diana took particular care to make sure they were all right before she went to invite other children to make their sandwiches. Halfway through the transcript Marilyn highlighted what she observed Diana doing (see Table 5.5): 
Table 5.5: Extract illustrating teachers adding new ideas and deepening discussion

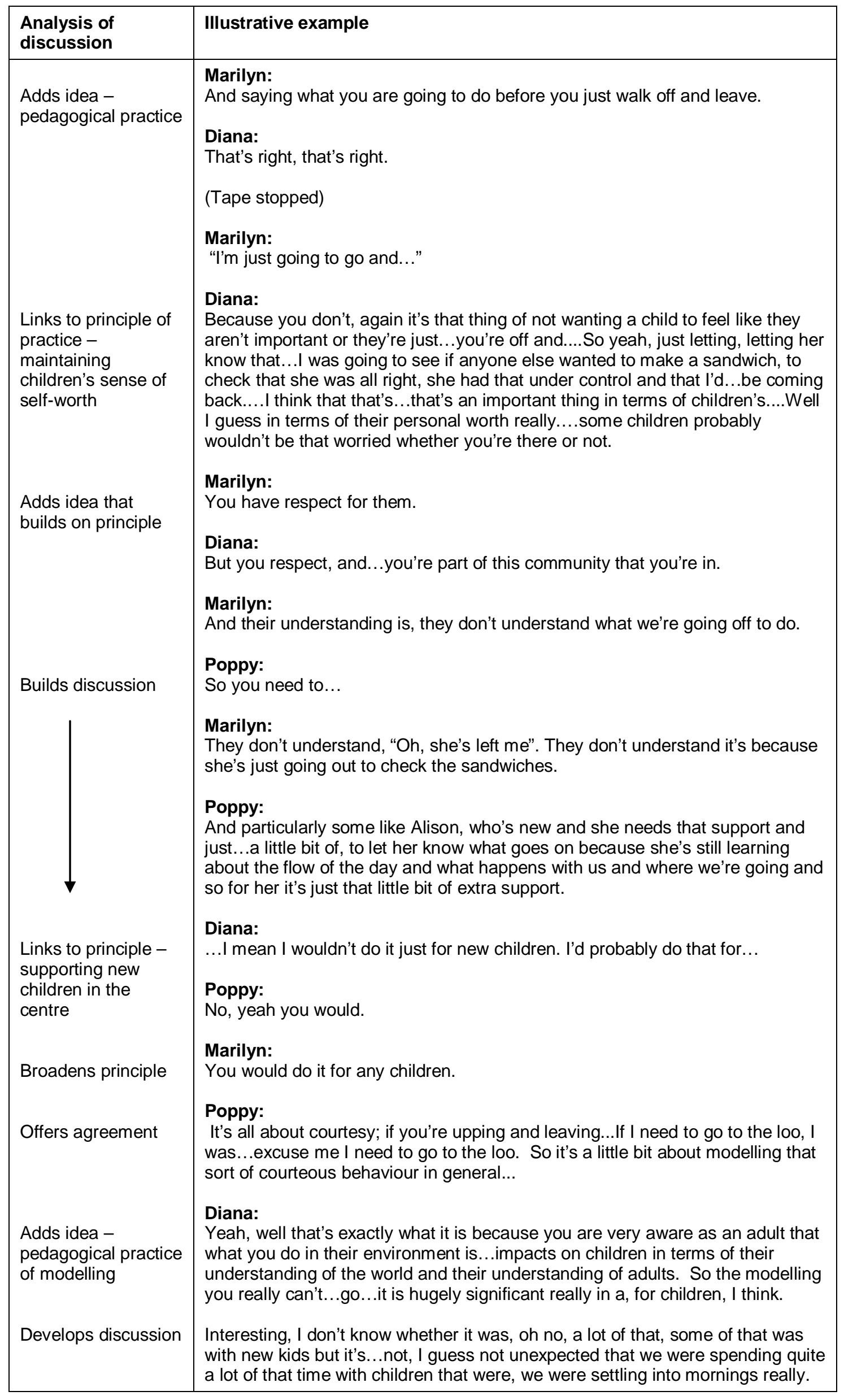


Adds new idea teachers' role in settling children into the new group

Builds discussion

Adds new idea principle of timely support for children

Adds new idea teacher-child ratios

Articulates principle - determining priorities for working with children

Builds discussion

\section{Marilyn:}

Because you quite often do to start of with because the others have, once they're into the routine they are quite happy off doing their own thing until they need you or whatever.

\section{Poppy:}

And I think that's the thing too, is being aware of knowing which children need that little bit more support to get the most out of their kindergarten experience.

Some need very little adult input and guidance and some really need that initially and then they build up their confidence and they're fine and they're off. But if they don't get that support initially then they'll struggle to sort of....

\section{Diana:}

Well, I think part of it too is the fact that you are working with, in...a reasonably big ratio...1 to 13 or something like that. So again it's part of that thing of prio...I mean it would be great to give all those children as much input as you could but again it's working out where the greatest need is on that particular day at the particular time basically. And who...who is, where the greatest benefit is going to be for where you're putting your adult attention in, I guess.

\section{Poppy:}

Yeah, that's very true. Because really the ratios are so big and you can't have meaningful and quality interactions with 15 children at any one time. So you do have to prioritise, I guess that's the reality of, of kindergarten.

[CS2/SRI1/E8]

This extract highlights the fluidity of teachers' discussions, their active engagement in the process of negotiating meaning about their practices, and the principles that underpin these practices. In addition, this discussion reveals the influence of reified practices (Wenger, 1998) within this centre: first, when Diana notes (and the other teachers agree) that she would use a similar strategy of telling a child why she was leaving the activity whether or not the child was new to the centre, and second, in the agreement between the teachers about the important role that they have in modelling appropriate behaviours to the children.

Teachers used the specific situations they watched as a bridge to talking about more general principles of practice and broader issues related to their work as EC teachers. Within the team, Diana played a key role in shifting the focus of discussions towards broader aspects of teaching and the impact of macro-level influences on practice. For example, in the final interview with this team, Diana picked up on Poppy's belief about the importance of children enjoying themselves at kindergarten without always having to have a particular learning outcome in mind, and shifted the discussion towards a philosophical debate about the purpose of ECE and assessment practices in particular. Her colleagues enabled her to share her 
thinking at length and demonstrated their understanding of her points through

affirmations and links back to their kindergarten practices (see Table 5.6).

Table 5.6: Shifting discussions towards broader aspects of practice

\begin{tabular}{|c|c|}
\hline $\begin{array}{l}\text { Analysis of } \\
\text { discussion }\end{array}$ & Illustrative example \\
\hline $\begin{array}{l}\text { Broadens discussion } \\
\text { to focus on curriculum. } \\
\text { Expresses concern } \\
\text { over compartmental- } \\
\text { isation of learning, and } \\
\text { valuing of particular } \\
\text { types of learning over } \\
\text { others. }\end{array}$ & $\begin{array}{l}\text { Diana: } \\
\text { And I remember once when we were at college, I think, and it may very well } \\
\text { have been you, Sue, talking about what is the curriculum in kindergarten, and } \\
\text { really what you were saying is that everything that happens at kindergarten is } \\
\text { the curriculum. Everything... and that is why I think that part of this whole } \\
\text { process - the learning stories, and everything we do - is this...we've sort of } \\
\text { started to... what is happening, we're now setting it all in little boxes: " Oh, this } \\
\text { is valuable learning, and woah, we better do a story about that"; but that's } \\
\text { just, or this is just.... when in actual fact, it's all learning, it's all valuable, and } \\
\text { it's all experiences that are important to children. }\end{array}$ \\
\hline $\begin{array}{l}\text { Identifies impact of } \\
\text { new assessment } \\
\text { practices on what } \\
\text { teachers value and } \\
\text { how they engage with } \\
\text { children. }\end{array}$ & $\begin{array}{l}\text { Obviously they need to enjoy them; if they're not enjoying them, who would } \\
\text { want to come here? So...that's what I mean about the way I think this....and } \\
\text { I'm not saying we shouldn't do them or anything like, the way I've noticed it's } \\
\text { starting to affect the way you think about how you interact with children, and } \\
\text { what's happening when you're playing with children, and when you're } \\
\text { working with children. }\end{array}$ \\
\hline $\begin{array}{l}\text { Queries purposes of } \\
\text { such assessment and } \\
\text { how it benefits } \\
\text { children. Suggests that } \\
\text { audience for much } \\
\text { assessment may be } \\
\text { parents and ERO, } \\
\text { rather than children } \\
\text { and teachers. }\end{array}$ & $\begin{array}{l}\text { Now, it's sort of like there's a higher value placed on certain activities, or } \\
\text { certain experiences or interactions that you're having, and a lesser on other } \\
\text { ones; and I think that that is really an outcome of this drive with the planning, } \\
\text { assessment, and evaluation that has been such an on-going over the last few } \\
\text { years...there's such a big drive in that area at the moment, and the recording } \\
\text { of all of that; and to a large degree, I do have to say, well, to whose benefit is } \\
\text { it actually all for at the end of the day? And we have to be careful that it } \\
\text { doesn't become... detrimental and... sometimes I feel the push for it is not } \\
\text { actually for the children who it should... be benefiting the children, which it } \\
\text { should be; it's actually more in terms of how it's going to look to someone } \\
\text { that's going to come and read it in three years... how you're conveying that } \\
\text { knowledge. ...how you're conveying it to parents, and what does this mean, } \\
\text { and when they're reading this, what does it say about you... }\end{array}$ \\
\hline Indicates agreement & $\begin{array}{l}\text { Poppy: } \\
\text { Yeah, I think that's very true. }\end{array}$ \\
\hline $\begin{array}{l}\text { Queries who teachers } \\
\text { are accountable to, } \\
\text { and states her } \\
\text { position. }\end{array}$ & $\begin{array}{l}\text { Diana: } \\
\text { But...who are we actually meant to be accountable to?...I think, again, it's } \\
\text { the } 43 \text { kids that come in the door every morning and afternoon. They're the } \\
\text { ones that we are mostly accountable to, and I think that that's something that } \\
\text { I anyway personally have felt that that has - everyone talks about it, children, } \\
\text { but I don't actually feel that in some ways that that is the prime motivator }\end{array}$ \\
\hline $\begin{array}{l}\text { Suggests assessment } \\
\text { and planning } \\
\text { processes have } \\
\text { become dominated by } \\
\text { adult agendas and that } \\
\text { children are being lost } \\
\text { in the process. }\end{array}$ & $\begin{array}{l}\text { for...it just doesn't seem to be - it's viewed through the adult eye, and the } \\
\text { adult system, in terms of that whole assessment, planning, and evaluation; } \\
\text { and I think that we need to really take a breath and say... before we get too } \\
\text { carried away here, what... are the children - where are the children in this? } \\
\text { What are the children actually enjoying that, and where do they.... Let's just } \\
\text { get back to the very... like I said, enjoy that core function, initially. }\end{array}$ \\
\hline $\begin{array}{l}\text { Applies Diana's } \\
\text { comments to her own } \\
\text { practices when } \\
\text { identifying what is } \\
\text { valuable learning, } \\
\text { worthy of inclusion in a } \\
\text { learning story. }\end{array}$ & $\begin{array}{l}\text { Poppy: } \\
\text { Well, that's an interesting observation. I mean...I have done lots of stories } \\
\text { about children on the swings, and turn-taking, the fun they're having; but } \\
\text { they're afternoon stories. For children who are enjoying being at } \\
\text { kindergarten, and who are playing with us and chatting to us on the swing; for } \\
\text { a morning child, I guess you look at who your audience is. I guess it's } \\
\text { primarily the child, but there are other people involved, and so, for these } \\
\text { guys, I guess realistically I probably wouldn't think of it as such valuable } \\
\text { learning that I would document it in the same way. Whereas for an afternoon } \\
\text { child, wouldn't have done that; I guess it depends on the child. For some } \\
\text { children, if they've not really built up those relationships and friendships, and }\end{array}$ \\
\hline
\end{tabular}




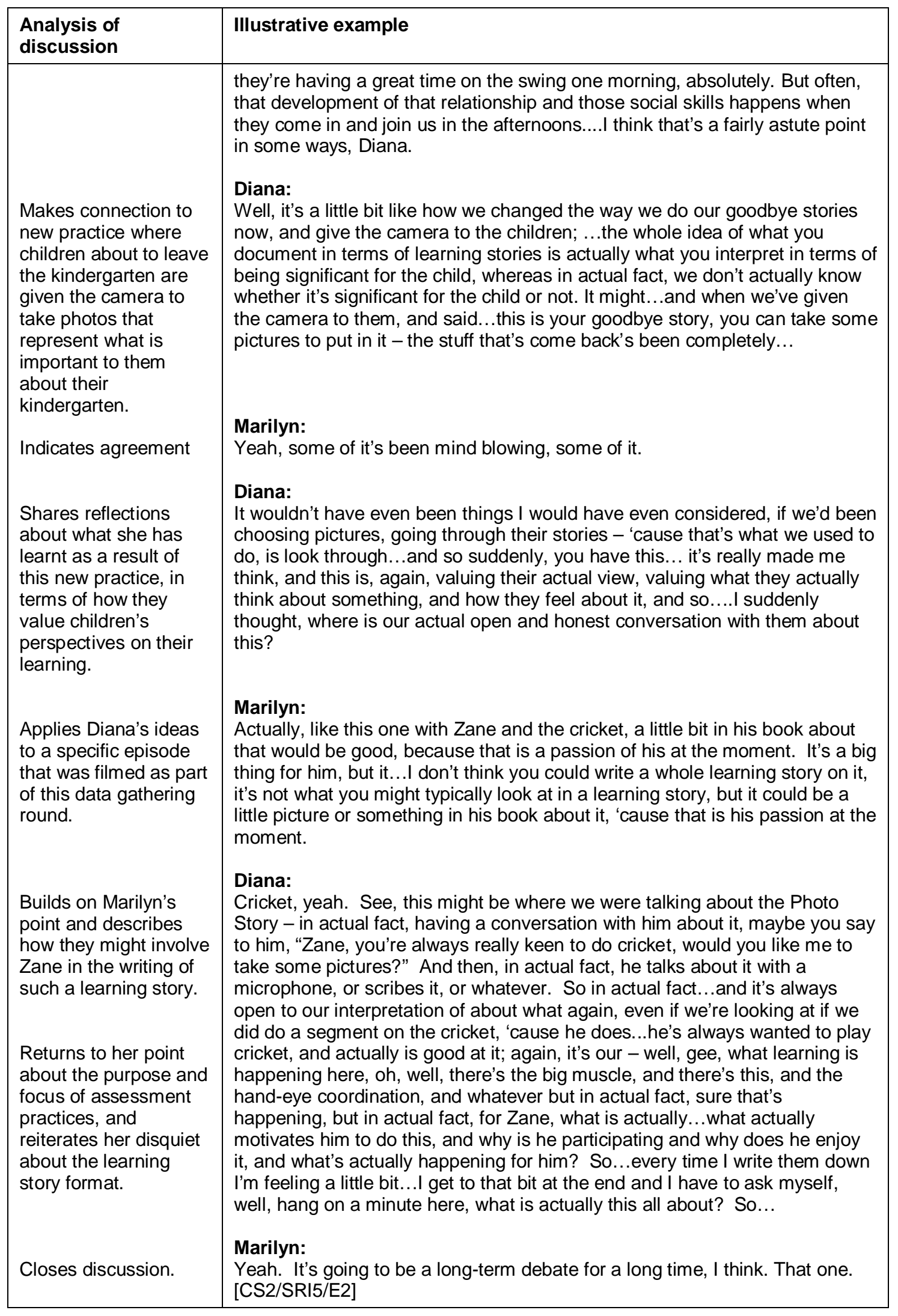

Reflections on such macro-level issues and how these impacted on teachers'

practices were relatively uncommon during the interviews. This could be an artefact

of having asked the teachers to share thinking and reflections about their 
interactions with children. The extract reveals, however, broader policy and theoretical discourses that may generally go unexamined by teachers but which could be highly influential for their practices.

In summary, the teachers at Summer Kindergarten utilised several behaviours that helped them to demonstrate alignment between their thinking and practices and thus enhanced their sense of community and collective approach to their work as teachers. Alignment behaviours of expressing agreement and finishing each other's sentences emphasised common understandings and, although they often expressed different views, these were offered in a style that avoided criticism.

These teachers sought to understand the episodes they watched, asking clarifying questions, offering information that built on the focus teacher's descriptions, and sharing their opinions. There were in-depth discussions characterised by long statements and shifts from the specific to general principles as teachers negotiated what the episodes meant in terms of their thinking and practices and in terms of what they knew about the children. Less often, teachers' discussions shifted to focus on macro-level issues impacting on their teaching. 


\section{Chapter 6: \\ Case Study Three: Ngā Rangatahi Tamariki Early \\ Learning Centre}

\section{Introduction}

Chapter 3 outlined the organisation of Ngā Rangatahi Tamariki ELC, explaining that teachers generally taught within a smaller team which resulted in distinctive daily programmes for each of the three groups. Here, data are reported across the whole case study, rather than by each smaller team, except where the uniqueness of specific results to one team make it appropriate to attribute the results to that team. The chapter follows the same framework used to present results for the first two cases, with data organised by the three research questions for this study: 1) teachers' thinking and reflections on their practices; 2) theories, principles of practice, and beliefs underpinning teachers' thinking; and, 3) the influence of the community of practice on teachers' thinking and practices.

\section{Teacher thinking and reflection at Ngā Rangatahi Tamariki ELC}

Teachers' articulation of their thinking and reflection, both -in-action and -on-action, about their practices varied considerably across the wider teaching team. Some teachers expressed significant discomfort at viewing themselves on the DVD (e.g., "It's just horrible looking at yourself, ay?" [CS3/SRI2/E4]) or used humour to alleviate tension: when I asked Summer to tell me when to pause the DVD, she replied, "Could you fast forward it?" [CS3/SRI2/E2]. The reticence of several teachers resulted in higher levels of prompting than was typical in most interviews (e.g., "So you're having some interaction with Toby there, is there anything you're sort of thinking about particularly with him?" [CS3/SRI2/E3]). The extent to which some teachers' discomfort with the process impacted on their ability to articulate their thinking and reflection needs to be considered when examining the case study three data. In addition, the participation of individual teachers in a maximum of two interviews (where some teachers in Case 
Studies One and Two participated in up to five) provided fewer opportunities for these teachers to build confidence and familiarity with the stimulated recall process.

Teachers' reflection and discussion focused on both children's actions and their own practices. Some teachers showed an increasing focus on their own practice, and of the thinking and reflection that underpinned this, during their second interview. Discussion within teams beyond the focus teacher varied across episodes and was predominantly focused on each situation, rather than making connections with previous incidents or discussions.

\section{Knowing the children}

Teachers explained what children were doing, drew on existing knowledge, and described new insights gained about children during the episodes. Teachers from each group described 'reading' children's non-verbal cues in order to adjust interactions. Teachers with the younger infants focused particularly on reading these cues in order to understand children's intentions and to build their knowledge of them as individuals. Analysis of references to Jessie demonstrates how the infant group teachers interpreted her non-verbal cues and adjusted their responses to her (see Table 6.1):

Table 6.1: Teacher interpretations of, and responses to Jessie

\begin{tabular}{|c|c|}
\hline $\begin{array}{l}\text { Analysis of teachers' } \\
\text { behaviour }\end{array}$ & Illustrative examples \\
\hline $\begin{array}{l}\text { Teachers watching the video } \\
\text { read Jessie's signals about the } \\
\text { bottle, and interpret these cues } \\
\text { by connecting to Paige's earlier } \\
\text { comment about the speed of the } \\
\text { bottle's teat. }\end{array}$ & $\begin{array}{l}\text { Bernice: } \\
\text { Could I say something? It just looked like Jessie was trying to hold } \\
\text { the bottle for herself. } \\
\text { Paige: } \\
\text { And I took her hand down. } \\
\text { Alexis: } \\
\text { Looks like she's trying to get your attention, eh? } \\
\text { Paige: } \\
\text { Looks like she's pulling away from the bottle. These bottles, she's } \\
\text { only just gone onto the bottle properly. She's on these new bottles } \\
\text { that are really, really fast and so she sometimes can't.... } \\
\text { Sue: } \\
\text { Can't cope with it. } \\
\text { Paige: } \\
\text { But it actually looks like she's trying to pull away from the bottle. }\end{array}$ \\
\hline
\end{tabular}




\begin{tabular}{|c|c|}
\hline Analysis of teachers' & Illustrative examples \\
\hline & $\begin{array}{l}\text { Bernice: } \\
\text { Cos I remember you saying at that moment...that the bottle's really } \\
\text { fast... } \\
\text { [CS3/SRI3/E9] }\end{array}$ \\
\hline $\begin{array}{l}\text { Bernice interprets Jessie's non- } \\
\text { verbal cue as wanting to } \\
\text { communicate with Alexis }\end{array}$ & $\begin{array}{l}\text { Bernice: } \\
\text { Looks like Jessie is trying to communicate with Alexis. } \\
\text { [CS3/SRI3/E11] }\end{array}$ \\
\hline $\begin{array}{l}\text { Bernice interprets Jessie's cue } \\
\text { as wanting to join in with others. } \\
\text { Paige draws on previous } \\
\text { knowledge that Jessie likes to } \\
\text { be held and supports her to } \\
\text { spend time on the floor by using } \\
\text { her interest in dangling scarves. }\end{array}$ & $\begin{array}{l}\text { Bernice: } \\
\text { Cos she's, but she's too far....I think she's trying to join in there. } \\
\text { Paige: } \\
\text { I think when I placed her down on the ground, she is a bit of a baby } \\
\text { that likes to be held and so the more, the more...that I get given her I } \\
\text { like to put her straight on the ground so that she doesn't feel like I'm... } \\
\text { just been holding her all the time so. I think, and I know she likes the } \\
\text { scarves. I think that's why I placed her on the ground. } \\
\text { Bernice: } \\
\text { Oh fair enough, yeah. But...you weren't to realise that's where she } \\
\text { actually, it looks like she's trying to tell us she wants to be over there. } \\
\text { [CS3/SRI3/E11] }\end{array}$ \\
\hline $\begin{array}{l}\text { Alexis draws on prior knowledge } \\
\text { of Jessie to interpret and } \\
\text { explain her response when her } \\
\text { mother (another teacher) moves } \\
\text { through an adjacent area of the } \\
\text { centre. }\end{array}$ & $\begin{array}{l}\text { Alexis: } \\
\text { Jessie's making noises cos as she was playing there she could } \\
\text { always see her mother walk past. That's why she's making faces. } \\
\text { [CS3/SRI6/E1] }\end{array}$ \\
\hline $\begin{array}{l}\text { Alexis interprets Jessie's } \\
\text { response as lack of interest in } \\
\text { the toy she is offering. }\end{array}$ & $\begin{array}{l}\text { Alexis: } \\
\text { Well she's giving me cues that she, she's not interested so, like for } \\
\text { example...she was looking at me but playing with something. With } \\
\text { me rattling something else I was going to try and to give her another } \\
\text { noise that would stimulate her to roll over but she didn't. } \\
\text { [CS3/SRI6/E1] }\end{array}$ \\
\hline $\begin{array}{l}\text { Paige draws on previous } \\
\text { knowledge of Jessie to interpret } \\
\text { her expression, and respond. }\end{array}$ & $\begin{array}{l}\text { Paige: } \\
\text { I'm acknowledging Jessie as well, she sort of tends to feel left out if } \\
\text { you don't speak to her or things like that. She gives you these looks } \\
\text { so trying to acknowledge her as well. } \\
\text { [CS3/SRI6/E2] }\end{array}$ \\
\hline $\begin{array}{l}\text { Bernice interprets Jessie's } \\
\text { movement as possibly her } \\
\text { mimicking Bernice's actions. }\end{array}$ & $\begin{array}{l}\text { Bernice: } \\
\text { I wonder if her arm came up. I did wonder because when I waited at } \\
\text { the mirror her shoulder came up, in the air slightly and then I did } \\
\text { wonder if she was mimicking. } \\
\text { [CS3/SRI6/E3] }\end{array}$ \\
\hline $\begin{array}{l}\text { Bernice interprets Jessie's cues } \\
\text { about not wanting to continue } \\
\text { with her bottle but chooses to } \\
\text { persist as Jessie has been sick } \\
\text { and she wants to increase her } \\
\text { fluid intake. }\end{array}$ & $\begin{array}{l}\text { Bernice: } \\
\text { I knew she was due for a feed and a sleep and she hasn't been well } \\
\text { so I, sticking, sticking to the times that we could. So she's finishing off } \\
\text { the bottle. } \\
\text { I knew she was trying to tell me that she didn't want it because it was } \\
\text { quite obvious but because she's been sick and she's had urine } \\
\text { infections we've been trying to get the fluid in, but I could hear by the } \\
\text { pitch that that was just not going to happen. } \\
\text { And she always objects a bit before she gives in. So I wasn't worried } \\
\text { about that crying - I knew what that was about. } \\
\text { [CS3/SRI6/E3] }\end{array}$ \\
\hline
\end{tabular}


In each of these situations, teachers interpreted Jessie's actions as intentional, despite her young age (51/2 - 7 months). Teachers viewed Jessie as actively engaged in communicating with them and others in the environment. Bernice took a leadership role in this interpretive process, particularly sharing her understandings with Paige who was less familiar with the philosophical and pedagogical approach used by this team.

When teachers referred to using existing knowledge or described children's actions, they predominantly focused on interactions with teachers and other children and the social and emotional aspects that underpinned these interactions. In the older group, teachers placed an emphasis on children developing social competency (such as turn-taking and sharing resources [e.g., CS3/SRI1/E2]) whilst teachers with the two infant and toddler groups emphasised children's emotional wellbeing [CS3/SRI5/E3] and secure attachments [CS3/SRI3/E6].

Teachers framed their interpretations of children's behaviours and interactions with others positively and negatively. For instance, Juanita commented that Jeremiah "interacts really well" yet later in the same episode described how she started making up nonsense rhymes in response to Anastasia's reading of a story at morning-tea time because:

Jeremiah had actually started barking long before the dog came up and I...thought, "Okay he's starting to...", we know with Jeremiah that it will quickly deteriorate. You know where he'll disrupt the other kids and spoil it for the other kids so that's... why I said, "Oh it's a horse" - ...so that he would, "No it's not!"...to get him, try and get his focus back into it. [CS3/SRI1/E4]

The wider age and developmental range of the children in the older group, together with the dynamics between individual children in this group, seemed to influence the teachers' views of their interactions and behaviour. Teachers commented positively when younger children successfully interacted with older ones during play (e.g., Juanita commented that Katalina "does so well playing with those two girls, eh, cos 
she's so much younger than them" [CS3/SRI4/E1]) as well as noting changes in group dynamics:

Jayde:

I think Sharee's used to just having Whina to herself. Cos they do spend time...

\section{Juanita:}

Yes cos I think there's a bit of a jealousy there, ay?... There's a bit of jealousy there as far as with Katalina.... [CS3/SRI4/E5]

Whilst teachers in the older group at times ascribed more negative intent to children's interactions [e.g., CS3/SRI1/E2], teachers in the toddler and infant groups focused more on safety aspects that arose from, for example, the unsteadiness of newly mobile children who might over-balance and hurt themselves or another child [CS3/SRI5/E3] or the unintentional hurt that might occur as a baby learnt to reach out and grasp something:

\section{Paige:}

I'm telling Jessie to be nice cos she's just realising about her hands and grabbing things... and she can be quite rough....with the other kids if she goes to grab them. [CS3/SRI6/E2]

On several occasions teachers reflected-on-action as they tried to understand what was influencing children's behaviour. For example, Spring identified that Nicholas had recently started hitting other children and wondered whether he was indicating he wanted more challenge and if it was time to think about his transition to the older group [CS3/SRI2/E4]. In the older group, Sharee's determination that Juanita was a boy led to an in-depth discussion amongst the teachers as to what underlay her thinking (see Table 6.2): 


\section{Table 6.2: Teachers' discussion about Sharee's thinking}

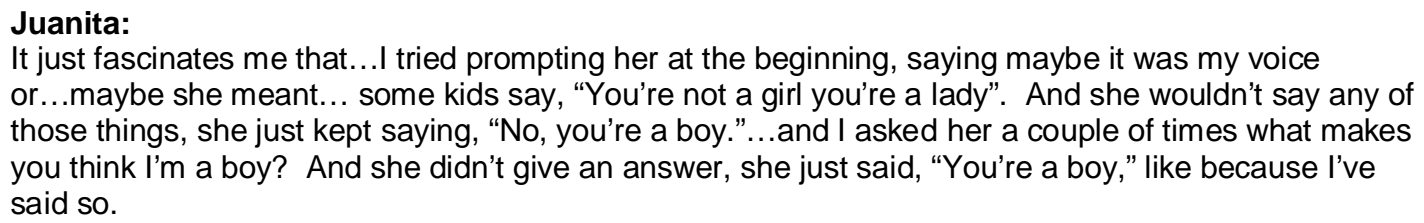

It just fascinates me that...I tried prompting her at the beginning, saying maybe it was my voice or...maybe she meant... some kids say, "You're not a girl you're a lady". And she wouldn't say any of those things, she just kept saying, "No, you're a boy."... and I asked her a couple of times what makes you think I'm a boy? And she didn't give an answer, she just said, "You're a boy," like because I've said so.

\section{Giselle:}

That's that, "I'm right, you're wrong".

\section{Juanita:}

Cos l've said so... it was that whole...

\section{Anastasia:}

With her Nan?

\section{Juanita:}

Yeah, it might be too. Nan's gay, and so maybe... and has a female partner so maybe... Maybe, l've got a deeper voice ...that's why I thought the voice was the thing. Was that maybe she was saying it because of that but like I said she just, and Whina was like "no"...."No she's a girl". "No, you're a boy," she was going so...

\section{Anastasia:}

She wasn't laughing or...

\section{Juanita:}

No, no she wasn't. She wasn't going, "No you're a boy". That's probably why I kept pressing her was to find out what made her, when I go back in a few days I'll be like, "Sharee, you know I'm a girl ay?"

....and I was thinking the camera's right over there, like you were saying the camera's right there and why can't you just...to me or something like, "You know I've got breasts, don't you?"...or whatever, just to, that's what Sue said at the end, "How did you..."

\section{Giselle:}

Hard to find out how far you can take it.

\section{Juanita:}

I mean I just kept thinking what's the appropriate thing to say to her? "For goodness sake..."

\section{Giselle:}

I'm a girl, I'm a girl.

\section{Anastasia:}

Well, even the example with Conrad...that could have prompted it too.

\section{Juanita:}

Yeah absolutely, that's why I said, we're all girls except Conrad... and Whina was like, "Yes"...

\section{Jayde:}

It would have been interesting to see what she says if you'd said, "You've seen me wear a skirt," cos she always comments whenever you wear a skirt.

\section{Juanita:}

Oh yeah true. Maybe I'll wear a skirt on Monday.

(Discussion shifts to talking about another situation and then returns to this episode).

\section{Jayde:}

Could it be also because she's got a new baby cousin and it's just been her for so long with her grandparents and her mum.... and then this new baby's just come along and they seem to be really into the baby? Not forgetting about Sharee but whether or not she's starting to feel, "I have to share".

\section{Conrad:}

Is it a boy?

\section{Anastasia:}

Is it a boy or girl? 


\section{Jayde:}

It's a girl. You know how she's really close to her Nan? I wonder if that might...

\section{Anastasia:}

Though she does know with the harakeke ${ }^{10}$...the boy and the girl magnet, she knows the boy and the girl.

Juanita:

That's what I mean. That's why I'm interested...how you were asking? What were you thinking? What's getting, not the whole...It was more interesting me how she'd come to that conclusion. How she'd absolutely come to that conclusion cos she'd never said it to me before. She's never said...or if we...how we all do, we go, "Oh no, well I'm a boy," then you could understand that and Jeremiah would joke like that, "Oh because you're a boy, oh that's right cos you're a girl," and those kind of things but whereas hers came from completely out of the blue, "You couldn't wait for a prince because you're a boy".

\section{[CS3/SRI4/E5]}

Juanita's description revealed her reflection-in-action during the episode when she explored several possible explanations for Sharee's stance, and considered what it would take to prove her gender to Sharee. Further explanations drawing on their shared knowledge of Sharee were posited by other teachers as they engaged in collective reflection-on-action to make sense of the situation.

Whilst teachers paid significant attention to children's interactions and behaviour during the episodes, explicit references to children's learning interests were less frequent. Activities that the older children enjoyed participating in were identified (e.g., puzzles and socio-dramatic play) as were children's interests in playing with rhymes [CS3/SRI1/E4], playing with particular children [CS3/SRI1/E1], and exploration of "being bigger" than others [CS3/SRI4/E3]. Amongst the toddler group, teachers identified learning interests that children had including climbing [CS3/SRI2/E2], posting objects [CS3/SRI2/E3], and looking at books [CS3/SRI2/E4]. Spring also described documenting two children's approaches to learning: Nicholas was described as "very hands on and touches everything and investigates everything with his hands" whilst "Terrence is very...explorative on his own and will just quietly investigate things" [CS3/SRI2/E1]. Teachers with the infant group identified several learning interests amongst their children, including playing with scarves [CS3/SRI3/E1] and bubbles [CS3/SRI3/E7]. They also identified children

10 Flax bush. 
were learning about relationships with adults and children [CS3/SRI6/E2], building their capacity to spend time on the floor (rather than being held) [CS3/SRI6/E4], and developing the physical skills to move towards and grasp objects [CS3/SRI6/E4].

The age of children in both the infant and toddler groups meant that teachers were frequently introducing children to new experiences and observing their reactions, rather than identifying specific, enduring learning interests. Thus, in one episode, Summer took Charlotte outside to the sandpit:

... and so I got a little tray and filled it up with the wet sand and we sat there
cos it was a nice sunny spot and I thought, "Well I won't take her inside cos it
was a waste of a really nice day". And so we sat there and I showed her the
wet sand and how it could, just had clumps and then there was dry sand there
as well and showed her how it just fell through my fingers. I wasn't too sure
how she was with that but... she wasn't sure about the texture. It may have
been her first time. So I put it on my hand and slowly moved it and then put
her hand on top of it and so she wasn't sure but she was curious. She was
curious enough to touch it slightly. And we just moved from dry sand to wet
sand. [CS3/SRI5/E7]

During such episodes, teachers increased their understanding and knowledge about individual children. Charlotte's situation provided insights into how knowing the child influenced teachers' practices during their interactions. Charlotte featured in episodes in the first infant group teachers' interview but four weeks later had transitioned to the toddler group and featured in episodes used in these teachers' second interview. During the first interview, teachers drew on their knowledge of Charlotte explicitly: in addition to knowing she had quite well-developed fine motor skills for her age and offering her a specific toy to see how she would manipulate it, Bernice described their responses to her interest in vocalising:

\section{Bernice:}

Charlotte's very much into banging. Banging on walls, banging anything. But that verbalised, the noises she's making, that, l'd been going to talk to you yesterday. She's actually in control there because she's got me doing it. She's led that activity. She's made that noise first cos she knows that we will respond back. So my thinking is support that, that confidence in her and that self-esteem that she can contribute to her own learning...And she's a wonderful example. She gets us doing crazy things. Everyone goes round going "pop, pop, pop". It's Charlotte's contribution. That's why we love to copy her. [CS3/SRI3/E6] 
In contrast, in the toddler group teachers' second interview Spring's focus was more on getting to know Charlotte as she observed her interest in:

taking things in and out of the little boxes. And so every time I just piled more nicnaks and stuff into the boxes she'd sort through it and pull little things out which I thought was really interesting and I was thinking that as I was doing it so I kept putting little bits back in.

Spring later commented:

So there's lots of little things that I was noticing as...I was interacting with her and, because she's...new to the group and I didn't really know her at all before she came. So it was quite, I enjoyed spending that time with her. [CS3/SRI5/E4]

In summary, teachers drew extensively on children's non-verbal cues, particularly for younger ones, in order to adjust and match their interactions to the children's. Teachers interpreted children's actions as intentional, regardless of their age, focusing much of their attention on children's interactions and behaviour. This focus on behaviour, especially for teachers with the older children, was influenced by the wider age range of children in this group and the particular dynamics that existed between children. The very young age of most children attending the centre resulted in teachers often introducing children to new experiences, with children's responses to these new situations rather than on-going learning interests at the centre of teachers' thinking.

\section{Teaching strategies and interactions}

Teachers at Ngā Rangatahi Tamariki ELC articulated their use of a wide range of teaching strategies during the interviews. Whilst most of these strategies are common in ECE teaching, their work with predominantly very young children and the adoption of a particular pedagogical approach by the infant group teachers revealed extensive use of certain clusters of interactive strategies. Language used in teachers' descriptions indicated a mix of deliberately versus intuitively selected interactive strategies (see Table 6.3): 
Table 6.3: Ngā Rangatahi Tamariki teachers' use of general ECE teaching strategies

\begin{tabular}{|c|c|}
\hline $\begin{array}{l}\text { Building on } \\
\text { earlier } \\
\text { experiences }\end{array}$ & $\begin{array}{l}\text { Juanita: } \\
\text { We'd been doing work on hands and bodies so really it was the experience of } \\
\text { gloop. They'd enjoyed gloop in the past and in the past we've done things with } \\
\text { smellies and also like yesterday I did the dye, spraying the dye so there was a } \\
\text { couple of...nothing, wowing or scientific or anything like that was purely, part of it } \\
\text { was part of the programming [CS3/SRI1/E1] }\end{array}$ \\
\hline $\begin{array}{l}\text { Supporting } \\
\text { children }\end{array}$ & $\begin{array}{l}\text { Conrad: } \\
\text {...went straight to the table where I saw Jasmine working there in peace by } \\
\text { herself. Because before I saw a group there but they'd left it. And so, but } \\
\text { Jasmine was the only one that stayed there and just continued with it so I thought } \\
\text { l'd just sit with her and just... be with her and to support her in what she was doing } \\
\text { [CS3/SRI1/E3] }\end{array}$ \\
\hline Asking questions & $\begin{array}{l}\text { Anastasia: } \\
\text { And by getting... by asking them questions too and showing them a dog instead of } \\
\text { me straightaway going, "It's a dog" - like getting them to say [CS3/SRI1/E4] }\end{array}$ \\
\hline $\begin{array}{l}\text { Scanning the } \\
\text { wider } \\
\text { environment }\end{array}$ & $\begin{array}{l}\text { Alexis: } \\
\text { For me as a teacher I've learnt to, I mean I'm not there physically but I'm always } \\
\text { looking or scanning to see if that child's okay cos I'm interacting with another child. } \\
\text { So I keep gazing back [CS3/SRI3/E1]. }\end{array}$ \\
\hline Modelling to child & $\begin{array}{l}\text { Bernice: } \\
\text { That is a toy we've had forever. And ever, and ever and not one child turns it. So } \\
\text { I was role modelling cos I know that Charlotte's got quite good fine motor skills } \\
\text { already. Yeah, and yet they won't do it and I was thinking maybe Charlotte will } \\
\text { [CS3/SRI3/E6]. }\end{array}$ \\
\hline Demonstrating & $\begin{array}{l}\text { Storm } \\
\text { I think there I was showing them different ways to use that box cos he was just } \\
\text { using it for like a drum....And showing him how the shapes went in it } \\
\text { [CS3/SRI5/E6] }\end{array}$ \\
\hline Positioning & $\begin{array}{l}\text { Paige: } \\
\text { I think before that I was sitting up and I wasn't at his level and then I....thought, } \\
\text { "Oh, my gosh I should be at his level so that he can see me and he's not straining } \\
\text { his eyes" so that's why I'm on the ground [CS3/SRI6/E2]. }\end{array}$ \\
\hline Suggesting & $\begin{array}{l}\text { Anastasia: } \\
\text {...like me suggesting more to the kids to give them a kind of idea what to do next } \\
\text { [CS3/SRI4/E1]. }\end{array}$ \\
\hline $\begin{array}{l}\text { Conversing with } \\
\text { children }\end{array}$ & $\begin{array}{l}\text { Conrad: } \\
\text { No, it's just that... most of the time it was quite quiet and I...sometimes tried to } \\
\text { make conversations with Jasmine [CS3/SRI1/E3]. }\end{array}$ \\
\hline Singing & $\begin{array}{l}\text { Paige: } \\
\text { Previous times when I've put Leighton to sleep, a lot of the times I've noticed that } \\
\text { he likes to be sung to sleep. He likes some noise, he likes music [CS3/SRI3/E3]. }\end{array}$ \\
\hline $\begin{array}{l}\text { Offering praise } \\
\text { and celebrating } \\
\text { children's } \\
\text { achievements }\end{array}$ & $\begin{array}{l}\text { Summer: } \\
\text { And we celebrate their...like with Toby walking, we might say, "Look at Toby, he's } \\
\text { walking". We'll wait until he's...taken a couple of steps and tumbles over and then } \\
\text { celebrate it. Otherwise he'll just get distracted and he won't try and walk } \\
\text { [CS3/SRI2/E4]. }\end{array}$ \\
\hline $\begin{array}{l}\text { Encouraging } \\
\text { children's } \\
\text { thinking }\end{array}$ & $\begin{array}{l}\text { Juanita: } \\
\text { You're always really good at that though, Anastasia...the words that you use are } \\
\text { really great to encourage them, not just giving them the answer straightaway and } \\
\text { that sort of stuff [CS3/SRI4/E1]. }\end{array}$ \\
\hline
\end{tabular}




\begin{tabular}{|c|c|}
\hline $\begin{array}{l}\text { Offering } \\
\text { alternative ideas }\end{array}$ & $\begin{array}{l}\text { Giselle: } \\
\text { At this point Sharee's trying to prove a point that she's bigger than everybody else. } \\
\text { Juanita: } \\
\text { She said that a few times. "Oh Katalina's little". She said it about three times. } \\
\text { Giselle: } \\
\text { Yeah. I'm lit..."Katalina's not big, Katalina's little, ay?" And so I gave an example, } \\
\text { "But Katalina's bigger than Mere or Daniel" "Yes you are big but I'm bigger than } \\
\text { you as well" } \\
\text { [CS3/SRI4/E3]. }\end{array}$ \\
\hline $\begin{array}{l}\text { Observing } \\
\text { children }\end{array}$ & $\begin{array}{l}\text { Bernice: } \\
\text { That was the scarf that had been moved to the centre, ay, that was on the hook. } \\
\text { Cos I remember thinking that last time she would have played with that it would } \\
\text { have been on the wire, where she could pull it and it would rebound but it was } \\
\text { quite....I was waiting to see if she could actually pull it hard enough to see whether } \\
\text { it would come down cos it wasn't up there very tightly. But I was wondering if she } \\
\text { could see the difference from the day before. Like, "Hey, hang on it's not coming } \\
\text { down"...it was quite interesting to watch [CS3/SRI3/E3]. }\end{array}$ \\
\hline $\begin{array}{l}\text { Following } \\
\text { children's lead }\end{array}$ & $\begin{array}{l}\text { Bernice: } \\
\text {...we were having conversations through the mirror. She was looking at me at the } \\
\text { mirror so I was responding back to her. Because I read somewhere this year the } \\
\text { reason, well a theory is the reason why children like mirrors is because of the } \\
\text { instant gratification they get from...their image in the mirror. See, it's just working } \\
\text { with her with that and watching her to see....I know...they say they don't see } \\
\text { themselves but I wonder with her, just some of her actions and she repeats them } \\
\text { back to the mirror and...I was just watching to see how... [CS3/SRI6/E3]. }\end{array}$ \\
\hline $\begin{array}{l}\text { Responding to } \\
\text { children's cues }\end{array}$ & $\begin{array}{l}\text { Paige: } \\
\text { Charlotte had just put a book, when we just paused before she pushed my hand } \\
\text { away. I went to go and help her and she pushed my hand away so I just sat back } \\
\text { and let her try and do it on her own cos it was obvious that she didn't want my help } \\
\text { [CS3/SRI3/E1]. }\end{array}$ \\
\hline
\end{tabular}

The emphasis teachers placed on observing children closely, following their lead, and responding to children's cues influenced their thinking about their practices in two specific ways. First, teachers described a temporal aspect to their thinking and practices, deliberately considering the timing of their interactions and recognising shifts in children's daily patterns [CS3/SRI2/E4]. Teachers tried to maintain an unhurried feel to the programme to keep children calm [CS3/SRI3/E8] but also delayed responding to children on occasions to help them develop the capacity to deal with moderate amounts of frustration:

\section{Bernice:}

She started to cry but I let her cry because I think that a small amount of frustration is fine. She's got to learn that, and given time Jessie would be fine. We know her well enough now to.... One cry doesn't cut it....Frustration is not a bad thing. [CS3/SRI6/E3] 
At times teachers waited to be invited into children's play [CS3/SRI1/E3], for children to approach them [CS3/SRI4/E7], and to see what children could manage on their own before they intervened:

Paige:

I, at that point, wasn't helping her cos I was trying to see what she could accomplish on her own. So at the moment I'm not helping her but I think I do. But I...wanted to see how far she could go and what she could do on her own without help from me. [CS3/SRI3/E1]

Second, teachers made conscious choices about whether to intervene, and the extent of their intervention. Giselle described Sharee's engrossment in an activity and her decision not to intervene and disturb her exploration, beyond checking that Sharee was all right on her own [CS3/SRI1/E1]. Paige described her reflection-inaction as she initially went to move Jessie closer to a book she wanted but then realised what she was doing and held back [CS3/SRI6/E4]. Anastasia discussed her use of different strategies with three children completing a puzzle together, where she tried to offer individualised support to each child without dominating the interactions [CS3/SRI4/E1]. Paige shared her thinking when she moved an object closer to a child so it was within the child's reach if she stretched for it [CS3/SRI6/E4], and Bernice described her intention to "be there" for a child without intervening in her play:

And I'm also not talking a lot...I don't have to talk a lot, I can just be there. Just be, yeah. Without interfering with what they're doing by talking and then that takes their attention away from their thought process...looks like you're doing nothing but you're actually doing something. [CS3/SRI3/E6]

At other times teachers proactively engaged children in interactions and in play situations. Teachers described engaging children by offering resources [CS3/SRI5/E1], inviting their contributions [CS3/SRI1/E4], being aware of children on the periphery of play experiences [CS3/SRI3/E6], acknowledging their presence and inviting their participation [CS3/SRI6/E2]. Teachers described re-gaining children's attention [CS3/SRI1/E4] and maintaining their interest in activities [CS3/SRI6/E4]. In addition to regularly introducing new materials to the children (described earlier in this 
chapter), teachers encouraged children to engage in parallel play [CS3/SRI1/E3] and created opportunities for them to interact with other children:

Spring:

....probably just really...trying to get as many kids involved in an activity so that they're involved in something. I suppose just using them to include the other kids and using the boxes to try and change it and keep their attention... They were obviously interested and it was like a sort of group thing... to get the children playing with the same toy as a group. That's something that some of our kids don't really do. They don't foster friendships with each other.... [CS3/SRI2/E1]

A particular feature of the infant teachers' practice was the way in which they described their intentions to the babies and involved them in decision-making (e.g., Alexis asking Charlotte if she had finished with her piece of toast [CS3/SRI1/E2]). Alexis described it thus: "Even though the babies are babies you still have to acknowledge what you're doing. Like when I put his pants on I tell him every process. That's what I was doing" [CS3/SRI3/E10].

Teachers described using eye contact to let children know of their availability [CS3/SRI3/E6] and mimicking children's actions or speech to show their awareness of children's interests [CS3/SRI1/E1]. They described instances where they cuddled children to help them transition into play after a sleep [CS3/SRI2/E2] or used physical contact to sooth and calm a child [CS3/SRI6/E2] or to strengthen the developing relationship between themselves and the child:

\section{Bernice:}

I do remember thinking that as I stroked his hand I was...to be gentle and I was just giving him that touch. He actually held my hand for a long time after that. His hand lay in, kept that gentle, but he was very gentle with it. Though mimicking maybe the touch?... Had he made that connection? I don't know. It was nice to see it in action though. [CS3/SRI3/E10]

The young age of most children meant that many interactions took place during routine events such as feeding, changing, and settling children for sleeps, and supporting them through transitions into the centre and between play and routine events. Teachers described specific strategies used to encourage children to take a 
bottle [CS3/SRI3/E4], bring up wind [CS3/SRI3/E9] and settle for sleeps

[CS3/SRI3/E8], and for managing transitions when mothers left the centre:

Spring:

And then I noticed, I was looking at Charlotte and her mum kissing. Her mum was going "Kiss" and she was giving her kisses so then when her mum left that's what I'm doing with the animals, I'm giving her kisses on the cheeks to just...do what her mum was doing. And she did so start to kiss the animals back...And so when I first got her from her mum I was sitting up with her higher and distracting her and then I sat down on my bottom and she was on my knee and then the next bit I put her down on the ground so I just... did it slowly so that, almost so she wouldn't notice that that was how I was going to distance myself from her. [CS3/SRI5/E4]

Children's health and safety influenced teachers' thinking and practices: teachers described organising the physical environment to protect children from falling [CS3/SRI2/E2], keeping infants out of the direct sun [CS3/SRI5/E7], and ensuring that children were warm enough when they played outside [CS3/SRI5/E2]. Teachers also articulated several strategies used to guide children's behaviour including reminding children about being gentle with others [CS3/SRI6/E2] and to avoid intruding on others' space [CS3/SRI1/E1]. Teachers reminded children to take turns with resources [CS3/SRI4/E3], sometimes modelling sharing equipment [CS3/SRI1/E2]. Distracting children [CS3/SRI6/E4], re-directing them into other activities [CS3/SRI4/E5] and ignoring behaviour were other strategies teachers chose to use:

Giselle:

I offered for him to come and play and I offered him the train... and because he couldn't have the train that Daniel was playing with he then sulked. And I said to him, "When you're ready to get up you can come play with us". And so I just left him. As you said, he would then get up and he goes to Juanita.

Sue:

And that's a kind of consistent way you would...manage with him?

\section{Juanita:}

Yeah. He always used to, we discovered that he would do that especially if he'd hurt somebody else. So he would hurt somebody then he would throw himself on the ground which of course got him the attention and off the person that was hurt so we decided to just ignore it...make sure he was safe but just ignore it basically. Or, you know, pick him up and move him to somewhere else without talking to him. And...he's still doing it but it's not for as long or... before he'd actually bang his head on the ground or on the concrete or... And it was purely to get that attention. ...so now you see it in a few minutes 
he's, what's that ad where they say a tantrum's not much fun when nobody's

watching. You know the ad...he's got to that point. [CS3/SRI1/E2]

In summary, these teachers described using a wide range of teaching strategies during interactions with children, selected both deliberately and intuitively. Several clusters of interactive behaviours were especially apparent, including their focus on observing and responding to children's cues and following children's lead. Teachers considered the timing and extent of their interactions, at times electing not to intervene or to do so unobtrusively whilst at other times being proactive in engaging children's interest. Due to the young age of most children, teachers engaged in many interactions within routine events and transitions and were concerned with children's health and safety.

\section{Insights gained from the stimulated recall interview process}

The video-SR interview process enabled teachers to gain new insights about aspects of their practices as they viewed and discussed the recorded episodes together. For instance, in the first interview Juanita noted that Jasmine was on the periphery of the group playing with the train set with Giselle, seemingly wanting to participate. When the teachers were invited to add any final comments, Juanita shared how the episode had caused her to reflect on her own practices:

\section{Juanita:}

What it did for me was actually...I just keep watching Jasmine. I know the thing was between you and Daniel and...but I kept watching Jasmine and thinking....

And it...made me think about when I'm working with children to actually think about, who might be standing out there not knowing quite how to join you...that's what it made me think, oh when I was watching Jasmine my eyes were, I kept thinking, "Oh well, she tried"...she held the duck and Giselle acknowledged the duck and all those kind of things. But she...didn't know how to join in, I don't think. [CS3/SRI1/E2]

During the second interview with the older group teachers, Juanita returned to this episode as part of a broader conversation about the learning that had occurred for these teachers as a result of their involvement in the research. She commented about the reminder the episode had provided for her own practices: 
I actually have since the last one, thought l'd look, actually look to see if Jasmine's okay. If she's not just wandering around trying to fit in somewhere. So just those things are the things it's great to have a reminder of. Look, actually looking around, not just in the group you've got sitting beside you. [CS3/SRI4/FR]

Her insights were shared by Giselle who articulated the changes in her own practices that had occurred as a result of that episode:

That's what I found this time, "look outside the box"...like I looked over and saw Jeremiah and beforehand I asked Jeremiah if he was okay and he was like, "I'm fine," and it was like "Okay, then, you can just stay there then". I made sure that everybody was okay with the group that I had but I also made sure that [if] there was another child in the room and I made sure that they were okay and if they wanted to join they could have come and joined us but they were fine but so - looking outside the box that's what I found from the last time with Jasmine. [CS3/SRI4/FR]

The stimulated recall process enabled teachers to re-evaluate current perceptions. Both the toddler and the older group teachers gained new insights into their mealtime routines, events they said felt "more chaotic than actually seeing that" [CS3/SRI1/E4]. Early in the toddler group lunchtime episode, Spring commented, "That was quite a hectic lunchtime actually", stating that children sitting at the table had constantly gotten up and that there were lots of children in highchairs to feed. As the episode proceeded, Summer noted "it's interesting that the kids actually sit quite nicely at the table. Whereas looking at it now...I think, because we're so busy all we see is them getting off the chair" [CS3/SRI2/E5]. Later in their discussion they noted that two of the children sitting at the table, rather than in highchairs, had only been doing so for about a week, altering their perceptions of these children:

\section{Spring:}

I think this has...highlighted to me about the children that...the things that you miss when you're busy...

\section{Summer:}

And the capability that they actually have. [CS3/SRI2/E5]

Part of the value of the stimulated recall process for the teachers was the emphasis on their own thinking about their practices. In the final reflection in their second interview, Anastasia shared her thoughts about the process: 
And it's good cos...usually when I used to watch videos I would be quite scared to say, "This is what I was doing," and these have been good cos I've...voiced what I was doing. Cos some other person will say, "Well, how come you didn't do that?" Rather than hearing me out and go, "Oh that's what I would have done," or I mean, "You could have done this." [CS3/SRI4/FR]

In summary, teachers' descriptions of selected teaching strategies revealed their interactions spanned the continuum from non-interventionist through to actively engaging children in new learning experiences, with their decisions often based on careful observation and reading children's non-verbal cues, and a philosophy of following children's lead. Teachers' respect for children was evident, as was a strong focus on ensuring children's well-being through paying attention to health and safety aspects.

\section{Beliefs, principles and theories underlying the Ngā Rangatahi}

\section{Tamariki ELC teachers' practices}

This section of the chapter turns attention to the second research question, namely the beliefs, principles and theories that underpinned the Ngā Rangatahi Tamariki ELC teachers' practices. Transcripts were examined for statements that indicated, explicitly or implicitly, the values and knowledge that informed their practices. Discussion in the previous section on teacher thinking and reflection has acknowledged several influences on teachers' views about children and on how they perceive their practices. For example, teachers viewed children as acting intentionally and drew on their theoretical knowledge about child development, attachment theory and guiding children's behaviour to inform their practices. These aspects are not discussed further here.

Two specific themes stand out concerning the beliefs and theories that underpinned these teachers' practices, and are reported here: first, the influence of the RIE-Pikler philosophy on the infant teachers' practices, and second, the valuing of the team aspect evident in the older group teachers' data. 


\section{The influence of the RIE-Pikler philosophy on the infant teachers' practices}

The infant group team were influenced by the RIE-Pikler (Gerber, 1979; Gerber \& Weaver, 2002; Resources for Infant Educarers, 2006) philosophy of care and education for infants which they had adopted early in 2009. Bernice was the most knowledgeable about this pedagogical approach, having experienced it on practicum during her teacher education programme and undertaken further professional development, and on several occasions offered feedback to Alexis and Paige about their practices being congruent with the philosophy. Teachers referred also to Baby Moves (Hermsen-von Wanrooy, 2002) when articulating their decisions about how they held the babies and placed them on the floor. In addition to their descriptions of attending to children's cues, seeing children as intentional, describing their actions, and 'being there' for children (referred to earlier in this chapter), teachers described the conversational nature of their interactions with the infants that drew on children's physical responses [CS3/SRI3/E1] and developing trust between infant and teacher [CS3/SRI3/E1].

Teachers described waiting for infants to make decisions. Although not always easy, Bernice described the impact of this approach:

...cos I know the hardest thing [with RIE] we found was to sit back and allow children to be, make their own decisions and not interfere but now...I can do it quite well. I don't have too much problem doing it now. But it's...we're seeing the fruits of our labour. We're seeing children...we compare them to how they were last year: similar ages and how much more content and persistent and their problem solving. Whereas the last year, it was like "waaaaa" and we attended them straightaway...so we didn't give them that time but I think we're seeing it in Jessie, we're seeing it in Jacob, we are seeing it in the older ones. It's like, "Wow, this has all been worth it"... because they are making choices without us. [CS3/SRI6/E4]

Bernice went on to comment on other challenges to their practices that they had faced:

There are people growl you, ignoring them....But actually you're giving them skills and giving them the space to learn those skills and discover their own strengths and work on them... But I know that frustration was the hardest one for me to deal with at the beginning... but now I'm quite comfortable to have a child reach a certain level of frustration before I actually interject and think, "Well, you're not happy"...time to stop that now. But it's healthy to have some frustration. [CS3/SRI6/E4] 
In addition to being able to cope with moderate levels of frustration, teachers believed their infants were staying engrossed in activities for longer, were more confident and not so reliant on adults, and were making successful transitions to the toddler group [CS3/SRI6/E4] as a result of their implementation of the RIE-Pikler approach.

These teachers' adoption of an explicit pedagogical stance appeared influential in their ability to analyse and articulate their thinking and practices, both in-action and on-action, with multiple examples where they described the reasoning behind their actions:

\section{Paige:}

The reason why I picked him up was because he was starting to get fidgety and thinking he was hungry. The reason while I'm holding him towards me was because actually I recently just read that it's best to hold babies towards you instead of away from you for that relationship purpose. [CS3/SRI6/E2]

Interview data also revealed these teachers' willingness to reflect on and critique practices within the team. They described regular on-going discussions and reflection within the team arising from the process of implementing this new pedagogical approach in order to develop a shared understanding of new practices [CS3/SRI6/E5]. Individual team members recognised and self-critiqued when they reverted to practices inconsistent with their newly adopted philosophy [CS3/SRI6/E1].

\section{Valuing the team ethos: The older group teachers' beliefs}

Whilst all three teams articulated the importance of teamwork, the older group teachers highlighted and celebrated working closely together as a team, making reference to team aspects throughout both interviews. They identified that individual teachers' different styles collectively meant the children were offered richer experiences [CS3/SRI4/FR] and described how they worked together to achieve their programme goals. For instance, in describing his thinking whilst leading the morning tea routine, Conrad shared how this worked in practice: 
And you can actually see the team working in there and like when I actually turn to do the Milo and have Anastasia behind me dishing out for the kids that were calling out, "Oh, who wanted more toast?" and then when I switched over she'd come over and taken and handed out the Milos and then you got Jayde and them on the other side who were tending to the needs of the children... [CS3/SRI4/E2]

Although one teacher might be responsible for leading a group activity with the children, other teachers acknowledged they had a responsibility to support that teacher. As Juanita described it, "if all of you are there then all of you should manage it for the person who's doing it...none of us should just be sitting there watching Anastasia take it" [CS3/SRI1/E4]. Later, she melded this concept with the notion of distributed leadership:

I'd like to think that it's not about being the leader, it's about being, "Who is the leader today?" Do you know what I mean, it's like I said about Anastasia with the [morning tea time], for me it's me sitting there managing the rest of it so that Anastasia can do her bit, or Jayde can or Conrad and so on and so forth. [CS3/SRI1/FR]

Being able to read each other's cues and step in to offer support was another aspect of teamwork these teachers valued. Anastasia described an example: "... if I see Jayde, like she's looked at me and l've looked at her and I know then to step in and not leave her with the group" [CS3/SRI1/FR] whilst Juanita referred to hearing a colleague's tone of voice or the children's voices rising and being able to say, "Look, actually, you need to walk away now, because this isn't going to work and you're not going to stop this. I need to take over and have a change of guard really" [CS3/SRI1/FR]. Whilst such offers were not seen as taking over or suggesting that the teacher was not coping, teachers acknowledged that it was harder for some teachers to ask for help than others [CS3/SRI4/FR].

The interview process highlighted that individual teachers sometimes got placed in situations where support from their colleagues was not readily at hand. In one episode Jayde had been with most of the older group children in a small outside area separated from the main playground, and had juggled keeping two children safe whilst they climbed ladders to look at plants and a garden ornament at the top 
of a clay bank whilst another child was upset and two further children were arguing. The episode was chosen for use in the interview because of the multiple interactions demanded of Jayde. Whilst the other teachers acknowledged how well Jayde had managed the situation, it highlighted to them that they had not been there to support her. At the end of this episode, Juanita commented:

\begin{abstract}
We need to look more at where is somebody and who's around me and what I take is "Well, us three are here but actually most of the children are out there with Jayde"...that kind of thing that, looking around the corner rather than...cos that is exactly what takes away from those...teachable moments. The moments that you did have were then completely lost by all that. You were having to stop a fight and then your child comes back screaming and crying at your legs and...those things are probably something as a team we need to "Where were we?" What were we doing when you were there? [CS3/SRI4/E4]
\end{abstract}

The value teachers placed on the team ethos seemed to support their reflection and critique of themselves, individually and collectively. The final section of this chapter focuses on how the community of practice that was Ngā Rangatahi Tamariki ELC influenced these teachers' thinking and reflection about their practices, including their willingness to engage in reflection and critique.

\title{
The influence of a community of practice on teacher thinking and reflection
}

This section of the chapter reports data regarding the third research question, specifically those aspects of the community of practice that was the Ngā Rangatahi Tamariki ELC teaching team, and the influences that this had on their collective thinking and reflections about their interactions with children. Interview transcripts were examined for patterns of alignment behaviours used by teachers, and for the ways that they negotiated meaning about their thinking and their practices.

Teachers at Ngā Rangatahi Tamariki ELC engaged in the co-construction mode of teacher discussion more frequently than teachers in the other two case studies, primarily due to excellent teacher:child ratios and the physical environment of the centre. These factors meant that teachers worked in close physical proximity to each other; 
several episodes involved two or more teachers, with each contributing their thinking about their practices and co-constructing understandings of the situations.

\section{Alignment behaviours amongst Ngā Rangatahi Tamariki teachers}

Several alignment behaviours reflecting how these teachers worked as a community of practice were identified, including indicating agreement, finishing each other's sentences, humour and using language that indicated a team approach. The previous section of this chapter has outlined the strong value placed on teamwork by teachers, particularly those in the older children's group.

Examining the language used by all teachers showed that collective pronouns (such as "we", "us", "our" and related conjunctions) and "team" were often used. Team leaders made use of such collective pronouns more frequently than the members of their teams, perhaps as a strategy for inculcating the lesser qualified newcomers into the social practices of the community (Wenger, 1998). References to "my team" were made more frequently by teachers with less experience and/or training, suggesting high levels of alignment and engagement in the team, despite their more 'junior' status.

These teachers used humour readily during the interviews. In addition to using humour as a device for acknowledging anxiety about the interview process teachers explicitly described using humour and laughter as a team device for coping with the challenges of teaching and for building team cohesion. Juanita commented [CS3/SRI1/FR] that "I think that that's the other part of us as a team is that we laugh with each other, we laugh about each other and we...bring that into our teaching" before adding that using humour helped when team members made mistakes.

Most instances of teachers indicating agreement were in response to what another teacher had said about children. Teachers also indicated agreement around programme aspects such as the organisation of events like morning tea and their relationships with parents: 


\section{Paige:}

Like I notice that...some of the times if I'm sitting there talking to Susie [parent] or something and she's got a problem with one of her children, and then I'll relate those problems back to my own children and say, "Well these are the things that worked for me. You know, like maybe you can do...."

\section{Bernice:}

It's that partnership, isn't it? As well.

We're in a really special, we can play a special role outside the normal early childhood education role. Where we...have more of an influence over our parents. [CS3/SRI3/E5]

Identifying with what had happened in an episode enabled teachers to demonstrate understanding of their colleagues' experiences. For example, Anastasia empathised with her colleagues after they identified the challenges in helping some children settle for their sleep after lunch:

It's hard when you know that you've got a relationship with a child and they think its playtime when it's really sleep time. Like she'll just keep looking and laughing but I'm like, "Lie down and go to sleep." [CS3/SRI4/E6]

On occasions these teachers used the alignment behaviour of finishing each other's sentences. These instances usually indicated shared understandings of individual children and of team processes, such as when Conrad finished Juanita's sentence about a child:

\section{Juanita:}

He just sat there. Just sat there the whole time doing that for quite some time. I think, almost the whole session he sat there doing that. Which actually isn't...him. Usually...

\section{Conrad:}

He's one to come and go. [CS3/SRI1/E1]

\section{Negotiating meaning within the teaching team}

Transcripts were examined to see how teachers worked together to build common understandings about their practices based on what they had observed in the videorecorded episodes. Negotiating meaning involved coming to a common understanding of what was going on during the episodes and making sense of their practices and of the children they taught. Within the Ngā Rangatahi Tamariki ELC 
team each team leader played an influential role, especially in terms of clarifying what was happening, offering information and opinions, and critiquing practice. Team leaders made more frequent contributions to the discussions than other team members as teachers negotiated meaning about the episodes.

In the older group interviews the interactions between Juanita and Anastasia, another senior member of the team, were particularly influential in the process of making meaning about episodes. Clarifying questions were mostly asked by Juanita, usually focused on what children were doing (e.g., "Is that Theo crying?" [CS3/SRI1/E3]); she also offered information or her opinion more often than other teachers. Most instances where teachers offered information or opinions focused on individual children such as Juanita's comments to Anastasia about Sharee:

\section{Juanita:}

She seemed to take from your lead too, Anastasia where she, after a while she stopped being the, "Oh this goes here and that goes there"...

\section{Anastasia:}

Yeah.

\section{Juanita:}

And I think that the thing, the catalyst was the fact that she got a couple of bits wrong and when you said, "Oh, there's a gap there, do you think that goes there"...she...sat back after that. She was like, "Oh, heck, maybe I don't know". [CS3/SRI4/E1]

Within the toddler group interviews Spring, the supervisor, made significantly more contributions than other teachers. Overall, these teachers were quite reticent in sharing their views about what was happening in the episodes, whether as focus teacher or as observer. They seldom asked clarifying questions or offered their opinions or further information. When these did occur they focused on children rather than teacher practices (e.g., Storm's comment about the influence of a nice day in late winter: "I think it was cos the kids hadn't been outside. Like all year and they were just exploring, I think" [CS3/SRI5/E7]). 
These teachers described what was happening in the situations more often than they shared what they had been thinking about, such as Summer's description of her interactions with children who had just woken up from their afternoon sleep:

\section{Summer:}

Kerrin had a big sleep and she got up really happy and...she doesn't really do that much. So I was giving her a cuddle. I was also looking out for Toby and Kristina's safety cos they're climbers. Especially Toby he'll just climb right over if he could. So I was...just...checking back towards the barrier just to keep my hand there so they don't go over or fall over.

It's always really cramped, eh. They're always right on top of each other.

\section{Spring:}

Very good multitasking, Summer.

\section{Summer:}

At that stage I had ended up taking the chair away cos they just kept climbing up there. But I was still looking out for their safety and doing Kerrin as well. As well as looking out for Kristina just...a once over around the room. Not excluding anyone. [CS3/SRI2/E2]

In this team, most detail about teacher thinking during interactions was provided by Spring, as in this example where a toddler, Kristina, was "reading" a book to her:

\section{Spring:}

I deliberately didn't talk to her for a little while. I just wanted, she was quite happy to sit next to me and read and I actually was thinking like usually I, maybe I talk too much, that might be my problem. This particular time I decided I'm just going to sit there and see what she does and actually let her read it to me and it's...just be there for her if she needs me.

And when I did talk I think I tried to not talk much. See there, I was doing the start and I decided to stop with her.

And that's just because I have just been fascinated with Kristina doing that. [CS3/SRI2/E4]

In contrast to the toddler group, all three infant group teachers actively participated in the interviews, describing in detail what was happening in the episodes and emphasising their responses to children's cues. Few clarifying questions were asked, perhaps because they worked in a confined physical space and had been alongside during most episodes used in the interviews. Teachers seldom interjected except to reinforce what they were seeing on the DVD. 
Team leaders provided significant amounts of feedback to other staff members, through reinforcing practices, offering advice, and critiquing practices. Juanita's leadership in this area was evident in the earlier discussion on the team focus within the older group teaching team (see pp. 190-192). In the infant group, Bernice reinforced Alexis's and Paige's practices on numerous occasions; whilst at times this was phrased in general terms (e.g., responding "It was perfect" at the end of Paige's episode [CS3/SRI6/E2]), more often she provided detailed feedback. For example, Bernice gave feedback on Paige's interactions as she prepared to give Jacob his bottle:

\section{Bernice:}

Paige, it was when you were telling Jacob...that you had his bottle ready and I love this - "Do you want to come?" - I love seeing that being used and it's...

\section{Paige:}

I like to see children react like...with this...Jacob...just lay there and then you...can pick up that he gets tired...

\section{Bernice:}

But it's a big thing because you've not been in that group that long and you're getting used to that RIE and what we're doing. But to see you do it is... it was really cool that you gave him..."I'm going to pick you up." [CS3/SRI3/E2]

Spring's leadership was evident in her reinforcement of other teachers' interactions and the advice she offered them, especially with Autumn, an unqualified and rather reserved teacher. Autumn was nervous and had little to say about her first episode, and Spring offered clear advice:

\section{Autumn:}

In this one I'm not really sure what I'm doing with this child, I think, like what I can do...just cos of the camera, really.

Sue:

Yep, so it's sort of making you...

\section{Autumn:}

So it's like...just want to bring an empathy to the kids. 


\section{Spring:}

So you probably could have drawn the kids in more and kept them there by talking to them and creating...stack things on top of that toy. Like Kerrin...just turned around and just looking at nothing cos there's nothing really going on.

\section{Autumn:}

I wasn't keeping them there.

\section{Spring:}

...but like your voice and your excitement for the activities could keep them there. Like..., "Wow, look there's a square!" You know, they'll all go and look possibly. I mean, it's just not always because sometimes [they] don't feel like playing with that. But you know you are a, we are tools, we are toys in the environment as well. That's all, that's all I'm seeing, really, but you were probably just as nervous. [CS3/SRI2/E3]

Spring built on this in the second interview, six weeks later, when she gave the following feedback about another of Autumn's episodes:

\section{Spring:}

I have to say it's more interactive than the last time and you're, we can't hear because there's a lot of other noise but I can see your lips moving now. I can see you...

\section{Autumn:}

Moving around.

\section{Spring:}

Yeah, but you are moving around more and like your head is moving. Like when Charlotte went over there you were doing something but I saw you do look whereas in the last one I think that was limited. So I definitely see a change, ay? And you might not be talking as much to keep them involved but you're tapping things and touching things and...here comes Pita and you welcome him.

\section{Storm:}

Yeah cos you're scanning the room...just checking up on everybody.

\section{Spring:}

And even where you're sitting, your back's to the wall which is better as well. And you got a stash of tissues. [CS3/SRI5/E1]

A characteristic of the $\mathrm{Ngā}$ Rangatahi Tamariki teachers was their willingness to critique their own and each other's practices. The episode, described in an earlier section of this chapter, where Jayde was left managing children by herself was the catalyst for extensive critique amongst teachers about their practices and their 
collective responsibility to check whether other teachers needed support. Teachers also critiqued themselves as they watched the DVD, as in this example involving Bernice:

I think...I could have lowered that book for her to have a look at. Now that I look at it....Cos now I can see she was actually trying to look....And I've missed that.

And... is it because I'm seeing it from a different angle that I...? Cos I'm so busy blowing bubbles and watching their faces and not actually realised she's lifted herself quite high. Mmm, it's interesting. [CS3/SRI3/E6]

Teachers also critiqued their colleagues' practices as they watched the recorded episodes. In this situation Alexis suggested that Bernice had misinterpreted an infant's cues that he is ready for a sleep:

From where I was sitting I could see that he wasn't ready, I mean, not that I'm saying that she's trying to put him... but we would, we read them all to see if they're ready to go to sleep. That's why Bernice was doing that. But for me, if that was me I wouldn't put them down because he was... moving like that would indicate, I'm reading their cues, that they're not ready. [CS3/SRI3/E1].

In summary, each of the three smaller teams within Ngā Rangatahi Tamariki ELC had a mix of more articulate, confident teachers and quieter, more hesitant teachers, and this influenced how they collectively worked as a community of practice. Whilst fewer alignment behaviours were observed during the interviews, and not all teachers contributed their views when discussions turned towards making sense of the episodes, there was a strong sense in each group of the value they placed on being a team and of their feelings of inclusion within the team. Team leaders appeared to play an important role in fostering this sense of inclusion through, for example, using inclusive language, actively trying to make sense of what was happening in the episodes, and offering feedback, both affirming and critical, of their colleagues' practices. 


\section{Chapter 7: \\ Discussion and implications}

\section{Introduction}

This chapter discusses the results for each case study presented in the previous three chapters, together with cross-case analysis of key themes emerging from the cases. The chapter begins by discussing the types of reflection that participating teachers engaged in along with the overarching focus of their thinking. Following the pattern used in the presentation of each case study, the discussion of results is then organised by the study's three research questions:

- What do teachers in the three case study centres think about and reflect on with regard to their interactions with children?

- What guiding principles, theories, and beliefs underlie these teachers' practices, and to what extent are these articulated or implicit?

- How does being a member of a community of practice influence teachers' thinking and reflection on their teaching interactions?

Methodological issues, the limitations of the study, and the implications of this study for ECE teaching practice and future research are also considered before the chapter concludes with a summary of the contributions of this research.

\section{Teacher thinking and reflection about their interactions}

This section begins with an overarching discussion on the different modes of thinking and reflection that teachers engaged in before shifting focus to the content of teachers' thinking and reflection, namely, children as their core focus of attention, teachers' own teaching intentions and use of teaching strategies, and the busy nature of teaching in ECE settings. 


\section{Teacher modes and patterns of reflection}

This thesis began with a discussion of the key influences on my thinking and the assumptions that underpinned this research, including my belief that effective ECE teachers deliberately thought about and selected teaching strategies and interactive behaviours whilst they were engaged in interactions with children. Schön's (1983, 1987) distinction between reflection-in-action and reflection-on-action provided a conceptual framework for explaining my view that teachers actively thought about their teaching during interactions as well as after the event whilst video stimulated recall seemed an appropriate methodological approach to use to elicit teachers' thinking about their interactions with children.

Schön's $(1983,1987)$ definition of reflection-in- and -on-action presents these as generally temporally separate activities. The former is concerned with reflection in the moment of the activity, often in response to the unexpected, as the practitioner reflects on implicit understandings "which he surfaces, criticizes, restructures, and embodies in further action" (Schön, 1983, p. 50) and which result in an immediate shift in practice. In contrast, reflection-on-action generally takes place after the event and does not affect the original episode.

The use of group interviews for the stimulated recall process influenced teachers' reflection in several ways (see pp. 234-235 for further discussion on methodological issues). In addition to individual teachers sharing their thinking and reflection during the episodes as is intended with this methodology, teachers also engaged in individual and collective reflection-on-action on the episodes. Attempts made during analysis to code data as reflection-in-action or reflection-on-action proved problematic (Gass, 2001): teachers did not always use the past tense to describe what they were thinking about at the time but often described their thinking as though they were there in the moment, for example: 


\section{Rachel:}

And I think it's, instead of being the teacher here and doing a "what dinosaurs are all about" and trying to extend there it was just about play, just about playing with him and relaxing...he just wants adult company here...the closeness... and we really are just going in and out of those wood piles in there that have been set up. There we go....and Alastair is here. Thinking "Here we go, the interactions might start here" - awareness of Edward coming in...see Edward's coming in with another agenda in here - it's fire and quite a power, powerful statement. I'm not sure where he wants to take that, again...Just trying to get some language in there with Edward as well, extend that language a little bit, getting a little bit more contact...but really Jacob really wanting my company and pulling back - getting quite cross with me and saying "I just want to play." [CS1/SRI1/E1]

This descriptive in-the-moment style and the inclusion of substantial background detail by many teachers provided context for other teachers (and me) to understand more fully what was happening in the episode. Calderhead (1987) interpreted the offering of similarly high levels of background information by student teachers in his study as their attempts to, first, help the researcher comprehend their thinking and, second, to put their "non-verbal thinking into words" (p. 186). In the context of these group interviews, offering information to help others understand their thinking and actions was understandable and helpful.

The above description also reveals that in the moment of teaching, Rachel had specific learning intentions, responded to the children's cues and chose her interactive strategies, but the situation did not contain the required element of surprise to produce reflection-in-action as Schön (1983) described. Thus, whilst Rachel was actively thinking, this lack of surprise within the episode meant that reflection, in terms of an evaluative response of the effectiveness of her teaching, was not provoked.

Whilst there was some evidence of teachers' reflection-in-action (e.g., how Jane managed the challenge of several children wanting her attention at once [CS1/SRI1/E3], Diana's realisation that she was responding to Peita differently than to other children [CS2/SRI4/E1], Juanita's surprise at Sharee's insistence that Juanita was a "boy" [CS3/SRI4/E5]), Schön's (1983) definition suggests that most of 
what teachers thought about during their interactions cannot be described as reflection-in-action. Instead, much of these teachers' thinking is more accurately described as interactive thinking (Marland \& Osborne, 1990). Extensive evidence of teachers responding to children based on their knowledge of them and drawing upon principles of practice and their beliefs about teaching and learning (Marland, 1986; Mitchell \& Marland, 1989) was apparent across the three case studies.

Teachers, particularly the Summer Kindergarten team, shifted seamlessly between the three modes of interactive thinking, reflection-in-action and reflection-on-action. The act of describing their thinking and reflections during the episode seemed to provoke reflection-on-action, often in the following sentence. These moves often resulted in teachers' wider, collective knowledge being shared and a shift in emphasis from the specific situation to more general, principled talk (Horn \& Little, 2010) (e.g., teachers' movement from discussing Margaret's attempts to join a group to considering principles underpinning kindergarten practices [CS2/SRI1/E4]) .

Watching the video-recorded episodes together meant that teachers shifted at times from recall of their thinking at the time to engaging in the new act of watching the video (Yinger, 1986). Teachers identified aspects unseen or unrecognised during the actual episode (such as the Ngā Rangatahi Tamariki ELC toddler team's response to watching the lunchtime routine where they identified children's behaviour as much more settled and appropriate than they recalled during the actual routine [CS3/SRI2/E5]). For other teachers, watching the video offered new insights into children's subsequent actions, particularly for part-time teachers and for the Summer Kindergarten team whose teacher:child ratios meant they often did not see episodes that had occurred elsewhere in the kindergarten environment. Such instances served to shift teachers into collective reflection-on-action.

Teachers' rapid shifts between interactive thinking and reflection-in- and -on-action, between individual and collective reflection, and between recall of the episode and 
gaining new insights present a complex tapestry and highlight the challenges in trying to unpick what is actually happening when teachers view video-recorded episodes of their interactions with children. Calderhead's (1987) discussion of the features of teachers' verbal reports is helpful here: he noted teachers included comments beyond their actual thinking in order for the researcher to make sense of their teaching or to express memories of earlier episodes that had come to mind and influenced their decisions. Calderhead highlighted the complexity of teachers' thinking, noting that teachers' reports may include attending to and interpreting cues, attending to immediate and longer-term goals, and having new insights about how best to proceed in the situation. Teachers may also report juggling competing interests, processing information from multiple sources, and using interactive strategies for multiple purposes.

The addition of Marland and Osborne's (1990) concept of interactive thinking alongside Schön's $(1983,1987)$ notions of reflection-in- and -on-action enables a more complete picture of these teachers' thinking about their interactions with children to be revealed. Teachers' constant weaving between these modes of thinking and reflection epitomises the fluidity of teacher thinking, particularly within the context of a community of practice (see pp. 223-233 for discussion of the influence of the community of practice on teacher thinking and reflection).

\section{The centrality of children in teachers' thinking and reflection}

Overwhelmingly, children were at the heart of what teachers in this study thought about and reflected on with regards to their interactions. Children were positioned centrally within teachers' descriptions of what they were thinking about during the episodes, and were the focus of much of the collective discussion and reflection that took place between the teachers, echoing Moyles et al.'s (2002a) findings that early years' practitioners have children "firmly at the centre of their work" (p.118) and perceive their relationships with children to be directly related to effective curriculum facilitation. Teachers valued the importance of strong relationships with children and 
drew on these extensively within their pedagogy (see pp. 209-211 for discussion on how teachers enacted a relational pedagogy within their interactions).

Data reported in each case study revealed teachers knew a great deal about the children attending their centre, both individually and within their family contexts. Teachers readily shared knowledge about individual children as they collectively negotiated understanding about each episode, reflecting both socio-cultural and developmental frames of reference. Teachers' knowledge included children's interests and learning dispositions, and familiarity with their families and events that occurred outside the centre as well as their understandings of developmental aspects such as children's temperaments and personalities and individual children's development within cognitive, language, physical and social domains.

Whilst teachers in each case study articulated extensive knowledge of individual children, there were variations in the focus of knowledge between cases. Teachers at both Moana ELC and Summer Kindergarten expressed deeper levels of knowledge about children's lives outside the centres than teachers in Ngā Rangatahi Tamariki ELC. These variations may be explained to some extent by differences in the teachers' patterns of discussion during the interviews as $\mathrm{Ngā}$ Rangatahi Tamariki ELC teachers widened their discussion beyond the interview episodes on fewer occasions than the other teams. In addition, the considerably younger age of most children attending Ngā Rangatahi Tamariki ELC meant that these teachers were seldom able to gain knowledge about children's lives outside the centre from the children themselves and were more reliant on information from parents and families.

Several studies have highlighted the importance of teacher knowledge about individual children and students (Hedges \& Cullen, 2005; Marland \& Osborne, 1990; Paterson, 2007; Stremmel \& Fu, 1993) suggesting that these teachers' knowledge about individual children was a critical aspect of their thinking about their 
interactions. Siraj-Blatchford et al. (2002) found that the "more knowledge the adult has of the child the better matched their support and the more effective the subsequent learning" (p. 48) whilst Kugelmass and Ross-Bernstein (2000) found that "child referenced" (p. 22) knowledge - knowledge of individual children gained from previous interactions and observations - influenced the verbal and non-verbal interactive patterns of the teacher in their study.

Variations between teachers were evident in terms of their elaboration of knowledge about individual children and in how they expressed their understandings of children's learning. Teachers at Moana ELC and Summer Kindergarten shared the knowledge that they held about children more explicitly and frequently than the $\mathrm{Nga} a$ Rangatahi Tamariki ELC teachers. Whilst some of these differences may be due to anxiety with the video-SR process, they parallel Degotardi and Davis's (2008) findings that practitioners' interpretations of infants' behaviours ranged from descriptive through to deeply interpretive.

Children's transitions within the centre provided interesting insights into teachers' on-going development of knowledge about individuals. Charlotte's transition from the infant group to the toddler group in Ngā Rangatahi Tamariki ELC revealed how teachers' knowledge of her influenced their practices: teachers in the infant group had built up a significant body of knowledge about Charlotte's development and learning interests and were able to engage in reciprocal interactions built on her interests that she initiated. Whilst teachers in the toddler group observed Charlotte's play closely and responded sensitively to her actions as she transitioned into the group, their emphasis was necessarily on getting to know Charlotte rather than on enriching her learning experiences. These episodes highlight how transitions between groups can serve to interrupt children's learning journeys as teachers establish relationships and develop their own understandings and knowledge about individual children. Furthermore, they illustrate how teachers' knowledge, or lack of it, about individual children influences their interactions. 
An episode from Summer Kindergarten highlighted how transitions can also disrupt teachers' knowledge about children. Margaret's transition from the younger afternoon group to the older morning group and her close friend's discovery of a new 'best friend' resulted in a loss of social networks and a consequent loss in confidence. Whilst Poppy had realised that Margaret's "best buddy [has] got a new best buddy and they go causing havoc together and so Margaret is left on the sideline and she's trying to figure out where she can fit in..." [CS2/SRI1/E4], it took the team's combined reflection to update their collective knowledge about Margaret.

Teachers gained their knowledge of children from several sources, most particularly their own observations of, and interactions, with children. Further knowledge was gained from discussions with colleagues about interactions they had had with children, and from conversations with children and their extended family members. Such sources of knowledge parallel those used by primary school teachers in Mayer and Marland's (1997) study where they investigated whether knowledge of students was an important component of teachers' practical knowledge. The effectiveness of such knowledge was found to be influenced by three qualities: its richness, relevance and validity. Data presented in each results chapter in this study indicate that teachers' knowledge of children reflected the first two qualities of richness (i.e., knowledge was holistic and detailed) and relevance to children's learning and development. Mayer and Marland suggest that teachers in their study ensured the validity of their knowledge by accessing most information themselves from direct observation and interactions with students and their parents, as did teachers in this study, and by triangulating their evidence. Whilst the knowledge about children evident in these teachers' descriptions may have met Mayer and Marland's criteria for validity because of its first-hand nature, for the most part teachers' knowledge about children was not subjected to any great level of critique, either by the teacher sharing it or by his or her colleagues. In particular, teacher assumptions and beliefs that may affect how knowledge about children was interpreted were seldom surfaced and discussed. 
Those occasions where such discussions were held occurred most often in teachers' collective reflections, suggesting that opportunities for collaborative dialogue and reflection are important for enabling teachers to critique their knowledge and interpretations about children (see pp. 223-233 for further discussion about the influence of a community of practice on teacher thinking and reflection).

Despite more than one child being involved in most episodes, teachers' descriptions predominantly focused on their knowledge of children as individuals, rather than on groups of children and how they collectively engaged in learning experiences in the centres. Whilst on the one hand this indicates that teachers valued and used their knowledge of children to individualise their responses, it also suggests an individual psychological influence on their thinking rather than a collective, socio-cultural focus. Such findings lend weight to the arguments made by Anning et al. (2009), Cullen (1996) and Hedges (2000) that New Zealand EC teachers are still heavily influenced by developmental theories despite the emergence of a professional and academic sociocultural discourse (see p. $220 \& 240-241$ for further discussion on the influence of $T e$ Whāriki (Ministry of Education, 1996) and the EC assessment exemplars (Ministry of Education, 2004, 2009) on teachers' constructs of children as individual learners).

In summary, teachers in this study readily articulated their understandings and interpretations of children, positioning them at the centre of their thinking and reflection about their interactions. They drew on their extensive knowledge about children and their ability to read children's cues to engage in responsive teaching (Mitchell \& Marland, 1989; Stremmel \& Fu, 1993). Such practices are well aligned with the extensive literature on relational pedagogy (e.g. Papatheodorou \& Moyles, 2008) and effective early years pedagogy (Moyles et al., 2002a; Siraj-Blatchford et al., 2002), and are in line with the philosophical and theoretical underpinnings of $T e$ Whāriki (Ministry of Education, 1996; Peters, 2008). The next section of this chapter discusses teacher thinking and reflection about their teaching intentions and use of teaching strategies. 


\section{Teacher intentions and use of teaching strategies}

Teaching in EC is complex (Hedges, 2000; MacNaughton \& Williams, 2009; Moyles et al., 2002a), requiring teachers to make rapid decisions about which strategies to use to support and extend children's learning (Dockett \& Fleer, 1999; NAEYC, 1997). Across each case study centre, teachers described their use of a wide range of teaching strategies and interactive behaviours (e.g., questioning, suggesting, positioning, scaffolding, describing, directly instructing) which they elected to use on the basis of their existing knowledge of individual children, and which were adjusted in response to children's cues and responses (Mitchell \& Marland, 1989). In addition to identifying specific strategies used, a common theme amongst all teachers was their emphasis on building strong relationships with children.

Teachers' relationships with children were positioned as foundational to their practice, with close attention paid to relational aspects when describing and reflecting on interactions. Descriptions of being respectful, considering power dynamics, valuing contributions and trusting children illustrate the beliefs and thinking that underpinned these teachers' relationships with children. This emphasis on their relationships with children is unsurprising, given its centrality within the current professional discourse and wider literature. Within the New Zealand context, the emphasis on "responsive and reciprocal relationships" (Ministry of Education, 1996, p. 14) as an underpinning principle of Te Whāriki is also evident in recent empirical literature: Brennan's (2007) study of how children were enculturated into a childcare setting revealed the importance of strong relationships between teachers and children. Similarly, Dalli et al.'s (2009) Centre of Innovation project affirmed the value of primary caregiving within a "relationship-based care and learning" (p. 38) pedagogical approach.

Internationally, the importance of relationships within EC pedagogy is well documented, as illustrated by Bowman, Donovan and Burns' (2001) review of research concerning the education of preschool children where they conclude "if 
there is a single critical component to quality, it rests in the relationship between the child and the teacher/caregiver" (p. 322). Several empirical studies also highlight the importance that practitioners place on developing strong relationships with children (Goodfellow, 1998; Kugelmass \& Ross-Bernstein, 2000; Moyles et al., 2002a). More recent constructs of relational pedagogy (Papatheodorou \& Moyles, 2008) provide a theoretical frame for considering these teachers' emphasis on relationships as a core element of their pedagogical practice. Whilst teachers' relational pedagogical thinking and practices differed across each centre, a common explicit respectfulness demonstrated to children that their teachers valued them as individuals within the collective context of the centre group.

Beyond this emphasis on respectfulness, Chapter 4 presented data on the Moana ELC teachers' thinking and reflection concerning their relational pedagogy, particularly around issues of power, trust and participation. Teachers' thinking about these aspects and the interactive strategies that they employed revealed their intentions to engage children as active, powerful participants in learning situations where responsibility for the direction and outcome of the learning situation was shared between teachers and children. In Chapter 5, analysis of the Summer Kindergarten teachers' thinking and reflection revealed their emphasis on the quality and importance of their relationships with children as foundational to children's experiences in the kindergarten, and as the basis for developing on-going learning partnerships. Tensions in enacting relational pedagogy occurred for these teachers in two ways: first, balancing external emphases on specific outcomes (especially concerning literacy and numeracy) with their focus on relational aspects and, second, in ensuring that strong relationships were developed and maintained with all children in the large kindergarten groups, given the 1:12-14 teacher-child ratios across the two sessions. Chapter 6 presented data indicating that the teachers at Ngā Rangatahi Tamariki ELC also used a relational pedagogical approach, most explicitly through the infant teachers' adoption of the RIE/Pikler philosophy (Gerber 
\& Weaver, 2002). Data analysis revealed that teachers' practices, particularly the timing of their interactions and their conscious decisions to intervene or hold back from interactions, were influenced by their close observations of children and attention to their verbal and non-verbal cues. The very young age of many of the children attending Ngā Rangatahi Tamariki contributed to the emphasis on relationships apparent amongst these teachers.

Siraj-Blatchford et al.'s (2002) research into effective pedagogy found that no single pedagogical strategy was most effective but rather that "the effective pedagogue orchestrates pedagogy" (p. 43). Whilst teachers did not always explicitly label their interactions, their descriptions of how they engaged with children revealed that collectively they incorporated a wide range of typical teaching strategies into their practice. Furthermore, their ability to adjust their use of teaching strategies (Hedges, 2000; Jordan, 2004), both with individual children and across groups of children, was evident within each case study. In addition to drawing upon extensive existing knowledge about children to inform their interactions, as noted earlier in this chapter, teachers in each centre actively observed children and read their cues during interactions (Kugelmass \& Ross-Bernstein, 2000). This enabled teachers to engage in "responsive teaching" (Stremmel \& Fu, 1993, p. 341) in which they mediated their own teaching interactions through on-the-spot decisions (Kugelmass \& RossBernstein, 2000; Stremmel \& Fu, 1993).

Across the three case studies, a comprehensive set of strategies was apparent that enabled teachers to read and respond to children's cues. Some of these, such as scanning and being aware of the wider environment, observing children closely, and being unhurried allowed teachers to create a climate and environment where they were alert to, and tuned into, children's play and actions, and thus were more easily able to respond to children. Other strategies, such as adjusting the level of support given to a child or re-framing a problem to help a child consider a different approach to solving it, revealed how teachers made moment-by-moment judgements and 
adjustments in their practice. Rachel's description of "moving forward and back and coming in and out..." [CS1/SRI3/FR] illustrates this as she attempted to get the best "fit" or level of support for each child (Trawick-Smith \& Dziurgot, 2010). The importance of being able to judge when to intervene or hold back, as well as being able to use a range of teaching strategies flexibly, is widely recognised (Chappell, Craft, Burnard \& Cremin, 2008; Dockett \& Fleer, 1999; Goodfellow, 1998; Hedges, 2000).

Whilst teachers across all three cases were explicit about their intentions to engage children in learning experiences and to support children's learning generally, specific teaching intentions were voiced less often. Where specific intentions were articulated, children's learning interests and play agendas were often used by teachers to achieve them. Few learning experiences were identified by teachers as having been deliberately planned in order to meet specific learning intentions, although this may reflect the study's methodology where teachers were asked to describe their thinking at the time rather than their previous planning. The provision of the PMP at Summer Kindergarten is a good case in point, as the teachers' explanation of their intentions for this component of their programme arose out of directly questioning them about this, rather than from their recall of their thinking and reflection during the three PMP episodes. The infant group teachers at Ngā Rangatahi Tamariki, drawing on their adoption of Pikler/RIE pedagogical practices (Gerber \& Weaver, 2002), were most overt in describing their intentions during interactions and actively invited babies' responses to their intended actions, through gesture and verbalisation similar to those outlined by Dalli et al. (2009).

Research into effective pedagogy indicates that the most effective practitioners actively support children to develop strategies for dealing with conflict situations (Moyles et al., 2002a), including supporting children to be assertive, and talk through problems (Siraj-Blatchford et al., 2002). Whilst teachers in each case study actively guided and supported children's behaviour, differences were evident in how they did 
so. The Moana ELC teachers took an active problem solving approach, described by Rachel as intended to shift the focus from "a behaviour management thing to empowering them" [CS1/SRI3/FR], where they discussed with children what was happening, sought the children's solutions and offered their own suggestions. The large group size and subsequent demands on children to be able to turn-take and share resources were influential at Summer Kindergarten. Teachers identified that they often needed to deliberately teach children strategies to successfully negotiate taking turns and to be available as a resource that children could turn to for help when facing difficulties. Within Ngā Rangatahi Tamariki ELC, differences were apparent across the three smaller teams; teachers with the infant and toddler groups focused much of their guidance on supporting children's awareness of their impact on other children as they gained increasing control over their bodies, reminding children to take care and be gentle with others. Several factors, including the wider age and developmental range of children and some challenging behaviours shown by individuals, seemed to influence the older group teachers' thinking and emphasis on children's social competency. Whilst these teachers actively tried to understand factors that might be influencing children's behaviours and used a range of strategies to distract and divert children when conflict was brewing, there were fewer examples where they talked through with children what had happened and how they might resolve the situation.

The discussion of teachers' thinking and reflection about their teaching strategies has focused thus far on those used during their interactions with children. In addition, teachers described thinking about how they organised and maintained the physical environment in order to support children's learning. Such planning and organisation of the learning environment is described as "pedagogical framing" by SirajBlatchford et al. (2002, p. 43) and as "distal guided interaction" by Stephen and Plowman (2008, p.643) and is seen as an integral and important component of effective pedagogy. The provision of an appealing play-based learning environment 
was perceived by teachers as important for provoking interest and engaging children in play, for fostering social relationships with others, and for providing resources that enhanced content learning. The unique characteristics of each centre resulted in specific attention being paid to some different aspects of the environment with, for example, the Ngā Rangatahi Tamariki ELC teachers concerned about protecting very young children, especially when outside. In contrast, the role that places such as the morning and afternoon tea table and the dough table could play in helping children to learn about kindergarten and settle into the large group were noted by the Summer Kindergarten teachers.

Whilst the discussion above has focused on the ways in which teachers in the three case studies thought about and reflected on their teaching interactions in a deliberate manner, the results indicate that teachers' selection of strategies also occurred intuitively; furthermore, there were variations between teachers in their ability to articulate their teaching practices and why they had chosen specific strategies at particular moments. Whereas some teachers were able to clearly describe both their thinking and their interactions, others' descriptions about what was happening in the episode focused on the children's actions to the extent that their thinking and behaviour as teachers remained somewhat invisible. That some teachers found it hard to talk about their teaching is not surprising given the empirical literature suggesting that much of teachers' thinking and decision-making occurs tacitly (Roth et al., 2001; Zeichner, 1994; Zeichner \& Liston, 1996). Within EC contexts specifically, studies have found that teachers struggle to articulate their practices; Moyles et al. (2002a) found that although teachers would enthusiastically talk about children, they had considerably more difficulty in articulating their pedagogical decisions and were taken aback by the range and complexity of their pedagogy revealed through the reflective dialogue process (Moyles et al., 2002b). Stephen (2010) found that although teachers were frequently observed using pedagogical strategies such as scaffolding and co-construction, they found 
articulating their practice challenging, and saw such practices "as "just something we do' and taken for granted" (p. 23). Stephen argued that such attitudes contribute to teachers' reluctance to talk about their pedagogy and limit opportunities to reflect on and enhance their practices.

The differences in teacher articulateness in this study can be explained to some extent by differences in the participants' qualification levels. Although the original intention in the research design was to involve only centres with fully qualified staff, the third case study centre, Ngā Rangatahi Tamariki ELC, included a mix of qualified, in-training and unqualified staff. Whilst generally the qualified staff were considerably more articulate about their practices than their in-training or unqualified colleagues, in line with Moyles et al.'s (2002a) findings, one qualified teacher was reticent whilst another teacher early in her teacher education programme clearly articulated both her practices and her underlying thinking. Similarly, one qualified teacher in the Moana ELC team appeared to find it difficult to articulate her thinking and teaching decisions.

Given that qualification levels on their own do not fully explain the differences between teachers' levels of reflectivity and their ability to articulate their thinking, it is possible that personal factors such as self-confidence together with professional experience and skills in reflection and the dynamics within the team combine to influence teachers' abilities to surface, articulate and critique their teaching practices. A later section of this chapter (see pp. 223-233) discusses the influence of the teams' communities of practice on individual and collective reflections on practice.

In summary, similar patterns of teacher thinking and reflection about their use of teaching strategies and behaviours emerged across the three case studies in three key areas. First, teachers in each case study positioned their relationships with children as foundational and emphasised their use of a relational pedagogy, although the latter was enacted differently within each team. Second, each team collectively used a broad range of typical EC teaching strategies during their 
interactions with children. Third, teachers read children's cues and responded to them sensitively, adjusting their interactions to suit individuals. In contrast, more variation existed between the centres in terms of teachers' articulation of their teaching intentions (although collectively, teachers did not often articulate their specific teaching intentions), how they guided children's behaviour, and how they thought about the physical environment, perhaps indicative of the different organisation and philosophy of each centre. Whilst both deliberately and intuitively selected teaching strategies were evident in each centre, differences in teachers' abilities to articulate their thinking and reflection were also noted, partially influenced by the different qualification levels of staff at Ngā Rangatahi Tamariki ELC.

\section{Multi-tasking and the busyness of teaching}

The busyness of teaching in EC settings was an issue that arose predominantly in the Moana ELC and Summer Kindergarten teachers' discussions. Whilst Ngā Rangatahi Tamariki ELC catered overall for younger children, including very young babies who required highly individualised teaching and care, their ratios were improved over those mandated by regulation. In addition, on several days of filming (during winter months) children's attendances were low, thus improving their ratios further. Few episodes were recorded where teachers juggled interactions with several children, whilst the centre structure (manager, supervisor and three team leaders) meant that managerial and administrative roles were distributed and did not appear to intrude into teachers' time with the children.

In contrast, Moana ELC and Summer Kindergarten teachers made repeated reference to maintaining interactions with several children simultaneously and to balancing their interactions with other roles and responsibilities, including administrative roles and communicating with parents. The organisational structure of Moana ELC meant that Rachel, as supervisor, spent significant periods of time liaising with the parent management committee and in organising enrolments of new children. Other teachers consciously supported Rachel in this role, covering for her 
when she was called away to the phone or became involved in conversations with committee members. For teachers at Summer Kindergarten, two key issues were apparent: first, the challenges arising from working with large groups of children (between 35 and 43 each session) and, second, transitional aspects that resulted from ever-changing groups of children. This latter issue was highlighted by the data collection period spanning five months including the long Christmas holiday break, during which 11 children left the kindergarten to start school, resulting in children transitioning from the afternoon group to the morning group and new children starting in the afternoon session. Although common in New Zealand kindergartens (and some other EC services), working with such large groups of children created tensions for those teachers concerned about the impact of poor ratios on children's access to teachers. Similar findings were evident in Hedges and Cullen's (2005) study where both teachers and parents believed that the group size in the kindergarten constrained teachers' interactions with children.

Stephen (2010) highlighted that teachers faced many tasks in busy settings that influenced how effectively they could support children's learning. In this study, teachers' frequent references to juggling multiple demands, including remembering to pass on information to colleagues and parents, illustrated the complicated nature of EC teaching that is apparent before they even began to think about delving more deeply into children's learning interests. Hedges (2007) identified that teachers could use several strategies to develop communities of inquiry, including participating in sustained interactions and considering what children's play represented beyond participation in the actual play experience. Such roles are challenging to achieve when teachers are working with poor ratios (Wood, 2009), yet this is the reality for many New Zealand EC services, given regulated group sizes and ratios. Even where ratios are improved in centres with full day licences, there is empirical evidence to suggest that qualified teachers face similar tensions juggling teaching and non-teaching demands (Aitken, 2005). 


\section{Principles, theories, and beliefs influencing teachers' thinking and reflections on practice}

The second research question in this study asked what guiding principles, theories, and beliefs underlay these teachers' practices, and the extent to which these were explicitly or implicitly articulated. Data analysis revealed considerable evidence of teachers, across the three case studies, articulating beliefs - about, for example, children, teaching, learning, team work, programmes, and equity - that underlay their thinking and informed their practices. Several clusters of beliefs evident across the cases, including teachers' respect for children, the centrality of relationships and importance of relational pedagogy (Papatheodorou \& Moyles, 2008), and guiding children's behaviour and interactions with others, have been discussed in earlier sections of this chapter.

Within individual cases, teachers also articulated beliefs not always expressed by those in the other centres. Given that this study did not set out to ascertain the full gamut of teachers' beliefs, this may reflect the choice of episodes used in the interviews rather than indicating that other teachers did not hold these beliefs. Further beliefs about teacher practices with children were evident: at Moana ELC Rachel's awareness of her own powerful position as teacher, and commitment to empowering children as learners (Anning, 2009), and the team's willingness to trust children explicitly influenced their practices. The large group size at Summer Kindergarten influenced teachers' articulated beliefs about children's access to their attention and to the resources available within the learning environment, and about balancing the needs of individual children with those of the wider group.

Teachers' revealed beliefs also went beyond their immediate interactions with children. At Summer Kindergarten, Diana was instrumental in raising issues about the purpose of assessment and to whom they, as teachers, were accountable. The ensuing lengthy discussion revealed tensions for these teachers between assessing 
children's learning holistically, enabling children to be creative without predetermined goals, having fun at kindergarten, and hearing children's voices about what was important to them versus what they perceived as external pressures to produce documentation that externally evaluated the kindergarten, including setting goals for learning that may not be meaningful to children. Teachers in both Moana ELC and Ngā Tamariki Rangatahi ELC explicitly revealed beliefs about the importance and role of teaching in a team.

Whilst teachers in each case study revealed beliefs about relationships with parents and extended families within the wider community context, these appeared to be significantly influenced by their local situation. At Moana ELC teachers described valuing parental support and input into the programme, reflective of the governance and organisational structure of the centre that involved a parent management committee and parental assistance with programme delivery. They also suggested the semi-rural community that their families came from influenced children's play, perceiving that these children were used to lots of space and needed, therefore, opportunities for active play. Teachers at Summer Kindergarten believed there should be close links between the kindergarten and children's families and community: for example, visiting the local beach was a common activity and was valued as a source of curriculum experiences. Teachers also felt the kindergarten supported families by providing experiences not easily offered at home. Teachers at Ngā Rangatahi Tamariki believed they had a unique relationship with parents, many of whom were new parents. They felt their role was influential and believed they shared parenting information and advice in non-judgemental ways. Parents' regular visits to the centre during the day to feed their infants gave opportunities for teachers to model caring behaviours and interactions, and to engage in unhurried conversation with them about parenting, their babies' development and their lives outside the centre. 
The influence of Te Whāriki (Ministry of Education, 1996) and Kei Tua o Te Pae (Ministry of Education, 2004, 2009) on the discourse of these teachers was noticeable. Teachers used the language of these documents consistently, for example referring to children as "competent and confident learners" (Ministry of Education, 1996, p. 9) and to "learning dispositions" (Ministry of Education, 2004, p. 18) and had adopted a credit-based frame of reference where they focused on what children could do, rather than on what they could not. Such appropriation of the discourse of Te Whāriki corresponds with Alvestad and Duncan's (2006) findings that teachers had adopted the language and philosophy of Te Whāriki as their own. That teachers in this study often talked about children as individual learners is unsurprising given that Te Whāriki presents a vision of the child as an individual learner (Alvestad \& Duncan, 2006) and this perspective is re-emphasised in the exemplars presented in Kei Tua o Te Pae.

Analysis of data across the three case studies revealed considerably more evidence of teachers' articulation of their beliefs than of their theoretical understandings about teaching and learning. Explicit references to theoretical positions were made infrequently; teachers' descriptions of their thinking during interactions were predominantly focused on their actions, with implicit reference to theories underlying their practice. These findings are unsurprising given that considerable empirical evidence exists that teachers in EC settings find it difficult to articulate the theoretical underpinnings of their practices but draw on these implicitly (Anning, 2009; Kugelmass \& Ross-Bernstein, 2000; Moyles et al., 2002a, 2002b; Stephen, 2010).

When teachers did refer, implicitly or explicitly, to theoretical positions, an eclectic range across developmental, socio-cultural and learning theories was evident. The Summer Kindergarten teachers' discussion of their perceptual motor programme was a striking example as they drew upon their understandings of developmental theory (e.g., the influence of children's physical development on other 
developmental domains and notions of maturation and readiness), learning theories (e.g., children's intrinsic or extrinsic motivation to attempt a physically challenging activity), and socio-cultural theories (e.g., teachers actively working with children in their zone of proximal development within planned activities).

Implicit references to theory were evident through teachers' descriptions. Summer Kindergarten teachers, in particular, made several general references to aspects of child development. Occasional explicit references were made to particular developmental aspects such as Poppy's comment about physical development occurring from the inside outwards, and Diana's reference to helping a child delay gratification.

References to socio-cultural understandings were most frequently made by Moana ELC teachers who used socio-cultural language such as "scaffolding" children's learning and "co-constructing" understanding with children, and affirmed children's cultures and homes. On one occasion, Rachel referred to socio-cultural theory when critiquing her teaching: "actually I did a little bit of scaffolding here and I went over the top. It wasn't within her zone of proximity..." to which Inez replied: "Proximal development?" [CS1/SRI5/E1]. Teachers at both Moana ELC and Summer Kindergarten also made reference to learning dispositions (Carr \& Claxton, 2001) when describing children's persistence with difficulties. Implicit references to learning theories occurred most frequently amongst the Summer Kindergarten teachers and occasionally amongst the Ngā Rangatahi Tamariki ELC teachers. Teachers referred to children having different learning styles, breaking learning down into smaller chunks, providing positive role-models, providing positive reinforcement, and children's motivation for learning.

The infant group teachers at Ngā Rangatahi Tamariki ELC were the only teachers to explicitly name the philosophical and theoretical influences underpinning their pedagogical approach, the RIE/Pikler approach (Gerber, 1979; Gerber \& Johnson, 
1998). These teachers had made a deliberate decision to adopt this approach about seven months prior to data collection, and teachers referred to "talking about Baby Moves every day" as they observed the impact of their changing practices. In this respect the infant group teachers at Ngā Rangatahi Tamariki ELC provide an interesting contrast to other teachers in the study. Their adoption of the RIE/Pikler philosophy was recent enough that the resultant shifts in practice were still being embedded and the impact of their changed practices was evident for them in aspects such as children's transitions and engagement in exploratory play. These teachers' explicit articulation of the RIE/Pikler approach contrasted sharply with other teachers' descriptions, suggesting that the latter drew on theories which, although influential on their practices, had become so embedded in their thinking and reflection that they were referred to implicitly, if at all (Kugelmass \& Bernstein-Ross, 2000).

The contrast between the extent to which teachers expressed beliefs underlying their thinking and reflection and their generally limited and implicitly expressed references to theories is interesting. It is possible that teachers' beliefs have grown out of their theoretical understandings and remain as the concrete artifacts of now implicitly held theories.

Finally, the earlier discussion on teachers' knowledge of children identified that teachers seldom subjected their knowledge to any great level of scrutiny and critique. Similarly, whilst teachers occasionally acknowledged that they "got it wrong" in terms of their choice of teaching strategies, it was rare for teachers to critique their own or others' teaching or the philosophical or theoretical assumptions underpinning them. These findings appear to parallel those evident in the literature on professional learning communities in the school sector. Borko (2004) noted "discussions that support critical examination of teaching are relatively rare" (p. 7), and argued that such conversations are essential for the improvement of teachers' practices. Timperley and Earl (2008) concur, noting that whilst "relationships of respect and challenge" (p. 122) are fundamental to effective learning conversations amongst teachers: 
In most of our conversations, the participants showed respect and consideration for one another through confirmation and offers of support, but very few moved beyond support to challenging interpretations and actions, particularly in the interests of students. Instead they seemed to accept all contributions as equally valid and avoided challenging others' ideas. Yet it is this element of challenge that moves conversations beyond superficial talk to exploring deeper meanings for the purpose of improvement. (p. 124)

The following section discusses results for the third research question, the influence of a community of practice on teachers' thinking and reflection, and includes further discussion about the Ngā Rangatahi Tamariki ELC teachers' use of critique and feedback.

\section{The influence of a community of practice on teacher thinking and}

\section{reflection}

The preceding three chapters presented data illustrating how teachers engaged in behaviours that maintained social cohesion within the team and negotiated meaning about the episodes they viewed during the interviews, using Wenger's (1998) community of practice and the parallel literature on professional learning communities (Stoll et al., 2006) as theoretical frameworks for interpreting the data. In analysing these data I was mindful of the literature reminding one that a group of teachers does not necessarily equate to a community of practice or professional learning community (Grossman, Wineburg \& Woolworth, 2001), although the team nature of EC teaching potentially leads to a greater degree of "de-privatisation" (McLaughlin \& Talbert, 2006) of teachers' practice and collective negotiation of curriculum and teaching than might occur in school settings. In the following crosscase analysis and discussion I argue that the three case study teaching teams were communities of practice but that each community was uniquely framed and patterned, reflective of structural factors (e.g., the organisation and type of ECE centre) (Aitken, 2005) and of the teachers as individuals and as members of a collective community. 


\section{Maintaining social cohesion through alignment behaviours}

Wenger's (1998) concept of alignment, how members of a community coordinate their energy and activities in order to belong and contribute to the community's work, together with the literature on professional learning communities (Borko et al., 2008; Crespo, 2009; Horn \& Little, 2010) provided the sources for considering how teachers in these case studies interacted with each other in socially cohesive ways during the interviews and contributed to the development of analytical categories (see data analysis section of Chapter 3 for details).

Each of the three case study centres used a combination of alignment behaviours that collectively created a unique pattern of social cohesion between teachers. Thus,

the Moana ELC interviews were characterised by alignment behaviours that emphasised agreement and being 'in tune' with each other: they frequently used agreement and affirming statements, identified with what had happened in the episodes and finished each other's sentences. These teachers knew each other well, with most having taught together for several years, and actively supported each other throughout the video-SR interview process. This was reflected in their use of sympathetic comments to colleagues that they had done the best they could during episodes and may have contributed to an alignment behaviour unique to this team: teachers' expressions of vulnerability as they identified instances where they felt inadequate or that their interactions had not been successful. Other factors may have also encouraged these teachers' supportive interactions: first, they had approached me to participate in the research, and second, they knew this was the first time I had used this data collection methodology. These factors may have increased their commitment to making the process work.

A different set of alignment behaviours was evident amongst Summer Kindergarten teachers. These teachers actively indicated agreement with each other, including building agreement over several statements and using language that emphasised agreement, and frequently finished each other's sentences. In contrast to their 
strong agreement statements, alternative views or explanations offered were often framed tentatively or gently, enabling different views to be expressed without appearing critical. These alignment behaviours smoothed the processes of negotiating meaning amongst these teachers for whom the interview process appeared, at times, to surface issues of philosophy and practice for the first time in the context of this newly formed team.

The alignment behaviours used by the Ngā Rangatahi Tamariki ELC teachers were different again from those used by Moana ELC and Summer Kindergarten teachers. Whilst Ngā Rangatahi Tamariki ELC teachers also used agreement statements and finished each other's sentences on numerous occasions, particularly noticeable was their use of language that included all teachers, whether old-timers or newcomers (Wenger, 1998), and which engendered a team ethos. The regular use of collective pronouns by team leaders promoted a climate in which less qualified or experienced teachers were included and able to contribute, even if at a more limited level (see p. 228 for discussion on how the Ngā Rangatahi Tamariki community of practice enacted Wenger's (1998) concept of legitimate peripheral participation). Use of phrases such as "my team" by more junior teachers indicated that these teachers did feel included and able to engage as legitimate members of the team (Wenger, 1998). The extensive use of humour by these teachers also built social cohesion, acting as a device for coping with the stresses of both the interview process and the demands inherent in teaching, and mediating hierarchical differences between team members.

Collectively, the alignment behaviours evident during interviews illustrate how teachers actively work to develop social cohesion within their communities of practice. Such behaviours are important, given that EC teachers work in close proximity with each other on a daily basis (Aitken, 2005; Bary et al., 2007). Furthermore, the wider literature on the development of professional learning communities in schools suggests that developing trust and collaborative norms are 
important if teachers are to deprivatise and interrogate their practices (Grossman et al., 2001; McLaughlin \& Talbert, 2006; Stoll et al., 2006). The use of alignment behaviours by these teachers can be interpreted as indicative of their support for their colleagues as they engaged in the demanding and unfamiliar process of viewing themselves on video and discussing their practices within the context of their community. However, both Grossman et al. (2001) and Nuttall (2004) provide examples of where social cohesion behaviours, particularly those around agreement, can serve to mask tensions and inhibit collaboration. Grossman et al. (2001) suggested that evolving communities go through a period of pseudocommunity characterised by "a false sense of unity [and] suppression of conflict" (p. 988) whilst Nuttall (2004) found that teachers' efforts to maintain social cohesion led, conversely, to some members of the team feeling professionally isolated. Clearly, developing social cohesion through the use of alignment behaviours is part of the work of but, on its own, does not lead to a community of practice. The next section discusses another important aspect of the work of ECE communities of practice: the negotiation of meaning about children and their learning and about teachers and their practices.

\section{Negotiating meaning within communities of practice}

A core concept of Wenger's (1998) social learning theory is that individuals within a community of practice negotiate meaning about their experiences through their participation in the community and through the processes and artifacts, or reification, which the community uses to illuminate and develop shared understandings of their practices. Examples of how teachers engage in negotiating meaning within professional learning communities are found within the literature with, for example, Horn and Little (2010) suggesting that the conversational routines used by teachers in their study were a form of participation whilst the stories of practice that they shared reified practice. In this study, teachers in each centre collectively negotiated meaning about their individual and shared experiences and, thus, the community influenced the thinking and reflection of individual members about their practices. 
Just as each case study centre had their own patterns of alignment behaviours, differences in how they negotiated meaning and about which aspects of practice were evident.

Teachers engaged in negotiating meaning through three main ways: trying to understand what was happening in the episode (what was going on), making sense of what they had viewed (what might this mean), and critiquing practice (reinforcing or criticising practices, offering alternatives). The Moana ELC teachers were keenly interested in understanding what was happening in each episode: they frequently asked questions to clarify their understanding and shared their ideas, opinions and prior knowledge that they had about children involved in the situations. Entry into understanding the episodes was facilitated by the focus teachers whose rich descriptions of what was going on provided detailed contextual and background information. Across most episodes teachers' negotiation of meaning focused intensely on the children involved, rather than on teacher practices or the programme. Exceptions to this focus occurred mostly during periods of collective reflection when teachers turned attention to their own practices and broader aspects such as the learning environment and their relationships with parents. Instrumental in this team's negotiation of meaning about their work was the leadership role played by Rachel (see pp. 230-233 for discussion of the role of team leader across the three case study centres).

Summer Kindergarten teachers also asked clarifying questions and shared their ideas and opinions. These teachers offered new ideas frequently, resulting in lengthy, wideranging discussions. In much the same way that their use of alignment behaviours to develop social cohesion reflected their newly developing teaching community of practice, so too did the ways in which they negotiated meaning about their thinking and practices. The interviews provided a catalyst for discussion and revealed philosophical differences that had not previously been aired and which at times teachers seemed reluctant to explore fully during the interviews. Whilst these teachers 
offered new ideas to deepen the discussion or reinforced each other's practices, they seldom criticised what they observed. However, these teachers did expand their discussions in two ways unique to this team: first, shifting their focus beyond children to broader issues such as assessment and accountability and, second, engaging in principled talk (Horn \& Little, 2010) where discussion moved from the specific instance to general principles of practice. In a manner consistent with the development of a new community, instances where practices were being articulated and explicitly agreed upon in a process of reification within the new team were also evident.

A very different picture of how teachers negotiated meaning emerged from the $\mathrm{Ngā}$ Rangatahi Tamariki ELC interviews, reflective of how this team closely matched Wenger's (1998) construct of a community of practice as one where newcomers are included and become members of a community through the process of legitimate peripheral participation. So, although the interviews drew on episodes involving all teachers relatively equally, the less experienced and qualified staff tended to offer shorter, descriptive accounts focused on what was happening rather than on their thinking and reflections during the interactions whilst senior staff tended to offer more analytical accounts and engaged more fully in collective reflective discussions. Each team leader was highly influential, making more contributions than other team members, clarifying what was happening within episodes, offering information and opinions, and critiquing practice. Other aspects of their leadership are discussed more fully later in this chapter (see pages 230-233) but their involvement in community processes of critiquing practice is noted here. Ngā Rangatahi Tamariki ELC was unique in the extent to which teachers reinforced or critiqued others' practices, criticised their own practices, and offered explicit alternatives and advice. Team leaders were particularly instrumental in giving feedback and offering advice to the newcomers, those less qualified and experienced teachers, in a direct manner. In addition, team leaders demonstrated self-critique more often than did the members of their teams, modelling reflection-on-action to their less experienced colleagues. 
Taken together, these three teams illustrate how communities of practice can engage in processes of negotiating meaning in ways that reflect the unique membership and structure of each community. Comparing and contrasting these three teams highlights that the social configurations of ECE communities of practice are not homogenous but that each community will reflect both the individual members and their collective membership (Wenger, 1998). Whilst not representative (nor meant to be) of the array of New Zealand EC services, these three services also collectively exemplify some of the diversity of teams evident in the sector, whilst simultaneously illustrating that the construct of communities of practice is sufficiently broad to encompass this diversity. This thesis argues, therefore, that Wenger's community of practice social learning theory provides a useful framework for understanding how the thinking and reflection of individual teachers is influenced and mediated by their participation in their centre community of practice. In the next section of this chapter, the discussion turns to an examination of how teachers' interactions during the interviews contributed to, or hindered, thinking and reflectionon-action about their practices.

\section{Patterns of teacher talk as an influence on reflection-on-action within communities of practice}

Empirical evidence exists to demonstrate that teachers' talk in professional learning communities influences participants' engagement and the effectiveness of their discussion for addressing issues of practice. Horn and Little (2010) found that teachers' talk can effectively serve to turn their attention towards, or away from, teaching. Data from this study revealed how at times teachers' attempts to support and empathise with their colleagues over challenging instances turned attention away from important issues that underlay the situation (for example, Rachel's experience of frustration when the morning tea routine interrupted her exploration of a new computer programme with children). Conversely, conversations where attention is turned towards teaching lead more frequently to principled talk (Horn \& 
Little, 2010) as was evidenced by the Summer Kindergarten teachers' discussions about the sandwich-making activity and about assessment practices. In addition, teachers' seamless shifts between modes of discussion (focus teacher reflection, co-construction and collective reflection) and between the video-recorded episodes and wider events, especially for the Moana ELC and Summer Kindergarten teachers, encouraged discussion to shift from the specific to the general. Moving from an individual's recall and reflection on an episode to a collective discussion created opportunities for deeper reflection, drawing on the team's joint knowledge.

Teachers' style of talk has also been found to influence the extent to which members of a professional learning community can engage in meaningful discussion about what occurred in a situation (Crespo, 2009; Horn \& Little, 2010). Extracts from the data used to illustrate findings for each case study (see Chapters $4-6$ ) clearly indicate, even when false starts and idiosyncratic speech patterns are removed for ease of reading, how these teachers engaged in rough draft (Horn \& Little, 2010) or exploratory (Crespo, 2009) speech as they recalled their interactive thinking and reflection-in-action at the time and collectively reflected-on-action. Similarly, Engeström's (1994) study of teachers' planning meetings found high levels of conditional phrases and an absence of imperatives. Such speech patterns provide openings for other teachers to contribute their perspectives and for a collective dialogue to develop.

\section{Learning and leading within communities of practice}

Whilst the discussion to date has focused particularly on the ways in which teachers engaged in alignment behaviours to maintain social cohesion and how they negotiated meaning about the episodes used in the video-SR interviews, other aspects of Wenger's (1998) theory were also apparent: particular attention is now paid to the mediating effect of the community on teachers' learning and teachers' roles as old-timers or newcomers. The role of leaders within effective professional learning communities is also discussed. 
Wenger (1998) suggests that learning is a characteristic of practice and that communities can be a site for both the acquisition of knowledge, particularly for newcomers, and for the creation of knowledge as a result of constant fine-tuning between participants' experiences and their competence. Throughout the interviews there was evidence of how teachers' mutual engagement in viewing and discussing the episodes led to new insights about their own practices, programme routines and activities, and their understandings of children. The combination of three factors was important here: first, the visual record of the episode (recorded from an outsider's stance) that enabled participation, whether teachers had been part of the episode or not; second, the opportunity to hear others' perspectives on the situation, from an insider (focus teacher) and outsider (other members of the team who had not been part of the situation) stance; and third, being able to collaboratively reflect-on-action without the pressure to respond to children in the moment of the interaction. Across all the centres, teachers acquired new knowledge (e.g., about individual children) but they also created new knowledge as they fine-tuned their understandings and practices through the process of articulating and discussing their interactive thinking (Marland \& Osborne, 1990) and their reflection-in- and -on-action (Schön, 1983, 1987). The acquisition of new knowledge about practice was particularly evident with the less experienced Ngā Rangatahi Tamariki ELC teachers; in one interview Spring explicitly offered advice to Autumn about alternative strategies to engage children's interest and then commented in the second interview on the changes she observed in Autumn's practices. In another example, Giselle outlined how her practices had changed following the first interview in which the video footage had revealed a child's unsuccessful attempts to join her group.

Wenger's (1998) concept of old-timers and newcomers was, as noted earlier, most evident in the Ngā Rangatahi Tamariki ELC team. However, teachers in the other case studies were also positioned in these roles, albeit to a lesser extent. Within the Moana ELC team, Jane and Inez, as the least experienced teachers, received more 
advice and reinforcement of their thinking and practices from Rachel and, to a lesser extent, Meg. At Summer Kindergarten Diana was the newcomer, despite being the most experienced of the three teachers, due to her recent appointment to the kindergarten (paralleling Aitken's (2005) findings). Diana's newcomer status was played out as the team discussed, and she grew to understand, the reified practices of Summer Kindergarten, illustrated eloquently through the teachers' discussion of the perceptual motor programme. The Summer Kindergarten team also illustrate Wenger's (1998) point that the arrival of newcomers can create "generational discontinuities" (p. 99) within both a community and its reified practices. During interviews Diana repeatedly drew on examples from her previous experiences to explain her thinking and practices during the episodes. Her articulation of these practices which had been reified in other EC services provoked, at times, a reexamination of the existing reified practices of Summer Kindergarten (see, for example, the discussion around the purpose of assessment and documentation of children's learning in Chapter 5, pp. 168-170).

Consideration of the old-timers'/newcomers' roles played by individual members of the three case study teams also focuses attention on the important role played by team leaders. The contribution of strong leadership to effective professional learning communities is well acknowledged within the literature (Bary et al., 2007; Horn \& Little, 2010; McLaughlin \& Talbert, 2006), particularly in terms of determining the quality of teachers' participation (Johnson \& Scull, 1999; Printy, 2008; Stoll et al., 2006) and in developing and reinforcing collaborative norms of behaviour (Cosner, 2009). Previous discussion has highlighted how team leaders in Ngā Rangatahi Tamariki ELC specifically developed an inclusive climate through their use of collective pronouns and how they explicitly gave less experienced colleagues feedback and advice on their practices. Explicit manifestations of leadership authority were more apparent within Moana ELC and Ngā Rangatahi Tamariki ELC. Leaders in these centres contributed more extensively to the discussions, engaged 
in self-critique to a much greater extent, and exerted their authority on occasions. In contrast, Marilyn's leadership within the Summer Kindergarten team was less overt, reflective of, perhaps, Marilyn's relative inexperience as team leader and a more egalitarian team structure which allowed for greater levels of distributed leadership (Bary et al., 2007).

To conclude this section, the reader is reminded of the review of Wenger's (1998) social theory of learning (see Chapter 2, pp. 47-51) which included reference to fourteen indicators that a community of practice had formed (pp. 125-126). Although the research design and data collection for this project did not set out to explicitly gather data investigating whether each centre was a community of practice, given that this line of inquiry emerged more fully during the project, there is evidence that each case study met at least some of these indicators and, thus, existed as a community of practice during data collection. So, whilst membership within the community was, on one level, defined by their employment as teachers within the centres, teachers' use of inclusive language and explicit reference to the importance of working together as a team indicated agreement that they all belonged within the community. Their active engagement in socially cohesive behaviours sustained their mutual relationships and facilitated shared ways of working together whilst their interactions as they negotiated meaning together revealed a rapid and free sharing of information, with discussions that were clearly built on previous conversations and understandings. The shared nature of these teachers' work was reflected through their use of reified local practices and artifacts together with their knowledge of insider information including, as Wenger described it, their "local lore, shared stories, inside jokes [and] knowing laughter" (p. 125). Collectively these interactions and behaviours contributed to the on-going maintenance of the communities of practice that were Moana ELC, Summer Kindergarten and Ngā Rangatahi Tamariki ELC. 


\section{Limitations of this study}

Attention is now turned to a discussion of the limitations of this study, including the research design and methodological aspects that influenced data collection and analysis. As a qualitative study, findings from this research cannot be generalised. The three participating centres self-selected into the project: Moana ELC requested to be involved during the preparation of my research proposal whilst both Summer Kindergarten and Ngā Rangatahi Tamariki ELC responded to an invitation to participate. The selection processes used for the project may have resulted in a biased sample of cases; furthermore, the existing relationship with most of the teachers may have influenced their sharing of their reflections.

Chapter 3 outlined the rationale for the choice of video-SR interviews as the main data collection method (see pp. 70-73) for investigating teachers' interactive thinking (Mitchell \& Marland, 1989) and reflection-in-action (Schön, 1983, 1987) and described adaptations to the method used to address the collective nature of teaching in New Zealand EC contexts. The use of group interviews did influence the extent to which teachers recalled their thinking at the time of the episode or shifted focus into reflecting-on-action (Schön, 1983, 1987) and negotiating meaning with their colleagues. As noted earlier in this chapter, teachers did not neatly separate out their interactive thinking (Marland \& Osborne, 1990) and reflection-in- and -onaction but, rather, moved seamlessly between the different modes. Such behaviours lend weight to Lyle's (2003) argument that a limitation of the method is determining whether participants' reports truly represent what they were thinking about at the time of the episode. Certainly, the use of the group interviews in this study did result in, as Yinger (1986) suggests, instances of teachers responding to the new event of watching the video.

However, whilst accepting that these adaptations created a limitation in terms of methodological purity, their use also allowed other aspects of teacher thinking and practice to emerge that were unlikely to have done so if the interviews had been 
undertaken individually. Group interviews reflected the reality of team teaching more accurately, and enabled community of practice aspects to emerge. These results offer further insights into a feature of New Zealand ECE practice not extensively addressed in previous research.

Beyond the methodological issues just raised, a key limitation was my decision not to use the secondary data sources (particularly the teacher reflective journals and staff meeting transcripts) to triangulate the data from the video-SR interviews. Whilst I chose not to report data from these sources because of their general inadequacy in furthering understandings of teachers' thinking and reflection, their absence does impact on the construct validity of this study. Whilst the usefulness of the staff meeting data could not be influenced (given that these were representative of typical meetings), providing a more prescriptive set of instructions for the teacher reflective journals together with more direct follow-up with individual teachers may have resulted in in-depth journals from more teachers.

This study did not set out to investigate EC teachers' thinking and reflection per se. Rather, it narrowed the focus to teachers' thinking and reflections about their interactions with children. The research design reflects this narrower focus and, in doing so, limited the scope and focus of teachers' reflection. The video-recorded episodes used in the interviews were of teachers' interactions with children rather than of other aspects of their practice (such as interactions with parents or organising the learning environment), and interviews were scheduled 24 hours after the episodes were recorded. The interview instructions asked teachers to recall what they had been thinking about at the time of the episode, focusing their attention on the immediacy of the moment rather than on broader aspects of practice or on issues influencing their practice. Further, teachers were not explicitly asked to critique their own or others' practices, and were not given opportunities during subsequent interviews to re-visit and reflect further on previously discussed episodes. 
These factors influenced the nature of teachers' thinking and reflection when considered against theoretical frameworks and constructs of reflection. Teachers engaged in reflection predominantly about technical aspects of teaching rather than about assumptions underpinning their practice or about moral and ethical dimensions of teaching (van Manen, 1977), particularly when describing their interactive thinking and reflection-in-action. Similarly, when considered against Griffiths and Tann's (1992) levels of reflection, teachers recalled reflection indicative of the first three levels: rapid reflection, repair, and review. The data collection timeframes did not enable teachers to demonstrate reflection at the research or retheorising levels. The lack of opportunity to re-visit episodes discussed in previous interviews meant that teachers were unable to engage in Schön's $(1983,1987)$ spiral of reflection involving appreciation, action and re-appreciation, although two teachers did send emails several months later, indicating their on-going reflection on issues raised during the interviews.

In a related issue, teachers' planning meetings were video-recorded to provide additional supporting data enabling me to understand their processes and practices, but were not used as the basis for interviews with teachers. A significant portion of most of the five recorded staff meetings was devoted to administrative aspects and practical details about the provision of the programme, rather than to discussion of teachers' plans for individuals or groups of children. Teachers' planning at a more informal level (before the children arrived, in passing conversations with other teachers, or at the end of the sessions) was not systematically recorded. Thus, although the use of video-SR interviews enabled rich, naturalistic data to be collected, a limitation of the study is that they represent a portion of these teachers' thinking, reflection and practices rather than a complete picture.

Across the three case studies teachers participated in varying numbers of interviews. I elected to undertake two interviews with each of the three smaller teaching teams at Ngā Rangatahi Tamariki, so that the overall number of interviews was relatively 
similar across each case study. In retrospect, this introduced a methodological variation at the teacher level that I had not considered fully at the time, with each teacher able to participate in a maximum of two interviews compared with the five interviews in the other two centres. In addition, factors outside my control (such as illness) meant that not all teachers attended all their scheduled interviews. Enabling the Ngā Rangatahi Tamariki ELC teachers to participate in more interviews may have helped address the anxiety expressed by some at seeing themselves on video and their reticence during the interviews.

The structure and timing of the interviews is also an important consideration. Each interview was scheduled for two hours and involved approximately one hour of video-recorded episodes. At the beginning of each interview I outlined to teachers the number and approximate overall length of episodes and it is possible that they curtailed their recall and discussions at some points in order to complete the interviews within the negotiated timeframe.

The final point regarding the limitations of this study concerns the interplay between my extensive experience as an EC teacher and lecturer and my relative inexperience as a researcher undertaking the interviews. As an experienced teacher, what these teachers talked about in the interviews resonated and made sense to me and at times I found it extremely difficult to refrain from contributing my thoughts to the discussion. Having read the transcript of my first interview, my supervisors commented on my involvement; I addressed this issue directly in future interviews by explicitly explaining the strategies I would use to avoid over-involvement. I also found I needed to guard against reading more into teachers' discussions during data analysis as a result of my teaching background, and acknowledge the influence of my teaching background on this project. 


\section{Implications of this study}

In this section I present a model to help explain the findings of this study concerning these teachers' thinking and reflection within their communities of practice. Implications arising from the research concerning ECE policy and practice and for future research are also presented.

\section{A model of teacher thinking and reflection within a community of practice}

Earlier discussion in this chapter revealed that teachers focused much more intensely and explicitly on the children, and what they knew about them, when thinking about their interactions than they did on their own pedagogical decision making, strategies and underlying theories. These findings concur with research from other EC and wider teaching contexts (Moyles et al., 2002b; Stephen, 2010; Zeichner \& Liston, 1996) that teachers position children at the centre of their thinking and that they also find it challenging to articulate their pedagogical decision-making and the theoretical and philosophical ideas underpinning their practices. That these teachers knew so much about the children and engaged in responsive, respectful interactions with them is, of course, a very positive finding of the research. It is when these results are contrasted with how teachers positioned and included themselves within their thinking and reflection about their interactions that an imbalance in teachers' thinking starts to appear. In order to illustrate this, a model of teacher thinking and reflection as evidenced in this research is presented for discussion (see Figure 7.1). 


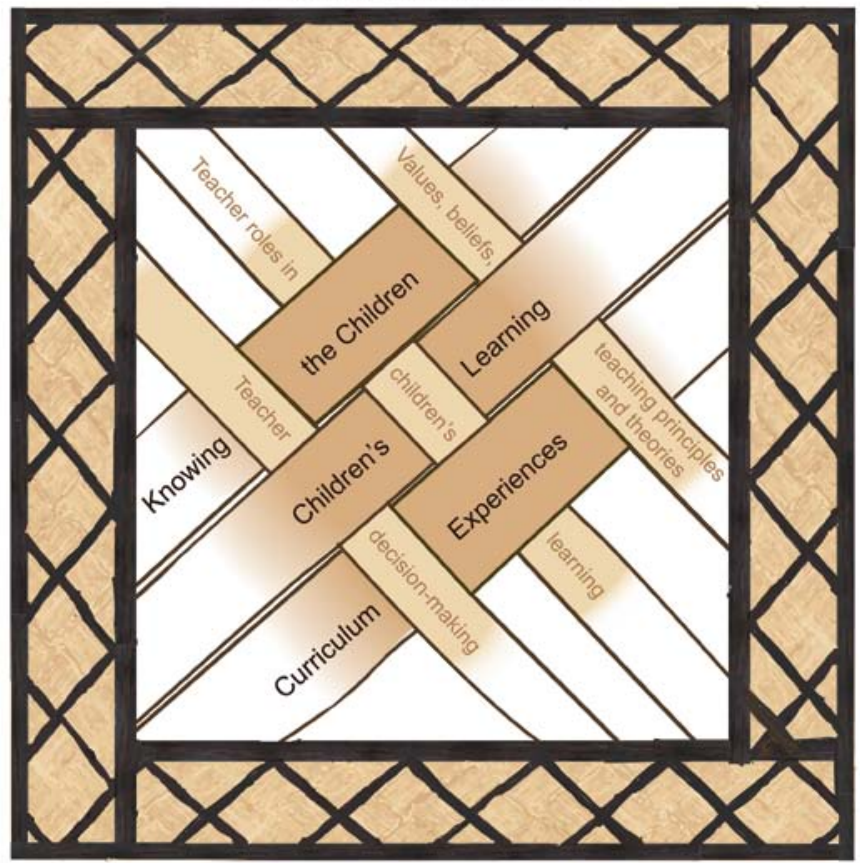

Figure 7.1: A Model of Teacher Thinking and Reflection within a Community of Practice

The metaphor of a woven mat, or whāriki, is familiar to New Zealand EC teachers, thanks to Te Whāriki (Ministry of Education, 1996) which uses the metaphor to illustrate how the curriculum is woven and enacted in EC settings in ways reflective of local social and cultural contexts. The model of teacher thinking presented here draws upon that familiar metaphor to illustrate how some aspects of teachers' thinking about their interactions are more thoroughly and explicitly articulated than others. I argue that this imbalance weaves a whāriki that is not as strong and robust as it might otherwise be if teachers and teaching were foregrounded to a greater extent.

The model presents three strong, broad strands, representing teachers' knowledge of individual children (including their temperaments, development, and families), their holistic focus on children's learning interests, and their understanding and provision of curriculum experiences for children. Woven through these wide, robust strands are three narrower, weaker strands representing teachers' articulation of underlying theories, philosophies and values that influence their practice, their 
teaching roles, and their teaching intentions and decision-making during interactions. The unevenness between the broad child- and curriculum-focused strands and the narrower teacher-focused strands creates gaps in the whāriki, reducing its strength and, by inference, the strength of teaching and learning in ECE settings.

It is the contention of this thesis that further attention needs to be paid to teaching and to teacher thinking and metacognition in order to strengthen the whāriki woven out of the interplay between teaching and learning. Such a contention is not new: Siraj-Blatchford (2009) has argued that "not only do we need to foreground the role of the teacher, but we need to value and reposition teaching as central to quality early childhood education" (p. 157) whilst Fleer (2010) positioned teachers and children as "two sides of the same coin ... dialectically related to each other" (2010, p. 16). The findings of this research offer additional support to the position taken by Siraj-Blatchford and Fleer whilst providing a New Zealand perspective on the issue. They also serve as a reminder that, despite the international acclaim for Te Whāriki (Papatheodorou, 2008), there are aspects of our practice deserving of further attention in order to strengthen the quality of EC provision in this country.

It is important that consideration of this argument does not lead to teachers in this study being positioned as inadequate in their practice. Clearly, the discussion about teachers' knowledge of individual children, their ability to read children's cues and adjust their use of teaching strategies, and their use of relational pedagogy indicates much about the quality of their work. Beyond the EC studies cited previously in this thesis, the wider empirical literature on teacher thinking and reflection is rich with examples of the difficulties that teachers have in surfacing their tacit knowledge and articulating their practice (Ainley \& Luntley, 2007; McGee \& Penlington, 2001). That some of these teachers also found such articulation challenging is unsurprising.

Furthermore, the enduring dominant discourse in ECE, here and overseas, has been one of child-centredness where teachers and teaching have been positioned in 
the background of children's development and learning. According to Fleer et al., (2009), Stephen (2010) and Siraj-Blatchford (2009), for many years prevailing interpretations of Piaget's work - the traditionally dominant influence on New Zealand EC practice - have neglected his emphasis on the role of adults and peers in children's learning whilst highlighting the notion of the child as the 'lone scientist'. Whilst a socio-cultural discourse, and more latterly sociocultural-historical discourse (Anning et al., 2009), may be displacing these traditional and somewhat mistaken (Siraj-Blatchford, 2009) understandings of Piaget's work, especially in academic and policy spheres, they are still strongly influential amongst practitioners (Cullen, 1996; Farquhar \& Fleer, 2007), particularly for teachers whose initial training was underpinned by a traditional developmental paradigm.

Professional EC literature and resources in New Zealand reinforce this child-centred discourse (Grey, 2010). Arguably, the two most influential resources currently used by teachers are Te Whāriki (Ministry of Education, 1996) and Kei Tua o Te Pae (Ministry of Education, 2004, 2009). Whilst the focus in these documents on children (via learning outcomes and assessing learning) is understandable, given their respective roles as a curriculum document and assessment resources, collectively they do not foreground teaching. The reflective questions and illustrative examples of experiences to help achieve the learning outcomes outlined in Te Whāriki emphasise the provision of curriculum experiences and environmental organisation whilst providing little direct guidance for teachers on how their teaching interactions can enhance children's learning. Similarly, whilst the commentaries around the Kei Tua o Te Pae exemplars provide some insights into how teachers' actions supported children's learning, both the "where to next" sections of the exemplars and the commentary emphasise the provision of experiences rather than explicit teaching interactions.

Whilst Ngā Arohaehae Whai Hua (Ministry of Education, 2006), the self-review guidelines for ECE, does position teacher practices explicitly and centrally within the 
self review process - "review is the deliberate and ongoing process of finding out how well our practices enhance children's learning and development" (p. 8) - a more recent Education Review Office report found only $14 \%$ of EC services reviewed had a sound understanding of self review and were able to undertake quality reviews (Education Review Office, 2009). A shift in professional development priorities funded by the Ministry of Education from 2010 has meant that whilst professional development providers may draw upon the conceptual model provided in Ngā Arohaehae Whai Hua, programmes focused specifically on self review are no longer funded.

It can be argued the pervasiveness of the child-centred discourse outlined above is evident in teachers' thinking and reflections in several ways. First, for some teachers in the study their identity as teachers was closely aligned to the children: when asked what they were thinking about during the interactions, these teachers tended to describe what the children were doing and references to their roles and interactions were framed as reactions to children's actions. Whilst, on the one hand, such descriptions may surface interactions indicative of relational pedagogy (Papatheodorou \& Moyles, 2008), they also suggest a view of teaching at the nondirective end of Bredekamp and Rosegrant's (1992) continuum of teaching behaviours. Second, with teaching less visible within a child-centred discourse, when teachers did talk about their practices, it was often at the level of description (what was said and done) rather than at the analytical level where their underlying professional knowledge and values were made explicit. Given that Davis (2006) suggests that such descriptive reflection is unproductive, these findings have implications for EC practice, policy, initial teacher education and professional development as outlined in the next section of this chapter.

The model presented in Figure 1 (p. 239) above includes a border that holds the warp and weft strands of the whāriki in place and which represents the community of practice that was each teaching team. The border reflects the bounded nature of a 
community of practice in which membership is determined by inclusion and mutual engagement (Wenger, 1998). Moreover, it illustrates the important influence of each community on the thinking and reflections of individual members, evident as these teachers engaged in collective reflection during the interviews.

From the outset, this study used each team as the unit of analysis. Within each team there were, however, differences amongst the teachers in terms of the extent to which they were able to articulate their thinking and reflection, as well as what they actually thought about. Aspects of these individual differences were reported in Chapters 4 through 6. Whilst most evident amongst the teachers at Ngā Rangatahi Tamariki ELC where the team comprised a mix of qualified, in-training and unqualified teachers, it was also noted that qualifications alone could not account for differences in teachers' articulateness. Factors such as teachers' knowledge becoming increasingly tacit as their experience increased (Schön, 1983, 1987) and their personal reflective attributes were also likely to have been influential. What is evident in the results of this study is that membership of their communities of practice and engagement in collaborative, collegial reflection contributed to these teachers' thinking and reflection, a finding supported by the wider empirical literature (Convery 1998; Francis, 1995; Yost et al., 2000; Zeichner \& Liston, 1996). This finding has important implications for how communities of practice in the EC profession are developed and strengthened in order to enhance teacher thinking, reflection and practices.

Earlier discussion indicated my stance at the outset of this research that Schön's distinction between reflection-in- and -on-action provided a useful construct for explaining teachers' thinking during, as well as after, their interactions with children. In contrast to Convery's (1998) argument that reflection-in-action could be applied to almost all aspects of a teacher's work, data from this study clearly demonstrated that teachers used a mix of reflection-in- and -on-action (even during periods of the interviews where other teachers were not contributing) and also engaged in thinking 
about their interactions that could not be described as reflection. As such, whilst Schön's concept of reflection-in-action remains valuable for describing those instances where teachers do reflect in the moment, as a result of experiencing surprise, there remains much of teachers' thinking about their interactions with children that falls between the tacit knowledge Schön $(1983,1987)$ describes as knowing-in-action and their deliberate reflection-in-action. Results presented here suggest that Marland and Osborne's (1990) concept of interactive thinking is useful in addressing this gap and thus enables the breadth of teacher thinking and reflection to be more adequately explained.

\section{Implications for ECE policy and practice}

A number of implications arising from this research are evident. In this section, implications for ECE policy and practice, including those affecting initial teacher education and professional development, are outlined.

Strengthening teachers' focus on their own teaching and how it impacts on children's learning is a key area for development in the sector. A comprehensive set of strategies, at a macro-level (i.e., government, sector and organisational level), service level, and individual team and teacher level are needed to create the conditions necessary for such change to take place. First, the construct of teaching as central to the learning process (Fleer, 2010; Siraj-Blatchford, 2009) needs to be more actively examined. Whilst New Zealand academics (Cullen, 1996; Hedges, 2007; Jordan, 2009; Meade, 1999) have contributed to discussions about such a role for EC teachers, greater engagement by the EC community is required to develop a broader re-conceptualisation of the role of the teacher.

To engage in such re-conceptualisation requires access to underpinning conceptual ideas and the opportunity to explore how such ideas are enacted in practice. Particularly important is that teachers do not interpret a foregrounded construct of their role as meaning an emphasis on didactic techniques or neglect their focus on 
the children in their attempts to re-position their own role. Instead, it is a matter of teachers focusing on teaching and learning, rather than teaching or learning.

For teachers steeped in a child-centred construct, re-positioning themselves as active, equal partners in the teaching-learning process with children is likely to be challenging, particularly when their professional knowledge has become tacit. Surfacing existing professional knowledge in order to understand its impact on practice as well as understanding more recent theoretical paradigms is a necessary step in considering a broader construct of teaching.

Being able to thoughtfully reflect about one's practice requires sophisticated reflective skills and knowledge and an attitude of wholeheartedness (Dewey, 1933). Variability amongst teachers is likely to exist, influenced by a number of factors including the degree to which they were prepared to engage in reflective practice by their teacher education programme, their own personal attributes, and the climate that exists within their centre or service. Adding complexity to this issue is the still high proportion of unqualified practitioners in the sector and the numbers of teachers who gained their teaching credentials through combining an array of lower-level qualifications. Such practitioners are unlikely to have engaged in in-depth learning about reflective practices; expecting them to learn to reflect on their teaching from working alongside qualified colleagues is unrealistic, given the evidence from this study about how challenging it was for some teachers to articulate their own teaching.

Data from this study have demonstrated the influence of the community of practice on teachers' thinking and reflection, and thus provide one mechanism for supporting teachers to engage in collective reflection about their practices. To do so effectively, however, communities of practice require external structural support (e.g., time and spaces for regular, on-going meetings) (Carr \& Chambers, 2006; Stoll et al., 2006) and internal processes that build trust (Blair, 2008; Cosner, 2009; Herrington et al., 
2008; Stoll et al., 2006) and which turn conversations towards teaching (Horn \& Little, 2010) and critique of practice (Timperley \& Earl, 2008). Whilst many EC services will have the internal capacity to develop themselves as communities of practice, as evidenced by the centres in this study, data from an Education Review Office review suggests many others lack the leadership and culture of reflective practice and professional learning (Education Review Office, 2010) needed to develop an effective community of practice. Supporting such services is likely to require significant investment of professional development over extended periods of time in order to address attitudinal aspects alongside developing the knowledge and skills to be able to engage in reflective dialogues with team members.

Discussions of the impact of structural constraints on teachers engaging in collaborative reflective discussion with each other are evident in the literature (Aitken, 2005; Nuttall, 2004). Many services struggle to find sufficient time for teachers to meet regularly to discuss issues of teaching and learning (Aitken, 2005; Hedges, 2007; Nuttall, 2004). Resourcing regular opportunities for teachers to engage in collaborative, reflective dialogue is important for the development of shared, consistent understandings of teacher roles, especially where teachers' concepts of these are undergoing change, and for the on-going reflection and critique of teachers' practices and examination of children's learning.

The use of video-recordings of teachers' interactions with children has potential to assist teachers in articulating their thinking and reflections and in developing shared understandings of practice. Teachers in each of the three case studies indicated they found the stimulated-recall process a powerful form of professional development, as it created opportunities for shared dialogue, gave teachers a broader view of what was happening in the centre, and enabled them to focus on aspects not visible to them during the busyness of their teaching. Internationally and locally, a growing body of empirical evidence is also pointing to the usefulness of video as a tool for enabling close examination of teaching practices by teachers 
(Cremin et al., 2006; Dalli et al., 2009; Grey, 2010; Haggerty, 1998; Moyles et al., 2002b; Sherin \& van Es, 2009; Wood \& Bennett, 2000). The findings from this research support the use of video-recorded episodes of teacher practice as the basis for developing shared understandings and discussion of pedagogical practices.

The results of this study also have implications for initial teacher education and professional development providers. It may be timely for providers to examine the extent to which their programmes explicitly foreground teacher thinking, metacognition, and reflection, thus positioning teachers alongside children and teaching alongside learning. Finally, it has been argued that the child-centred emphasis within professional documents has contributed to an imbalance in teacher thinking with less emphasis placed on the teacher's role, despite the official discourse being underpinned by socio-cultural theory. I suggest that teachers' understanding of their role would be strengthened if future resources positioned teaching more explicitly and centrally within the teaching/learning relationship.

\section{Implications for future research}

This study points to several potential areas for future research to build on these findings, namely:

- How initial teacher education and professional development programmes can effectively support teachers to develop metacognition and reflective practices, including which models and approaches are more effective.

- The factors (personal, experiential, contextual) that enable individual teachers to reflect more effectively and critically about their teaching practices.

- Factors that contribute to, or inhibit, effective communities of practice in EC settings.

- How EC teachers can be supported to re-position their teaching in the foreground alongside current emphases on children. 


\section{Contributions of this research to the literature}

This study makes contributions to the literature on teacher reflection and thinking, ECE pedagogy, communities of practice and professional learning communities, and stimulated recall method. First, applying Schön's $(1983,1987)$ concepts of knowingin-action, and reflection-in- and -on-action to EC teaching in New Zealand enabled this theory to be examined using a new professional context. The finding that teachers engaged in explicit thinking during their interactions that fell between Schön's tacit knowing-in-action and explicit reflection-in-action indicates a gap in Schön's theory. Drawing on the concept of interactive thinking (Marland \& Osborne, 1990; Mitchell \& Marland, 1989) to address teacher thinking not covered by Schön's concepts has enabled a fuller explanation of EC teachers' thinking and reflection.

Second, this study has illuminated the content of EC teachers' thinking and reflection during interactions, most particularly the centrality of children in their thinking. Teachers' use of their extensive knowledge about individual children, their emphasis on relationships and their responsiveness to the cues they receive from children provides empirical evidence of relational pedagogy (e.g. Papatheodorou \& Moyles, 2008) and of teachers' engagement with the philosophical underpinnings of Te Whāriki (Ministry of Education, 1996).

In contrast to teachers' explicit articulation of their knowledge of and responsiveness to children, this study also found that teachers were less able to articulate their thinking and reflections about their own teaching intentions, use of teaching strategies, and the theories and principles influencing their practices. Whilst similar findings have emerged from studies in the schooling sector, these results contribute to the currently limited empirical literature about teacher thinking and reflection in the EC sector.

Bringing these findings together in a model of EC teacher thinking illustrates the differences between teachers' explicit articulation of their thinking about children compared with their teaching. The use of a woven mat or whāriki as a metaphor for 
teachers' thinking is deliberate, given New Zealand teachers' familiarity with the metaphor through Te Whāriki (Ministry of Education, 1996). The uneven whāriki woven from broad, robust child- and curriculum-focused strands and narrower, weaker teacher-focused strands creates gaps in the whāriki, reducing its strength. The thesis argues that the current child-centred discourse evident in the data and within much of the New Zealand professional literature and resources backgrounds teaching and that greater attention to teaching and to teacher thinking and metacognition is necessary to strengthen teaching and learning in ECE settings.

Third, in drawing upon Wenger's (1998) theory, this study has revealed how each case study centre team operated as a uniquely framed and patterned community of practice, evident through their adoption of a range of alignment behaviours, the ways in which they collectively negotiated meaning about their practices, how members acquired new knowledge, and their roles as old-timers or newcomers. The study provides empirical evidence of the usefulness of Wenger's community of practice model for understanding how teaching teams mediate individual teachers' thinking and practices whilst also being broad enough to cover the diversity of New Zealand ECE centres.

This study has also drawn upon the professional learning community literature to understand the processes through which teachers engaged in collective reflection about their practices. In doing so, the study contributes to the literature from an EC perspective in a field heavily dominated by research in the schooling sector.

Fourth, this study has made a methodological contribution. Undertaking the video-SR interviews with the teaching team, rather than with individuals, resulted in teachers recalling their thinking and reflection at the time of the episode (as intended with this method) as well as engaging in individual and collective reflection on the episodes. The group interviews uncovered teacher practices within, and the influence of, the community of practice in ways not possible with individual interviews, thus allowing insights into the under-researched area of ECE communities of practice. The study 
therefore contributes to a growing body of empirical literature indicating the value of variations to the stimulated recall method, particularly where researchers are interested in social influences on participants' thinking.

Finally, whilst not intending to investigate approaches to professional development, this study has highlighted the usefulness of examining video-recorded episodes of teaching within teams and the mediating role of the ECE community of practice on teachers' individual reflection and practice. That teachers find it challenging to articulate their own teaching intentions and practices, and rarely critique their own or others' practices or the veracity of their knowledge about children provides further insights into possible directions for future professional development initiatives.

\section{Conclusion}

To conclude, this project aimed to explore what EC teachers thought about and reflected on regarding their interactions with young children. The findings across the three case study centres have highlighted the child-centred, relational nature of teacher practices and thinking whilst also revealing the more implicit nature of their thinking about their own teaching, and the influence of centre communities of practice on teachers' thinking and reflection. As such, it is hoped that this project will also assist students and practising teachers in understanding aspects of their own work of teaching in ECE and contribute to strengthening the sector. 


\section{References}

Ainley, J., \& Luntley, M. (2007). Towards an articulation of expert classroom practice. Teaching and Teacher Education, 23, 1127-1138.

Aitken, H. (2005). Participating in an early childhood community of practice: The experiences of a group of newly qualified teachers. Unpublished Masters thesis, University of Waikato.

Allen, R., \& Casbergue, R. (1997). Evolution of novice through expert teachers' recall: Implications for effective reflection on practice. Teaching and Teacher Education, 13(7), 741-755.

Alvestad, M., \& Duncan, J. (2006). "The value is enormous - it's priceless I think!" New Zealand preschool teachers' understanding of the early childhood curriculum in New Zealand: A comparative perspective. International Journal of Early Childhood, 38(1), 31-45.

Anderson, D., Nashon, S., \& Thomas, G. (2009). The evolution of research methods for probing and understanding metacognition. Research in Science Education, 39(2), 181-195.

Anning, A. (2009). The co-construction of an early childhood curriculum. In A. Anning, J. Cullen \& M. Fleer (Eds.), Early childhood education: Society and culture ( $2^{\text {nd }}$ ed.) (pp. $\left.67-79\right)$. London: Sage.

Anning, A., Cullen, J., \& Fleer, M. (2004). Research contexts across cultures. In A. Anning, J. Cullen \& M. Fleer (Eds.), Early childhood education: Society and culture (pp. 1 - 15). London: Sage.

Anning, A., Cullen, J., \& Fleer, M. (2009). Research contexts across cultures. In A. Anning, J. Cullen \& M. Fleer (Eds.). Early childhood education: Society and culture $\left(2^{\text {nd }}\right.$ ed. $)($ pp. $1-24)$. London: Sage.

Antonsson, H., Graneheim, U., Lundstrom, M., \& Astrom, S. (2008). Caregivers' reflections on their interactions with adult people with disabilities. Journal of Psychiatric and Mental Health Nursing, 15, 484-491.

Athey, C. (2007). Extending thought in young children: A parent-teacher partnership $\left(2^{\text {nd }}\right.$ ed.). London: Paul Chapman.

Barnes, D. (1976). From communication to curriculum. Harmondsworth: Penguin.

Barnes, D. (1992). The significance of teachers' frames for teaching. In T. Russell \& T. Munby (Eds.), Teachers and teaching: From classroom to reflection. London: Falmer Press.

Bary, R., Waugh, O., Martin, L., Moana, P., Deans, C., Charlton, M. et al. (2007). Ako ngatai: Teaching and learning together as one: From leadership to enquiry: Teachers' work in an infants' and toddlers' centre: Massey Child 
Care Centre Final report to the Ministry of Education round two Centre of Innovation programme. Wellington: Ministry of Education.

Beck, C., \& Kosnik, C. (2001). Reflection-in-action: In defence of thoughtful teaching. Curriculum Inquiry, 31(2), 217-227.

Bee, H., \& Boyd, D. (2010). The developing child $\left(12^{\text {th }}\right.$ ed.). Boston: Allyn \& Bacon. Berthelson, D., \& Brownlee, J. (2007). Working with toddlers in childcare: Practitioners' beliefs about their role. Early Childhood Research Quarterly, 22(3), 347-362.

Berthelson, D., Brownlee, J., \& Boulton-Lewis, G. (2002). Caregivers' epistemological beliefs in toddler programs. Early Childhood Development and Care, 172, 503-516.

Black, A., \& Halliwell, G. (2000). Accessing practical knowledge: How? Why? Teaching and Teacher Education, 16, 103-115.

Blair, D. (2008). Mentoring novice teachers: Developing a community of practice. Research Studies in Music Education, 30(2), 99-117.

Blanton, M., \& Stylianou, D. (2009). Interpreting a community of practice perspective in discipline-specific professional development in higher education. Innovation in Higher Education, 34, 79-92.

Borko, H. (2004). Professional development and teacher learning: Mapping the terrain. Educational Researcher, 33(8), 3-15.

Borko, H., Jacobs, J., Eiteljorg, E., \& Pittman, M. (2008). Video as a tool for fostering productive discussions in mathematics professional development. Teaching and Teacher Education, 24(2), 417-436.

Bouchard, C., Bigras, N., Cantin, G., Coutu, S., Blain-Brière, B., Eryasa, J. et al. (2010). Early childhood educators' use of language-support practices with 4year-old children in child care centers. Early Childhood Education Journal, 37(3), 371-379.

Boud, D. (2009). Relocating reflection in the context of practice. In H. Bradbury, N. Frost, S. Kilminster \& M. Zukas (Eds.), Beyond reflective practice: New approaches to professional lifelong learning (pp. 25 - 36). London: Routledge.

Bowman, B., Donovan, M., \& Burns, M. (Eds.). (2001). Eager to learn: Educating our preschoolers. Washington: National Academy Press.

Bredekamp, S. (Ed.). (1987). Developmentally appropriate practice in early childhood programs serving children from birth through age 8. Washington, DC: National Association for the Education of Young Children. 
Bredekamp, S., \& Rosegrant, T. (1992). Reaching potentials: Appropriate curriculum and assessment for young children. Washington, DC: National Association for the Education of Young Children.

Brennan, M. (2007). A culture of tenderness: Teachers' socialisation practices in group care settings. European Early Childhood Education Research Journal, 15(1), 137-146.

Calderhead, J. (1981). Stimulated recall: A method for research on teaching. British Journal of Educational Psychology, 51, 211-217.

Calderhead, J. (1987). Developing a framework for the elicitation and analysis of teachers' verbal reports. Oxford Review of Education, 13(2), 183-189.

Calderhead, J. (1989). Reflective teaching and teacher education. Teaching and Teacher Education, 5(1), 43-51.

Carr, M. (2001). Assessment in early childhood settings: Learning stories. London: Paul Chapman.

Carr, M., \& Claxton, G. (2001). Tracking the development of learning dispositions. Assessment in Education: Principles, Policies and Practice, 9(1), 9-37.

Carr, N., \& Chambers, D. (2006). Cultural and organisational factors facing online learning communities of teachers. Education Information Technology, 11, 269-282.

Chappell, K., Craft, A., Burnard, P., \& Cremin, T. (2008). Question-posing and question-responding: The heart of 'possibility thinking' in the early years. Early Years, 28(3), 267-286.

Chen, F-C., \& Wang, T. (2009). Social conversation and effective discussion in online group learning. Education Technology Research Development, 57, $587-612$.

Clark, C. (1995). Thoughtful teaching. London: Cassell.

Clarke, A. (1995). Professional development in practicum settings: Reflective practice under scrutiny. Teaching and Teacher Education, 11(3), 243-261.

Clarkin-Phillips, J. (2007). Distributing the leadership: A case study of professional development. Unpublished MEd thesis, University of Waikato.

Claxton, G., \& Carr, M. (2004). A framework for teaching learning: The dynamics of disposition. Early Years, 24(1), 87-97.

Cohen, L., Manion, L., \& Morrison, K. (2000). Research methods in education. London: Routedge Falmer.

Convery, A. (1998). A teacher's response to 'reflection-in-action'. Cambridge Journal of Education, 28(2), 197-205.

Cooke, B. (1991). Thinking and knowledge underlying expertise in parenting: Comparisons between expert and novice mothers. Family Relations, 40, 3-13. 
Cosner, S. (2009). Building organizational capacity through trust. Educational Administration Quarterly, 45(2), 248-291.

Cowie, B., \& Carr, M. (2009). The consequences of socio-cultural assessment. In A. Anning, J. Cullen \& M. Fleer (Eds.), Early childhood education: Society and culture ( $2^{\text {nd }}$ ed.) (pp. $\left.105-116\right)$. London: Sage.

Cremin, T., Burnard, P., \& Craft, A. (2006). Pedagogy and possibility thinking in the early years. Thinking Skills and Creativity, 1(2), 108-119.

Crespo, S. (2009). Elementary teacher talk in mathematics study groups. Educational Studies in Mathematics, 63, 29-56.

Cullen, J. (1996). The challenge of Te Whāriki for future developments in early childhood education. Delta, 48(1), 113-125.

Dahlberg, G., Moss, P., \& Pence, A. (1999). Beyond quality in early childhood education and care: Postmodern perspectives. London: Falmer Press.

Dalli, C., Kibble, N., Cairns-Cowan, N., Corrigan, J., \& McBride, B. (2009). Reflecting on primary caregiving through action research: The centre of innovation experience at Childspace Ngaio infants and toddlers' centre. The First Years: Ngā Tau Tuatahi, 11(2), 38-45.

Davis, E. (2006). Characterizing productive reflection among preservice elementary teachers: Seeing what matters. Teaching and Teacher Education, 22(3), 281-301.

Day, C. (1999). Professional development and reflective practice: Purposes, processes and partnerships. Pedagogy, Culture and Society, 7(2), 221-233.

De Kruif, R., McWilliam, R., Maher Ridley, S., \& Wakely, M. (2000). Classification of teachers' interaction behaviours in early childhood classrooms. Early Childhood Research Quarterly, 15(2), 247-268.

Deans, J., Brown, R., \& Young, S. (2007). The possum story: Reflections of an early childhood drama teacher. Australian Journal of Early Childhood, 32(4), 1-6.

Degotardi, S., \& Davis, B. (2008). Understanding infants: Characteristics of early childhood practitioners' interpretations of infants and their behaviours. Early Years, 28(3), 221-234.

Denscombe, M. (2007). The good research guide for small-scale social research Projects ( $3^{\text {rd }}$ ed.). Maidenhead: Open University Press.

Denzin, N., \& Lincoln, Y. (2008). Introduction: The discipline and practice of qualitative research. In N. Denzin \& Y. Lincoln, (Eds.), Strategies of qualitative inquiry ( $3^{\text {rd }}$ ed.) (pp. 1 - 44). Los Angeles: Sage.

Dewey, J. (1933). How we think: A restatement of the relation of reflective thinking to the educative process. Chicago: Henry Regnery. 
Dockett, S., \& Fleer, M. (1999). Play and pedagogy in early childhood: Bending the rules. Sydney: Harcourt.

Durden, T., \& Dangel, J. (2008). Teacher-involved conversation with young children during small group activity. Early Years, 28(3), 251-266.

Earl, L., \& Timperley, H. (2008). Understanding how evidence and learning conversations work. In L. Earl \& H. Timperley (Eds.), Professional learning conversations: Challenges in using evidence for improvement (pp. 1 - 12). Dordretch: Springer.

Education Review Office. (2009). Implementing self review in early childhood services. Retrieved 6/04/2011 from http://www.ero.govt.nz/NationalReports/(category)/Early\%20Childhood/(categoryld)/1

Edwards, K. (2009). The inside story: Early childhood practitioners' perceptions of teaching science. Unpublished Masters thesis, Victoria University of Wellington.

Edwards, S. (2007). From developmental constructivism to socio-cultural theory and practice: An expansive analysis of teachers' professional learning in early childhood education. Journal of Early Childhood Research, 5(1), 83-106.

Eisenhardt, K. (2002). Building theories from case study research. In A. Huberman $\&$ M. Miles (Eds.), The qualitative researcher's companion (pp. $5-36$ ). Los Angeles: Sage.

Eisner, E. (1998). The enlightened eye: Qualitative inquiry and the enhancement of educational practice. Upper Saddle River, NJ: Prentice Hall.

Engeström, Y. (1994). Teachers as collaborative thinkers: Activity-theoretical study of an innovative teaching team. In I. Carlgren, G. Handal \& S. Vaage (Eds.), Teachers' minds and actions: Research on teachers' thinking and practice (pp. 43 - 61). London: Falmer Press.

Ethell, R., \& McMeniman, M. (2000). Unlocking the knowledge in action of an expert practitioner. Journal of Teacher Education, 51(2), 87.

Evans, M. (2009). Using stimulated recall to investigate pupils' thinking about online bilingual communication: Code-switching and pronominal address in L2 French. British Educational Research Journal, 35(3), 469-485.

Farquhar, S., \& Fleer, M. (2007). Developmental colonisation of early childhood education in Aotearoa/New Zealand and Australia. In L. Keesing-Styles \& $\mathrm{H}$. Hedges, (Eds.), Theorising early childhood practice: Emerging dialogues (pp. 27 - 49). Castle Hill, NSW: Pademelon Press.

Fenwick, T. (2008). Understanding relations of individual collective learning in work: A review of research. Management Learning, 39(3), 227-243. 
Fleer, M. (1995). Challenging developmentally appropriate practice: An introduction. In M. Fleer, (Ed.), DAPcentrism: Challenging developmentally appropriate practice (pp. 1 - 9). Watson, ACT: Australian Early Childhood Association.

Fleer, M. (2010). Early learning and development: Cultural-historical concepts in play. Cambridge: Cambridge University Press.

Fleer, M., \& Richardson, C. (2009). Cultural-historical assessment: Mapping the transformation of learning. In A. Anning, J. Cullen \& M. Fleer (Eds.), Early childhood education: Society and culture ( ${ }^{\text {nd }}$ ed.) (pp. $\left.130-143\right)$. London: Sage.

Fleer, M., Anning, A., \& Cullen, J. (2009). A framework for conceptualising early childhood education. In A. Anning, J. Cullen \& M. Fleer (Eds.), Early childhood education: Society and culture ( ${ }^{\text {nd }}$ ed.) (pp. 187 - 203). London: Sage.

Frampton, K., Perlman, M., \& Jenkins, J. (2009). Caregivers' use of metacognitive language in child care centers: Prevalence and predictors. Early Childhood Research Quarterly, 24(3), 248-262.

Francis, D. (1995). The reflective journal: A window to preservice teachers' practical knowledge. Teaching and Teacher Education, 11(3), 229-241.

Frank, N., \& Keith, A. (2008). Launching a cross-organizational CoP for school leaders: Overcoming barriers to engagement and meeting diverse needs. In C. Kimble, P. Hildreth, \& I. Bourdon (Eds.), Communities of practice: Creating learning environments for educators (Vol 2) (pp. 255 - 278). Charlotte, NC: Information Age.

Gass, S. M. (2001). Innovation in second language research methods. Annual Review of Applied Linguistics, 21, 221-232.

Gass, S., \& Mackey, A. (2000). Stimulated recall methodology in second language research. Mahwah, NJ: Lawrence Erlbaum.

Gerber, M. (Ed.). (1979). The RIE manual: For parents and professionals. Los Angeles: Resources for Infant Educarers.

Gerber, M., \& Johnson, A. (1998). Your self-confident baby. How to encourage your child's natural abilities from the very start. New York: John Wiley.

Gerber, M., \& Weaver, J. (2002). Dear Parent: Caring for infants with respect. Los Angeles, CA: Resources for Infant Educarers.

Gilbert, J. (1994). The construction and reconstruction of the concept of the reflective practitioner in the discourses of teacher professional development. International Journal of Science Education, 16(5), 511-522.

Goodfellow, J. (1998). There's a student teacher in my centre: Cooperating teachers' perspectives. Australian Journal of Early Childhood, 23(2), 36-45. 
Grainger, S. (2003). Accessing the professional artistry of teaching. Unpublished PhD thesis, Griffith University, Australia.

Greeno, J. (1997). On claims that answer the wrong questions. Educational Researcher, 26(1), 5-17.

Greeno, J., \& The Middle School Through Applications Project Group. (1998). The situativity of knowing, learning, and research. American Psychologist, 53(1), 5-26.

Grey, A. (2010). Self-review as practical philosophy: A case study in early childhood education in Aotearoa New Zealand. Unpublished EdD thesis, Auckland University of Technology.

Grieshaber, S. (2008). Interrupting stereotypes: Teaching and the education of young children. Early Education and Development, 19(3), 505-518.

Griffiths, M., \& Tann, S. (1992). Using reflective practice to link personal and public theories. Journal of Education for Teaching, 18(1), 69-84.

Grimmett, P., MacKinnon, A., Erickson, G., \& Riecken, T. (1990). Reflective practice in teacher education. In R. Clift, W. Houston, \& M. Pugach (Eds.), Encouraging reflective practice in education: An analysis of issues and programs (pp. 20-38). New York: Teachers College Press.

Grossman, P., Wineburg, S., \& Woolworth, S. (2001). Toward a theory of teacher community. Teachers College Record, 103(6), 942-1012.

Habhab-Rave, S. (2008). Workplace learning in communities of practice: How do schoolteachers learn? In C. Kimble, P. Hildreth, \& I. Bourdon. (Eds.), Communities of practice: Creating learning environments for educators (Vol 2 (pp. 213 - 232). Charlotte, NC: Information Age.

Haggerty, M. (1998). Sighting, citing and siting Te Whāriki: Exploring the use of video feedback as a tool for critical pedagogy: The experiences of five early childhood centres. Unpublished MEd thesis, Victoria University of Wellington.

Harford, J., \& MacRuairc, G. (2008). Engaging student teachers in meaningful reflective practice. Teaching and Teacher Education, 24, 1884-1892.

Hatherly, A., \& Richardson, C. (2007). Building connections: Assessment and evaluation revisited. In L. Keesing-Styles \& H. Hedges (Eds.), Theorising early childhood practice: Emerging dialogues (pp. 51 - 70). Castle Hill: Pademelon Press.

Hatton, N., \& Smith, D. (1995). Reflection in teacher education: Towards definition and implementation. Teaching and Teacher Education, 11(1), 33-49.

Hedges, H. (2000). Teaching in early childhood: Time to merge constructivist views so learning through play equals teaching through play. Australian Journal of Early Childhood, 25(4), 16-21. 
Hedges, H. (2007). Funds of knowledge in early childhood communities of inquiry. Unpublished PhD thesis, Massey University.

Hedges, H., \& Cullen, J. (2005). Subject knowledge in early childhood curriculum and pedagogy: Beliefs and practices. Contemporary Issues in Early Childhood, 6(1), 66-79.

Hennessy, S., \& Deaney, R. (2009). "Intermediate theory" building": Integrating multiple teacher and researcher perspectives through in-depth video analysis of pedagogic strategies. Teachers College Record, 111(7), 1753-1795.

Hermsen-von Wanrooy, M. (2002). BabyMoves. Nelson: Author.

Herrington, M., Kendall, A., Hughes, J., Lacey, C., Smith, R., Dye, V. et al. (2008). Space, resistance, and identities: University-based teacher educators developing a community of practice. In C. Kimble, P. Hildreth, \& I. Bourdon. (Eds.). Communities of practice: Creating learning environments for educators (Vol 2) (pp. 191 - 212). Charlotte, NC: Information Age.

Hibbert, K., \& Rich, S. (2006). Virtual communities of practice. In J. Weiss, J. Nolan, J. Hunsinger, \& P. Trifonas (Eds.), The international handbook of virtual learning environments (pp. 563 - 579). Dordretch: Springer.

Hipp, K., Huffman, J., Pankake, A., \& Olivier, D. (2008). Sustaining professional learning communities: Case studies. Journal of Educational Change, 9, 173-195.

Horn, I., \& Little, J. (2010). Attending to problems of practice: Routines and resources for professional learning in teachers' workplace interactions. American Educational Research Journal, 47(1), 181-217.

Jay, J., \& Johnson, K. (2002). Capturing complexity: A typology of reflective practice for teacher education. Teaching and Teacher Education, 18(1), 73-85.

Johnson, N., \& Scull, J. (1999). The power of professional learning teams. Improving Schools, 2(1), 34-43.

Jordan, B. (2009). Scaffolding learning and co-constructing understandings. In A. Anning, J. Cullen \& M. Fleer (Eds.), Early childhood education: Society and culture ( $2^{\text {nd }}$ ed.) (pp. $\left.39-52\right)$. London: Sage.

Kerno, S. J. (2008). Limitations of communities of practice: A consideration of unresolved issues and difficulties in the approach. Journal of Leadership and Organisational Studies, 15(1), 69-78.

Kimble, C., \& Hildreth, P. (2008). Introduction and overview. In C. Kimble, P. Hildreth, \& I. Bourdon (Eds.), Communities of practice: Creating learning environments for educators (Vol 1) (pp. ix - xviii). Charlotte, NC: Information Age.

Kontos, S. (1999). Preschool teachers' talk, roles, and activity settings during free play. Early Childhood Research Quarterly, 14(3), 363-382. 
Korthagen, F. (2004). In search of the essence of a good teacher: Towards a more holistic approach in teacher education. Teaching and Teacher Education, 20(1), 77-97.

Kugelmass, J., \& Ross-Bernstein, J. (2000). Explicit and implicit dimensions of adultchild interactions in a quality childcare center. Early Childhood Education Journal, 28(1), 19-27.

Lave, J., \& Wenger, E. (1991). Situated learning: Legitimate peripheral participation. Cambridge: Cambridge University Press.

Lieberman, A., \& Miller, L. (Eds.). (2008). Teachers in professional communities. New York: Teachers College Press.

Lincoln, Y., \& Guba, E. (2002). Judging the quality of case study reports. In A. Huberman \& M. Miles (Eds.), The qualitative researcher's companion (pp. 205 - 216). Los Angeles: Sage.

Loughran, J. (2002). Effective reflective practice: In search of meaning in learning about teaching. Journal of Teacher Education, 53(1), 33-44.

Luttenberg, J., \& Bergen, T. (2008). Teacher reflection: The development of a typology. Teachers and Teaching, 14(5), 543-566.

Lyle, J. (2003). Stimulated recall: A report on its use in naturalistic research. British Educational Research Journal, 29(6), 861-878.

MacNaughton, G., \& Williams, G. (2009). Techniques for teaching young children: Choices for theory and practice ( $3^{\text {rd }}$ ed.). French Forest, NSW: Pearson Education.

Marland, P. (1986). Models of teachers' interactive thinking. The Elementary School Journal, 87(2), 209-226.

Marland, P., \& Osborne, B. (1990). Classroom theory, thinking, and action. Teaching and Teacher Education, 6(1), 93-109.

Mauigoa-Tekene, L. (2006). Enhancing teachers' questioning skills to improve children's learning and thinking in Pacific Island early childhood centres. New Zealand Journal of Teachers' Work, 3(1), 12-23.

Maxwell, J. (2005). Qualitative research design: An interactive approach. Los Angeles: Sage.

Mayer, D., \& Marland, P. (1997). Teachers' knowledge of students: A significant domain of practical knowledge? Asia-Pacific Journal of Teacher Education, 25(1), 17-34.

Maykut, P., \& Morehouse, R. (1994). Beginning qualitative research: A philosophic and practical guide. London: Falmer Press. 
McGee, C., \& Penlington, C. (2001). Research on learning, curriculum and teachers' roles. Report 4, Teacher knowledge, beliefs and thinking. Hamilton: Waikato Institute for Research in Learning and Curriculum.

McLaughlin, M., \& Talbert, J. (2006). Building school-based teacher learning communities. Professional strategies to improve student achievement. New York: Teachers College Press.

Meade, A. (1999). Good practice to best practice: Extending policies and children's minds. Early Childhood Folio, 3, 33-40.

Meade, A., with Cubey, P. (1995). Thinking children: Learning about schemas. Wellington: NZCER \& Institute for Early Childhood Studies, Victoria University of Wellington.

Mena Marcos, J., \& Tillema, H. (2006). Studying studies on teacher reflection and action: An appraisal of research contributions. Educational Research Review, 1, 112-132.

Merriam, S. (1998). Qualitative research and case study applications in education. San Francisco: Jossey-Bass.

Mertens, D. (1998). Research methods in education and psychology. Integrating diversity with quantitative and qualitative methods. Los Angeles: Sage.

Miles, M., \& Huberman, A. (1994). Qualitative data analysis: An expanded sourcebook ( $2^{\text {nd }}$ ed). Thousand Oaks, CA: Sage.

Ministry of Education. (1996). Te Whāriki: Early childhood curriculum. Wellington: Learning Media.

Ministry of Education. (2004). Kei Tua o Te Pae Assessment for learning: Early childhood exemplars: Books 1-9. Wellington: Learning Media.

Ministry of Education. (2006). Ngā arohaehae whai hua: Self-review guidelines for early childhood education. Wellington: Learning Media.

Ministry of Education. (2009). Kei Tua o Te Pae Assessment for learning: Early childhood exemplars: Books 10-20. Wellington: Learning Media.

Mitchell, J., \& Marland, P. (1989). Research on teacher thinking: The next phase. Teaching and Teacher Education, 5(2), 115-128.

Moyles, J., Adams, S., \& Musgrove, A. (2002a). Study of pedagogical effectiveness in early learning. (Research Report No 363). UK: Department for Education and Skills.

Moyles, J., Adams, S., \& Musgrove, A. (2002b). Using reflective dialogues as a tool for engaging with challenges of defining effective pedagogy. Early Childhood Development and Care, 172(5), 463-478. 
National Association for the Education of Young Children. (1997). Developmentally appropriate practice in early childhood programs serving children from birth through age 8. Washington, DC: NAEYC.

Niesz, T. (2010). Chasms and bridges: Generativity in the space between educators' communities of practice. Teaching and Teacher Education, 26(1), 37-44.

Noddings, N. (1984). Caring: A feminine approach to ethics and moral education. Berkeley: University of California Press.

Nuttall, J. (2004). Why don't you ask someone who cares? Teacher identity, intersubjectivity, and curriculum negotiation in a New Zealand childcare centre. Unpublished PhD thesis, Victoria University of Wellington.

O'Connor, A., \& Diggins, C. (2002). On reflection: Reflective practice for early childhood educators. Wellington: Open Mind.

Papatheodorou, T. (2008). Exploring relational pedagogy. In T. Papatheodorou \& J. Moyles, (Eds.), Learning together in the early years: Exploring relational pedagogy (pp. 3 - 17). Hoboken: Routledge.

Papatheodorou, T., \& Moyles, J. (Eds.). (2008). Learning together in the early years: Exploring relational pedagogy. Hoboken: Routledge.

Paterson, D. (2007). Teachers' in-flight thinking in inclusive classrooms. Journal of Learning Disabilities, 40(5), 427-435.

Paulus, T. (2009). Online but off-topic: Negotiating common ground in small learning groups. Instructional Science, 37, 227-245.

Pentimonti, J., \& Justice, L. (2010). Teachers' use of scaffolding strategies during read alouds in the preschool classroom. Early Childhood Education Journal, 37(4), 241-248.

Peters, S. (2008). Responsive, reciprocal relationships: The heart of the Te Whāriki curriculum. In T. Papatheodorou \& J.Moyles (Eds.), Learning together in the early years: Exploring relational pedagogy (pp. 23 - 32). Hoboken: Routledge.

Pohio, L. (2009). Reggio Emilia pedagogy in early childhood education: How can this approach enhance visual arts experiences in New Zealand? He Kupu, 2(2). Downloaded May 15, 2011, from: http://www.hekupu.ac.nz/ index.php?type=issue\&issue $=12$

Printy, S. (2008). Leadership for teacher learning: A community of practice perspective. Educational Administration Quarterly, 44(2), 187-226.

Pui-Wah, D., \& Stimson, P. (2005). Articulating contrasts in kindergarten teachers' implicit knowledge on play-based learning. International Journal of Educational Research, 41(4-5), 339-352. 
Putnam, R., \& Borko, H. (2000). What do new views of knowledge and thinking have to say about research on teacher learning? Educational Researcher, 29(4), 4-15.

Reid, L. (2007). Teachers talking about writing assessment: Valuable professional learning? Improving Schools, 10(2), 132-149.

Resources for Infant Educarers (RIE). (2006). Unfolding of infants' natural gross motor development. Los Angeles, CA: Resources for Infant Educarers.

Richards, L. (2005). Handling qualitative data: A practical guide. London: Sage.

Robinson, L. (2007). Discourses of teaching in selected childcare settings. Unpublished MEd thesis, Massey University.

Rogoff. B. (2003). The cultural nature of human development. Oxford: Oxford University Press.

Roth, W-M., Lawless, D., \& Masciotra, D. (2001). Spielraum and teaching. Curriculum Inquiry, 31(2), 183-207.

Ryder, D. (2007). Making meaning: A team of early childhood education teachers working towards registration from a group perspective. Unpublished Masters thesis, Canterbury University.

Schepens, A., Aelterman, A., \& van Keer, H. (2007). Studying learning processes of student teachers with stimulated recall interviews through changes in interactive cognitions. Teaching and Teacher Education, 23(4), 457-472.

Schön, D. (1983). The reflective practitioner: How professionals think in action. New York: Basic Books.

Schön, D. (1987). Educating the reflective practitioner: Towards new design for teaching and learning in the professions. San Francisco: Jossey-Bass.

Sherin, M., \& Han, S. (2004). Teacher learning in the context of a video club. Teaching and Teacher Education, 20(2), 163-183.

Sherin, M., \& van Es, E. (2009). Effects of video club participation on teachers' professional vision. Journal of Teacher Education, 60(1), 20-37.

Siraj-Blatchford, I. (2009). Quality teaching in the early years. In A. Anning, J. Cullen \& M. Fleer (Eds.), Early childhood education: Society and culture ( $2^{\text {nd }}$ ed.) (pp. 147 - 157). London: Sage.

Siraj-Blatchford, I., \& Manni, L. (2008). "Would you like to tidy up now?" An analysis of adult questioning in the English Foundation Stage. Early Years, 28(1), 522.

Siraj-Blatchford, I., Sylva, K., Muttock, S., Gilden, R., \& Bell, D. (2002). Researching effective pedagogy in the early years. (Research Report No. 356, Department for Education and Skills). London: HMSO. 
Stake, R. (2008). Qualitative case studies. In N. Denzin \& Y. Lincoln (Eds.), Strategies of qualitative inquiry ( $3^{\text {rd }}$ ed.) (pp. 119 - 150). Los Angeles: Sage.

Stephen, C. (2010). Pedagogy: The silent partner in early years learning. Early Years, 30(1), 15-28.

Stephen, C., \& Plowman, L. (2008). Enhancing learning with information and communication technologies in pre-school. Early Childhood Development and Care, 178(6), 637-654.

Stipek, D., \& Byler, P. (1997). Early childhood education teachers: Do they practice what they preach? Early Childhood Research Quarterly, 12, 305-325.

Stoll, L., Bolam, R., McMahon, A., Wallace, M., \& Thomas, S. (2006). Professional learning communities: A review of the literature. Journal of Educational Change, 7, 221-258.

Stremmel, A., \& Fu, V. (1993). Teaching in the zone of proximal development: Implications for responsive teaching practice. Child and Youth Care Forum, 22(5), 337-350.

Sylva, K., Siraj-Blatchford, I., Sammons, P., Melhuish, E., \& Taggert, B. (1999). Effective provision for pre-school education technical paper 6. London: University of London, Institute of Education/DfEE.

Terreni, L. (2010). A history of visual art education in early childhood in New Zealand: Looking backwards to go forwards. International Art in Early Childhood Research Journal, 2(1). Downloaded May 15, 2011, from: http://www.artinearlychildhood.org/artec//images/article/ARTEC 2010 Research Journal 1 Article 2.pdf

Thornton, K. (2009). Blended action learning: Supporting leadership learning in the New Zealand ECE sector. Unpublished PhD thesis, Victoria University of Wellington.

Timperley, H., \& Earl, L. (2008). Using conversations to make sense of evidence: Possibilities and pitfalls. In L. Earl \& H. Timperley (Eds.), Professional learning conversations: Challenges in using evidence for improvement ( $\mathrm{pp}$. 121 - 126). Dordretch: Springer.

Trawick-Smith, J., \& Dziurgot, T. (2010). Untangling teacher-child play interactions: Do teacher education and experience influence "good-fit" responses to children's play? Journal of Early Childhood Teacher Education, 31(2), 106128.

van Es, E., \& Sherin, M. (2008). Mathematics teachers' "learning to notice" in the context of a video club. Teaching and Teacher Education, 24, 244-276.

van Manen, M. (1977). Linking ways of knowing with ways of being practical. Curriculum Inquiry, 6(3), 205-228. 
van Wikj, N., Simmonds, A., Cubey, P., \& Mitchell, L., with Bulman, R., Wilson, M., \& Wilton Playcentre members. (2006). Transforming learning at Wilton Playcentre. Wellington: NZCER.

Vartuli, S. (1999). How early childhood teacher beliefs vary across grade level. Early Childhood Research Quarterly, 14(4), 489-514.

Vygotsky, L. (1998). The problem of age. In R. Rieber (Ed.), The collected works of L. S. Vygotsky: Vol. 5: Child psychology (pp. 187 - 206). New York: Plenum Press.

Wenger, E. (1998). Communities of practice: Learning, meaning, and identity. Cambridge: Cambridge University Press.

Wiersma, W., \& Jurs, S. (2009). Research methods in education: An introduction ( $9^{\text {th }}$ ed.). Boston: Pearson Education.

Williams, S., Mastergeorge, A., \& Ontai, L. (2010). Caregiver involvement in infant peer interactions: Scaffolding in a social context. Early Childhood Research Quarterly, 25(2), 251-266.

Wood, E. (2009). Developing a pedagogy of play. In A. Anning, J. Cullen \& M. Fleer (Eds.). Early childhood education: Society and culture ( $2^{\text {nd }}$ ed.) (pp. $\left.27-38\right)$. London: Sage.

Wood, E., \& Attfield, J. (2005). Play, learning and the early childhood curriculum (2 ${ }^{\text {nd }}$ ed.). London: Paul Chapman.

Wood, E., \& Bennett, N. (2000). Changing theories, changing practice: Exploring early childhood teachers' professional learning. Teaching and Teacher Education, 16, 635-647.

Wright, J., Ryder, D., \& Mayo, E. (2006). New Beginnings Preschool Centre of Innovation: Final research report. Putting identity into community: Nurturing an early childhood learning community through visual art and project work in the curriculum. Wellington: Ministry of Education.

Wylie, C. (2001). Early childhood education: An enduring legacy. Early Childhood Folio, 5, 3-5.

Yildirim, R. (2008). Adopting communities of practice as a framework for teacher development. In C. Kimble, P. Hildreth, \& I. Bourdon (Eds.), Communities of practice: Creating learning environments for educators (Vol 2) (pp. 233 254). Charlotte, NC: Information Age.

Yin, R. (2009). Case study research: Design and methods ( $4^{\text {th }}$ ed.). Los Angeles: Sage.

Yinger, R. (1986). Examining thought in action: A theoretical and methodological critique of research on interactive teaching. Teaching and Teacher Education, 2(3), 263-282. 
Yost, D., Sentner, S., \& Forlenza-Bailey, A. (2000). An examination of the construct of critical reflection: Implications for teacher education programming in the $21^{\text {st }}$ century. Journal of Teacher Education, 51(1), 39-49.

Zeichner, K. (1994). Research on teacher thinking and different views of reflective practice in teaching and teacher education. In I. Carlgren, G. Handal \& S. Vaage (Eds.), Teachers' minds and actions: Research on teachers' thinking and practice (pp. 9 - 27). London: Falmer Press.

Zeichner, K., \& Liston, D. (1996). Reflective teaching: An introduction. Mahwah, NJ: Lawrence Erlbaum. 
Kia ora

PhD project: Early childhood teachers' thinking and pedagogical practices

I am currently enrolled in my PhD at Victoria University of Wellington where I am investigating how EC teachers' engage in reflection and thinking about their practices, and what theoretical ideas influence their interactions with young children in EC settings. My research design involves undertaking three case studies in different ECE centres: an education and care centre, a free kindergarten, and an infant and toddler education and care centre. This research has been assessed and approved by Victoria University College of Education Ethics Committee.

I am inviting teaching teams in centres to consider participating in this project. The project would involve me coming into your centre over the period of about one term (approximately 10 weeks) in order to video-tape teachers' interactions with children in a variety of situations and to then conduct group stimulated recall interviews with the team. Individual team members would also be asked to keep a reflective journal (either written or audio-taped).

Because teaching in ECE centres occurs as a team, each case study would be of the centre rather than of individual teachers within the centre. Thus, all members of the teaching team would need to be prepared to be involved in the study. The data gathering would involve:

- An initial visit to your centre in order to discuss in detail the research processes, address any issues that you and/or the management may have about the research, and to familiarise myself with your centre;

- A 3 - 4 day orientation period getting to know your centre, and enabling both you and the children to become more familiar with me and with the video camera. During these visits, I would also collect contextual data (e.g., physical layout and daily organisation of the programme) and information about your centre/staff philosophy and your planning and assessment systems. I would also appreciate the opportunity to observe a planning meeting at some stage during the data collection period.

- Spending approximately one day per fortnight in the centre undertaking video recordings of the teachers interacting with children during a range of situations. Given the free-flowing nature of children's activities and teacher movements across the programme, including inside/outside flow I will need to take a flexible approach to the videoing.

- On the day following the videotaping, I would return to the centre to undertake a semi-structured interview with the teaching team to enable you to view selected episodes from the videos and describe your thinking/reflection during the interactions. These interviews will be video- and audio-taped to assist with the transcription of the data. Each interview would probably take 2 hours each and would be scheduled for a time that was suitable for the teaching team (either during the day or in the evening). The team will be in control of the video remote control during these interviews and will be asked to stop the recording at points where any of you wish to comment on your practices and/or thinking. Repeat viewings and prompt 
questions may be used in order to probe more deeply into your thinking and practices during the recorded interactions.

- Each member of the teaching team will also be asked to keep a reflective journal during the timeframe of the case data gathering period, focusing particularly on their reflection-on-action around the video data. This journal could be recorded in a written journal or by using a small tape recorder that I would provide to you (and then have transcribed).

To assist in the selection of the case study centres, I have identified the following criteria:

- Centres are teacher-led

- $80 \%$ or more of the staff are qualified, registered teachers

- The centre is not currently engaged in a research project (nor has been in the previous three years)

- The centre is a smaller centre in terms of staffing - less than 6FTE's

- Staff are employed predominantly fulltime, rather than part-time

- All staff want to be involved

- The case study centres are located in different geographical communities, though along the west coast from Levin to Wellington

- The centre has a stable staffing situation - staff turnover in the six months preceding involvement in the study does not exceed one staff member in those centres with up to three teachers, and two staff members in those centres with four to six teachers.

Having been involved in ECE for almost thirty years now, it is highly likely that I will have worked with many teachers in centres in one capacity or another. Because this project would involve me working with teachers in a different professional capacity, during the initial orientation visit it will be important to clarify how we will work together as researcher and research participants. My supervisors, Professor Luanna Meyer and Dr Judith Loveridge, are also available to discuss any issues that prospective participants may have about the research project. Their contact details are:

Professor Luanna Meyer

Phone: (04) 4639598

Email: Luanna.meyer@vuw.ac.nz
Dr Judith Loveridge

Phone: (04) 4636028

Email: Judith.loveridge@vuw.ac.nz

If you are interested in being considered for selection as a case study centre for this research project, please complete the attached "Expression of interest" form and return to me in the reply-paid envelope. If you require further information, please feel free to contact me, as follows:

Sue Cherrington

Phone: (04) 4639552

Email: sue.cherrington@vuw.ac.nz

Yours sincerely

Sue Cherrington 
PhD project: Early childhood teachers' thinking and pedagogical practices

Expression of Interest: Case Study Centres

We are interested in being considered for inclusion in the $\mathrm{PhD}$ project, Early childhood teachers' thinking and pedagogical practices.

Centre Name:

Contact Person:

Address:

Phone:

Teaching team members:

Our centre meets the following criteria (circle appropriate):

- Teacher-led centre $\quad$ Yes No

- $80 \%+$ of staff are qualified, registered teachers $\quad$ Yes No

- No involvement in last three years in a research project Yes No

- Centre employs less than 6 full-time equivalent teachers Yes No

- Most staff are employed fulltime $\quad$ Yes No

- All staff want to be involved $\quad$ Yes No

- Our centre is located between Wellington and Levin on the west coast of the district

Yes No

- We have had a stable staffing situation in the last six months Yes No 


\section{Appendix 2: Employer information letter and consent form}

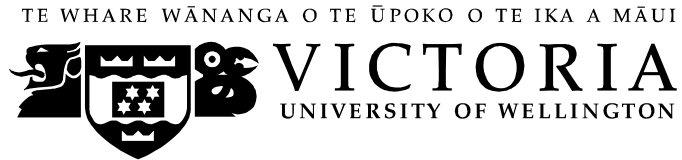

COLLEGE OF EDUCATION

Kia ora

\section{PhD Project: Early Childhood Teachers' Thinking and Pedagogical Practices}

The teachers at have agreed to participate in my $\mathrm{PhD}$ research project where I am investigating EC teachers' reflection and thinking about their teaching practices and interactions with young children in EC settings. This letter is to inform you of the project and to seek your approval as the centre's Management Committee.

My research design involves undertaking three case studies in different ECE centres: an education and care centre, a free kindergarten, and a centre catering predominately for infants and toddlers. For my project I intend to focus on two specific questions:

1) What do teachers in the three case study centres think about and reflect on with regard to their interactions with children?

2) What guiding principles/theories underlie these teachers' practices, and to what extent are these articulated or implicit?

The case study will be of the centre rather than of individual teachers within the centre. The data gathering will involve me working with the centre over the period of approximately 10 weeks in order to video-tape teachers' interactions with children in a variety of situations and to then conduct group stimulated recall interviews with the team. Each team member will also be asked to keep a reflective journal (either written or audio-taped).

Data gathering activities will include:

- An initial visit in order to discuss in detail the research processes and address any issues that teachers may have about the research.

- A 2 - 3 day orientation period getting to know the centre, and enabling teachers and the children to become more familiar with me and with the video camera. During these visits, I would also collect contextual data and information about the centre/staff philosophy and their planning and assessment systems. I would also like to observe a planning meeting at some stage during the data collection period.

- Spending approximately one day per fortnight in the centre undertaking video recordings of the teachers interacting with children during a range of situations.

- On the afternoon/evening following the videotaping, undertaking a semistructured interview with the teaching team to enable them to view selected episodes from the videos and describe their thinking/reflection during the interactions. These interviews will be video- or audio-taped to assist with the transcription of the data. Each interview would probably take 2 hours and will take place during teachers' non-contact time or in the evening, so they will not disrupt the programme. 
- Each member of the teaching team will also be asked to keep a reflective journal during the timeframe of the case data gathering period, focusing particularly on their reflection-on-action around the video data.

As part of the initial orientation visit I will negotiate a set of ground rules to ensure that both teachers and children feel safe and comfortable with the video recording process. The video-tapes recorded form raw data for the study, and as such copies are unable to be passed on to the teachers to use for other purposes in the centre (such as use in parent evenings/workshops, with ERO, team analysis of other aspects of practice) as this would breach the ethical approval.

Participation in this project will require the informed consent of the teachers, and of the parents/guardians of children who may be included in the recorded teaching episodes. I will be available to talk with any parents who wish to discuss the project further before signing the consent form.

The identity of the centre and participating teachers will remain confidential in the written thesis and any papers that are prepared for presentation and/or publication. Pseudonyms will be used for the staff and centre, and children identified by letters only (e.g., Child A, Child B). The teachers will receive a copy of the centre's individual case study at the conclusion of the research.

The centre team has the right to withdraw from the project up until the completion of the data gathering phase. If an individual teacher wishes to withdraw from the project, this will be discussed with the individual and the wider team to determine whether the whole centre then wishes to withdraw. If the wider team does not wish to withdraw, then I will continue data gathering in the centre but will avoid filming the individual or involving them in the interview process.

This research has been assessed and approved by Victoria University College of Education Ethics Committee. If you have further questions about the project I am very happy to discuss these with you, either at a Management Committee meeting or by telephone. My contact details are:

Sue Cherrington

Phone: (04) 4630552

Email: sue.cherrington@vuw.ac.nz

My supervisors, Professor Luanna Meyer and Dr Judith Loveridge, are also available to discuss any issues that the Management Committee or the teachers may have about the research project. Their contact details are:

Professor Luanna Meyer

Phone: (04) 4639598

Email: Luanna.meyer@vuw.ac.nz
Dr Judith Loveridge

Phone: (04) 4636028

Email: Judith.loveridge@vuw.ac.nz

Yours sincerely

Sue Cherrington 


\section{PhD Project: Early Childhood Teachers' Thinking and Pedagogical Practices}

Approval to for Centre to participate in the project

I have been given and have understood an explanation of this research project. I have had an opportunity to ask questions and have them answered to my satisfaction.

I give Sue Cherrington permission to undertake a case study as part of her $\mathrm{PhD}$ research in centre.

I do not give Sue Cherrington permission to undertake a case study as part of her $\mathrm{PhD}$ research in centre.

Signed:

Name (please print clearly):

Chair, Centre Management Team

Date: 


\section{Appendix 3: Teacher information letter and consent form}

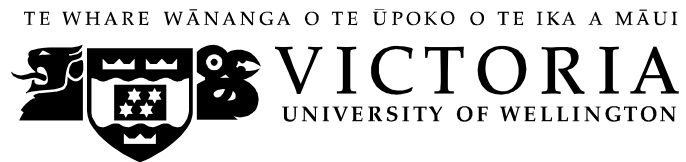

COLLEGE OF EDUCATION

Kia ora

\section{INFORMATION SHEET: \\ PhD Project: Early Childhood Teachers' Thinking and Pedagogical Practices}

Thank you for expressing interest in being part of my $\mathrm{PhD}$ research project where I am investigating how EC teachers' engage in reflection and thinking about their practices, and what theoretical ideas influence their interactions with young children in EC settings. This sheet provides you with information about the project and includes an informed consent form for you to sign if you are willing to be a participant in the project.

\section{Research design}

My research design involves undertaking three case studies in different ECE centres: an education and care centre, a free kindergarten, and a centre catering predominately for infants and toddlers. For my project I intend to focus on two specific questions:

3) What do teachers in the three case study centres think about and reflect on with regard to their interactions with children?

4) What guiding principles/theories underlie these teachers' practices, and to what extent are these articulated or implicit?

The first question is about the notion of an artistry of teaching (Eisner, 1998). I am interested in focusing particularly on how teachers stay in tune or develop intersubjectivity with young children during interactions, and whether and how they use reflection-in-action (Schön, 1983, 1987) during their teaching. I am also interested in exploring the impact on pedagogical practices of teaching within a team context, whether there are differences in teachers' practices when they are responding to child-initiated activities as opposed to when they are leading the learning activity, and to what extent teachers are engaging in both 'pedagogical interactions' and 'pedagogical framing' (Siraj-Blatchford et al, 2002). The second research question seeks to understand whether and how these teachers draw on theory to inform their choice of pedagogical strategies in their teaching. Within this question I am particularly interested in the exploring the match between teachers' articulated theory base and their practices.

\section{Data gathering processes}

The data gathering will involve me coming into your centre over the period of approximately ten weeks in order to video-tape your interactions with children in a variety of situations and to then conduct group stimulated recall interviews with the team. Each team member will also be asked to keep a reflective journal (either written or audio-taped).

Because teaching in ECE centres occurs as a team, each case study will be of the centre rather than of individual teachers within the centre. Thus, all members of the 
teaching team need to be prepared to be involved in the study. The data gathering will include:

- An initial visit to your centre in order to discuss in detail the research processes, address any issues that you and/or the management may have about the research, and to familiarise myself with your centre;

- A 2 - 3 day orientation period getting to know your centre, and enabling both you and the children to become more familiar with me and with the video camera. During these visits, I would also collect contextual data (e.g., physical layout and daily organisation of the programme) and information about your centre/staff philosophy and your planning and assessment systems. I would also appreciate the opportunity to observe a planning meeting at some stage during the data collection period.

- Spending approximately one day per fortnight in the centre undertaking video recordings of the teachers interacting with children during a range of situations. I want to take a broad view of teaching interactions and the situations in which teaching may take place, as by doing so I think there is greater potential for exploring the complexity of teacher thinking and practices in ECE settings. Therefore, the video recording will aim to include teaching interactions such as those that occur when children are engaged in choice-based play experiences, in routine events (such as meal times, toileting, and rest/sleep times), in transition times (such as when children arrive at the beginning of the day, or when they move from play to routine events), and during more formalised teacher-directed group situations. Given the free-flowing nature of children's activities and teacher movements across the programme, including inside/outside flow I will need to take a flexible approach to the videoing.

- On the day following the videotaping, I would return to the centre to undertake a semi-structured interview with the teaching team to enable you to view selected episodes from the videos and describe your thinking/reflection during the interactions. These interviews will be video- or audio-taped to assist with the transcription of the data. Each interview would probably take 2 hours each and would be scheduled for a time that was suitable for the teaching team (either during the day or in the evening). The teaching team will be in control of the video remote control during these interviews and will be asked to stop the recording at points where a teachers wishes to comment on their practices and/or thinking. Repeat viewings and prompt questions may be used in order to probe more deeply into your thinking and practices during the recorded interactions.

- Each member of the teaching team will also be asked to keep a reflective journal during the timeframe of the case data gathering period, focusing particularly on their reflection-on-action around the video data. This journal could be recorded in a written journal or by using a small tape recorder that I would provide to you (and then have transcribed).

As part of the initial orientation visit we will negotiate a set of ground rules for the video recording along the lines of the following points:

o There will be opportunities for staff to indicate situations prior to filming that they specifically do or do not want included

o We will arrange a signal for staff to indicate that filming should cease, e.g., because of their comfort levels, their reading of children's comfort levels, their sense that a situation with/between children was escalating and they don't want to make the situation worse. 
o I will be able to stop video-taping if I sense that my presence is becoming disruptive (e.g., children are getting excited by the video) and the situation is becoming less typical or "authentic".

o I will keep track over the course of the data gathering period that I am covering a range of teaching situations, staff, contexts within the centre so that the episodes recorded for possible future analysis reflect the breadth of ECE teaching.

o The video-tapes recorded form raw data for the study, and as such copies are unable to be passed on to you to use for other purposes in the centre (such as use in parent evenings/workshops, with ERO, team analysis of other aspects of practice) as this would breach the ethical approval.

o Other ground rules as negotiated.

\section{Ethical approval}

This research has been assessed and approved by Victoria University College of Education Ethics Committee.

\section{Informed consent}

Participation in this project requires your informed consent. Attached to this information sheet is a consent form which needs to be completed and returned to me, if you are willing to be a participant in the project.

The identity of each centre and participating teacher in the project will remain confidential in the written thesis and any papers that are prepared for presentation and/or publication. Pseudonyms will be used for the staff and centre, and children identified by letters only (e.g., Child A, Child B).

Because children will be included in the video recordings of your teaching interactions I will need to gain informed consent from the parents of each of the children attending the centre. I would appreciate your assistance with the distribution and return of these consent forms. I will be available to talk with any parents who wish to discuss the project further before signing the consent form. In addition to gaining informed consent from the parents, I will be sensitive to children's reactions to the video camera and will cease filming if children become distressed with the camera operating.

\section{Withdrawal from the project}

The centre team has the right to withdraw from the project up until the completion of the data gathering phase. If an individual teacher wishes to withdraw from the project, this will be discussed with the individual and the wider team to determine whether the whole centre team then wishes to withdraw. If the wider centre team does not wish to withdraw, then I will continue data gathering in the centre but will avoid filming the individual or involving them in the interview process.

\section{Researcher/participant relationships}

Having been involved in ECE for thirty years now, it is highly likely that I will have worked with many teachers in centres in one capacity or another. Because this project would involve me working with you in a different professional capacity, during the initial orientation visit it will be important to discuss how we will work together as researcher and research participants. My supervisors, Professor Luanna Meyer and Dr Judith Loveridge, are also available to discuss any issues that prospective participants may have about the research project, either prior to agreeing to participate or during the actual case study period. Their contact details are: 
Professor Luanna Meyer

Phone: (04) 4639598

Email: Luanna.meyer@vuw.ac.nz
Dr Judith Loveridge

Phone: (04) 4636028

Email: Judith.loveridge@vuw.ac.nz

Thank you for considering involvement in the project. If you would like to discuss any aspect of this project further, my contact details are as follow:

Sue Cherrington

Phone: (04) 4639552

Email: sue.cherrington@vuw.ac.nz

Yours sincerely

Sue Cherrington 


\section{PhD Project: Early Childhood Teachers' Thinking and Pedagogical Practices}

\section{Informed Consent Form - Teachers}

Please tick the boxes to indicate your agreement with the statements and to provide informed consent for participation in this project.

I have been given and have understood an explanation of this research project. I have had an opportunity to ask questions and have them answered to my satisfaction.

(

I understand that I may withdraw myself (or any information I have provided) from this project (before data collection is complete) without having to give reasons or without penalty of any sort.

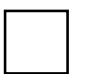

I understand that the data collected will be kept confidential to the researcher and her supervisors, and the person who transcribes the tape recordings of the group interviews and reflective journals. The transcriber together with any VUW IT technicians who provide technical assistance with the editing of video tapes gathered for this project will be asked to sign confidentiality agreements.

$\square$ understand that the published results will not use my name or the name of the centre, or include descriptions that in any way identify me or the centre.

I understand that the video recording of teaching episodes and tape recordings of interviews will be electronically wiped within five years of the conclusion of the project.

I understand that I will have an opportunity to review the transcripts of the group interviews and my reflective journal for errors before publication.

I understand that the data I provide will not be used for any other purpose or released to others without my written consent.

I understand that I will receive a copy of my centre's individual case study at the conclusion of the research.

I agree to take part in this research.

I do not agree to take part in this research.

Signed:

Name of participant (please print clearly)

Date: 


\title{
Appendix 4: Parents information letter and consent form
}

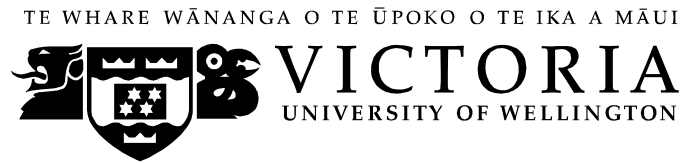

\author{
COLLEGE OF EDUCATION
}

Kia ora

\section{INFORMATION SHEET FOR PARENTS/GUARDIANS: PhD Project: Early Childhood Teachers' Thinking and Pedagogical Practices}

The teachers at have agreed to participate in my $\mathrm{PhD}$ research project where I am investigating EC teachers' reflection and thinking about their teaching practices and interactions with young children in EC settings. This sheet provides you with information about the project.

The project involves three case studies in different ECE centres. In each centre I will be spending time over a period of one term (approximately ten weeks) video-taping teachers' interactions with children in a variety of situations and then interviewing the teachers about their practices. The focus throughout the project is on the teachers and their practices, rather than on the children that they are working with.

The data-gathering in your child's case study centre will take place between June and August 208. I will begin the data gathering with a four day orientation period getting to know the centre, and enabling the children and teachers to become more familiar with me and with the video camera. I will then spend approximately one day per fortnight in the centre undertaking video recordings of the teachers interacting with children during a range of situations, including when children are engaged in play experiences, in routine events (such as meal times and rest/sleep times), in transition times (such as when children arrive at the beginning of the day, or when they move from play to routine events), and during more formalised teacher-directed group situations.

Following the videotaping, I will return to the centre to undertake an interview with the teaching team where they will watch selected episodes from the videos and describe what they were thinking about during the interactions. These interviews will take place during teachers' non-contact time or in the evening, so they will not disrupt the programme.

This research has been assessed and approved by Victoria University College of Education Ethics Committee.

The teachers have completed Informed Consent Forms indicating their willingness to be involved in the project and their understanding of the ethical issues involved. Because I cannot video-record teachers' interactions with children without also including children in the recordings, I am seeking your informed consent for your child to be videoed as part of this project as a participant in episodes of teacher interactions.

Attached to this information sheet is a consent form which I would appreciate you completing and returning to me in the return envelope (via the centre staff), if you are willing for your child to be a participant in the project. 
As well as gaining your informed consent, I will be sensitive to children's reactions to the video camera and will cease filming if children become distressed with the camera operating.

I understand that many parents participate in your child's centre as parent helpers during sessions. Whilst the focus of the video-recording will be on the teachers' interactions with the children, it is possible that parents are also included in video recordings as part of episodes that are filmed or in the background. I am also seeking your informed consent to participate in the project as part of episodes of teacher interactions that are filmed for this research. There is a section of the consent form for you to indicate your informed consent to participating in this study in the capacity outlined above.

The identity of the centre, teachers, children and parents in the project will remain confidential in the written thesis and any papers that are prepared for presentation and/or publication. Pseudonyms will be used for the staff and centre, and children will be identified by letters only (e.g., Child A, Child B). The video recordings and transcriptions of tapes and films will be stored in secure files for the duration of the project and all raw data will be destroyed five years following the completion of the project. Where technical support is provided to assist me with editing of video footage or transcription of interviews, the personnel involved will be required to sign an confidentiality agreement.

You have the right to withdraw your child, or yourself, from the project up until the completion of the data gathering phase. If you do not wish your child to be videoed I will endeavour to conduct the videoing on days or sessions where your child does not attend. If your child attends full-time I will arrange a system with the teachers to be able to identify children who cannot be recorded on video so that I can cease filming if your child enters the episode.

A copy of the case study written for your child's centre will be provided for your perusal at the centre, upon completion of the project.

I am very happy to discuss the project further with you, if you require additional information before signing the consent form. I will be in the centre for the orientation visits on $3-6$ June 2008 and my contact details are:

Sue Cherrington

Phone: (04) 4639552

Email: sue.cherrington@vuw.ac.nz

My supervisors, Professor Luanna Meyer and $\mathrm{Dr}$ Judith Loveridge, are also available to discuss any issues that you may have about the research project, either prior to agreeing to participate or during the actual case study period. Their contact details are:

Professor Luanna Meyer

Phone: (04) 4639598

Email: Luanna.meyer@vuw.ac.nz
Dr Judith Loveridge

Phone: (04) 4636028

Email: Judith.loveridge@vuw.ac.nz

Yours sincerely

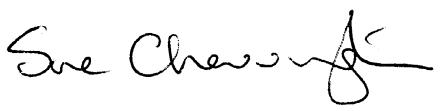

Sue Cherrington 


\section{PhD Project: Early Childhood Teachers' Thinking and Pedagogical Practices}

\section{Informed Consent Form - Parents/Guardians}

Please tick the boxes to indicate your agreement with the statements and to provide informed consent for participation in this project.

I have been given and have understood an explanation of this research project. I have had an opportunity to ask questions and have them answered to my satisfaction.

I understand that I may withdraw permission for my child or myself to be included in video-recordings (before data collection is complete) without having to give reasons or without penalty of any sort.

I understand that the data collected will be kept confidential to the researcher and her supervisors. Any VUW IT technicians who provide technical assistance with the editing of video tapes gathered for this project will be asked to sign a confidentiality agreement.

$\square$ I understand that the published results will not use my name, my child's name or the name of the centre, or include descriptions that in any way identify my child, the centre or myself.

I understand that the video recording of teaching episodes and tape recordings of interviews will be electronically wiped within five years of the conclusion of the project. (print name please), who is under my guardianship, may be video-recorded as part of this research.

I agree that I, recorded as part of this research. (print name please), may be video-

Signed:

Name of Parent/Guardian (please print clearly)

Date: 


\section{Appendix 5: Interview protocol}

\section{Schedule for Stimulated Recall Interviews:}

The purpose of the video-SR interviews is to provide EC teachers who have been the subject of video-taped observations with the opportunity to express what they were thinking and reflecting on at the time that they were engaged in interactions with the children.

Interviews will be scheduled during non-contact times or during the evenings to enable all teachers to participate and to avoid interruptions. I will provide refreshments and hope to establish a relaxed, yet focused tone for the interviews where teachers are encouraged to openly discuss their thinking and reflections.

The interviews will use the following protocol:

1. Introduction and explanation of the interview process, including:

a. Overview of the episodes video-taped during previous visits to the centre

b. Explanation of how the selected episodes for discussion were chosen

c. Description of DVD chapters and the mechanics of using the DVD to play the episodes

d. Stopping the DVD to discuss elements of teachers' thinking. During the first playing of the DVD, teachers will select when to stop the video for discussion. A subsequent playing of individual episodes may occur if there are aspects that I am interested in discussing further.

e. Opportunities for clarification of the process and setting of further ground-rules

A mock-up of a possible interview introduction is presented as Appendix A.

2. Undertaking the interview, including:

a. Tape recording the interviews for future transcribing and analysis

b. Use of an unstructured approach to the interview where the teachers have predominate control of when to stop the DVD and discuss their thinking and practices

c. Use of a range of possible prompt questions to elicit deeper responses

Examples of possible prompts and questions are included in Appendix B.

3. Concluding the interview, including:

a. Confirming details for the next round of video-taping and video-SR interviews.

b. Inviting participants to signal particular episodes that they might want to focus on in the next round of video-taping.

c. Checking for potential ethical considerations that may have arisen since the previous data collection round.

A mock-up of a possible conclusion to the interview is included in Appendix C.

Appendix A: Mock-up of possible interview introduction: 
Last week I spent (days) observing in the centre and video-taping a large number of episodes where teachers were interacting with children. These episodes cover a wide range of situations from free play in the (insert area) through to (insert event) routine events, teacher-initiated (episode) through to child-initiated (episode), and indoors through to outside play. When I wasn't video-taping I spent time observing to help gain an in-depth sense of what being at (name of centre) centre was like.

Overnight the video footage has been edited into a series of $5-6$ episodes that I would like to share with you now. When choosing episodes I have aimed for a balance of all participating teachers, and of the context or focus of the episodes.

The video footage has been edited onto DVD in chapters. For episodes longer than 10 minutes I have selected a portion to use tonight. As we proceed through the footage please pause the video at any point where you would like to describe what you were thinking about as you were interacting with the child/ren.

Because you work together every day, you will know each other's practices well and so there may be aspects that you want to comment on, after the individual who is the focus of the interaction has had an opportunity to describe their thinking.

I would like to confirm that everyone is comfortable with this session being audioand video-taped. This will allow me to concentrate on what you are saying rather than trying to keep up with my note-taking. I remind you that in my thesis report and any subsequent presentations or publications that you will identified by the pseudonym that you have selected.

Before we begin are there any aspects that anyone would like clarified? Are there any other ground-rules that we need to establish or reconfirm before we start?

\section{Appendix B: Possible prompts and questions to ask during stimulated recall interviews:}

- I'm interested in what you were thinking/trying to do at that point, when you...

- So, what was happening for this child, do you think?

- What were you trying to do there?

- What were you responding to there?

- What influenced your decision to act as you did at that point?

- Are there particular cues/signals that this child was giving to you that made you shift or change what you were doing?

- Were there responses from the child that you found surprising/ intriguing/ made you realise you weren't sure what s/he was thinking/trying to achieve? What effect did these responses have on your thinking and actions?

- Were there goals or plans that you had in mind that influenced your interactions? Directions that you were keen for the interaction or the learning to move in?

- What was significant for you in this interaction? Why?

- When you look at your non-verbal interactions with children, to what extent do you feel that you responded "naturally" or were more deliberate in your actions?

- If you think about the roles that you played in the interaction, do you think that you were mostly the "leader" or the "follower" (or some other combination or role)? Why did you take on these specific roles? 
Appendix C: Possible mock-up for the conclusion of the interview and confirming the details for the next round of data-gathering (video-taping and stimulated recall interview):

Thank you very much for discussions that we've had today. After tonight there may be other thoughts and ideas that occur to you as you reflect on your teaching over the coming days - please feel free to write about these in your reflective journals or to record them on the individual tape recorders, and to talk about them with each other and with me on my next visit. If you do tape them please remember to start your reflection with the data and a notation that this is a reflection on action?

l'd like to plan out the next round of video-taping and interview so that the details are confirmed. Is it still all right for me to visit on (day), and for us to have our interview on (date and time)?

On my next day of videoing, l'll still be trying to get a broad range of episodes covered. As we proceed through this process, there may be aspects/episodes that you would like me to focus on during the videoing or that I happen to video during the course of the day that you would particularly like to discuss in our interview please just let me know on the day.

I know that prior to the last round of video-taping that you alerted me to children who might be uncomfortable about being filmed and to any children who I do not have permission to video. Has anything changed in the interim that I need to be aware of before I come back next time? 


\section{Appendix 6: Data analysis - final coding categories}

\begin{tabular}{|c|c|c|c|}
\hline \multicolumn{4}{|c|}{ Alignment Behaviours } \\
\hline $\begin{array}{l}\text { Coding } \\
\text { category }\end{array}$ & Category description & $\begin{array}{l}\text { Literature source } \\
\text { (where applicable) }\end{array}$ & Example from data \\
\hline Conflict & $\begin{array}{l}\text { Conflicting views are expressed, } \\
\text { teachers make defensive statements or } \\
\text { teachers correct others }\end{array}$ & $\begin{array}{l}\text { Wenger, 1998; } \\
\text { Grossman et al, } \\
2001\end{array}$ & $\begin{array}{l}\text { Poppy: It is the most rewarding part, yeah. Just that spending time with them. } \\
\text { Diana: God, I hate that word rewarding, you know. Yeah. I mean, I was talking to } \\
\text { someone the other day about teaching - I think it was someone who was looking to do } \\
\text { their teacher training - and they sort of said that really awful line, you know, "I'd like to do } \\
\text { something where I can make a difference". (laughs). And I thought I'll have to bite my } \\
\text { tongue; because, to me, that kind of approach is so patronising - it's just such a } \\
\text { patronising approach, really, and, you know, is that whole... } \\
\text { [CS2/SRI5/E1] }\end{array}$ \\
\hline $\begin{array}{l}\text { Doing the } \\
\text { best you can }\end{array}$ & $\begin{array}{l}\text { Speaker is reassured that they did the } \\
\text { best they could in the circumstances, or } \\
\text { within the constraints they worked under. }\end{array}$ & $\begin{array}{l}\text { Empathising - } \\
\text { Borko et al., 2008; } \\
\text { Niesz, 2009; } \\
\text { Pointing out } \\
\text { strengths - Borko et } \\
\text { al., } 2008\end{array}$ & $\begin{array}{l}\text { Jane: See it's all kind of happening really quick, really, it's hard to see what's going on. } \\
\text { Meg: And you're probably not able to see the stuff out to the side. } \\
\text { [CS1/SRI1/E3] }\end{array}$ \\
\hline $\begin{array}{l}\text { Expresses } \\
\text { vulnerability }\end{array}$ & $\begin{array}{l}\text { Teachers express vulnerability about } \\
\text { their own practices, or ask for others' } \\
\text { advice on what they should have done. }\end{array}$ & & $\begin{array}{l}\text { Rachel: Yeah. And it took me a little moment to think what is this happening here? And } \\
\text { then she started... to tell you the truth, she started talking about the sun and I was } \\
\text { thinking, "huuuh, wow, what's my knowledge base on this?" And l'm thinking, "oh gaw, I } \\
\text { don't...", because she was that intent on this little bit of painting that was happening here I } \\
\text { was very conscious of not giving her the wrong information. So fortunately we still had } \\
\text { that... } \\
\text { [CS1/SRI2/E5] }\end{array}$ \\
\hline $\begin{array}{l}\text { Finishing } \\
\text { sentences }\end{array}$ & $\begin{array}{l}\text { One teacher finishes off the sentence } \\
\text { another has started. Often followed by } \\
\text { the first teacher picking up on the end of } \\
\text { the sentence and elaborating the idea. }\end{array}$ & $\begin{array}{l}\text { Rough draft talk - } \\
\text { Horn \& Little, 2010; } \\
\text { Exploratory talk - } \\
\text { Crespo, } 2009\end{array}$ & $\begin{array}{l}\text { Meg: Yep. I'll just... I've given them the warning that I... } \\
\text { Rachel: You've heard them. } \\
\text { [CS1/SRI2/E4] }\end{array}$ \\
\hline
\end{tabular}




\begin{tabular}{|c|c|c|c|}
\hline \multicolumn{4}{|c|}{ Alignment Behaviours } \\
\hline Humour & Use of humour, jokes, inside knowledge & Wenger, 1998 & $\begin{array}{l}\text { Jayde: Oh in the end I think I went ... } \\
\text { (All talking and lots of laughter) } \\
\text { Jayde: And it was, that was it, where is someone? } \\
\text { Juanita: What's that song? Is anybody out there? } \\
\text { [CS3/SRI4/E4] }\end{array}$ \\
\hline $\begin{array}{l}\text { Identifying } \\
\text { with what } \\
\text { happened }\end{array}$ & $\begin{array}{l}\text { Identifying with the content of the } \\
\text { situation or with the teacher involved }\end{array}$ & Borko et al., 2008 & $\begin{array}{l}\text { Inez: Ah, this is Harriet with her flag, she's made a flag. } \\
\text { Jane: She brought that in to show me, yeah. } \\
\text { [CS1/SRI4/E2]. }\end{array}$ \\
\hline $\begin{array}{l}\text { Imposing } \\
\text { authority }\end{array}$ & $\begin{array}{l}\text { Senior members of the team assert their } \\
\text { power or authority over other team } \\
\text { members in the discussion }\end{array}$ & Cosner, 2009; & $\begin{array}{l}\text { Rachel: Oh yes, they were all coming down the front weren't they? I have great faith in } \\
\text { my teaching staff that they'll handle that for me. } \\
\text { [CS1/SRI5/E6] }\end{array}$ \\
\hline $\begin{array}{l}\text { Indicating } \\
\text { agreement }\end{array}$ & $\begin{array}{l}\text { Statements indicating agreement with } \\
\text { what another teacher has said or done. } \\
\text { Sometimes this occurs by a teacher } \\
\text { rephrasing what another teacher has } \\
\text { said. }\end{array}$ & & $\begin{array}{l}\text { Juanita: It wasn't that that she's playing with them it's just so that "I've got them" rather } \\
\text { than you. } \\
\text { Giselle: Yeah that's what she was doing. } \\
\text { Anastasia: "Cos I want them and I don't want you to have them." } \\
\text { [CS3/SRI4/E3] }\end{array}$ \\
\hline $\begin{array}{l}\text { Offering } \\
\text { different views }\end{array}$ & $\begin{array}{l}\text { Statements where a teacher has offered } \\
\text { a different view from that expressed by } \\
\text { another teacher - not a conflict situation } \\
\text { but examples of another way of looking } \\
\text { at something, a different perspective or } \\
\text { opinion. }\end{array}$ & Crespo, 2009 & $\begin{array}{l}\text { Inez: As long as I can be queen bee. } \\
\text { Meg: Yeah, as long as I can be the centre of attention. } \\
\text { Rachel: But I think in... but in those moments there you're so conscious you've got to get } \\
\text { it right for them. } \\
\text { [CS1/SRI4/E9] }\end{array}$ \\
\hline Social talk & $\begin{array}{l}\text { References to teachers' lives outside of } \\
\text { the centre or to common social activities }\end{array}$ & $\begin{array}{l}\text { Chen \& Wang, } \\
2009\end{array}$ & Meg: We all know what Rachel had for morning tea on a Tuesday. \\
\hline
\end{tabular}




\begin{tabular}{|c|c|c|c|}
\hline \multicolumn{4}{|c|}{ Alignment Behaviours } \\
\hline & & & $\begin{array}{l}\text { Rachel: I'd been to the gym. } \\
\text { [CS1/SRI2/E3] }\end{array}$ \\
\hline $\begin{array}{l}\text { Supportive, } \\
\text { positive } \\
\text { statements }\end{array}$ & Showing interest, affirmations & $\begin{array}{l}\text { Providing } \\
\text { suggestions and } \\
\text { encouragement - } \\
\text { Borko et al., } 2008\end{array}$ & $\begin{array}{l}\text { Rachel: Oh, it's great and I think he's actually taking a little bit in, because he does that } \\
\text { and he'll remember because he's got such a retentive memory. } \\
\text { Jane: And obviously Anton's really engrossed as he's there.... } \\
\text { [CS1/SRI1/E7] }\end{array}$ \\
\hline $\begin{array}{l}\text { Trivial, } \\
\text { irrelevant }\end{array}$ & $\begin{array}{l}\text { Off-topic statements which seem } \\
\text { unhelpful, are unrelated to the discussion } \\
\text { or do not contribute to the discussion }\end{array}$ & $\begin{array}{l}\text { Off-task behaviours } \\
\text { - Paulus, } 2009\end{array}$ & $\begin{array}{l}\text { Jane: Yeah, and the boys were fine so I just kind of left them to it and went over to } \\
\text { hang out with my man Finn. } \\
\text { Inez: } \quad \text { Motor bike boy. } \\
\text { [CS1/SRI4/E1] }\end{array}$ \\
\hline
\end{tabular}

\section{Building understanding}

What was going on?

\begin{tabular}{|l|l|l|l|l|l|l}
\hline $\begin{array}{l}\text { Focus teacher } \\
\text { describes } \\
\text { context and } \\
\text { background to } \\
\text { episode }\end{array}$ & $\begin{array}{l}\text { Focus teacher offers descriptive } \\
\text { comments about the context or } \\
\text { background to the episode. These help } \\
\text { other teachers to understand their } \\
\text { practices and thinking in the situation. }\end{array}$ & $\begin{array}{l}\text { Inez: Christopher had asked me earlier on to help him with a piece of wood that he had, there was a little } \\
\text { broken bit on the end of it and he wanted help. I'd had to go down and work down the end there and I promised to } \\
\text { come back to him. } \\
\text { [CS1/SRI1/E2] }\end{array}$ \\
$\begin{array}{l}\text { Focus teacher } \\
\text { description of } \\
\text { episode }\end{array}$ & $\begin{array}{l}\text { Focus teacher's descriptions of their } \\
\text { thinking or actions during the episode, } \\
\text { and their thoughts about what children } \\
\text { were doing in the episode. }\end{array}$ & $\begin{array}{l}\text { Summer: At that stage I had, ended up taking the chair away cos they just kept climbing up there. But I was still } \\
\text { looking out for their safety and doing Kerrin as well. As well as looking out for Kristina just you know, a once over } \\
\text { around the room. Not excluding anyone. I think I had a conversation with Spring there for a minute. } \\
\text { [CS3/SRI2/E2] }\end{array}$ \\
\hline
\end{tabular}




\begin{tabular}{|c|c|c|}
\hline \multicolumn{3}{|c|}{ Building understanding } \\
\hline $\begin{array}{l}\text { Clarifying } \\
\text { questions }\end{array}$ & $\begin{array}{l}\text { Other teachers ask questions to clarify } \\
\text { the focus teacher's thinking or actions or } \\
\text { to clarify what was happening in the } \\
\text { episode }\end{array}$ & $\begin{array}{l}\text { Diana: What's she saying? } \\
\text { Marilyn: 'You have to do the balls before you can go to morning tea.' } \\
\text { [CS2/SRI3/E4] }\end{array}$ \\
\hline $\begin{array}{l}\text { Offers } \\
\text { information or } \\
\text { opinion to } \\
\text { build others' } \\
\text { understanding } \\
\text { s of the } \\
\text { situation }\end{array}$ & $\begin{array}{l}\text { Offers brief comments that assist others } \\
\text { to understand the situation. } \\
\text { Offers brief opinion on what is going on. } \\
\text { Makes an observation. }\end{array}$ & $\begin{array}{l}\text { Diana And we were talking the other day about how he'd got involved with carpentry and started using his } \\
\text { hands, and how that Poppy - I think it was Poppy, or Marilyn might have - how he was learning from watching, } \\
\text { and then he was starting to join in. } \\
\text { Poppy: He was actually doing something; as opposed to observing, he himself was doing some carpentry. } \\
\text { Marilyn: 'Cause l'd done a story beforehand of how he tends to observe, and he's in the background a lot and he } \\
\text { does just go in a little bit, but the more he works with those two, the more he's picking up. } \\
\text { [CS2/SRI3/E1] }\end{array}$ \\
\hline $\begin{array}{l}\text { Focus teacher } \\
\text { new insights }\end{array}$ & $\begin{array}{l}\text { Instances where the focus teacher has } \\
\text { noticed things from the episode as a } \\
\text { result of watching the video }\end{array}$ & $\begin{array}{l}\text { Bernice: And, yeah, is it because I'm seeing it from a different angle that I? Cos I'm so busy blowing bubbles } \\
\text { and watching their faces and not actually realised she's lifted herself quite high. Mmmm, it's interesting. } \\
\text { [CS3/SRI3/E5] }\end{array}$ \\
\hline \multicolumn{3}{|c|}{ Negotiating meaning - what might this mean? } \\
\hline $\begin{array}{l}\text { Adding new } \\
\text { ideas to the } \\
\text { discussion }\end{array}$ & $\begin{array}{l}\text { Statements build on existing discussions } \\
\text { but offer a new idea and lead the } \\
\text { discussion in a new direction; offer } \\
\text { alternative explanations or views to what } \\
\text { another teacher might be thinking without } \\
\text { critique. }\end{array}$ & $\begin{array}{l}\text { Rachel: See, you're not quite sure, what, how much use of computers at home. You can tell the ones that have } \\
\text { come and are quite expert and are quite ofay with it all and they can use those mouses quite confidently but the } \\
\text { ones who aren't on them so much... } \\
\text { [CS1/SRI1/E5] }\end{array}$ \\
\hline
\end{tabular}




\begin{tabular}{|c|c|c|}
\hline \multicolumn{3}{|c|}{ Building understanding } \\
\hline $\begin{array}{l}\text { Deepening or } \\
\text { extending } \\
\text { discussion }\end{array}$ & $\begin{array}{l}\text { Statements that build on what has } \\
\text { previously been said in order to expand } \\
\text { or deepen the discussion. Statements are } \\
\text { aligned to previous ones. }\end{array}$ & $\begin{array}{l}\text { Anastasia: I think it was good because with Mere with the whole taking turns and sharing which was good to see } \\
\text { that you know, she was working on that too. And in the end they both did the same. } \\
\text { Juanita: Mmm, I think, what it did for me was actually, I actually, I just keep watching Jasmine. I know the thing } \\
\text { was between you and Daniel and but I kept watching Jasmine and thinking.... } \\
\text { Anastasia: I thought of (unheard) } \\
\text { Juanita: Yeah you know. Ooh you know what's that? And it kind of made me think about when I'm working with } \\
\text { children to actually think about, who might be standing out there not knowing quite how to join you. You know, } \\
\text { that's, that's what it made me think, oh when I was watching Jasmine my eyes were, I kept thinking "oh well she } \\
\text { tried", you know, she held the duck and Giselle acknowledged the duck and all those kind of things. But she kind } \\
\text { of didn't know how to join in I don't think. I really don't think she... } \\
\text { Anastasia: She ended up coming over to the dough table with the duck. } \\
\text { [CS3/SRI1/E2] }\end{array}$ \\
\hline \multicolumn{3}{|c|}{ Critiquing practices } \\
\hline $\begin{array}{l}\text { Reinforcing } \\
\text { thinking or } \\
\text { practices }\end{array}$ & $\begin{array}{l}\text { Statements that explicitly reinforce a } \\
\text { teachers' thinking or practices (beyond } \\
\text { the general affirmations that might } \\
\text { indicate alignment activities) }\end{array}$ & $\begin{array}{l}\text { Marilyn: And also I really liked the way, in the sandpit, when you were explaining to Roger about the waiting, you } \\
\text { know, go and sit a safe distance, and then you said, you're going to need to wait. So you actually followed it up } \\
\text { with exactly what's going to happen. } \\
\text { [CS2/SRI4/FR] }\end{array}$ \\
\hline $\begin{array}{l}\text { Offers advice } \\
\text { to another } \\
\text { teacher }\end{array}$ & $\begin{array}{l}\text { Statements where a teacher offers advice } \\
\text { on how they could have proceeded, what } \\
\text { they might do in the future, to another } \\
\text { teacher }\end{array}$ & $\begin{array}{l}\text { Jane: Are they allowed to stand up there? (referring to new fence) I wasn't too sure whether I should have told } \\
\text { him to hop down but I was thinking, “I don't know, should I be letting him up there?" } \\
\text { Rachel: I think you just talk about the safety issues and stuff like that. I think we were going to make that all out } \\
\text { of bounds, that it was just for sitting on. I don't know, he finds it, it's not a challenge for him - he's quite enjoying it } \\
\text { up there. But I think it could actually lead to more, especially going behind that cupboard with those nails there. } \\
\text { [CS1/SRI1/E8] }\end{array}$ \\
\hline
\end{tabular}




\begin{tabular}{l}
\hline \multicolumn{2}{|l|}{ Building understanding } \\
\begin{tabular}{|l|l|l|}
\hline $\begin{array}{l}\text { Criticising } \\
\text { practices }\end{array}$ & $\begin{array}{l}\text { Statements that directly criticise practices } \\
\text { (in a more negative sense). Can be } \\
\text { critical of own practice, another teacher's } \\
\text { practice or team practice }\end{array}$ & $\begin{array}{l}\text { Bernice: I think I could have actually, I could have lowered that book for her to have a look at. Now that I look at } \\
\text { it. Yeah. Cos now I can see she was actually trying to look, I think, in the bottle. And I've missed that. } \\
\text { And, yeah, is it because I'm seeing it from a different angle that I? Cos I'm so busy blowing bubbles and watching } \\
\text { their faces and not actually realised she's lifted herself quite high. Mmmm, it's interesting. } \\
\text { [CS3/SRI3/E6] }\end{array}$ \\
\hline
\end{tabular}
\end{tabular}

\begin{tabular}{|c|c|c|}
\hline \multicolumn{3}{|c|}{ Teacher thinking and reflection } \\
\hline $\begin{array}{l}\text { Teacher - } \\
\text { child } \\
\text { interactions }\end{array}$ & $\begin{array}{l}\text { References to teachers' thinking \& } \\
\text { actions around the interactions that they } \\
\text { have with children. Includes references to } \\
\text { funds of knowledge held about a child, } \\
\text { knowledge about groups and group } \\
\text { dynamics, reading children's cues and } \\
\text { responding to these, and using } \\
\text { information shared by or about family. } \\
\text { Includes teacher thinking about using } \\
\text { specific teaching strategies or } \\
\text { interactions, reflections on their teaching } \\
\text { in the situation, references to coping with } \\
\text { multiple demands made by groups of } \\
\text { children. }\end{array}$ & $\begin{array}{l}\text { Rachel: Patrick's come and I know that he'll be wanting Anton to talk transformers so I'm just focusing on Anton } \\
\text { at the moment and we're going to go into Google. } \\
\text { And I thought to myself, "Right, let's just use the IT language" so we're talking about Google and search station. } \\
\text { He's got his book. We've come from the book corner with his dinosaur book... And I was really interested, I was } \\
\text { fascinated. I thought, "Oh, I haven't seen these before", so I ... was getting a bit excited myself that I'd actually } \\
\text { achieved something, and I'm thinking "Oh, slow down a little bit" because... } \\
\text { So again I'm actually thinking my thoughts, as the process going down "double click" I'm thinking how would I do } \\
\text { this, I'd double click so he's getting the language I would actually be physically doing myself. I was actually } \\
\text { surprised, and I shouldn't be, but he picked that up so quick ... "go back to the arrow", "click", "double click". He } \\
\text { was so on to it - very familiar with it, very capable with the mouse, moving the arrow around, very focused. } \\
\text { [CS1/SRI1/E7] }\end{array}$ \\
\hline $\begin{array}{l}\text { Teachers in } \\
\text { tune with each } \\
\text { other }\end{array}$ & $\begin{array}{l}\text { References to being in tune with other } \\
\text { team members (or vice versa) whereby } \\
\text { there is a flow and understanding } \\
\text { between teachers that doesn't require on } \\
\text { the spot explanation. Knowing the other } \\
\text { teachers will respond in an expected } \\
\text { way. }\end{array}$ & $\begin{array}{l}\text { Diana: The other really good thing about, I mean the point l'd like to make at this stage is knowing, working with } \\
\text { Marilyn and Poppy, I think we're all quite aware of ... I knew that if I sent them out with the dye Marilyn would } \\
\text { have figured out that it was something that was going on inside and she would follow it on. I knew that ... they } \\
\text { wouldn't get out there and she would say, "Well what are you doing with that? Ra, ra, ra", I knew that that } \\
\text { would ... so and also with Poppy, saying, "Well Poppy's around there," I knew that if he went around the corner } \\
\text { Poppy was there. She would have figured it out and pick up on that, well, hopefully she would. } \\
\text { [CS2/SRI2/E5] }\end{array}$ \\
\hline
\end{tabular}




\begin{tabular}{|c|c|c|}
\hline \multicolumn{3}{|c|}{ Teacher thinking and reflection } \\
\hline $\begin{array}{l}\text { Values, } \\
\text { beliefs, } \\
\text { teaching } \\
\text { principles and } \\
\text { theories }\end{array}$ & $\begin{array}{l}\text { References which explicitly or implicitly } \\
\text { link to a particular theoretical approach or } \\
\text { which indicate an underlying principle of } \\
\text { practice. Includes statements indicating } \\
\text { teachers' values }\end{array}$ & $\begin{array}{l}\text { Paige: I find it easy to bring up a baby's wind when their stomach's up on my shoulder and there's more } \\
\text { pressure against. That's why you see me burping the babies and right up here, not down here. } \\
\text { Bernice: And that's actually quite RIE as well and in Baby Moves. Posture. You're probably also remembering } \\
\text { to back to the workshop about Baby Moves. About putting them, either having them up or lying, not in between, at } \\
\text { that age anyway. She's enjoying the view. } \\
\text { [CS3/SRI3/E9] }\end{array}$ \\
\hline $\begin{array}{l}\text { Busyness and } \\
\text { multi-tasking }\end{array}$ & $\begin{array}{l}\text { References to being busy and/or coping } \\
\text { with multiple demands from children and } \\
\text { others. }\end{array}$ & $\begin{array}{l}\text { Rachel: Because there's so much going on. ... in that beginning of the day and you've got Mary over there and } \\
\text { then the account, the treasurer came in and I'm ... thinking, "Oh gosh, he wants to talk to me about that" and then } \\
\text { this child ... and you've got to ... and as well as during the day from nine o'clock that's it you're on. You're on full } \\
\text { bore and it's going clunk, clunk, clunk, clunk, clunk till three o'clock. } \\
\text { Meg: Before I even get there, because I'm thinking... } \\
\text { Rachel: Yeah. } \\
\text { Inez: And it's like that sharing that information because ... at that meet and greeting time parents come to } \\
\text { individual teachers as part of their... And then you usually get information and then they go. } \\
\text { Meg: And then somehow in the session I've got to remember to tell Rachel this, this, this and this and that's } \\
\text { why I said to Samantha out there, "Oh you'll have to go and tell Rachel about planting plants. I'll never remember } \\
\text { that", but I went out there and ... lunch time and it will cross over. } \\
\text { [CS1/SRI2/E1] }\end{array}$ \\
\hline $\begin{array}{l}\text { Broader } \\
\text { teaching roles } \\
\text { (beyond } \\
\text { interactions } \\
\text { with children) }\end{array}$ & $\begin{array}{l}\text { References to aspects of the teachers' } \\
\text { role beyond their interactions with } \\
\text { children, including administrative, non- } \\
\text { teaching, interactions with families, } \\
\text { assessment and planning }\end{array}$ & $\begin{array}{l}\text { Meg: I was actually thinking about the end of the day when we do our programming planning and our reflection, } \\
\text { that I had to store up quite a lot of information about our ESW and the child concern and the construction of the } \\
\text { kite thing. That's why I had hoped you'd got the kite making part. I was very much role modelling to the ESW how } \\
\text { it's done, that we don't make things and that. And so beforehand, and I was actually trying to think, trying to think, } \\
\text { "I've got to remember all this to talk about with the other staff at the end of the day", yeah. } \\
\text { [CS1/SRI5/E5] }\end{array}$ \\
\hline
\end{tabular}




\begin{tabular}{|l|l|l|}
\hline \multicolumn{2}{|l|}{ Teacher thinking and reflection } \\
\hline $\begin{array}{l}\text { Programme } \\
\text { aspects }\end{array}$ & $\begin{array}{l}\text { References to teachers' thinking about } \\
\text { the environment, routine events, } \\
\text { upcoming events in the programme, in- } \\
\text { the-moment planning for what's coming } \\
\text { next, value of aspects of programme or } \\
\text { environment for learning, teacher } \\
\text { decisions about how programme is } \\
\text { organised. }\end{array}$ & $\begin{array}{l}\text { Diana: ... the mat time thing again, I think it might have been [lecturer] at college that we did ... we talked about } \\
\text { mat time books and we did a whole section on books ... so usually for me I quite often do trot up to the library. I'm } \\
\text { pretty deliberate about the books I use at mat time especially with the younger children because you really want } \\
\text { something that's got very good visual pictures so that they can see quite well from a distance and that will engage } \\
\text { them and also a text that's not too, that's interesting but not too over complicated. } \\
\text { [CS2/SRI2/E3] }\end{array}$ \\
\hline $\begin{array}{l}\text { New insights } \\
\text { gained from } \\
\text { watching the } \\
\text { video }\end{array}$ & $\begin{array}{l}\text { References to new understandings } \\
\text { gained by any participating teacher as a } \\
\text { result of watching the video-recorded } \\
\text { episodes }\end{array}$ & $\begin{array}{l}\text { Summer: At the table the kids are sitting real nicely. It's not as hectic as we thought it was. } \\
\text { Spring And considering that Toby and Zac - this is really their first week, maybe they started it half way last } \\
\text { week sitting at that table so it's only been five days at the most really, ay? } \\
\text { Summer: Yeah. } \\
\text { Spring: Of them sitting at that table, so, and they're probably two of the ones that sat the stillest you know? } \\
\text { Storm: And they're the youngest. } \\
\text { Spring: Yeah. I think this has kind of highlighted to me about the children that ...the things that you miss when } \\
\text { you're busy... } \\
\text { Summer: And the capability that they actually have. } \\
\text { [CS3/SRI2/E5] }\end{array}$ \\
\hline
\end{tabular}




\begin{tabular}{|c|c|c|}
\hline \multicolumn{3}{|c|}{ Teacher thinking and reflection } \\
\hline $\begin{array}{l}\text { Making sense } \\
\text { of situations }\end{array}$ & $\begin{array}{l}\text { Interview sequences where teachers are } \\
\text { clearly trying to explain or make sense of } \\
\text { what was happening in a situation or for a } \\
\text { child. }\end{array}$ & $\begin{array}{l}\text { Diana: And it's interesting to know when you look at that too whether they're ... your saying that that } \\
\text { conversation and that with him about the whales ... but whether it is actually partially the fact that they're } \\
\text { interacting with the adult or the teacher that is their motivation or whether is solely the fact that they want to share } \\
\text { that information. You know what I mean? I think that a large part of that conversation that have the teachers in } \\
\text { those group situation is actually their ... I guess their desire in a way to actually interact with the adult that is in that } \\
\text { environment and that I think is part of that motivation. } \\
\text { Marilyn: But part of that motivation is that they know that you'll be interested in what they are going to say as } \\
\text { well. } \\
\text { Diana: That acknowledgement, seeking the acknowledgement and that validation really of who they are and } \\
\text { their knowledge or whatever really, isn't it? } \\
\text { [CS2/SRI1/E1] }\end{array}$ \\
\hline $\begin{array}{l}\text { Reflections on } \\
\text { action beyond } \\
\text { the video } \\
\text { episodes }\end{array}$ & $\begin{array}{l}\text { Extracts where the teachers reflect about } \\
\text { aspects of practice, the programme or } \\
\text { the children that are beyond the video- } \\
\text { recorded episodes, and are not merely } \\
\text { about the broader teaching role. }\end{array}$ & $\begin{array}{l}\text { Rachel: I actually think this whole group...the school's talking about that group that went up at the beginning of } \\
\text { the year, how magic they were. I actually think this group is too. They've got the same connection, supportive, } \\
\text { caring ... they've got a true affection towards each other. The boys and the girls and I think they're going to be } \\
\text { quite surprised. Different dynamics but when they go in how supportive they are going actually be of each when } \\
\text { that whole group - the next six weeks, what it is going to be like and you're just watching this and they're all doing } \\
\text { it for Lewis and you know it's actually quite a special little moment really } \\
\text { [CS1/SRI4/E5] }\end{array}$ \\
\hline
\end{tabular}




\section{IT TECHNICIAN CONFIDENTIALITY AGREEMENT}

I, will be providing technical support for the editing of video-tapes collected from the research project "Early childhood teachers' thinking and pedagogical practices"

No names of participants or identification of their ECE centres will be provided to me. Furthermore, all the information that is provided will be deemed confidential and I will ensure that it is not released to any third party.

Signature of the technician

Date 


\section{Appendix 8: Transcriber confidentiality form}

$\mathrm{I}$, will be the transcriber for the audio taped reflective journals and stimulated recall interviews collected from the research project "Early childhood teachers' thinking and pedagogical practices”

No names of participants or identification of their ECE centres will be provided to me. Furthermore, all the information that is provided will be deemed confidential and I will ensure that it is not released to any third party.

Signature of the transcriber

Date 